RAFAEL HAUCKEWITZ TODARO

OTIMIZAÇÃO DE MEDIDAS PIV NA INTERAÇÃO DE UM SPRAY DE ETANOL COM O AR CIRCUNDANTE EM UMA CÂMARA DE FLUXO CONTÍNUO

SÃO PAULO

2020 


\title{
OTIMIZAÇÃO DE MEDIDAS PIV NA INTERAÇÃ̃ DE UM SPRAY DE ETANOL COM O AR CIRCUNDANTE EM UMA CÂMARA DE FLUXO CONTÍNUO
}

\author{
Dissertação apresentada à Escola \\ Politécnica da Universidade de São Paulo \\ para obtenção do título de Mestre em \\ Ciências.
}

SÃO PAULO 


\title{
OTIMIZAÇÃO DE MEDIDAS PIV NA INTERAÇÃO DE UM SPRAY DE ETANOL COM O AR CIRCUNDANTE EM UMA CÂMARA DE FLUXO CONTÍNUO
}

\author{
Versão Revisada
}

Dissertação apresentada à Escola Politécnica da Universidade de São Paulo para obtenção do título de Mestre em Ciências.

Área de Concentração:

Engenharia Mecânica de Energia e Fluidos

Orientador:

Prof. Dr. Antonio Luiz Pacifico

Co-orientador:

Dr. Rodrigo de Lima Amaral

SÃO PAULO 
Autorizo a reprodução e divulgação total ou parcial deste trabalho, por qualquer meio convencional ou eletrônico, para fins de estudo e pesquisa, desde que citada a fonte.

Este exemplar foi revisado e corrigido em relaçăo à versăo original, sob responsabilidade única do autor e com a anuência de seu orientador.

Săo Paulo, de de

Assinatura do autor:

Assinatura do orientador:

Catalogação-na-publicação

Todaro, Rafael Hauckewitz OTIMIZAÇÄO DE MEDIDAS PIV NA INTERAÇÃO DE UM SPRAY DE ETANOL COM O AR CIRCUNDANTE EM UMA CÂMARA DE FLUXO

CONTíNUO / R. H. Todaro -- versão corr. -- São Paulo, 2020. $198 \mathrm{p}$.

Dissertação (Mestrado) - Escola Politécnica da Universidade de São Paulo. Departamento de Engenharia Mecânica.

1.escoamento bifásico gás-spray 2.otimização de medidas PIV 3.velocimetria por imagens de partículas I.Universidade de São Paulo. Escola Politécnica. Departamento de Engenharia Mecânica Il.t. 
Nome: TODARO, Rafael Hauckewitz

Título: OTIMIZAÇÃO DE MEDIDAS PIV NA INTERAÇÃO DE UM SPRAY DE ETANOL COM O AR CIRCUNDANTE EM UMA CÂMARA DE FLUXO CONTÍNUO.

Dissertação apresentada à Escola Politécnica da Universidade de São Paulo para obtenção do título de Mestre em Ciências.

Aprovado em: 11.09.2020

\section{Banca Examinadora}

Prof. Dr. César Monzu Freire.

Instituição: Universidade Federal do ABC.

Julgamento: Aprovado.

Prof. Dr. Roberto Guardani.

Instituição: Universidade de São Paulo.

Julgamento: Aprovado.

Prof. Dr. Antonio Luiz Pacífico.

Instituição: Universidade de São Paulo.

Julgamento: Aprovado. 
Dedico este trabalho aos meus pais, Leíde e Raimundo, e avós, Leusa e Joaquim, como forma de reconhecimento pelo esforço que sempre dedicaram à minha formação acadêmica e por todos os princípios que a mim foram ensinados. 


\section{AGRADECIMENTOS}

Ao meu orientador, Prof. Dr. Antônio Luiz Pacífico, pela oportunidade de desenvolver esta pesquisa com tamanho respeito e liberdade de opinião, pela confiança no meu trabalho, por todas as valiosas orientações de cunho acadêmico e por compreender, com amizade, as minhas limitações de tempo no decorrer do desenvolvimento deste trabalho.

Ao meu co-orientador, Dr. Rodrigo de Lima Amaral, por todo o empenho e dedicação com a presente pesquisa, desde o momento que teve sua participação aceita. Agradeço, ainda, por todo o suporte técnico oferecido a mim e pelas numerosas discussões sobre os tópicos que envolveram a qualidade dos conteúdos atrelados à técnica de $P I V$.

Ao LETE (Laboratório de Engenharia Térmica e Ambiental da Escola Politécnica da Universidade de São Paulo), especialmente ao Prof. Dr. Guether Carlos Krieger Filho, por ter aceito a minha participação no grupo de pesquisas associadas a combustão.

Ao Rafael da Cruz Ribeiro Berti, por ter cedido parte dos dados experimentais coletados durante o seu doutorado para tornar possível a execução deste trabalho.

Ao Instituto Mauá de Tecnologia, por ter apoiado todo o desenvolvimento desta dissertação junto às minhas obrigações profissionais diárias, mesmo ciente dos meus compromissos com a execução da presente pesquisa. De forma complementar, agradeço especialmente a $\operatorname{Prof}^{a} \operatorname{Dr}^{a}$ Patricia Antonio por todo o incentivo tangível à conclusão deste trabalho, o que abrange desde a consciência de compreensão até as ricas contribuições de caráter acadêmico que a mim foram dedicadas com amizade. A ela, o meu sincero agradecimento.

Aos membros da minha família que, apesar de prescindirem de minha presença em muitas ocasiões, nunca deixaram de me motivar.

A todos aqueles que, direta ou indiretamente, contribuíram para a conclusão deste trabalho. 
"The obvious is what no one sees, until someone expresses it with simplicity."

(Klalil Gibran) 



\section{RESUMO}

O estudo sobre o processo de formação da mistura ar-combustível na câmara de combustão é de interesse da indústria e imprescindível para compreender a forma com a qual a dinâmica da interação bifásica ar-spray influencia indicadores típicos utilizados na análise de motores. Para investigar a interação entre as fases do escoamento ar-spray é necessário utilizar técnicas experimentais avançadas, dentre as quais a Velocimetria por Imagens de Partículas (Particle Image Velocimetry - PIV) se mostra conveniente de ser aplicada por oferecer descrições quantitativa e qualitativa sobre as estruturas do escoamento. No entanto, a presença de forte ruído de imagem associada ao compromisso entre a iluminação do escoamento e a concentração de partículas traçadoras impõe limitações que afetam a coerência dos resultados PIV. É nesse contexto que o presente trabalho está inserido e intenciona contribuir com informações confiáveis acerca do desenvolvimento do escoamento ar-spray, investigando o mecanismo de interação entre as fases líquida e gasosa a partir de um método de otimização da técnica de PIV. Baseado em boas práticas $P I V$, a otimização foi sugerida a todas as etapas pós-aquisição de imagens e teve a relação sinal ruído do plano de correção e a coerência espacial do campo vetorial como parâmetros de referência. Como estudo de caso, foram utilizadas imagens primárias de trinta e quatro eventos de sprays de etanol formados por um injetor típico de sistemas de injeção direta. Os resultados mostraram que, apesar das gravações de imagens com baixa concentração de traçadores, a otimização dos campos foi alcançada a partir da combinação entre abordagens de correlação e estratégias de interrogação. Em decorrência à combinação proposta, campos híbridos foram obtidos e apresentam qualidade de sinal superior em mais de $300 \%$ em relação a resultados obtidos por metodologias comumente aplicadas em trabalhos contidos na literatura. A interação ar-spray foi analisada a partir da evolução temporal da média espacial dos campos híbridos por meio de grandezas associadas à cinemática do escoamento gasoso. Como resposta, a interação entre o gás circundante e o spray se mostrou atrelada à componente radial dos vetores velocidade e à pressão de injeção. Além disso, evidências mostraram que o campo de vorticidade pouco foi influenciado pela dinâmica do escoamento líquido e que a componente axial se comportou de maneira independente do arraste de gás para regiões internas aos sprays. Além da influência na cinemática do escoamento, parâmetros associados à configuração espacial dos sprays se mostraram dependentes da pressão de injeção.

Palavras-chave: escoamento ar-spray; otimização PIV; técnica de PIV. 


\begin{abstract}
The study about the process of formation of the air-fuel in the combustion chamber is interesting to industries and essential to understand the way the two-phase air-spray interaction influences typical indicators used in analysis of engines. To investigate the interaction between the air-spray flow phases, it is necessary to use advanced experimental techniques, among which the Particle Image Velocimetry (PIV) is convenient to be applied because it offers quantitative and qualitative descriptions about flow structures. However, the strong image noise associated with the compromise among the flow lighting and the seeding concentration offers limitations that affect the coherence of the PIV results. It is in this context that this work is inserted and aims to contribute with reliable information about the air-spray flow development, investigating the mechanism of interaction between the liquid and gas phase by a PIV optimization technique. Based on best-practice in PIV, the optimization was suggested to all postacquisition PIV images step and had the correlation planes' signal-to-noise ratio and the spatial coherence of the velocity fields as reference. As a case study, thirty-four events of sprays of ethanol formed by a typical injector of systems of direct injection were used. The results showed that, despite that acquisition of primary images with low concentration of seeding, the fields' optimization was achieved by a combination among correlation and interrogation strategies. Due to the combination proposed, hybrid fields were obtained and has signal quality upper that $300 \%$ compared with classical results contained in the literature. The air-spray interaction was analyzed based on the temporal evolution of the ensemble average of the hybrid fields by means of quantities associated with the gas flow kinematics. In response, the interaction between the surrounding gas and the spray were associated to the axial component of the velocity vectors and the injection pressure. Besides that, evidence showed that the vorticity field was subtly influenced by the dynamics of liquid flow and that the radial component behaved independently of gas entrainment to regions inside the sprays. In addition to the influence on flow kinematics, parameters associated with the spatial configuration of the sprays proved to be dependent on the injection pressure.
\end{abstract}

Key-words: air-spray flow; PIV optimization; PIV technique. 


\section{LISTA DE FIGURAS}

FIGURA 1.1 - OCORRÊNCIA RELATIVA DE UTILIZAÇÃO DAS TÉCNICAS DE MEDIÇÃO DE VELOCIDADE DE ESCOAMENTOS TURBULENTOS, TENDO COMO BASE AS PUBLICAÇÕES FEITAS NA PLATAFORMA ON-LINE GOOGLE BOOKS, ENTRE OS ANOS DE 1982 E 2008.......40

FIGURA 2.1 - ESTÁGIOS DO DESENVOLVIMENTO DE UM SPRAY OBTIDOS MEDIANTE AUMENTO DA PRESSÃO DE INJEÇÃO.

FIGURA 2.2 - REGISTROS FOTOGRÁFICOS DOS CINCO ESTÁGIOS DE DESENVOLVIMENTO DE UM SPRAY OBTIDOS MEDIANTE AUMENTO DA PRESSÃO DE INJEÇÃO EM UM INJETOR TIPO PRESSURE-SWIRL

FIGURA 2.3 - REPRESENTAÇÃO DOS TIPOS COMUNS DE SPRAYS PRODUZIDOS POR INJETORES DO TIPO MECÂNICO-CENTRÍFUGO: CONE-OCO (À ESQ.) E CONE SÓLIDO (À DIR.).

FIGURA 2.4 - REPRESENTAÇÃO DE UM SPRAY CONE-OCO FORMADO POR UM INJETOR MULTI-FUROS 46

FIGURA 2.5 - REGIÕES TÍPICAS PERTENCENTES A UM SPRAY CONE-SÓLIDO EM DESENVOLVIMENTO. . .47

FIGURA 2.6 - MORFOLOGIA DE UM SPRAY TÍPICO DE UM INJETOR TIPO CONE-OCO 48

FIGURA 2.7 - REPRESENTAÇÃO DAS ESTRUTURAS DE FORMAÇÃO DO SPRAY TIPO CONEOCO DESENVOLVIDO POR UM INJETOR COM ABERTURA EXTERNA (A) E MECÂNICOCENTRÍFUGO (B).

FIGURA 2.8 - MODELO DE FORMAÇÃO DE SPRAYS PRODUZIDOS POR INJETORES TIPO CONE-OCO.

FIGURA 2.9 - ESQUEMA ILUSTRATIVO DE ESTRUTURAS DE FLUXO DE AR: (1) O GRANDE VÓRTICE TOROIDAL ESTACIONÁRIO EM TORNO DO SPRAY, (2) A CORRENTE DE AR CENTRAL, (3) VÓRTICES ALEATORIAMENTE ORIENTADOS E POSICIONADOS NA REGIÃO 1, (4) PEQUENOS VÓRTICES (ANÉIS DE VÓRTICE) NO BORDAS INTERNAS (4B) E EXTERNAS (4A) DA REGIÃO 2 E NA ESTEIRA (4C), (5) ZONA DE RECIRCULAÇÃO DE ROTAÇÃO RÁPIDA PRESA À FOLHA DE LÍQUIDO 
FIGURA 2.10 - ENERGIA CINÉTICA TURBULENTA E SUA RESPECTIVA MÉDIA CALCULADAS PARA O GÁS E PARA O LÍQUIDO, CONSIDERANDO DIFERENTES POSIÇÕES AXIAIS E PRESSÕES DE INJEÇÃO. .54

FIGURA 2.11 - ZONAS DE INTERAÇÃO ENTRE O SPRAY E O GÁS CIRCUNDANTE. .55

FIGURA 2.12 - EVOLUÇÃO DA ENERGIA CINÉTICA DO GÁS AMBIENTE QUE CIRCUNDA O SPRAY DE COMBUSTÍVEL. .56

FIGURA 2.13 - REPRESENTAÇÃO ESQUEMÁTICA DE UM SISTEMA PIV BIDIMENSIONAL TIPO 2D-2C.

FIGURA 2.14 - ILUSTRAÇÃO ESQUEMÁTICA DAS ETAPAS QUE COMPÕEM A TÉCNICA DE PIV 2D-2C. .58

FIGURA 2.15 - EXEMPLO DE UMA APLICAÇÃO DA TÉCNICA DE REMOÇÃO DE RUÍDO DE FUNDO. A IMAGEM À ESQUERDA É A IMAGEM PRIMÁRIA, ENQUANTO À DIREITA, A IMAGEM PRÉ-PROCESSADA. . .61

FIGURA 2.16 - EXEMPLO DE UMA APLICAÇÃO DA TÉCNICA DE NORMALIZAÇÃO. A IMAGEM À ESQUERDA É A IMAGEM PRIMÁRIA PRÉ-PROCESSADA POR FILTROS DE REMOÇÃO DE BACKGROUND, ENQUANTO À DIREITA É APRESENTADO O RESULTADO DA APLICAÇÃO DA NORMALIZAÇÃO.

FIGURA 2.17 - DISTRIBUIÇÃO DE INTENSIDADE DE UMA ÚNICA IMAGEM DE PARTÍCULA (A) ORIGINAL E PRÉ-PROCESSADA POR UM FILTRO (B) GAUSSIANO 3X3 PIXELS, (C) SSM 3X3 PIXELS E (D) RMS 3X3 PIXELS.

FIGURA 2.18 - DIAGRAMA DE FLUXO DO ALGORITMO SCC. 64

FIGURA 2.19 - INCERTEZA DO DESLOCAMENTO DETERMINADA PARA IMAGENS SINTÉTICAS COMO UMA FUNÇÃO DO NÍVEL DE RUÍDO $\sigma N / I 0$ PARA DIFERENTES CONCENTRAÇÕES DE IMAGENS DE PARTÍCULAS, NPPP. O DIÂMETRO DAS IMAGENS DE PARTÍCULAS ESCOLHIDO É DE 3,0 PIXELS E A JANELA DE INTERROGAÇÃO MEDE 32 X 32 PIXELS

FIGURA 2.20 - PERDA DE CORRELAÇÃO POR RUÍDO DE IMAGEM COMO UMA FUNÇÃO DA RELAÇÃO SINAL-RUÍDO, DEFINIDA NA EQUAÇÃO (2.6). CADA SÍMBOLO REFERE-SE À UMA COMBINAÇÃO DE DIÂMETRO E DE CONCENTRAÇÃO DE IMAGENS DE PARTÍCULAS, ATRELADA À UMA COMBINAÇÃO DE INTENSIDADE DE RUÍDO $\sigma N / I 0$. 74 
FIGURA 2.21 - INCERTEZA DO DESLOCAMENTO DETERMINADA PARA IMAGENS SINTÉTICAS COMO UMA FUNÇÃO DO FATOR FE E DO TAMANHO DA JANELA DE INTERROGAÇÃO.

FIGURA 2.22 - ESPECTRO DE ABSORÇÃO (LINHA PONTILHADA) E DE EMISSÃO (LINHA CHEIA) DA RHODAMINAB.

FIGURA 2.23 - ILUSTRAÇÃO DA AQUISIÇÃO INDIVIDUAL TÍPICA DAS IMAGENS DO ESPALHAMENTO-MIE E DO SINAL DE FLUORESCÊNCIA DE UM ESCOAMENTO BIFÁSICO GÁS-SPRAY UTILIZANDO A TÉCNICA DE PIV BIFÁSICO.

FIGURA 2.24 - EXEMPLO DE UMA GRAVAÇÃO DO (A) ESPALHAMENTO-MIE DE UM SPRAY PRODUZIDO POR UM INJETOR TÍPICO DE MOTORES DE INJEÇÃO DIRETA E DO (B) SINAL DE FLUORESCÊNCIA FORNECIDO PELOS TRAÇADORES FLUORESCENTES. .78

FIGURA 2.25 - ILUSTRAÇÃO DA MONTAGEM DOS FILTROS ÓPTICOS UTILIZADA DURANTE A GRAVAÇÃO DAS IMAGENS DE FLUORESCÊNCIA.

FIGURA 2.26 - EXEMPLOS DE HISTOGRAMAS ACUMULATIVOS DA DISTRIBUIÇÃO DOS NÍVEIS DE CINZA DE IMAGENS (A) DE CADA FASE DE UM ESCOAMENTO AR-SPRAY E (B) COM AMBAS AS FASES PRESENTES . .86

FIGURA 2.27 - EXEMPLO DE UMA MÁSCARA OBTIDA PARA REPRESENTAR O ESCOAMENTO DE GÁS CIRCUNDANTE.

FIGURA 2.28 - EXEMPLO DA APLICAÇÃO DA TÉCNICA DE SEPARAÇÃO POR PICOS DE CORRELAÇÃO EM UMA REGIÃO DE INTERFACE AR-SPRAY. 88

FIGURA 2.29 - SEQUÊNCIA DAS ETAPAS PROPOSTAS POR BERTI (2018) COMO MÉTODO DE PRÉ-PROCESSAMENTO DAS IMAGENS.

FIGURA 2.30 - EXEMPLO DE UMA IMAGEM PRÉ-PROCESSADA NA ETAPA DE SUBTRAÇÃO DO SPRAY DE ETANOL

FIGURA 3.1 - SEÇÕES E COMPONENTES PRINCIPAIS DA IESC. .95

FIGURA 3.2 - DISPOSIÇÃO GEOMÉTRICA DO INJETOR E DAS PLACAS PERFURADAS PROPOSTA À IESC. 95 
FIGURA 3.3 - ARRANJO EXPERIMENTAL UTILIZADO NA GRAVAÇÃO DAS IMAGENS DE ESPALHAMENTO-MIE E DE FLUORESCÊNCIA

FIGURA 3.4 - CAMPO DE VISÃO ESCOLHIDO PARA OBSERVAR O ESCOAMENTO AR-SPRAY DESENVOLVIDO NA IESC.

FIGURA 3.5 - PAR DE IMAGENS PRIMÁRIAS DA FASE GASOSA EM UM INSTANTE DE INJEÇÃO DO SPRAY COM PRESSÃO DE 100 BAR. O PRIMEIRO FRAME É APRESENTADO À ESQUERDA, ENQUANTO O SEGUNDO, À DIREITA.

FIGURA 3.6 - HISTOGRAMAS DE NÍVEL DE CINZA DAS IMAGENS PRIMÁRIAS DA FASE GASOSA EM UM INSTANTE DE INJEÇÃO DO SPRAY COM PRESSÃO DE 100 BAR. O HISTOGRAMA DO PRIMEIRO E DO SEGUNDO FRAME É APRESENTADO À ESQUERDA E À DIREITA, RESPECTIVAMENTE.

FIGURA 3.7 - MÉDIA-TEMPORAL DA CONCENTRAÇÃO DE IMAGEM DE PARTÍCULA POR PIXEL

FIGURA 3.8 - VISÃO GLOBAL DO PRÉ-PROCESSAMENTO ALFA 101

FIGURA 3.9 - PAR DE IMAGENS DA FASE GASOSA PRÉ-PROCESSADAS POR FILTRAGEM RMS EM UM INSTANTE DE INJEÇÃO DO SPRAY COM PRESSÃO DE 100 BAR. O PRIMEIRO FRAME É APRESENTADO À ESQUERDA, ENQUANTO O SEGUNDO, À DIREITA.

FIGURA 3.10 - ESQUEMA ILUSTRATIVO REFERENTE ÀS ETAPA QUE COMPREENDE A APLICAÇÃO DOS FILTROS MORFOLÓGICOS. 104

FIGURA 3.11 - PAR DE IMAGENS DA FASE GASOSA PRÉ-PROCESSADAS PELOS FILTROS MORFOLÓGICOS EM UM INSTANTE DE INJEÇÃO DO SPRAY COM PRESSÃO DE 100 BAR. O PRIMEIRO FRAME É APRESENTADO À ESQUERDA, ENQUANTO O SEGUNDO, À DIREITA.

FIGURA 3.12 - PAR DE IMAGENS DA FASE GASOSA PRÉ-PROCESSADAS COM FILTRAGEM POR NORMALIZAÇÃO EM UM INSTANTE DE INJEÇÃO DO SPRAY COM PRESSÃO DE 100 BAR. O PRIMEIRO FRAME É APRESENTADO À ESQUERDA, ENQUANTO O SEGUNDO, À DIREITA. 
FIGURA 3.13 - PAR DE IMAGENS DA FASE GASOSA RESULTANTES DA APLICAÇÃO COMPLETA DO PRÉ-PROCESSAMENTO ALFA EM UM INSTANTE DE INJEÇÃO DO SPRAY COM PRESSÃO DE 100 BAR. O PRIMEIRO FRAME É APRESENTADO À ESQUERDA, ENQUANTO O SEGUNDO, À DIREITA. 108

FIGURA 3.14 - EFEITO DAS ETAPAS DO PRÉ-PROCESSAMENTO ALFA SOBRE OS HISTOGRAMAS DE NÍVEL DE CINZA DO PRIMEIRO FRAME PROCESSADO. (A) REFERE-SE À IMAGEM PRIMÁRIA; (B) À IMAGEM FILTRADA POR RMS; (C) À IMAGEM FILTRADA COM OPERADORES MORFOLÓGICOS; (D) À IMAGEM NORMALIZADA E (E) À ÚLTIMA APLICAÇÃO DE FILTRAGEM ESPACIAL POR RMS. 108

FIGURA 3.15 - EFEITO DAS ETAPAS DO PRÉ-PROCESSAMENTO ALFA SOBRE OS HISTOGRAMAS DE NÍVEL DE CINZA DO SEGUNDO FRAME PROCESSADO. (A) REFERE-SE À IMAGEM PRIMÁRIA; (B) À IMAGEM FILTRADA POR RMS; (C) À IMAGEM FILTRADA COM OPERADORES MORFOLÓGICOS; (D) À IMAGEM NORMALIZADA E (E) À ÚLTIMA APLICAÇÃO DE FILTRAGEM ESPACIAL POR RMS. 109

FIGURA 3.16 - VISÃO GLOBAL DO PRÉ-PROCESSAMENTO BETA 110

FIGURA 3.17 - PAR DE IMAGENS DA FASE GASOSA PRÉ-PROCESSADAS PELO FILTRO STD EM UM INSTANTE DE INJEÇÃO DO SPRAY COM PRESSÃO DE 100 BAR. O PRIMEIRO FRAME É APRESENTADO À ESQUERDA, ENQUANTO O SEGUNDO, À DIREITA. 111

FIGURA 3.18 - PAR DE IMAGENS DA FASE GASOSA PRÉ-PROCESSADAS PELO FILTRO GAUSSIANO COM $\sigma=0,1$ EM UM INSTANTE DE INJEÇÃO DO SPRAY COM PRESSÃO DE 100 BAR. O PRIMEIRO FRAME É APRESENTADO À ESQUERDA, ENQUANTO O SEGUNDO, À DIREITA. 111

FIGURA 3.19 - PAR DE IMAGENS DA FASE GASOSA PRÉ-PROCESSADAS PELO FILTRO SSM EM UM INSTANTE DE INJEÇÃO DO SPRAY COM PRESSÃO DE 100 BAR. O PRIMEIRO FRAME É APRESENTADO À ESQUERDA, ENQUANTO O SEGUNDO, À DIREITA.

FIGURA 3.20 - PAR DE IMAGENS DA FASE GASOSA PRÉ-PROCESSADAS UTILIZANDO O ALGORITMO DE INTENSITY CAPPING EM UM INSTANTE DE INJEÇÃO DO SPRAY COM PRESSÃO DE 100 BAR. O PRIMEIRO FRAME É APRESENTADO À ESQUERDA, ENQUANTO O SEGUNDO, À DIREITA. 
FIGURA 3.21 - PAR DE IMAGENS DA FASE GASOSA PRÉ-PROCESSADAS PELO FILTRO GAUSSIANO COM $\Sigma=1$ EM UM INSTANTE DE INJEÇÃO DO SPRAY COM PRESSÃO DE 100 BAR. O PRIMEIRO FRAME É APRESENTADO À ESQUERDA, ENQUANTO O SEGUNDO, À DIREITA.

FIGURA 3.22 - EFEITO DAS ETAPAS DO PRÉ-PROCESSAMENTO BETA SOBRE OS HISTOGRAMAS DE NÍVEL DE CINZA DO PRIMEIRO FRAME PROCESSADO. (A) REFERE-SE À IMAGEM PRIMÁRIA; (B) À IMAGEM FILTRADA POR RMS; (C) À IMAGEM TRATADA COM FILTRO GAUSSIANO; (D) À IMAGEM RESULTANTE DA APLICAÇÃO DA METODOLOGIA SSM; (E) À APLICAÇÃO DA CAPA DE INTENSIDADE E (F) ÚLTIMA APLICAÇÃO DA FILTRAGEM ESPACIAL COM FILTRO GAUSSIANO. 114

FIGURA 3.23 - EFEITO DAS ETAPAS DO PRÉ-PROCESSAMENTO BETA SOBRE OS HISTOGRAMAS DE NÍVEL DE CINZA DO SEGUNDO FRAME PROCESSADO. (A) REFERE-SE À IMAGEM PRIMÁRIA; (B) À IMAGEM FILTRADA POR RMS; (C) À IMAGEM TRATADA COM FILTRO GAUSSIANO; (D) À IMAGEM RESULTANTE DA APLICAÇÃO DA METODOLOGIA SSM; (E) À APLICAÇÃO DA CAPA DE INTENSIDADE E (F) ÚLTIMA APLICAÇÃO DA FILTRAGEM ESPACIAL COM FILTRO GAUSSIANO. 115

FIGURA 4.1 - MEDIDAS DO ESCOAMENTO DO AR SEM O SPRAY, PARA 100 BAR E 0,066 KG/S UTILIZANDO A ABORDAGEM SCC A PARTIR DA IMAGEM PRIMÁRIA: (A) MÉDIA TEMPORAL DO MÓDULO DE VELOCIDADE; (B) DISTRIBUIÇÃO DA RELAÇÃO SINAL-RUÍDO; (C) ROOT MEAN SQUARE DA FLUTUAÇÃO DO MÓDULO DE VELOCIDADE. 121

FIGURA 4.2 - MEDIDAS DO ESCOAMENTO DO AR SEM O SPRAY, PARA 100 BAR E 0,066 KG/S UTILIZANDO A ABORDAGEM SCC A PARTIR DA IMAGEM PRIMÁRIA. DISTRIBUIÇÃO DA INCOERÊNCIA DA (A) MÉDIA E DO (B) RMS DA FLUTUAÇÃO DO MÓDULO DE VELOCIDADE.

FIGURA 4.3 - COMPARAÇÃO ENTRE O ROOT MEAN SQUARE DA FLUTUAÇÃO DO MÓDULO DE VELOCIDADE (|U|'RMS), A INCOERÊNCIA NA DISTRIBUIÇÃO DE $|U|^{\prime} R M S$ E A DISTRIBUIÇÃO DA RELAÇÃO SINAL-RUÍDO (SNR) PARA DIFERENTES ESTRATÉGIAS DE PRÉ-PROCESSAMENTO E PROCESSAMENTO NA CONDIÇÃO DE 100 BAR E 0,066 KG/S: (A) IMAGEM PRIMÁRIA/SCC, (B) IMAGEM APÓS O PRÉ-PROCESSAMENTO BETA/SCC; (C) IMAGEM APÓS O PRÉ-PROCESSAMENTO ALFA/SCC; (D) IMAGEM PRIMÁRIA /RPC. 124

FIGURA 4.4 - COMPARAÇÃO DO MÓDULO DE VELOCIDADE INSTANTÂNEO PARA IMAGEM PRIMÁRIA/SCC, IMAGEM COM O PRÉ-PROCESSAMENTO BETA/SCC E IMAGEM PRIMÁRIA/RPC EM DIFERENTES TEMPOS DE INJEÇÃO DO SPRAY NA CONDIÇÃO DE 100 BAR E $0,066 \mathrm{KG} / \mathrm{S}$ CONSIDERANDO I $W f=36 p x$. 125 
FIGURA 4.5 - COMPARAÇÃO DO SNR ESTIMADO INSTANTANEAMENTE PARA OS CASOS IMAGEM PRIMÁRIA/SCC, IMAGEM COM O PRÉ-PROCESSAMENTO BETA/SCC E IMAGEM PRIMÁRIA/RPC EM DIFERENTES TEMPOS DE INJEÇÃO DO SPRAY NA CONDIÇÃO DE 100 BAR E $0,066 \mathrm{KG} / \mathrm{S}$ CONSIDERANDO I $\mathrm{W}=36 \mathrm{p}$.

FIGURA 4.6 - COMPARAÇÃO DO MÓDULO DE VELOCIDADE INSTANTÂNEO EM $t=0,800 \mathrm{~ms}$ ENTRE AS COMBINAÇÕES IMAGEM PRIMÁRIA/SCC, IMAGEM COM O PRÉPROCESSAMENTO BETA/SCC E IMAGEM PRIMÁRIA/RPC PARA IW $f$ IGUAIS A 24 PX, 16 PX, 12 PX E 10 PX. 130

FIGURA 4.7 - COMPARAÇÃO DO MÓDULO DE VELOCIDADE INSTANTÂNEO EM $t=$ 0,800 $m s$ ENTRE AS COMBINAÇÕES IMAGEM PRIMÁRIA/SCC, IMAGEM COM O PRÉPROCESSAMENTO BETA/SCC E IMAGEM PRIMÁRIA/RPC PARA I $W f$ IGUAIS A $24 p x, 16 p x$, $12 p x$ E $10 p x$. 131

FIGURA 4.8 - COMPARAÇÃO DO MÓDULO DE VELOCIDADE INSTANTÂNEO PARA IMAGEM PRIMÁRIA/SCC, IMAGEM COM O PRÉ-PROCESSAMENTO BETA/SCC E IMAGEM PRIMÁRIA/RPC EM DIFERENTES TEMPOS DE INJEÇÃO DO SPRAY NA CONDIÇÃO DE 100 BAR E 0,066 KG/S CONSIDERANDO IW $f=10 p x$ (PASSO 6). 133

FIGURA 4.9 - COMPARAÇÃO DO SNR ESTIMADO INSTANTANEAMENTE PARA OS CASOS IMAGEM PRIMÁRIA/SCC, IMAGEM COM O PRÉ-PROCESSAMENTO BETA/SCC E IMAGEM PRIMÁRIA/RPC EM DIFERENTES TEMPOS DE INJEÇÃO DO SPRAY NA CONDIÇÃO DE 100 BAR E 0,066 KG/S CONSIDERANDO IW $f=10 p x$ (PASSO 6). 134

FIGURA 4.10 - COMPARAÇÃO DO MÓDULO DE VELOCIDADE INSTANTÂNEO PARA IMAGEM PRIMÁRIA/SCC, IMAGEM COM O PRÉ-PROCESSAMENTO BETA/SCC E IMAGEM PRIMÁRIA/RPC EM DIFERENTES TEMPOS DE INJEÇÃO DO SPRAY NA CONDIÇÃO DE 100 BAR E $0,066 \mathrm{KG} / \mathrm{S}$ CONSIDERANDO I $f=10 p x \mathrm{E} S N R>2,5$ 135

FIGURA 4.11 - ILUSTRAÇÃO DAS OPERAÇÕES PERTENCENTES AO ALGORITMO CAPA DE VELOCIDADE.

FIGURA 4.12 - COMPARAÇÃO DO MÓDULO DE VELOCIDADE INSTANTÂNEO PARA IMAGEM COM O PRÉ-PROCESSAMENTO BETA/SCC E IMAGEM PRIMÁRIA/RPC EM DIFERENTES TEMPOS DE INJEÇÃO DO SPRAY NA CONDIÇÃO DE 100 BAR E 0,066 KG/S, CONSIDERANDO $I W f=10 p x$, SNRlimite $=2,5 \mathrm{E} s=1,5$. 
FIGURA 4.13 - COMPARAÇÃO ENTRE AS EVOLUÇÕES TEMPORAIS DO MÓDULO DA VELOCIDADE DO ESCOAMENTO BIFÁSICO AR-SPRAY EM INSTANTES ASSOCIADOS AO INÍCIO DA INJEÇÃO DE ETANOL NA IESC, CONSIDERANDO O EFEITO DOMINANTE DA PRESSÃO DE INJEÇÃO.

FIGURA 4.14 - COMPARAÇÃO ENTRE AS EVOLUÇÕES TEMPORAIS DA COMPONENTE HORIZONTAL DOS VETORES VELOCIDADE DO ESCOAMENTO BIFÁSICO AR-SPRAY REGISTRADOS EM INSTANTES ASSOCIADOS AO INÍCIO DA INJEÇÃO DE ETANOL NA IESC, CONSIDERANDO O EFEITO DOMINANTE DA PRESSÃO DE INJEÇÃO. 141

FIGURA 4.15 - COMPARAÇÃO ENTRE AS EVOLUÇÕES TEMPORAIS DA COMPONENTE VERTICAL DOS VETORES VELOCIDADE DO ESCOAMENTO BIFÁSICO AR-SPRAY REGISTRADOS EM INSTANTES ASSOCIADOS AO INÍCIO DA INJEÇÃO DE ETANOL NA IESC, CONSIDERANDO O EFEITO DOMINANTE DA PRESSÃO DE INJEÇÃO. 142

FIGURA 4.16 - COMPARAÇÃO ENTRE OS CAMPOS DE VORTICIDADE DO ESCOAMENTO BIFÁSICO AR-SPRAY REGISTRADOS EM INSTANTES ASSOCIADOS AO INÍCIO DA INJEÇÃO DE ETANOL NA IESC, CONSIDERANDO O EFEITO DOMINANTE DA PRESSÃO DE INJEÇÃO.

FIGURA 4.17 - COMPARAÇÃO ENTRE SPRAYS INJETADOS COM PRESSÃO 100 BAR (CASO 1) E 60 BAR (CASO 2) NOS INSTANTES 0,133 MS; 0,267 MS E 0,400 MS ASOI

FIGURA 4.18 - COMPARAÇÃO ENTRE AS EVOLUÇÕES TEMPORAIS DO MÓDULO DA VELOCIDADE DO ESCOAMENTO BIFÁSICO AR-SPRAY EM INSTANTES ASSOCIADOS AO DESENVOLVIMENTO PLENO DO SPRAY NA IESC, CONSIDERANDO O EFEITO DOMINANTE DA PRESSÃO DE INJEÇÃO.

FIGURA 4.19 - COMPARAÇÃO ENTRE AS EVOLUÇÕES TEMPORAIS DA COMPONENTE HORIZONTAL DOS VETORES VELOCIDADE DO ESCOAMENTO BIFÁSICO AR-SPRAY REGISTRADOS EM INSTANTES ASSOCIADOS AO DESENVOLVIMENTO PLENO DO SPRAY NA IESC, CONSIDERANDO O EFEITO DOMINANTE DA PRESSÃO DE INJEÇÃO. 146

FIGURA 4.20 - COMPARAÇÃO ENTRE AS EVOLUÇÕES TEMPORAIS DA COMPONENTE VERTICAL DOS VETORES VELOCIDADE DO ESCOAMENTO BIFÁSICO AR-SPRAY REGISTRADOS EM INSTANTES ASSOCIADOS AO DESENVOLVIMENTO PLENO DO SPRAY NA IESC, CONSIDERANDO O EFEITO DOMINANTE DA PRESSÃO DE INJEÇÃO. 
FIGURA 4.21 - COMPARAÇÃO ENTRE OS CAMPOS DE VORTICIDADE DO ESCOAMENTO BIFÁSICO AR-SPRAY REGISTRADOS EM INSTANTES ASSOCIADOS AO DESENVOLVIMENTO PLENO DO SPRAY NA IESC, CONSIDERANDO O EFEITO DOMINANTE DA PRESSÃO DE INJEÇÃO.

FIGURA 4.22 - COMPARAÇÃO ENTRE AS EVOLUÇÕES TEMPORAIS DO MÓDULO DA VELOCIDADE DO ESCOAMENTO BIFÁSICO AR-SPRAY EM INSTANTES POSTERIORES AO FIM DA INJEÇÃO DE ETANOL NA IESC, CONSIDERANDO O EFEITO DOMINANTE DA PRESSÃO DE INJEÇÃO.

FIGURA 4.23 - COMPARAÇÃO ENTRE AS EVOLUÇÕES TEMPORAIS DA COMPONENTE HORIZONTAL DOS VETORES VELOCIDADE DO ESCOAMENTO BIFÁSICO AR-SPRAY REGISTRADOS EM INSTANTES POSTERIORES AO FIM DA INJEÇÃO DE ETANOL NA IESC, CONSIDERANDO O EFEITO DOMINANTE DA PRESSÃO DE INJEÇÃO. 149

FIGURA 4.24 - COMPARAÇÃO ENTRE AS EVOLUÇÕES TEMPORAIS DA COMPONENTE VERTICAL DOS VETORES VELOCIDADE DO ESCOAMENTO BIFÁSICO AR-SPRAY REGISTRADOS EM INSTANTES POSTERIORES AO FIM DA INJEÇÃO DE ETANOL NA IESC, CONSIDERANDO O EFEITO DOMINANTE DA PRESSÃO DE INJEÇÃO. 150

FIGURA 4.25 - COMPARAÇÃO ENTRE OS CAMPOS DE VORTICIDADE DO ESCOAMENTO BIFÁSICO AR-SPRAY REGISTRADOS EM INSTANTES POSTERIORES AO FIM DA INJEÇÃO DE ETANOL NA IESC, CONSIDERANDO O EFEITO DOMINANTE DA PRESSÃO DE INJEÇÃO.... 150

FIGURA 4.26 - COMPARAÇÃO ENTRE AS EVOLUÇÕES TEMPORAIS DO MÓDULO E DAS COMPONENTES DOS VETORES VELOCIDADE EM DOIS PONTOS DO CAMPO DE VELOCIDADES: $P 1=11,68 ; 27,02[\mathrm{~mm}]$ (À ESQ.) E $P 2=11,68 ; 22,89[\mathrm{~mm}]$ (À DIR.). 152

FIGURA 4.27 - COMPARAÇÃO ENTRE AS EVOLUÇÕES TEMPORAIS DOS ÂNGULOS DOS VETORES VELOCIDADE DO ESCOAMENTO BIFÁSICO AR-SPRAY REGISTRADOS EM DIFERENTES INSTANTES DA INJEÇÃO DE ETANOL NA IESC, CONSIDERANDO O EFEITO DOMINANTE DA PRESSÃO DE INJEÇÃO 153

FIGURA A.1 - EXEMPLOS DE ELEMENTOS ESTRUTURANTES E SUAS RESPECTIVAS REPRESENTAÇÕES POR MATRIZES BINÁRIAS: (A) QUADRADO DE LADO 3; (B) CÍRCULO DE RAIO UNITÁRIO. FONTE: AUTOR.

FIGURA A.2 - EFEITOS PRODUZIDOS PELA DILATAÇÃO DE UMA IMAGEM SEM TRATAMENTO (A) POR DISCOS DE RAIO 5 (B), 10(C) E 20 (D). FONTE: AUTOR. 
FIGURA A.3 - EFEITOS PRODUZIDOS PELA EROSÃO DE UMA IMAGEM SEM TRATAMENTO (A) POR DISCOS DE RAIO 5 (B), 10(C) E 20 (D). FONTE: AUTOR.

FIGURA A.4 - REPRESENTAÇÃO DA MATRIZ DE PIXELS DA MATRIZ $A$ SUBMETIDA À EROSÃO (A) E À DILATAÇÃO (B) PELO ELEMENTO ESTRUTURANTE $v b$. FONTE: AUTOR. 174

FIGURA B.1 - MÁSCARAS DE CONVOLUÇÃO ORIUNDAS DO FILTRO GAUSSIANO CONFIGURADO COM OS PARÂMETROS DADOS POR (A), À ESQUERDA, E POR (B), À DIREITA. FONTE: ADAPTADO DE SOLOMON E BRECKON (2011). 176

FIGURA B.2 - EFEITOS DA FILTRAGEM GAUSSIANA À UMA IMAGEM-REFERÊNCIA (À ESQ.) APLICADA COM $\sigma=1 ; N=3$ (MEIO) E $\sigma=2 ; N=11$ (À DIR.). FONTE: AUTOR.

FIGURA C.1 - REPRODUÇÃO SIMBÓLICA DO CONCEITO DE CONECTIVIDADE DE VIZINHANÇA, CONSIDERANDO UMA IMAGEM REPRESENTADA NOVE PIXELS (A), SENDO (I,J) O CENTRAL. (B) REFERE-SE AOS PIXELS CONECTADOS POR VIZINHANÇA-4; (C) POR VIZINHANÇA-8. FONTE: AUTOR. .178

FIGURA D.1 - HISTOGRAMA DE UMA IMAGEM UTILIZADA COMO REFERENCIA PARA ILUSTRAR OS PARÂMETROS UTILIZADOS NO METODO INTENSITY CAPPING E PARA PERMITIR A IDENTIFICAÇÃO DOS PIXELS QUE SE COMPORTAM COMO BRIGHT SPOTS. FONTE: ADAPTADO DE SHAVIT, LOWE E STEINBUCK (2007)

FIGURA E.1 - EXEMPLO ILUSTRATIVO DE UMA SOBREPOSIÇÃO DE JANELA DE INTERROGAÇÃO, CONSIDERANDO 50\% NA DIREÇÃO HORIZONTAL E 75\% NA DIREÇÃO VERTICAL. FONTE: ADAPTADO DE DUARTE (2005) 184

FIGURA E.2 - EXEMPLO ILUSTRATIVO DA RELAÇÃO DE DEPENDÊNCIA EXISTENTE ENTRE A LOCALIZAÇÃO DOS VETORES, O TAMANHO DA JANELA DE INTERROGAÇÃO E A PORCENTAGEM DE SOBREPOSIÇÃO. (A) I $W=32$ PIXELS; 0\% DE OVERLAP; GRID = 32 PIXELS. (B) $I W=32$ PIXELS; 50\% DE OVERLAP; GRID = 16 PIXELS. FONTE: ADAPTADO DE LAVISION (2017). 185

FIGURA F.1 - CAMPO VETORIAL PROCESSADO A PARTIR DE IMAGENS PRIMÁRIAS DE UM ESCOAMENTO ROTACIONAL UTILIZANDO SCC. (A) I $W=16$ PIXELS, SEM MULTI-PASS; (B) $I W=8$ PIXELS, SEM MULTI-PASS; (C) $I W=32$ PIXELS; COM MULTI-PASS DECRESCENTE ATÉ 8 PIXELS. FONTE: ADAPTADO DE LAVISION (2017). 
FIGURA G.1 - MEDIDAS DO ESCOAMENTO DO AR SEM O SPRAY, PARA 100 BAR E 0,066 KG/S UTILIZANDO A ABORDAGEM SCC A PARTIR DA IMAGEM APÓS O PRÉ-PROCESSAMENTO BETA. MÉDIA TEMPORAL DO MÓDULO DE VELOCIDADE (A) E DA RELAÇÃO SINAL-RUÍDO (B). (C) RMS DA FLUTUAÇÃO DO MÓDULO DE VELOCIDADE. 188

FIGURA G.2 - MEDIDAS DO ESCOAMENTO DO AR SEM O SPRAY, PARA 100 BAR E 0,066 KG/S UTILIZANDO A ABORDAGEM SCC A PARTIR DA IMAGEM APÓS O PRÉ-PROCESSAMENTO BETA. MÉDIA TEMPORAL DO MÓDULO DE VELOCIDADE (A) E DA RELAÇÃO SINAL-RUÍDO (B). RMS DA FLUTUAÇÃO DO MÓDULO DE VELOCIDADE. 189

FIGURA G.3 - MEDIDAS DO ESCOAMENTO DO AR SEM O SPRAY, PARA 100 BAR E 0,066 KG/S UTILIZANDO A ABORDAGEM SCC A PARTIR DA IMAGEM APÓS O PRÉ-PROCESSAMENTO ALFA. MÉDIA TEMPORAL DO MÓDULO DE VELOCIDADE (A) E DA RELAÇÃO SINAL-RUÍDO (B). (C) RMS DA FLUTUAÇÃO DO MÓDULO DE VELOCIDADE. 190

FIGURA G.4 - MEDIDAS DO ESCOAMENTO DO AR SEM O SPRAY, PARA 100 BAR E 0,066 KG/S UTILIZANDO A ABORDAGEM SCC A PARTIR DA IMAGEM APÓS O PRÉ-PROCESSAMENTO ALFA. MÉDIA TEMPORAL DO MÓDULO DE VELOCIDADE (A) E DA RELAÇÃO SINAL-RUÍDO (B). RMS DA FLUTUAÇÃO DO MÓDULO DE VELOCIDADE. 191

FIGURA G.5 - MEDIDAS DO ESCOAMENTO DO AR SEM O SPRAY, PARA 100 BAR E 0,066 KG/S UTILIZANDO A ABORDAGEM RPC A PARTIR DAS IMAGENS PRIMÁRIAS. MÉDIA TEMPORAL DO MÓDULO DE VELOCIDADE (A) E DA RELAÇÃO SINAL-RUíDO (B). (C) RMS DA FLUTUAÇÃO DO MÓDULO DE VELOCIDADE. 192

FIGURA G.6 - MEDIDAS DO ESCOAMENTO DO AR SEM O SPRAY, PARA 100 BAR E 0,066 KG/S UTILIZANDO A ABORDAGEM RPC A PARTIR DAS IMAGENS PRIMÁRIAS. MÉDIA TEMPORAL DO MÓDULO DE VELOCIDADE (A) E DA RELAÇÃO SINAL-RUÍDO (B). RMS DA FLUTUAÇÃO DO MÓDULO DE VELOCIDADE. 193

FIGURA H.1 - FLUXOGRAMA DA ESTRATÉGIA DE PRÉ-PROCESSAMENTO ADOTADA PARA TRATAR AS IMAGENS PRIMÁRIAS UTILIZADAS NA ANÁLISE GÁS-SPRAY (CONTINUA). 194

FIGURA H.2 - FLUXOGRAMA DA ESTRATÉGIA DE PROCESSAMENTO ADOTADA PARA GERAR OS CAMPOS HÍBRIDOS. 196

FIGURA H.3 - FLUXOGRAMA DA ESTRATÉGIA DE PRÉ-PROCESSAMENTO EMPREGADA PARA GERAR OS CAMPOS SCC UTILIZADOS NA COMPOSIÇÃO DOS CAMPOS HÍBRIDOS. 197 
FIGURA H.4 - FLUXOGRAMA DA ESTRATÉGIA DE PÓS-PROCESSAMENTO COMPLETA

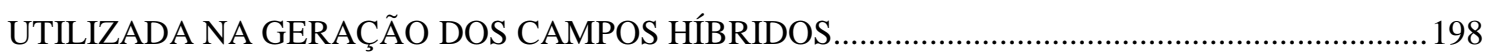




\section{LISTA DE TABELAS}

TABELA 3.1 - CONFIGURAÇÕES EXPERIMENTAIS ESCOLHIDAS PARA ANÁLISE DA

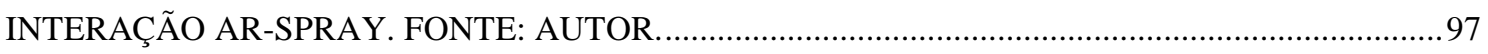

TABELA 3.2 - PARÂMETROS DE PROCESSAMENTO PIV UTILIZADOS NA ABORDAGEM MULTIGRID. FONTE: AUTOR

TABELA 4.1 - NOVA ESTRATÉGIA DE JANELAMENTO MULTIGRID BASEADA NA VARIAÇÃO DA SOBREPOSIÇÃO EM UMA JANELA DE INTERROGAÇÃO INICIAL DE 48 PIXELS. FONTE: AUTOR.

TABELA 4.2 - SÍNTESE DAS OBSERVAÇÕES EXPERIMENTAIS ACERCA DO ESCOAMENTO BIFÁSICO AR-SPRAY, CONSIDERANDO O EFEITO DOMINANTE DA PRESSÃO DE INJEÇÃO DO ETANOL. FONTE: AUTOR 154 


\section{LISTA DE ABREVIATURAS E SIGLAS}

ASOI After Start of Injection

ANFAVEA Associação Nacional de Fabricantes de Veículos Automotores

AWAMT Adaptive Weighted Angle and Magnitude Threshold

BS Bright Spots

BSOI Before Start of Injection

CCD Charge-Coupled Device

CMOS Complementary Metal Oxide Sensor

DNS Direct Numerical Simulation

EPE Empresa de Pesquisas Energéticas

GDI Gasoline Direct Injection

HWA Hot-Wire Anemometry

IESC Isothermal Ethanol Spray Chamber

ITTC International Towing Tank Conference

IW Interrogation Window

LDV Laser-Doppler Velocimetry

LES Large Eddy Simulation

MAD Median Absolute Deviation

MCI Motor de Combustão Interna

MKE Mean Turbulence Kinetic Energy

$\mathrm{Nd} \quad$ Neodymium-doped

OECD Organization for Economic Co-operation and Development

PDA Phase-Doppler Anemometry

PIV Particle Image Velocimetry

RMS Root Mean Square 
RPC Robust Phase Correlation

SCC Standard Cross Correlation

SNR Signal-to-Noise Ratio

SSM Subtract Sliding Minimum

TKE Turbulence Kinetic Energy

YAG Yttrium Aluminium Garnet

YLF Yttrium and Lithium Fluoride 


\title{
LISTA DE SÍMBOLOS LATINOS
}

\author{
$C(x, y) \quad$ Plano de correlação \\ $C_{i} \quad$ Altura do i-ésimo pico de correlação \\ $f(i, j) \quad$ Imagem de referência local \\ Fator associado à perda de correlação por movimentos registrados \\ $F_{I}$ \\ dentro do plano do plano de luz \\ fora do plano do plano de luz \\ Fator associado à perda de correlação devido à gradientes de \\ $F_{\Delta} \quad$ movimento \\ $F_{\sigma} \quad$ Fator associado à perda de correlação devido à ruído de imagem \\ $I_{o} \quad$ Máxima intensidade de ruído sintético \\ $I(i, j) \quad$ Pixel-alvo \\ $I W_{f} \quad$ Tamanho da janela de interrogação final \\ $I W_{i} \quad$ Tamanho da janela de interrogação inicial \\ $m(i, j) \quad$ Média das intensidades locais de uma imagem de referência \\ $N \quad$ Ordem da matriz kernel \\ $N_{I} \quad$ Quantidade de partículas dentro de uma janela de interrogação \\ $N_{P P P} \quad$ Concentração de imagens de partículas por pixel \\ $\operatorname{Norm}(i, j)$ \\ Intensidade luminosa do pixel resultante do processo de \\ normalização local \\ $N_{+} \quad$ Média espacial do campo de velocidades mais ruidoso \\ $N_{-} \quad$ Média espacial do campo de velocidades menos ruidoso \\ $S \quad$ Parâmetro de sensibilidade à exclusão de vetores \\ SNR limite $\quad$ Limite de SNR \\ $u \quad$ Componente radial do vetor velocidade
}


$U \quad$ Incerteza associada à magnitude dos vetores velocidade

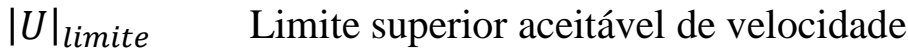

$|\bar{U}| \quad$ Módulo da velocidade média

$|U|^{\prime} \quad$ Módulo da flutuação de velocidade

$|U|_{R M S}^{\prime} \quad$ Root Mean Square do módulo da flutuação de velocidade

$v \quad$ Componente axial do vetor velocidade

$v_{i} \quad$ Velocidade contida em um janela de interrogação $i$

val Incoerência espacial 


\section{LISTA DE SÍMBOLOS GREGOS}

$\begin{array}{cl}\mathfrak{J} & \text { Transformada de Fourier } \\ \phi & \text { Relação Sinal-Ruído } \\ \Delta X_{R M S} & \text { Incerteza associada ao deslocamento médio } \\ \sigma & \text { Desvio padrão } \\ \sigma_{i} & \text { Desvio padrão das intensidades dos pixels de uma imagem i } \\ \sigma(i, j) & \text { Desvio padrão das intensidades locais dos pixels } \\ \sigma_{N} & \text { Intensidade de ruído de imagem }\end{array}$




\section{SUMÁRIO}

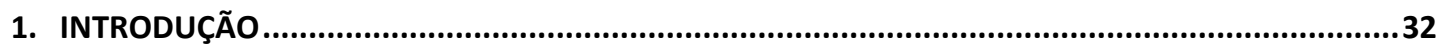

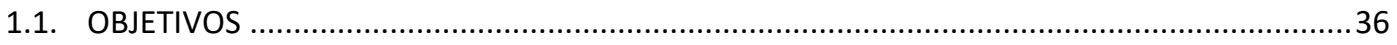

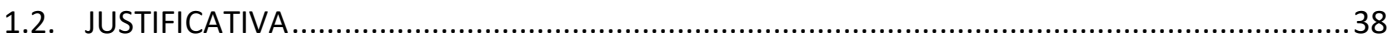

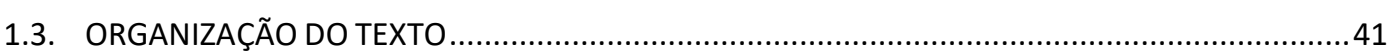

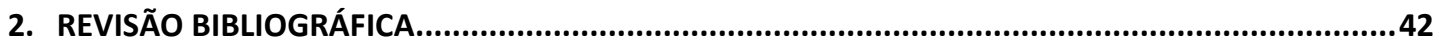

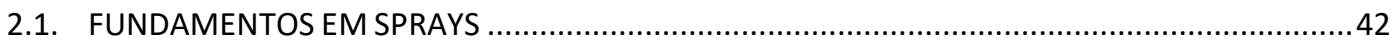

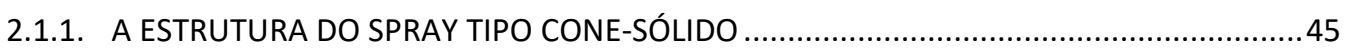

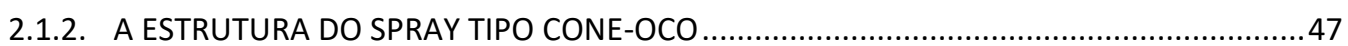

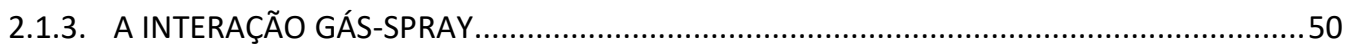

2.2. CONSIDERAÇÕES SOBRE A TÉCNICA DE VELOCIMETRIA POR IMAGENS DE PARTÍCULAS.........57

2.2.1. BOAS PRÁTICAS PARA A APLICAÇÃO DO MÉTODO PIV ................................................67

2.2.2. DESAFIOS DA APLICAÇÃO DA TÉCNICA DE VELOCIMETRIA POR IMAGENS DE PARTÍCULAS PARA CARACTERIZAR SPRAYS DE COMBUSTÍVEL DENSOS ............................................75

2.3. ESTRATÉGIAS PIV UTILIZADAS PARA CARACTERIZAR SPRAYS DENSOS APLICADOS EM MOTORES DE COMBUSTÃO INTERNA EQUIPADOS COM SISTEMA DE INJEÇÃO DIRETA ..........80

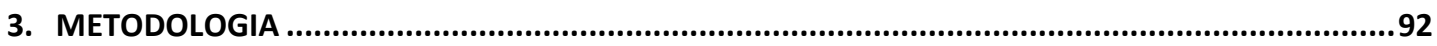

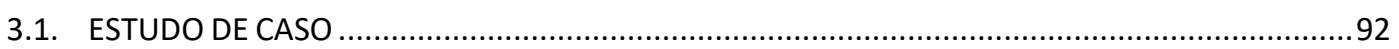

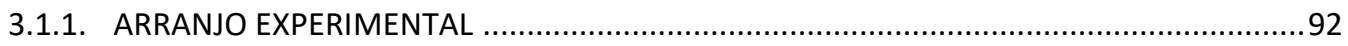

3.1.2. CASOS SELECIONADOS PARA ANÁLISE DA INTERAÇÃO AR-SPRAY ................................96

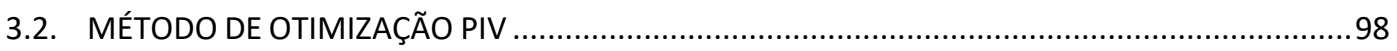

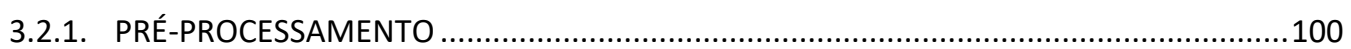

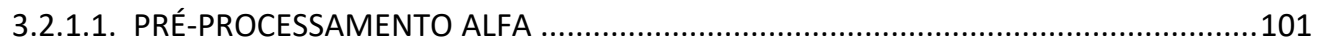

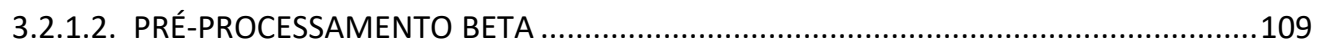

3.2.2. ESTRATÉGIA DE INTERROGAÇÃO E PROCESSAMENTO PIV .........................................116

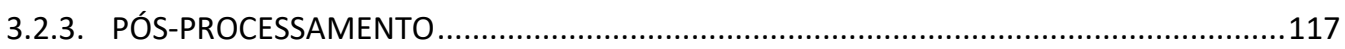

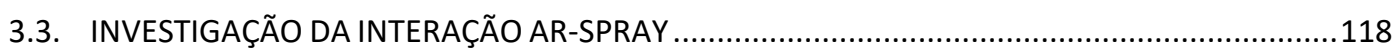

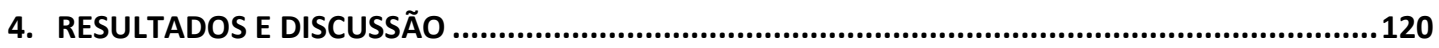

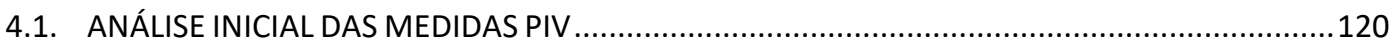

4.2. ANÁLISE DAS MEDIDAS COM PSEUDO-ALTA RESOLUÇÃO ESPACIAL ……….......................128

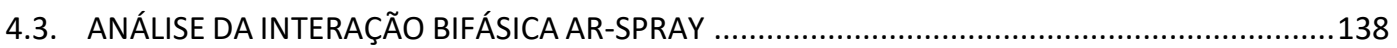

5. CONCLUSÃO

5.1. SUGESTÕES PARA O DESENVOLVIMENTO DE TRABALHOS FUTUROS .....................................157 


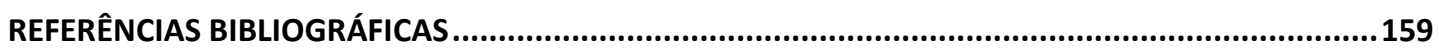

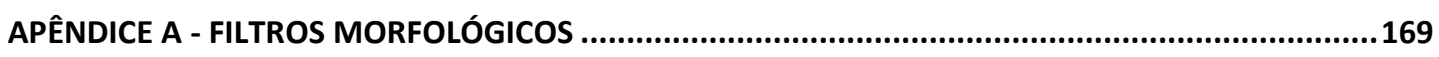

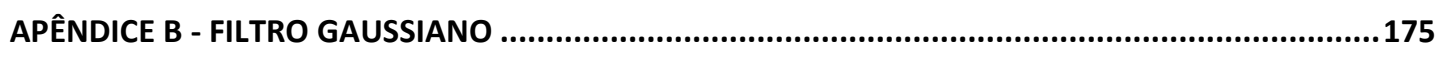

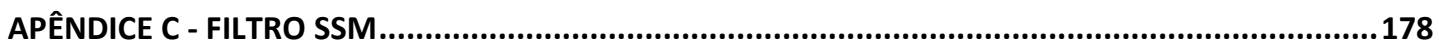

APÊNDICE D - O MÉTODO DA CAPA DE INTENSIDADE............................................................. 180

APÊNDICE E - ESTRATÉGIA DE SOBREPOSIÇÃO DE JANELAS DE INTERROGAÇÃO ...........................184

APÊNDICE F - MÉTODO DE PROCESSAMENTO PIV POR MÚLTIPLOS PASSOS.................................186

APÊNDICE G - MEDIDAS DO ESCOAMENTO DE AR CIRCUNDANTE OBTIDAS PARA O CASO $1 \ldots . . . . .188$

APÊNDICE H - FLUXOGRAMAS DAS ETAPAS DE PRÉ-PROCESSAMENTO E PROCESSAMENTO

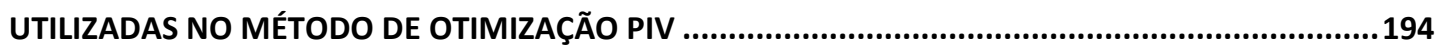




\section{INTRODUÇÃO}

A mobilidade urbana é um dos atuais e mais importantes desafios que as cidades contemporâneas vivenciam ao redor do mundo, muitas vezes causados por modelos inadequados de planejamento de transportes. Entretanto, embora exista um esforço considerável por parte dos governos mundiais para resolver o problema de mobilidade, dados da Organização para Cooperação Econômica e Desenvolvimento mostram que a demanda por transporte individual ainda apresenta constante crescimento em todo o mundo, fato que leva a crer que a mobilidade por meio de automóveis é, e permanecerá sendo durante as próximas décadas, uma alternativa utilizada por grande parte da população global. Por conseguinte, graças ao cenário de crescimento das frotas mundiais de veículos automotores, fica evidenciado que a indústria automobilística pode vislumbrar um potencial de crescimento a curto prazo (OECD/ITF, 2017; ANFAVEA, 2019; TISCHER e POLETTE, 2019).

Devido ao cenário apresentado, a indústria automobilística tem mostrado interesse em desenvolver pesquisas voltadas à busca por tecnologias que possam ser destinadas à propulsão dos novos veículos, os quais devem consolidar a alta eficiência de conversão energética com a geração de impacto ambiental diminuta. Em relação ao último aspecto, prescinde-se um incentivo adicional por parte da indústria em encontrar rapidamente uma alternativa factível para eliminar os combustíveis fósseis da matriz energética do setor de transportes nacional, uma vez que as frotas atuais são majoritariamente propelidas por motores de combustão interna (MCIs). Vale destacar que os MCIs, quando operados com combustíveis fósseis, são responsáveis por emitir consideráveis níveis de gases do efeito estufa, de hidrocarbonetos não queimados, de material particulado e de diversos outros poluentes na atmosfera, o que configura uma série de problemas ambientais a serem discutidos (ZABEU, 2018).

Uma das soluções promissoras e capaz de suprir as demandas mencionadas consiste na adoção de sistemas de injeção direta de combustível em motores de ignição por faísca e que, preferencialmente, utilizem o etanol como fonte energética. $\mathrm{O}$ intuito de utilizar este tipo de sistema de injeção decorre da boa combinação entre o baixo consumo de combustível, os menores níveis de emissão de poluentes, além das diversas benesses que o mesmo propicia aos motores, incluindo as maiores eficiências de conversão energética atualmente almejadas (BAUMGARTEN, 2006; MERKER, SCHWARZ e 
TEICHMANN, 2009; LI, NISHIDA e HIROYASU, 2011). Já o etanol é um forte candidato a propelir as próximas frotas por ser um dos combustíveis renováveis que mais tem sido produzido mundialmente em larga escala e que teve crescimento mais pronunciado nos últimos anos, quando comparado a outros insumos energéticos alternativos, segundo Dias e Carvalho (2017). Além disso, o álcool possui propriedades físico-químicas que produzem efeitos interessantes aos MCIs e às respectivas curvas características que os descrevem, aspectos tais que os tornam um candidato interessante para ser utilizado como propelente tanto de motores de ignição por faísca quanto de motores de ignição espontânea, com alta eficiência de conversão energética, conforme apresentam Turner (2007), Brusstar e Bakenhus (2010), Moreal et al. (2017, 2018) e Todaro et al. (2019).

Sendo o spray de combustível o elemento que carrega consigo a fonte energética dos MCIs, a ampliação do conhecimento sobre a relação existente entre o ar admitido pelo motor e o spray de combustível injetado nos cilindros é cogente para nutrir a discussão sobre o alcance de melhores eficiência de combustão em MCIs a partir da qualidade da mistura ar-combustível. Deste modo, ao considerar o uso do etanol como combustível nos novos motores, é iminente a necessidade de melhor caracterizar o spray do álcool no ambiente em que ele for injetado. Tal caracterização é conseguida através do estudo mais aprofundado acerca da interação fluidodinâmica entre as gotículas de combustível e o gás circundante, considerando uma condição típica aos motores equipados com sistema de injeção direta. Tal ciência contribui positivamente com a expansão do conhecimento sobre a interação gás-spray e amplia a base de dados para validação de diversos modelos de atomização e de resultados provenientes de modelos numéricos. Para tanto, a proposição de uma metodologia de medição e de análise confiáveis do escoamento bifásico gás-spray é fundamental para enriquecer o conhecimento sobre a interação que existe entre os fluidos (ROTTENKOLBER et al., 2002; BAUMGARTEN, 2006; MERKER, SCHWARZ e TEICHMANN, 2009; LI, NISHIDA e HIROYASU, 2011; ZABEU, 2018; BERTI, 2018).

Para o estudo e caracterização do spray de combustível em um determinado ambiente, é necessário investigar as relações que existem entre algumas propriedades físicas do fluido a ser atomizado e do ambiente gasoso que o receberá com o escoamento turbulento que se desenvolve durante o evento de injeção de um spray. As relações percebidas entre os fatores físicos mencionados são verificadas através da análise 
fluidodinâmica do escoamento gás-spray, que deve considerar a influência de adimensionais típicos às análises de escoamento turbulento e de classificação do regime de atomização (BEER e CHIGIER, 1972; LEFEBVRE, 1989). Além disso, o comportamento de cada uma das fases presentes no escoamento quanto às estruturas que as definem é comumente observado através dos campos vetoriais de velocidade, os quais podem servir de fonte provedora de informações sobre o caráter turbulento do escoamento bifásico. Adicionalmente, vale salientar que a interação espacial que existe entre as fases é governada por variáveis como o tamanho e a distribuição das gotas, além da distribuição de velocidade e de propriedades cinemáticas e termodinâmicas do gás ambiente, segundo Moon et al. (2007, 2010), Zhang et al. (2014) e Jedelsky et al. (2018).

Uma forma de caracterizar a interação cisalhante entre o ar e o spray de combustível se dá por meio do uso da técnica experimental de Velocimetria por Imagens de Partículas (Particle Image Velocimetry - PIV, em inglês), capaz de investigar a fluidodinâmica de um determinado escoamento de maneira não intrusiva. Nessa técnica, partículas traçadoras são inseridas no fluido de interesse e têm suas posições registradas por câmeras em diferentes instantes. Tais partículas devem ser criteriosamente selecionadas de modo a interferir de maneira irrisória nas estruturas do escoamento e devem ser inseridas ao fluido com concentração tal que os resultados provenientes da aplicação da técnica sejam confiáveis. Sucintamente, a etapa de análise pós-aquisição das imagens PIV aplicada a sprays é dividida em três grandes blocos: (i) pré-processamento, responsável por tratar as imagens de partículas primárias; (ii) processamento, etapa de obtenção dos vetores deslocamento médio representativo de uma população de partículas; (iii) pós-processamento, responsável por eliminar vetores de deslocamento que não estejam em conformidade às suas respectivas vizinhanças (WESTERWEEL, 1997; RAFFEL, WILLERT, et al., 2007; ADRIAN e WESTERWEEL, 2011; MOURA, 2017).

Contudo, é importante frisar que a aplicação da técnica de PIV destinada à análise do escoamento bifásico gás-spray apresenta alguns aspectos que podem denegrir a representatividade do resultado final em relação à realidade, tais como: (a) a inadequada concentração de imagens de partículas; (b) o elevado ruído de imagem em decorrência ao forte espalhamento de luz causado pela presença do spray; (c) a aplicação de estratégias de correlação sem análise detalhada do plano de correlação, isto é, uso de estratégias que não priorizam maximizar a relação sinal-ruído e (d) a aplicação em demasia de filtros de processamento do campo vetorial final que comprometa a fidelidade da relação entre a 
representação do escoamento e a realidade. Além disso, é importante destacar que o procedimento experimental deve ser elaborado de modo a garantir que a nulidade ou o mínimo de partículas traçadoras tenham seu movimento desenvolvido para fora do plano de luz e que os gradientes de movimento em uma sequência de imagens seja o menor possível (TOWERS, TOWERS e REEVES, 1999; KHALITOV e LONGMIRE, 2002; KOSIWCZUK, CESSOU, et al., 2005; RAFFEL, WILLERT, et al., 2007; ADRIAN e WESTERWEEL, 2011; SCHARNOWSKI e KÄHLER, 2016a; SCHARNOWSKI e KÄHLER, 2016b; MOURA, 2017; AMARAL, 2017; BERTI, 2018).

Diante da necessidade de melhor caracterizar a interação gás-spray evidenciada pelo cenário de crescimento potencial da indústria automobilística, verifica-se que a literatura apresenta diversos estudos acerca da dinâmica do respectivo escoamento bifásico, com foco principal na caracterização individual das estruturas de cada fase. A maioria dos trabalhos versam sobre a discussão dos resultados provenientes de ensaios de sprays de combustíveis fósseis, a partir do uso da técnica de PIV para descrever as estruturas do escoamento. Todavia, não é encontrada nessa maioria a presença de procedimentos que tratam as imagens primárias (isto é, as fotografias das imagens de partículas sem processamento digital) e/ou o plano de correlação detalhadamente, embora todos eles tenham direta ou indiretamente o objetivo de alcançar resultados que façam sentido à realidade, como é o caso dos estudos publicados por Moon et al. (2007) e por Zhang et al. (2014). Analogamente, são poucos os estudos que tratam sobre os aspectos que influenciam a qualidade do campo vetorial final a partir da análise do sinal no plano de correlação frente ao ruído e/ou apresentam uma análise do pré-processamento na qualidade dos resultados, conforme foi apresentado por Rottenkolber et al. (2002) e Berti (2018). Finalmente, mediante uma pesquisa detalhada na literatura, nota-se que é nula a quantidade de estudos dirigidos à otimização da técnica de velocimetria por imagens de partículas bifásico, aplicada à investigação acerca do escoamento gás-spray, para obter os parâmetros atrelados à fluidodinâmica do referido escoamento com melhor confiabilidade. É nesse âmbito que o presente trabalho está inserido e busca oferecer uma metodologia capaz de propiciar ao usuário do método uma ferramenta que o assegure quanto ao uso da técnica de $P I V$, especialmente em situações em que a qualidade dos resultados pode estar comprometida pela presença acentuada de fontes de ruído competentes para inferiorizar a magnitude dos fatores que compõem o número efetivo de partículas. Adicionalmente, o estudo intenciona investigar a interação gás-spray com base 
em eventos de injeção de sprays de etanol originados por um injetor típico de MCIs equipados com sistema de injeção direta. Para isso, pretende-se utilizar os resultados provenientes de um método de otimização PIV dedicado a produzir medidas coerentes e fidedignas à realidade.

\subsection{OBJETIVOS}

O presente trabalho tem como objetivo principal propor uma metodologia de otimização da técnica de $P I V$ que propicie conclusões legítimas acerca da interação entre o spray de etanol e o gás ambiente que o circunda. Para tanto, entender-se-á a otimização como um procedimento dedicado ao aprimoramento das etapas sucedentes à gravação de imagens $P I V$, com vistas à proposição de uma metodologia baseada em boas práticas em $P I V$, que objetiva caracterizar a interação gás-spray a partir de medidas válidas e coerentes. O objetivo secundário do trabalho consiste em estudar a interação entre as fases do escoamento gás-spray com base na cinemática da fase gasosa, considerando os resultados obtidos com a aplicação do método de otimização PIV proposto. Para tanto, balizado em observações contidas na literatura, o módulo, as componentes e o ângulo dos vetores velocidade que descrevem a cinemática do escoamento são selecionados como parâmetros de referência, além do campo de vorticidade. Adicionalmente, pretende-se avaliar os efeitos que pressão de injeção do spray oferece ao desenvolvimento do escoamento bifásico, considerando a penetração do spray em um ambiente circundante mantido a vazão constante. Sendo assim, o trabalho visa oferecer contribuições prática, com a melhoria da técnica de PIV; científica, com a análise da interação bifásica do escoamento gás-spray e tecnológica, com a verificação da influência da pressão de injeção no comportamento fluidodinâmico do escoamento em estudo.

No tocante ao aprimoramento da etapa de tratamento das imagens primárias gravadas, propor-se-á um método de pré-processamento que contempla a consecução de duas metodologias de tratamento de sinais. Ambas são produzidas a partir de técnicas de processamento digital de imagens e foram elencadas para atender às seguintes especificações: 
- eliminar o ruído de fundo e qualquer interferência luminosa proveniente do espalhamento-Mie que denigra a representação das imagens de partículas fluorescentes, com alta eficiência;

- suprimir a forma do spray nas imagens de fluorescência, sem utilizar as imagens primárias da fase líquida;

- garantir o melhor discernimento possível entre as partículas traçadoras presentes no ar e as gotículas de combustível, ambas coexistentes nas imagens referentes ao escoamento de fluido circundante, para que a última possa ser excluída na maior quantidade possível;

- manter as imagens das partículas traçadoras com alto contraste em relação ao plano de fundo das imagens primárias;

- alcançar boa distribuição de intensidade luminosa para as imagens de partículas;

- discorrer sobre a adequabilidade da concentração de traçadores presentes nas imagens primárias.

Quanto aos refinamentos da estratégia de interrogação e processamento $P I V$, bem como da etapa de pós-processamento, o presente estudo intenciona realizar as seguintes etapas:

- encontrar uma combinação ótima entre o tamanho da janela de interrogação, a estratégia de janelamento e a concentração de partículas traçadoras, sendo a última diagnosticada na etapa de pré-processamento;

- comparar a eficácia de um método de correlação que exime a necessidade de tratar as imagens primárias com os resultados provenientes da correlação entre as imagens tratadas pelas metodologias de pré-processamento propostas;

- tratar todos os dados provenientes da etapa de correlação com métodos de pósprocessamento mais robustos frente aos convencionalmente utilizados;

- julgar a qualidade dos resultados através de parâmetros típicos, como as coerências espacial e temporal, além da relação sinal-ruído do plano de correlação. 


\subsection{JUSTIFICATIVA}

Ao considerar o contínuo e crescente uso de veículos automotores equipados com motores de combustão interna, é importante a proposição de estudos sobre os caminhos pelos os quais a melhoria da conversão de energia atrelada à necessidade de formação mínima e restrita de poluentes serão alcançadas, uma vez que a população global ainda se locomove, e pretende continuar se locomovendo durante as próximas décadas, utilizando automóveis. Uma das maneiras de conseguir atingir esta expectativa é a partir da investigação do processo de queima da mistura ar-combustível promovido em motores com elevada eficiência de combustão, convenientemente utilizando fontes renováveis. Neste âmbito, os motores que dispõem de sistemas de injeção direta são fortes candidatos a serem utilizados nas frotas futuras (DANKERS et al., 2008; OECD/ITF, 2017; ZABEU, 2018; TISCHER e POLETTE, 2019).

Adicionalmente, vale ressaltar que o etanol é um dos combustíveis renováveis que mais tem sido produzido em larga escala e teve crescimento mais pronunciado nos últimos anos, quando comparado a outros insumos energéticos alternativos, como o biodiesel. Tal fato é apresentado no trabalho de Dias e Carvalho (2017), que divulgam as projeções de produção e comércio mundial do álcool, considerando uma série histórica conhecida. Além de sumarizar os dados prospectados pelo OECD/FAO (2015), os autores apresentam uma projeção que mostra que em 2024 o Brasil terá produção e consumo de etanol igual a $31 \%$ e $29 \%$ de todo o etanol produzido e consumido a nível global, respectivamente, o que o tornará o país representante da segunda maior parcela de consumidor e produtor do combustível no mundo, superado apenas pelos norteamericanos. É com essa motivação, portanto, que a iniciativa de adotar o spray de etanol aplicado a motores equipados com injeção direta de combustível é considerada no presente trabalho e espera ser justificada.

Em MCIs equipados com sistema de injeção direta, a formação da mistura arcombustível é um processo crítico à qualidade da combustão gerada e, consequentemente à sua eficiência. Nesses sistemas de conversão de energia, a mistura ar-combustível opera como uma variável dependente das características do spray e das interações que acontecem entre ele e o gás ambiente que o circunda (DANKERS, GOTTHARDT, et al., 2008; ROTTENKOLBER, GINDELE, et al., 2002; ZHANG, XU e HUNG, 2014). No entanto, a literatura contemporânea apresenta, na quase absoluta maioria dos casos, 
estudos voltados à análise de desenvolvimento de sprays de combustíveis fósseis, fato que complementa a primeira motivação acerca da execução do presente estudo.

As interações percebidas entre o spray de combustível e o ambiente podem ser avaliadas a partir das estruturas do escoamento por meio de critérios que vão desde a inspeção visual simples até a investigação em escala microscópica (SOID e ZAINAL, 2011). Logo, uma vez considerado conveniente o estudo aprofundado sobre as referidas estruturas que definem o escoamento, a escolha de métodos capazes de extrair informações sobre a interação entre o gás e o spray de combustível é cogente. Sendo assim, as técnicas experimentais não intrusivas capazes medir variáveis próprias ao escoamento bifásico ar-spray se tornam imprescindíveis.

O uso da técnica de PIV em análises de escoamentos turbulentos tem sido visto de modo recorrente como uma ferramenta experimental efetiva da mecânica dos fluidos. A grande utilidade do método advém da capacidade de medição instantânea do campo de velocidades de escoamentos turbulentos em uma dada região, de maneira indireta, não intrusiva. Como uma forma de evidenciar a grande evolução da frequência de aplicação do método, a Figura 1.1 mostra uma análise presente no trabalho de Westerweel, Elsinga e Adrian (2013) que apresenta o aumento do uso da técnica PIV comparado a outras duas: a HWA (Hot-Wire Anemometry) e o LDV (Laser-Doppler Velocimetry). Dentre os motivos que a torna uma das principais técnicas de medição indireta de velocidade, destaca-se o fato da técnica de PIV não apresentar interferência significativa nas estruturas do escoamento (admitindo a escolha adequada do traçador) e resolver o campo de velocidades de modo espacial e não só puntual, como é feito com o $H W A$ e o $L D V$. Vale destacar que, com base no cenário e nos dados apresentados e sintetizados pelos autores, a frequência de aplicação da técnica de $P I V$ promete se manter superior às demais nas próximas décadas. 
Figura 1.1 - Ocorrência relativa de utilização das técnicas de medição de velocidade de escoamentos turbulentos, tendo como base as publicações feitas na plataforma on-line Google Books, entre os anos de 1982 e 2008.

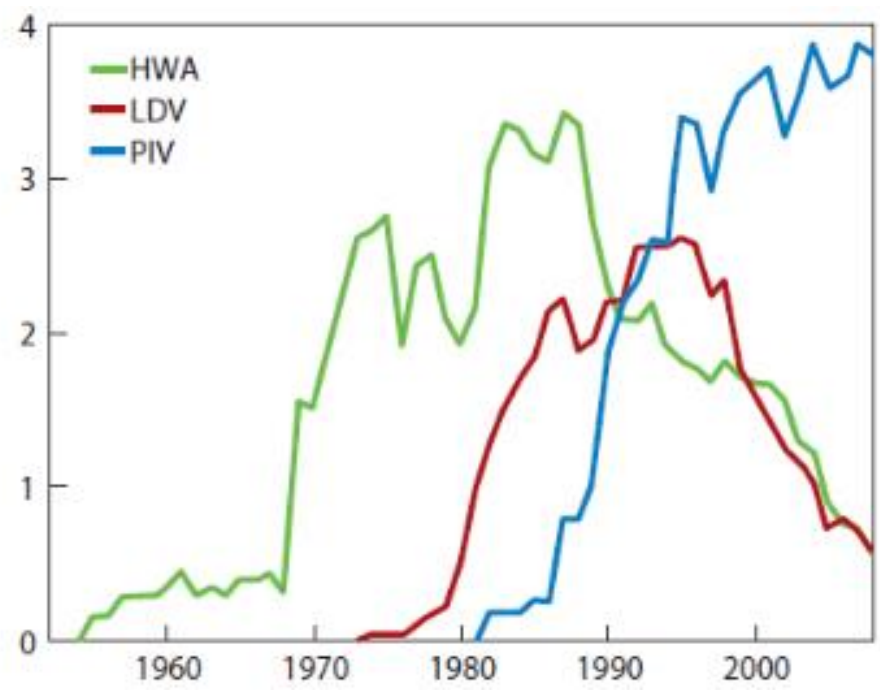

Fonte: Westerweel, Elsinga e Adrian (2013).

Dentre os vários trabalhos que utilizaram PIV como metodologia experimental para determinar campos de velocidade em escoamentos turbulentos, algumas aplicações em análise de sprays também foram feitas, como é o caso de Rottenkolber et al. (2002), Moon et al. (2007), Dankers et al. (2008), Li et al. (2011), Zhang et al. (2014), Berti (2018) e Zabeu (2018). Nestes trabalhos, enfatizou-se a real necessidade de desenvolver uma metodologia adequada de processamento das imagens de partículas, uma vez que, até então, identificar as partículas que representam a fase gasosa em meio à presença do combustível em regime de break-up é um grande desafio, principalmente nas regiões de interface entre ambos e na ponta do injetor.

Deste modo, o discernimento entre as partículas traçadoras presentes no ar e as gotículas de combustível é uma necessidade atual e muito pertinente à melhoria da compreensão do escoamento de cada uma das fases, bem como a interação entre ambas, circunstância que motivou a execução do presente trabalho. Além disso, o desenvolvimento de um método de otimização PIV é um incentivo maior à utilização segura do método por parte do usuário, o que confere maior confiabilidade aos resultados $P I V$. Por fim, vale salientar que os trabalhos presentes na literatura abrangem majoritariamente a observação do escoamento de sprays de combustíveis fósseis (principalmente o óleo diesel e a gasolina), o que torna ainda mais importante estudar as estruturas do escoamento associados aos combustíveis alternativos. 


\subsection{ORGANIZAÇÃO DO TEXTO}

O trabalho está dividido em cinco capítulos e conta com oito apêndices. O presente capítulo introduz o contexto no qual este trabalho se insere, acrescido aos objetivos prometidos e à justificativa com a qual pretende-se apresentá-lo. O capítulo 2 apresenta uma fundamentação teórica em sprays e discute sobre a técnica de PIV no tocante às boas práticas e aos desafios inerentes à sua aplicação. Por fim, nele é apresentada uma revisão bibliográfica dos trabalhos que investigaram a interação ar-spray a partir da aplicação do método PIV. O capítulo 3 expõe as principais informações sobre o estudo de caso avaliado no presente trabalho e os procedimentos utilizados para desenvolver as investigações acerca da interação ar-spray. O capítulo 4 apresenta os resultados obtidos com a aplicação da metodologia proposta. Já o capítulo 5 sumariza as conclusões do trabalho e elenca sugestões para trabalhos futuros. Por fim, coube aos apêndices sumarizar as principais características que permitem complementar as definições de alguns dos métodos de filtragem espacial de imagens, contemplar uma definição sintética sobre as principais componentes do método de processamento PIV utilizado no presente trabalho, apresentar os demais resultados obtidos durante a execução da análise inicial das medidas $P I V$ e oferecer, com base em fluxogramas, uma síntese dos procedimentos adotados no desenvolvimento do método de otimização PIV. 


\section{REVISÃO BIBLIOGRÁFICA}

A revisão bibliográfica oferecida no presente trabalho objetiva apresentar uma síntese das principais referências que abordam o spray no âmbito de sua descrição, discorrer sobre a aplicação da técnica de $P I V$ para medições de sprays e sumarizar considerações hodiernas sobre as estratégias que permitem assegurar o usuário da técnica quanto à qualidade dos resultados obtidos com a aplicação de velocimetria por imagens de partículas.

\subsection{FUNDAMENTOS EM SPRAYS}

A desintegração de um escoamento líquido em uma distribuição de pequenas partículas do mesmo fluido, desenvolvida em um meio gasoso com considerável diferença de velocidade comparada à do líquido, é a maneira de definir a forma e a premissa principal com a qual um spray é produzido, segundo Lefebvre (1989). Atrelada a esta definição, entende-se por atomização o processo de formação de sprays, sendo os atomizadores os dispositivos capazes de produzi-los e responsáveis por determinar a homogeneidade da distribuição do tamanho das gotas que os compõem.

O processo de desintegração de um escoamento líquido consiste, essencialmente, no aumento da superfície que o define até que instabilidades fluidodinâmicas oriundas desse processo sejam encarregadas de quebrar o fluxo em ligamentos e, posteriormente, em gotas. Tal processo de quebra sucessiva depende do caráter turbulento do escoamento no atomizador, das propriedades físico-químicas do fluido a ser atomizado e do ambiente que o receberá. No tocante ao estudo do desenvolvimento de sprays em um determinado meio gasoso, a quebra do escoamento líquido é entendida a partir de uma mudança de uma determinada condição inicial rumo à de transição, promovida por um balanço entre forças de inércia, de arrasto e gravitacional, capaz de predizer as trajetórias do escoamento atomizado em determinadas circunstâncias (BEER e CHIGIER, 1972). Contudo, o processo de desintegração e quebra do escoamento líquido pode ser dividida em duas partes principais: break-up primário (ou regime de quebra de jatos líquidos) e break-up secundário (ou regime de quebra de gotas líquidas). 
Segundo Lefebvre e McDonell (2017), o break-up primário é responsável pela desintegração de um jato líquido que provém de um bocal e se dirige a um ambiente gasoso, enquanto o secundário descreve a fenomenologia de quebra dos ligamentos e das gotas oriundas do regime de quebra de jatos líquidos. De acordo com os autores, ambos os mecanismos ocorrem simultaneamente em distintas regiões do spray e são funções das propriedades do líquido e do gás ambiente, sendo tais funções governadas por parâmetros adimensionais, a saber: o número de Reynolds (relação entre as forças de inércia e as forças viscosas); o número de Weber (relação entre as forças de inércia e a tensão superficial que atua na fronteira do spray líquido) e o número de Ohnesorge (relação entre o número de Weber e o de Reynolds, determinante dos tipos de regime).

Tendo em vista as dependências que as propriedades do líquido e do gás ambiente exercem sobre a formação de um spray, Lefebvre e McDoneel (2017) sugerem classificar o desenvolvimento de um spray em cinco categorias. Todas elas são determinadas a partir da pressão de injeção como variável independente, sendo a primeira considerada a partir de pressão relativa nula e a última, um valor tal que permita alto grau de atomização, portanto, entendida como máxima. As etapas sugeridas são nomeadas e mostradas esquematicamente na Figura 2.1, considerando um bocal atomizador por pressão com swirl. A Figura 2.2 apresenta as mesmas etapas através de fotografias experimentais.

Figura 2.1 - Estágios do desenvolvimento de um spray obtidos mediante aumento da pressão de injeção.

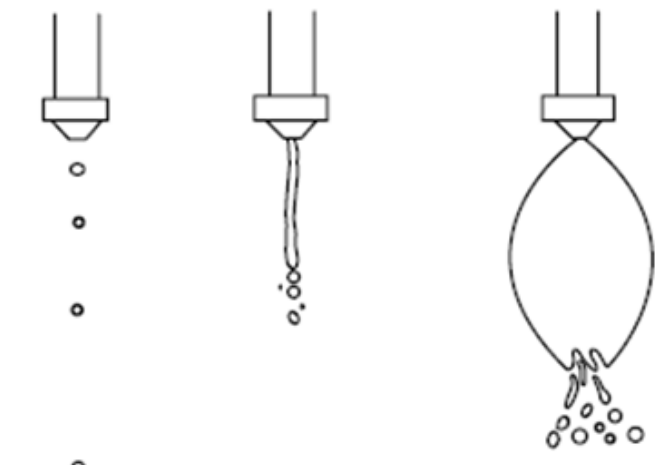

$\circ$

Dribble

Distored

Pencil

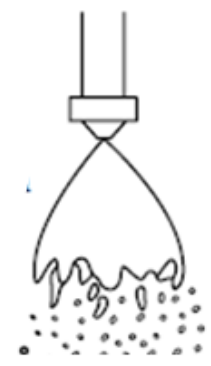

Atomização

Grosseira

Tulip

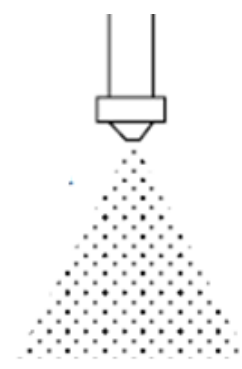

Atomização

Fina

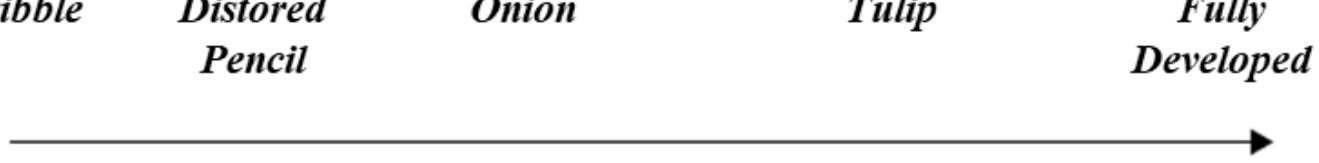

Aumento da pressão de injeção do fluido

Fonte: Adaptado de Lefebvre e McDonell (2017). 
Figura 2.2 - Registros fotográficos dos cinco estágios de desenvolvimento de um spray obtidos mediante aumento da pressão de injeção em um injetor tipo pressure-swirl.

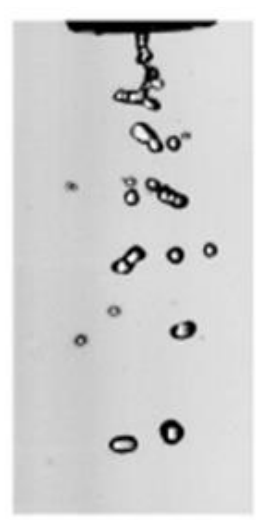

Dribble

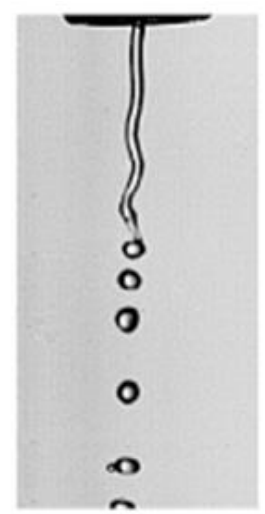

Distored Pencil

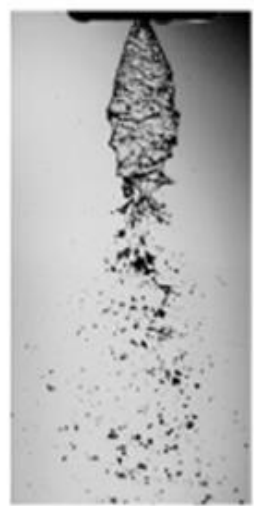

Onion

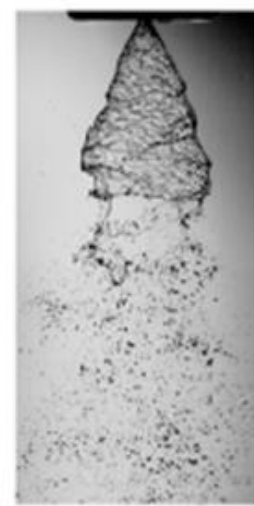

Tulip

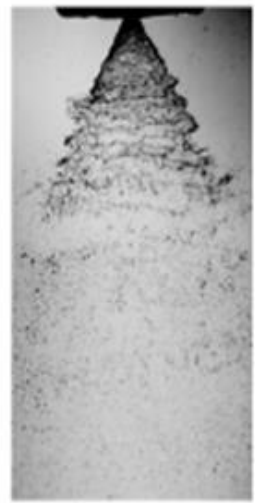

Fully

Aumento da pressão de injeção do fluido

Fonte: Lefebvre e McDonell (2017).

Considerando à presente revisão a fundamentação em sprays encontrados em aplicações da indústria automobilística voltadas ao estudo dos motores de combustão interna, a categoria conveniente de ser aqui discutida e amplamente estudada é a última. Para tanto, essencialmente, existem duas configurações geométricas encontradas para os sprays totalmente desenvolvidos, de modo tal que possam ser classificados e distinguidos entre si a partir dos tipos cone-oco (hollow cone em inglês) e cone sólido (solid cone em inglês). Os dois tipos são mostrados na Figura 2.3 e são produzidos por atomizadores do tipo mecânico-centrífugo (pressure-swirl em inglês). Os sprays tipo cone-oco são aqueles produzidos por injetores que geram gotículas concentradas na periferia de um cone, formando a sua espessura, enquanto para o tipo cone sólido, cujo injetor é conhecido como multi-furos (multi-hole em inglês), apresenta um volume maciço de fluido atomizado na forma de um cone. Para ambas as configurações espaciais, a pressão e a viscosidade do líquido, a geometria do injetor e as condições do gás ambiente são as variáveis que definem as características de um spray, tais como o ângulo de abertura, a penetração, a distribuição do tamanho de gotas, a distribuição de velocidades e de pressão e quaisquer outros parâmetros que possam ser utilizados como descritores de propriedades e aspectos atrelados ao spray (BEER e CHIGIER, 1972; LEFEBVRE, 1989). Segundo Prosperi et al. (2007), apesar dos sprays tipo cone-oco e cone-sólido terem distribuições espaciais de gotas diferentes, ambos contam com a presença de 
estruturas de recirculação que se desenvolvem ao longo da superfície dos cones durante a formação dos sprays. Os autores mostram este comportamento através dos campos de velocidade do ar obtidos para os dois casos, utilizando técnica de velocimetria por imagens de partículas.

Figura 2.3 - Representação dos tipos comuns de sprays produzidos por injetores do tipo mecânicocentrífugo: cone-oco (à esq.) e cone sólido (à dir.).
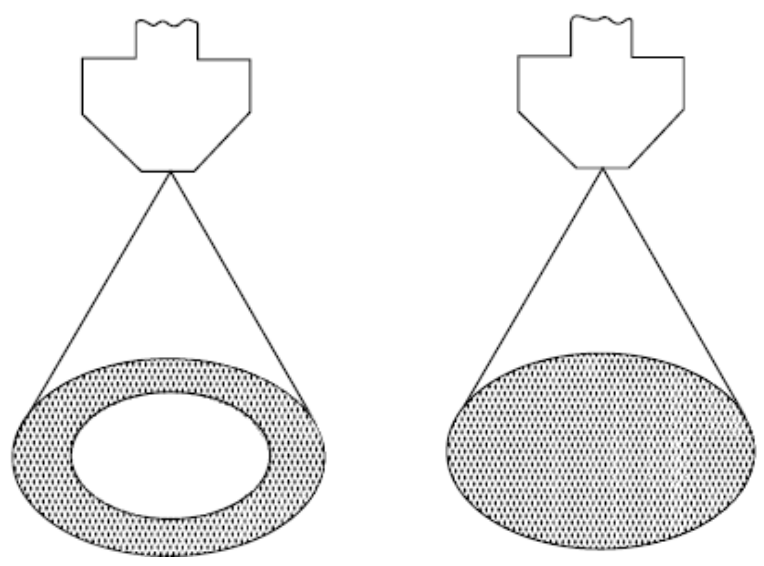

Fonte: Adaptado de Lefebvre e McDonell (2017).

\subsubsection{A ESTRUTURA DO SPRAY TIPO CONE-SÓLIDO}

O spray tipo cone-sólido é formado por injetores do tipo multi-furos (multi-hole em inglês), compostos por uma estrutura metálica maciça que contém orifícios e que é solidária à uma agulha (elemento responsável por permitir que o escoamento líquido passe através dos canais circulares, quando aberta). Nesse tipo de injetor, no qual cada orifício é responsável por formar um cone-sólido, o combustível sofre break-up primário à medida que sai dos furos, o que configura ao spray a sua região mais densa. Tal região é formada pela colisão e coalescência de grandes estruturas na forma de ligamentos e de gotículas, todas provenientes da ação conjunta da cavitação e da turbulência que ocorrem na região interna aos orifícios. A desintegração destas estruturas acontece, portanto, pela presença atuação de forças de natureza aerodinâmica, existentes devido à velocidade relativa entre as gotas e o gás circundante. As forças são as responsáveis pelo desencadeamento do break-up secundário e, consequentemente, pela formação de gotas cada vez menores e pelo aumento da taxa de evaporação em regiões mais distantes da ponta do injetor (BAUMGARTEN, 2006). Entretanto, vale destacar que graças à colisão e à coalescência das estruturas presentes, formam-se regiões de gotículas diametralmente 
maiores no eixo do spray se comparadas àquelas próximas da periferia do cone (LEFEBVRE e MCDONELL, 2017).

As forças aerodinâmicas são também responsáveis por retardar o movimento das gotículas que sofreram break-up, de modo que as partículas líquidas localizadas em maior distância frente àquelas mais próximas tenham menor velocidade. Deste modo, as gotículas presentes na região de fronteira entre o gás circundante e o spray são substituídas pelas gotículas que estão mais próximas ao injetor, e assim, a penetração do fluido atomizado aumenta e estruturas de recirculação são formadas. A partir desta condição, devido à presença de partículas com baixa energia cinética em regiões externas ao spray, a massa específica e a temperatura do gás ambiente, além da distribuição de velocidades, são as propriedades determinantes da evaporação do combustível e do pronunciamento do regime de quebra das gotas (ZABEU, 2018). A Figura 2.4 mostra uma representação esquemática do desenvolvimento de um spray tipo cone-sólido. Ampla discussão sobre os fenômenos descritos no presente tópico é realizada por Baumgarten (2006).

Figura 2.4 - Representação de um spray cone-oco formado por um injetor multi-furos.

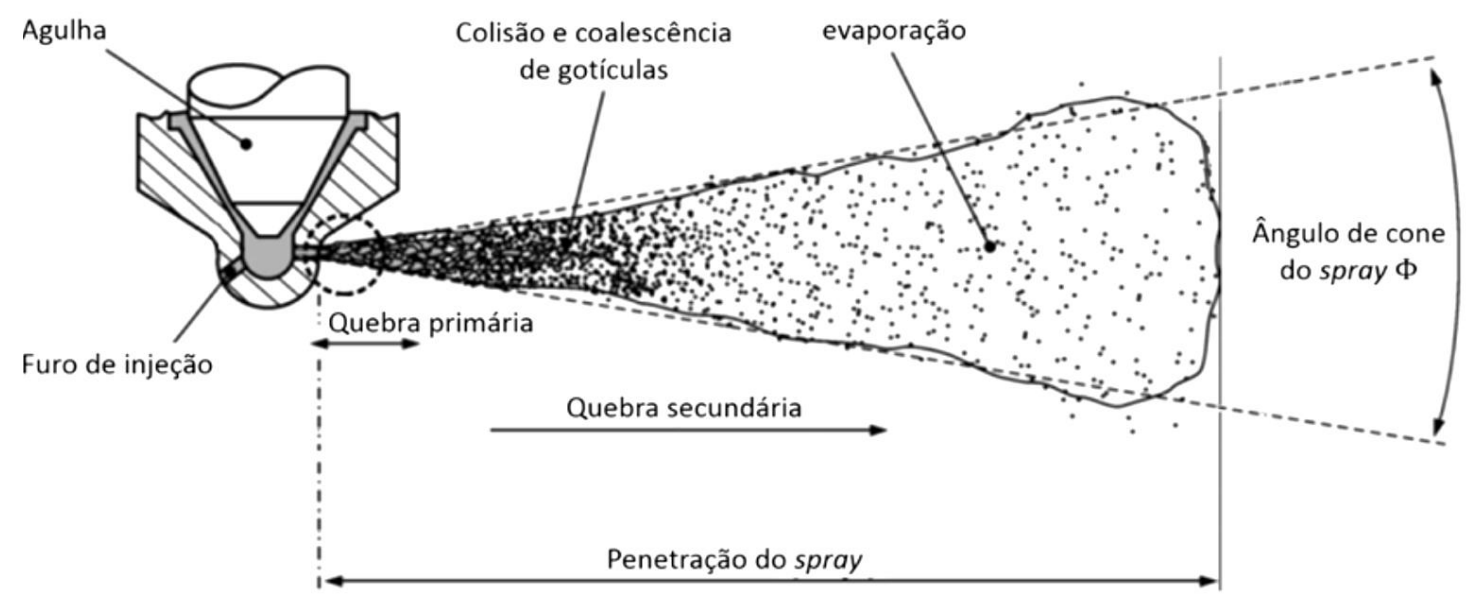

Fonte: Adaptado de Baumgarten (2006).

Zhu et al. (2011) apresentam um estudo que objetiva entender o processo de formação de um spray cone-sólido em um ambiente quiescente. Para tanto, foi utilizado um injetor tipo multi-furos, responsável por atomizar óleo diesel. O processo de formação do spray foi estudado pelos autores a partir da análise da interação entre o combustível e o gás circundante, utilizando como método o cálculo do fluxo de momento linear do ar nas regiões de superfície do spray e considerando que o escoamento é axissimétrico e que 
as gotículas de óleo diesel têm a mesma velocidade na região cisalhante. As informações de velocidade instantânea foram extraídas do campo de velocidades obtido através da aplicação do método PIV. Como resultado do estudo, Zhu et al. (2011) mostram que a maior intensidade de transferência de quantidade de movimento para o gás circundante acontece logo após a injeção e ao final dela. Além disso, os autores mostram que existe uma estrutura de recirculação que se propaga ao longo da região de interface e que é resultante do processo de transferência de quantidade de movimento percebida durante o início da penetração do spray. Logo, vale destacar que as estruturas de recirculação são formadas logo após a presença do combustível no gás ambiente e são intensificadas durante a evolução temporal da região de interface ar-spray. De acordo com os autores, o spray pode ser dividido em três regiões, as quais são mostradas na Figura 2.5.

Figura 2.5 - Regiões típicas pertencentes a um spray cone-sólido em desenvolvimento.

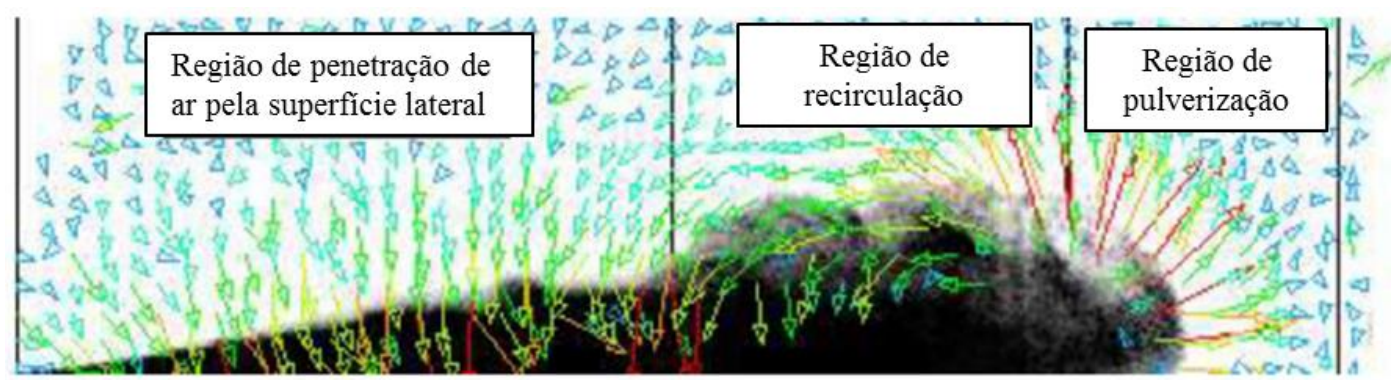

Fonte: Adaptado de Zhu et al. (2011).

\subsubsection{A ESTRUTURA DO SPRAY TIPO CONE-OCO}

O spray tipo cone-oco é formado por injetores tipo mecânico-centrífugo, responsáveis por introduzir o escoamento de fluido injetado com considerável componente radial. Os injetores contam com abertura externa e são compostos por uma estrutura metálica maciça que atua conjuntamente a uma agulha. O spray é formado quando o escoamento líquido passa através de canais cônicos formados entre a estrutura e a agulha, quando aberta.

Os sprays gerados por injetores do tipo cone-oco são recomendados para uso em ambientes com baixa pressão relativa e possuem maior eficiência de atomização frente aos do tipo cone-sólido, isto é, considerando um evento de injeção de um spray, possuem maior quociente entre a área superficial gerada durante o processo de atomização e o volume de fluido atomizado. Além disso, tais injetores propiciam menor penetração no 
gás ambiente e têm melhor homogeneidade da mistura ar-combustível (BAUMGARTEN, 2006).

De maneira distinta à observada nos injetores tipo cone-sólido, os sprays formados por um filme cônico de fluido têm a quebra dos ligamentos e de gotículas ativada por interações turbulentas e por forças de natureza aerodinâmica, principalmente. $O$ processo de break-up primário começa dentro do canal de injeção, local onde iniciam-se as perturbações na superfície do líquido e que são levadas à instabilidade devido à ação conjunta das forças aerodinâmicas exercidas pelo gás circundante. A partir de então, o processo de break-up secundário ocorre de forma análoga aos injetores tipo cone-sólido, cuja dinâmica de quebra é determinada pela presença de forças aerodinâmicas oferecidas às gotas graças à diferença de velocidade que existe entre elas e o gás ambiente (LEFEBVRE e MCDONELL, 2017). A Figura 2.6 mostra as regiões onde ocorrem o pronunciamento das instabilidades do escoamento do líquido, a quebra de ligamentos e de gotas. Nela é possível visualizar a presença de filamentos de líquido compartilhando a região que separa os locais de break-up primário e secundário, além da geração final de gotículas. Alternativamente, a Figura 2.7 mostra uma representação típica das estruturas do injetor hollow-cone tipo abertura externa (a) e mecânico-centrífugo (b), onde é possível verificar as regiões de break-up primário e secundário existentes durante o desenvolvimento do spray. Vale destacar que para o caso do injetor mecânico-centrífugo, há a formação de uma estrutura peculiar e ausente nos demais injetores mencionados: o pré-spray. O pré-spray é desenvolvido devido à incapacidade adquirida pela baixa velocidade das gotículas em gerar o movimento helicoidal. Assim, este pequeno aglomerado de gotas percorre o eixo de simetria do spray.

Figura 2.6 - Morfologia de um spray típico de um injetor tipo cone-oco.

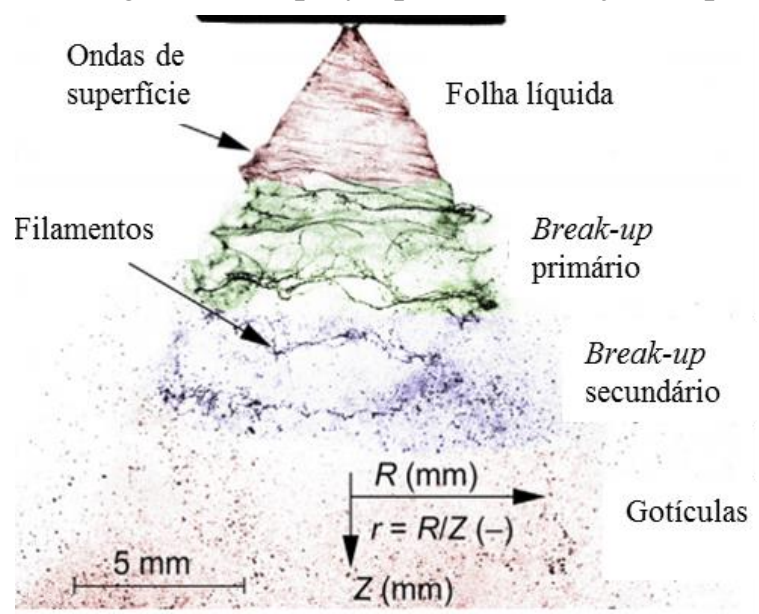

Fonte: Adaptado de Jedelsky et al. (2018). 
Figura 2.7 - Representação das estruturas de formação do spray tipo cone-oco desenvolvido por um injetor com abertura externa (a) e mecânico-centrífugo (b).

(a)

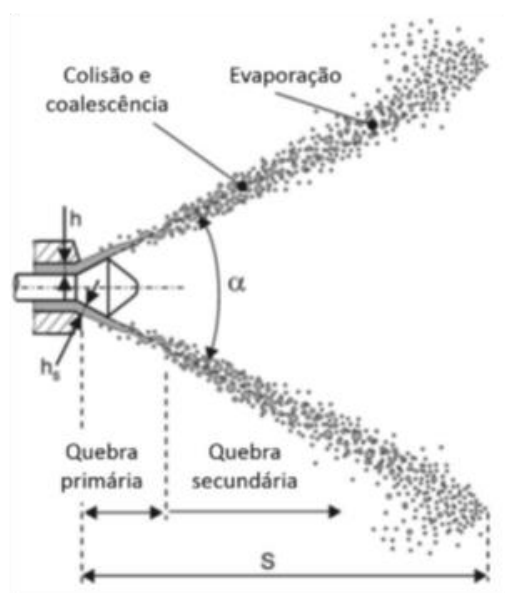

(b)

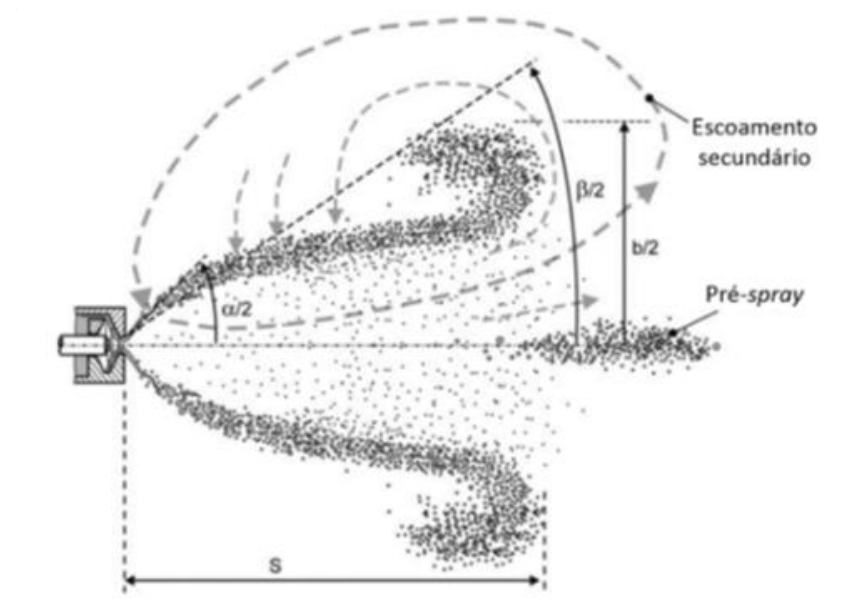

Fonte: Adaptado de Baumgarten (2006).

Rottenkolber et al. (2002), com o objetivo de caracterizar a evolução de sprays tipo cone-oco, estudaram o mecanismo de formação de um spray formado por um injetor tipo hollow-cone, cujo combustível atomizado por ele era a gasolina. A atmosfera que circundava as gotículas de gasolina consistiu em nitrogênio pressurizado em uma câmara de volume constante, que permitia elevar a pressão interna a um teto de 42 bar. Para conseguir obter a caracterização pretendida, os autores adotaram a técnica de PIV para determinar os vetores velocidade que compunham cada uma das fases presentes no escoamento. Como resultado do estudo, os autores propuseram um modelo de distribuição de velocidades ao redor do spray que identifica dois tipos de estruturas, ambas formadas durante a propagação do spray: a interna e a externa.

Considerando o modelo proposto, Rottenkolber et al. (2002) não distinguem a região de penetração de ar em relação à região de recirculação, contrário ao que foi proposto por Zhu et al. (2011). No entanto, esse fato decorre da presença de estruturas recirculantes externas com proporções tão elevadas que "mesclam" as regiões de recirculação identificadas nos sprays desenvolvidos por injetores multi-furos. De acordo com os autores, a estrutura interna ao spray apresenta uma distribuição de velocidade tal que a porção superior direciona as gotículas junto ao gás em direção ao injetor. A razão pela qual estabelece-se este movimento é a baixa pressão encontrada nas vizinhanças da saída do injetor, graças à propagação do cone oco de combustível. Contudo, o comportamento notado na porção inferior é fortemente influenciado pelas estruturas 
recirculantes externas e pela propagação do spray ao longo do seu eixo de simetria. Vale destacar que a região que divide as porções superior e inferior não tem comportamento definido pelos autores. A Figura 2.8 ilustra esquematicamente as estruturas interna e externa existentes durante o desenvolvimento de um spray formado por um injetor hollow-cone. A referida figura mostra uma comparação entre o comportamento das estruturas recirculantes percebido quando do aumento da pressão ambiente.

Figura 2.8 - Modelo de formação de sprays produzidos por injetores tipo cone-oco.

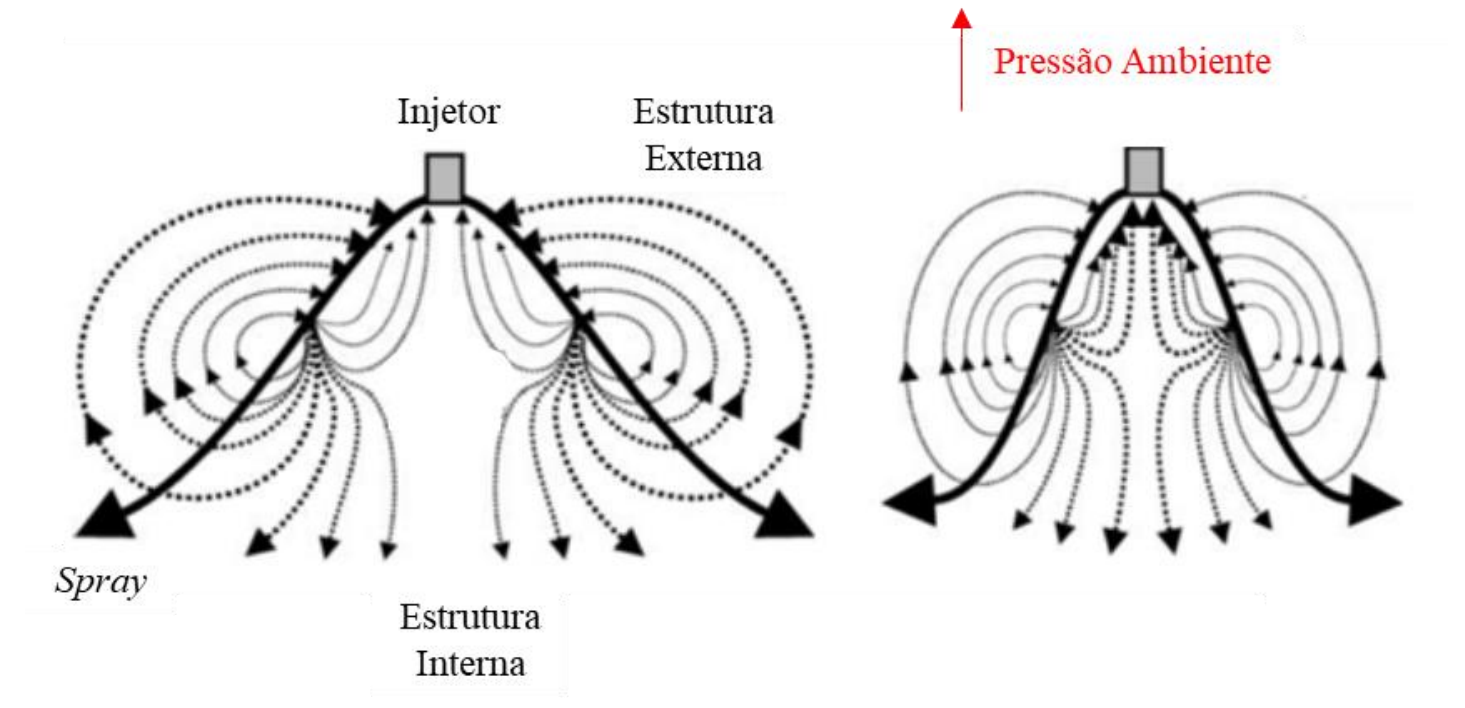

Fonte: Adaptado de Rottenkolber et al. (2002).

\subsubsection{A INTERAÇÃO GÁS-SPRAY}

A partir da descrição sobre os aspectos fenômeno e morfológicos que caracterizam o desenvolvimento de um spray, fica evidenciado que a forte interação dinâmica que existe entre as fases gás e líquido é inicialmente induzida pela velocidade relativa imposta no início da injeção do fluido incompressível. Além disso, é estabelecido que tanto a pressão do gás circundante ao spray como a pressão de injeção do líquido são variáveis que atuam sobre a morfologia do spray. As contribuições de cada um destes parâmetros, combinadas à existência de estruturas recirculantes produzidas em função das transferências dinâmicas de quantidade de movimento entre as fases, regulam as principais características do escoamento bifásico em questão, a saber: as distribuições de velocidade das fases; a distribuição e o tamanho das gotas; o ângulo de abertura do spray e a eficiência de atomização. É importante destacar que a última está diretamente atrelada à colisão e à coalescência de gotas, fenômenos estes responsáveis pela não uniformidade 
da distribuição espaço-temporal da fase líquida. Adicionalmente, tratando-se de escoamentos reativos, as características do spray supracitadas governam variáveis importantes como a forma da chama, a estabilidade e a eficiência de combustão e a emissão de produtos da combustão. Sendo assim, o estudo detalhado da região de cisalhamento ar-spray é de suma importância para o melhor entender a interação que acontece entre as fases, sobretudo os fenômenos pronunciados na região cisalhante. Consequentemente, fica claro que é interessante encontrar e melhor definir os motivos pelos quais ocorre a forte dependência mencionada entre as variáveis que influenciam a morfologia de um spray e a fluidodinâmica do escoamento bifásico, de modo tal que parâmetros que influem sobre o processo de atomização possam ser ajustados e a garantia da maior eficiência de conversão energética possa ser prometida (Jedelsky et al., 2018; Santolaya et al., 2013; Dikshit et al., 2009; Dankers et al., 2008; Domann e Hardalupas, 2002; Rottenkolber et al., 2002). Os autores do trabalho mais recente que versa sobre a investigação acerca da região de cisalhamento existente entre a fase gasosa e a fase líquida em eventos de sprays, Jedelsky et al. (2018), analisaram o estado da arte das referidas investigações e concluíram que:

"Entre vários estudos sobre sprays, apenas alguns lidam com os campos de velocidade resolvidos por fase; portanto, ainda é necessária uma medição detalhada da velocidade de ambas as fases."

Motivado pela ausência de informações mais robustas sobre o escoamento bifásico ar-spray, o trabalho de Jedelsky et al. (2018) investigou a interação entre as fases, utilizando um injetor mecânico-centrífugo tipo cone-oco, típico de uma turbina a gás, para atomizar querosene de aviação (JET-A1) em um ambiente quiescente. Os autores discutem sobre os fenômenos que regem a interação ar-líquido e estimam os campos de velocidade de ambas as fases presentes na região interna ao spray. Adicionalmente, as características espacial, direcional e espectral da turbulência são descritas qualitativamente, enquanto alguns parâmetros importantes são mensurados. Segundo os pesquisadores, a energia cinética turbulenta (TKE, sigla em inglês) e a sua respectiva média ( $M K E$, sigla em inglês) são os parâmetros capazes de orientar a melhor definição dos fenômenos pronunciados na região de cisalhamento entre o gás e o spray. Deste modo, tais parâmetros foram definidos quantitativamente pelos pesquisadores, baseados nos dados provenientes da aplicação da técnica de Anemometria por Doppler de fase 
(Phase-Doppler Anemometry - PDA - em inglês). A técnica de imagem por disparo único (single-shot imaging technique em inglês) foi utilizada para visualizar o filme de líquido, e então, prover detalhes acerca dos processos de quebra de ligamentos e de gotas.

Como resultado da pesquisa de Jedelsky et al. (2018), os autores idealizaram a Figura 2.9 como uma representação fiel do escoamento de gás circundante ao spray de querosene. A representação proposta advém dos resultados encontrados com a investigação detalhada do escoamento bifásico, a qual trouxe à tona cinco estruturas influentes sobre o desenvolvimento do spray no ambiente que o circunda. A primeira é o vórtice toroidal estacionário, cuja forma e existência depende das condições ambiente do gás, da geometria do atomizador e das paredes que confinam o escoamento ar-líquido. A presença desta estrutura de recirculação implica na reposição das partículas de ar que estão presentes na região interna ao spray formado por um cone-oco, além da transferência de partículas que pertençam à corrente de ar central, identificada pela estrutura (2). Adicionalmente, as linhas de corrente que definem o grande vórtice mostram que as componentes radiais e axiais da velocidade do gás circundante são fortemente influenciadas pela estrutura de recirculação. A estrutura (2) é definida visualmente como uma região que separa os vórtices com magnitudes espacial e cinemática diferentes, embora abrigue em suas vizinhanças espaciais partículas com elevados gradientes de velocidade. A presença de tais gradientes, atrelada às perturbações fluidodinâmicas do filme de líquido que se quebra, possivelmente motiva a produção de pequenos vórtices (ditos anéis de vórtices), identificados pela estrutura (4). Os anéis de vórtices apresentam-se instáveis durante o desenvolvimento do spray, uma vez que a intensidade com a qual são originados decai à medida em que viajam rumo à região de coexistência das gotículas menores. Adicionalmente, a estrutura (3) revela um fenômeno ligado à presença de gotas coalescidas, com baixa intensidade de turbulência e localizadas na região interna do spray. Mediante a atuação de tal estrutura, gotículas com alta inércia são mantidas na periferia externa dos vórtices, onde percebe-se baixa vorticidade. Vale destacar que, segundo Sornek, Dobashi e Hirano (2000), as gotas com número de Stokes compreendido entre 0,1 e 10 tendem à coalescência com as semelhantes, de modo a estarem localizadas em regiões circundantes à estrutura (3). Por fim, a zona de recirculação de rotação rápida é estabelecida nas proximidades da ponta do injetor e está atrelada ao filme de combustível produzido pelo injetor. Tal região é determinada pela estrutura (5), a qual prevalece com a forma deformada de um anel de vórtice e é produzida 
com rotação em sentido contrário ao vórtice toroidal nas regiões próximas ao eixo de simetria do spray. A estrutura (5) aparece nos locais onde o break-up primário produz gotas na ordem de unidades de milímetro. Ressalta-se, portanto, que nos locais onde a quebra do filme de líquido é iniciada, o gás circundante se dirige às regiões próximas ao eixo de simetria, e então, a corrente de ar central é estabilizada.

Figura 2.9 - Esquema ilustrativo de estruturas de fluxo de ar: (1) o grande vórtice toroidal estacionário em torno do spray, (2) a corrente de ar central, (3) vórtices aleatoriamente orientados e posicionados na região 1, (4) pequenos vórtices (anéis de vórtice) no bordas internas (4b) e externas (4a) da região 2 e na esteira (4c), (5) zona de recirculação de rotação rápida presa à folha de líquido.

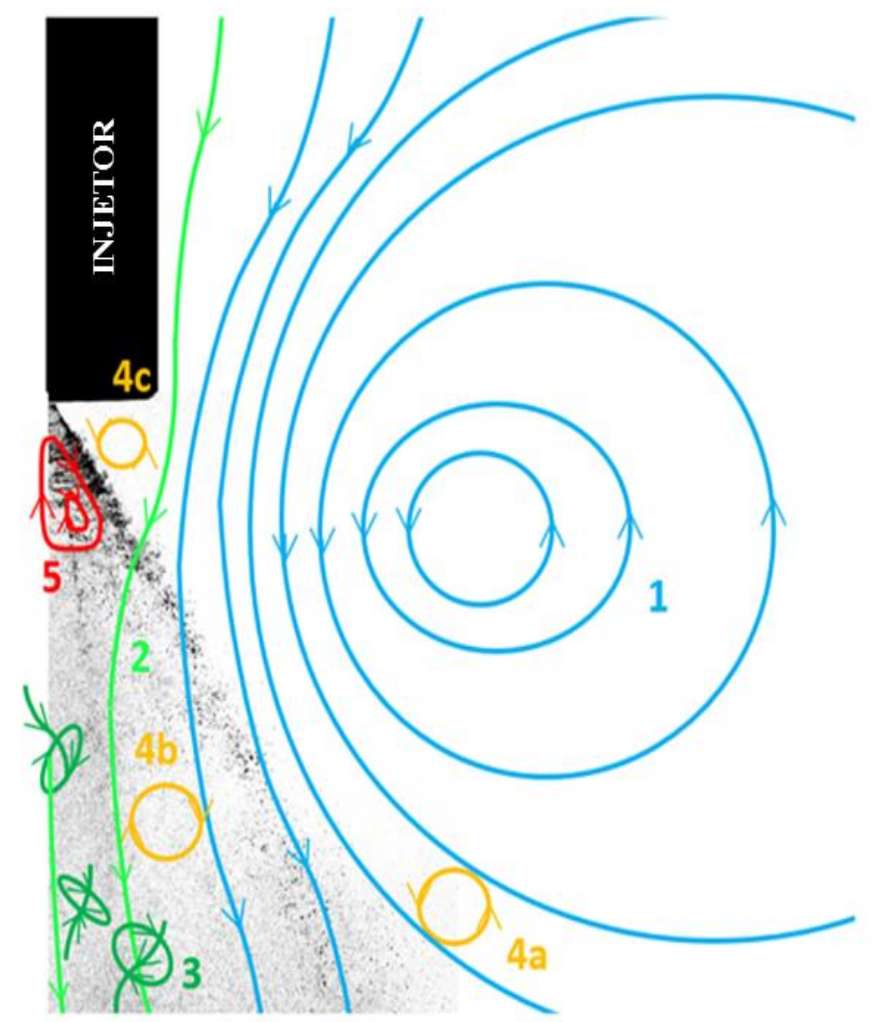

Fonte: Adaptado de Jedelsky et al. (2018).

A Figura 2.10 apresenta os resultados dos cálculos da energia cinética turbulenta e da média desta grandeza em diferentes posições e para três pressões de injeção, determinados por Jedelsky et al. (2018). Os resultados elucidam o processo de transferência de energia cinética das gotas de combustível para o ar, enquanto mostram que há um decaimento de ambas na direção axial. Os autores destacam que as estruturas de recirculação que identificam a interação entre o ar e o spray consomem uma parcela significativa da energia cinética do líquido, conforme é claramente percebido pela diminuição da participação da $M K E$ da fase líquida em todos os casos avaliados. 
Figura 2.10 - Energia cinética turbulenta e sua respectiva média calculadas para o gás e para o líquido, considerando diferentes posições axiais e pressões de injeção.

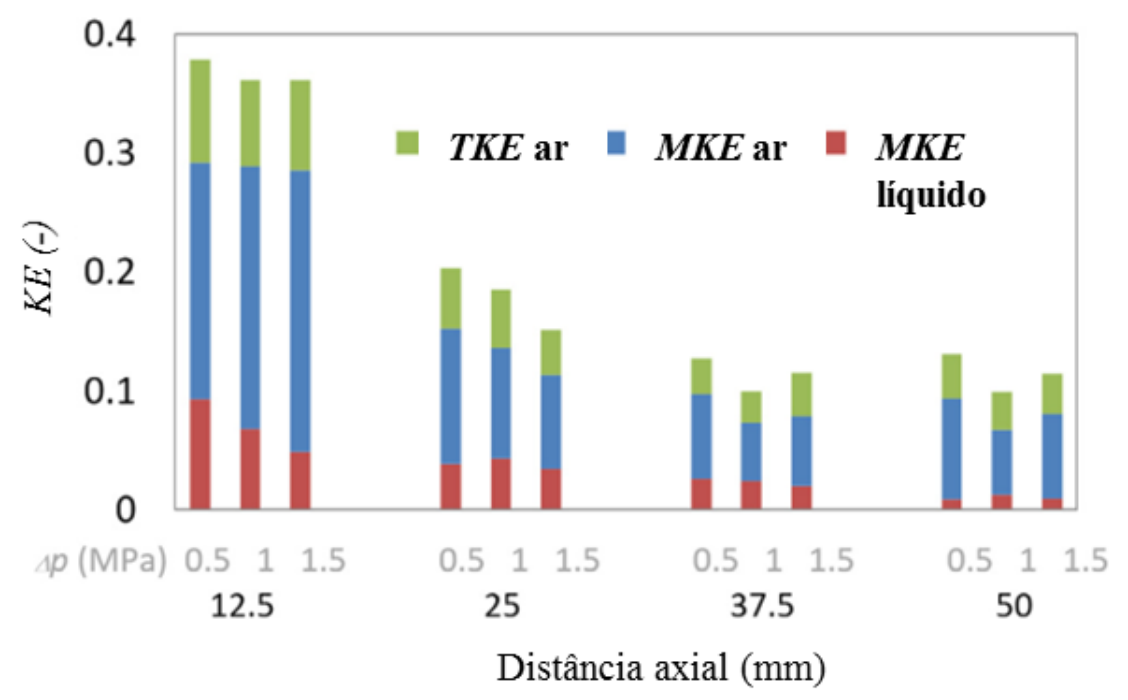

Fonte: Adaptado de Jedelsky et al. (2018).

De acordo com Jedelsky et al. (2018), é interessante investigar a presença das estruturas de recirculação aplicando técnicas de experimentais volumétricas ou tomográficas, as quais remetem ao uso da técnica de velocimetria por imagens de partículas. Em paralelo, a proposição de simulações numéricas LES ou DNS é recomendada para verificar a presença das estruturas mostradas na Figura 2.9, de modo a fornecer informações quantitativas mais precisas e a estudar mais a fundo as estruturas que definem a interação ar-spray. Os autores recomendam que as todas as informações divulgadas por eles podem ser úteis para o estudo aprofundado sobre o desenvolvimento da camada cisalhante em escoamentos bifásicos produzidos por injetores automotivos, uma vez que diversos aspectos atrelados à combustão são funções da dinâmica e das propriedades que definem a produção de um spray.

Buscando atender à demanda por informações mais detalhadas sobre a interação entre as fases gasosa e líquida presentes em um escoamento ar-spray, destacada recentemente por Jedelsky et al. (2018), Zhang et al. (2014) investigaram uma série de eventos de sprays formados por um injetor típico de motores de combustão interna equipados com sistema de injeção direta. Para tanto, os autores analisaram a transferência de quantidade de movimento entre as fases e a penetração do gás ambiente no spray de combustível, utilizando uma câmara de volume constante e uma atmosfera quiescente. $\mathrm{O}$ injetor utilizado é do tipo multi-furos, o qual produz sprays no formato de cone-sólido. Tendo como referência o ângulo dos vetores velocidade, Zhang et al. (2014) entenderam 
o desenvolvimento do spray a partir da proposição de três regiões, as quais são mostradas na Figura 2.11.

A região I (Zone I) é definida nas proximidades do injetor e é caracterizada pelo forte arrastamento do gás ambiente ocasionado pela baixa pressão gerada pela injeção do combustível, o qual destina as partículas de ar em direção ao eixo de simetria do spray. Já a região III (Zone III) é classificada como a região na qual o escoamento de ar é empurrado pelo spray e onde a mistura entre ambos acontece de modo mais pronunciado. Por fim, a região II (Zone II) pode ser entendida como uma região intermediária ou de transição entre ambas. Nesta zona, o gás ambiente é direcionado para a região I.

Figura 2.11 - Zonas de interação entre o spray e o gás circundante.

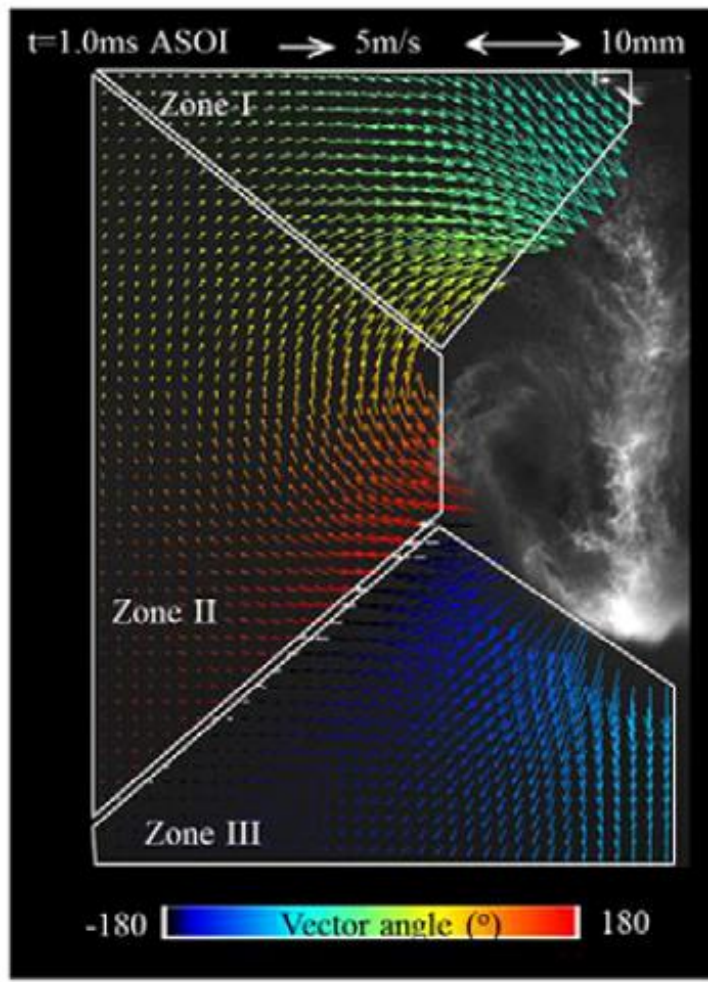

Fonte: Zhang et al. (2014).

De acordo com a discussão dos resultados promovida por Zhang et al. (2014), foi observado que a energia cinética da fase gasosa aumenta rapidamente devido à transferência de quantidade de movimento do spray para o gás e ao aumento da região de interface cisalhante entre as duas fases. Tal consideração foi apontada graças à análise da evolução da energia cinética total em cada uma das três regiões que permitem definir as interações entre o ar e o combustível, a qual permite discorrer sobre a transferência de 
quantidade de movimento que acontece entre ambas as fases. A evolução temporal da energia cinética total do escoamento em cada região é mostrada na Figura 2.12.

Figura 2.12 - Evolução da energia cinética do gás ambiente que circunda o spray de combustível.

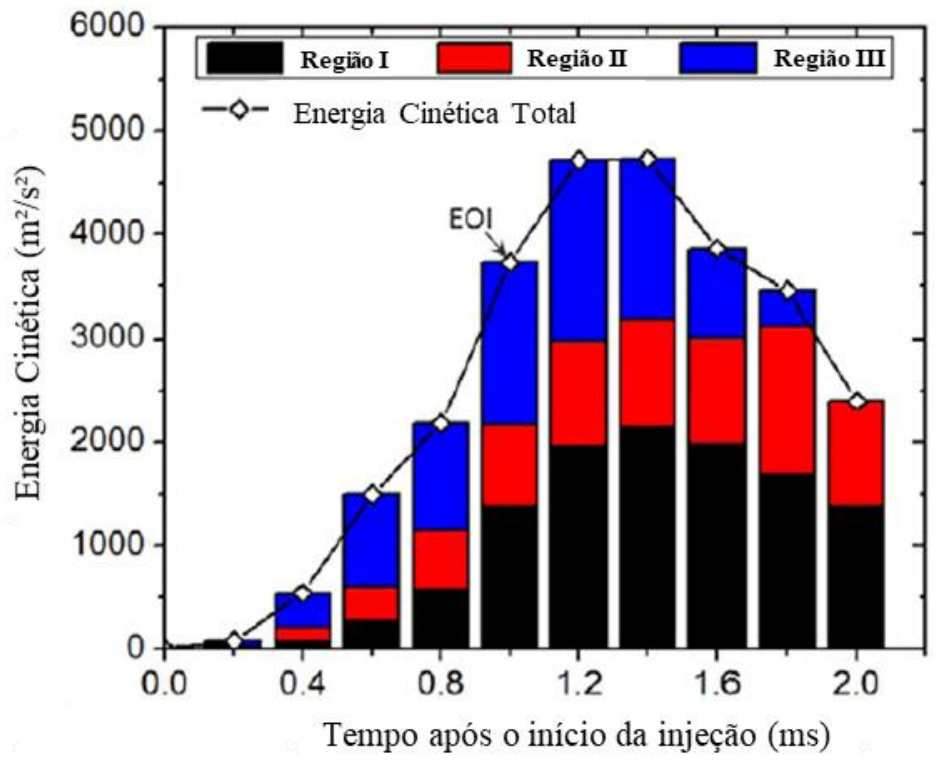

Fonte: Adaptado de Zhang et al. (2014).

Segundo os pesquisadores, o processo de transferência de quantidade de movimento que acontece durante o desenvolvimento do spray acontece como um mecanismo de compensação (feedback), devido à produção de estruturas de recirculação originadas no início do evento de um spray. A quantidade de movimento transferida entre o extremo do spray e o gás ambiente induz o desenvolvimento de vórtices. Consequentemente, os autores entendem que a propagação de vórtices ao longo do spray aumenta a interação entre as fases e a define. Além disso, o aumento da taxa com a qual a interação entre as fases acontece é refletido no aumento da região de interface e contribui com o aumento da energia cinética do gás circundante. Esse ciclo acontece de modo amplificado até o fim do período de injeção do combustível, no qual ainda é percebida a propagação dos vórtices na região de interface entre as fases. Por fim, após o instante no qual as propagações dos turbilhões são cessadas, o gás ambiente presente na região I passa a ocupar a região por ele pretendida, no caso o eixo de simetria do spray. Vale destacar que todas as conclusões advindas da interação bifásica ar-líquido foram obtidas por meio do campo de velocidades do escoamento e pela análise da quantidade de movimento. As magnitudes dos vetores velocidade foram verificadas a partir de resultados provenientes da aplicação da técnica de $L D V$. 


\subsection{CONSIDERAÇÕES SOBRE A TÉCNICA DE VELOCIMETRIA POR IMAGENS DE PARTÍCULAS}

A velocimetria por imagens de partículas ( $P I V$, sigla em inglês) é uma ferramenta experimental não intrusiva, quantitativa, que permite visualizar escoamentos com uma ampla gama de escalas de comprimento, de frequência e de tempo. A técnica de PIV é utilizada quando o objetivo é estudar aspectos atrelados à cinemática de um determinado escoamento, a partir do respectivo campo de velocidades. De modo geral, para determinálo, partículas traçadoras (seeding, em inglês), capazes de seguir o escoamento sem interferir no desenvolvimento de suas estruturas, são previamente dispersas de forma homogênea no fluido em análise. Os traçadores são iluminados por uma fonte de luz laser pulsada, a qual é escolhida na maioria dos experimentos atuais graças à elevada densidade de energia e à facilidade de controle temporal de emissão de pulsos. Elementos ópticos como lentes e espelhos podem ser utilizados para adequar as dimensões e a localização do feixe de luz laser. A luz espalhada pelas partículas é registrada em duas imagens sucessivas por uma câmera disposta ortogonalmente ao plano de luz, procedimento de gravação das imagens conhecido como quadro-duplo (double-frame em inglês). As imagens gravadas são igualmente divididas em seus domínios espaciais por regiões prédeterminadas, as chamadas janelas de interrogação (interrogation window em inglês). Um algoritmo de correlação é, então, utilizado com o intuito de determinar, para cada janela de interrogação, o deslocamento médio mais provável do conjunto de imagens de partículas, considerando como referência ambas as imagens capturadas. Consequentemente, em posse do intervalo de tempo considerado para gravar as duas exposições e do deslocamento estimado para o conjunto de partículas em análise, o vetor velocidade é deduzido para cada janela de interrogação (Raffel et al., 2007; Schröder e Willert, 2008).

A Figura 2.13 apresenta, esquematicamente, a versão bidimensional de um sistema PIV destinada à análise de um escoamento monofásico. Nesse arranjo adotado como padrão, duas componentes de velocidade são medidas em um plano definido pela espessura do feixe de luz. Tal sistema, portanto, é denominado 2D-2C, isto é, um sistema capaz de medir duas componentes de velocidade (2C) com um arranjo bidimensional (2D). Vale destacar que a técnica PIV oferece outros sistemas mais sofisticados: os 2D3C (stereo-PIV) e os 3D-3C (tomographic-PIV). No presente trabalho, todas as imagens 
utilizadas foram adquiridas a partir de um sistema 2D-2C, fato que motiva a discussão acerca dos desafios que este sistema possui na produção confiável de resultados.

Figura 2.13 - Representação esquemática de um sistema PIV bidimensional tipo 2D-2C.

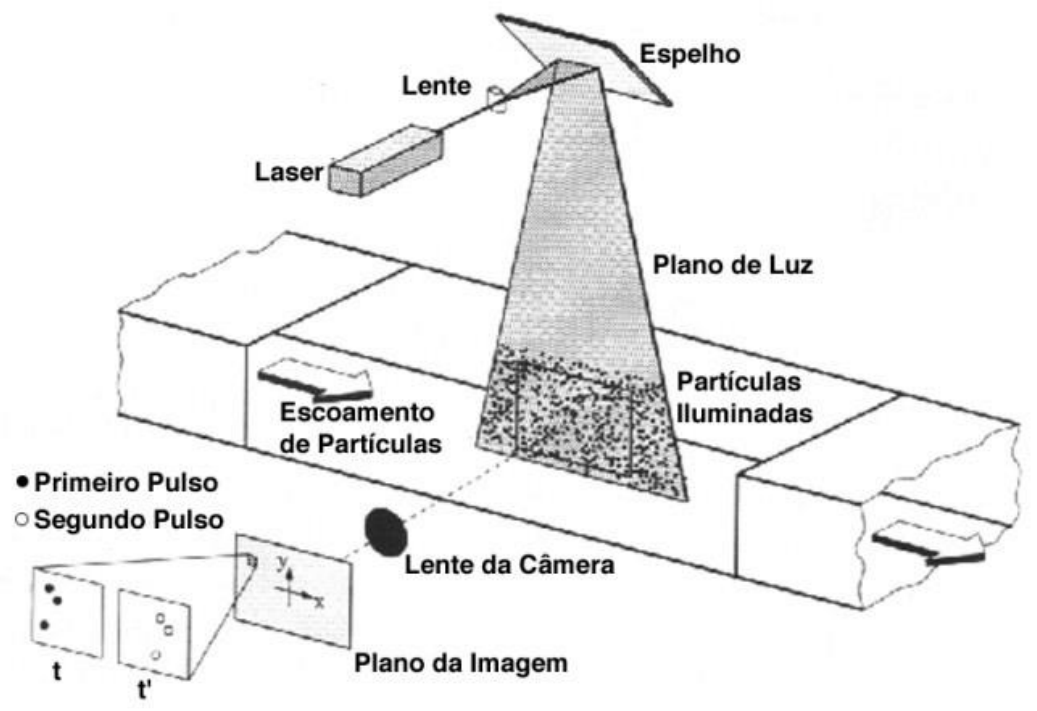

Fonte: Adaptado de Barja e Fiaschetti (2015).

As etapas que compõem o método $P I V$ são reunidas e apresentadas pelo esquema mostrado na Figura 2.14. Sucintamente, de acordo com Raffel et al. (2007) e com Adrian e Westerweel (2011) a aplicação completa da técnica compreende a realização de cinco etapas: Gravação; Calibração; Pré-processamento; Processamento e Pós-processamento. A seguir, serão reunidas as principais considerações, no âmbito de descrição, sobre as etapas que definem a aplicação da técnica de velocimetria por imagens de partículas.

Figura 2.14 - Ilustração esquemática das etapas que compõem a técnica de PIV 2D-2C.

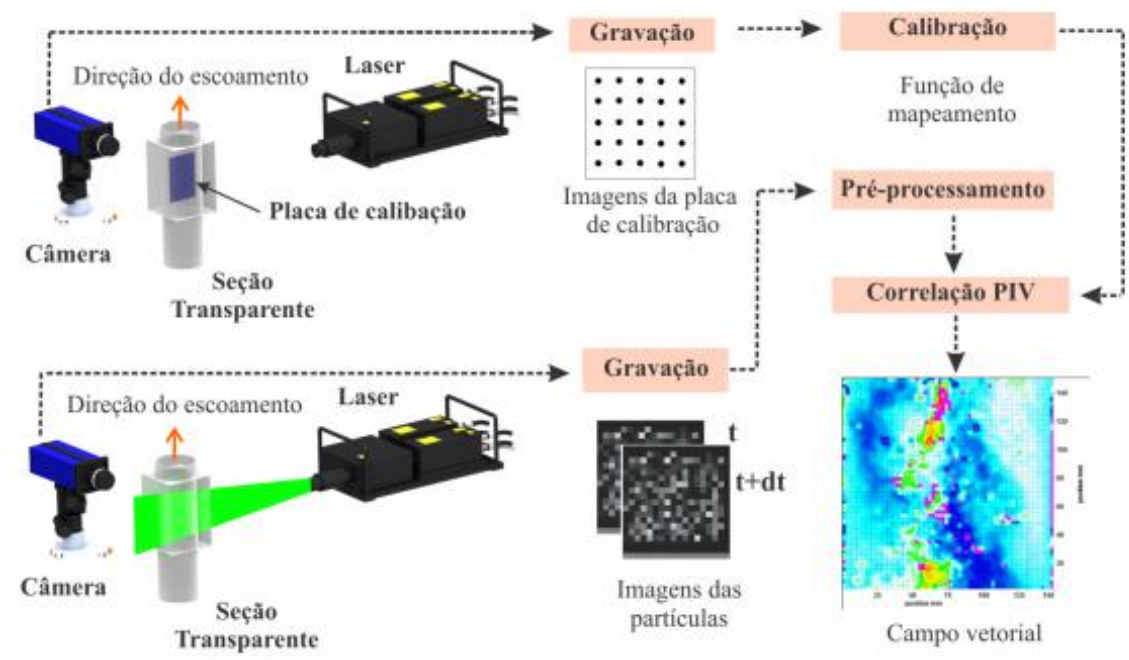

Fonte: Amaral et al. (2014). 
A etapa de gravação consiste na aquisição das imagens de partículas que representam o escoamento. Nela, deve-se procurar garantir que aspectos importantes à qualidade da imagem primária, tais como a iluminação proveniente do espalhamento de luz por parte das partículas traçadoras, o nível de contraste e o ruído de fundo estejam otimizados. Além disso, a influência da presença de objetos estacionários deve ser avaliada, uma vez que tais objetos podem causar ruídos significativos à imagem gravada. Já a etapa de calibração serve para atribuir às imagens o fator de escala, isto é, a relação que existe entre o deslocamento (em pixels) de cada conjunto de partículas correlato no plano de imagem e o deslocamento real (em dimensões físicas). Adicionalmente, vale destacar que é na etapa de calibração que as distorções e/ou erros de perspectiva podem ser corrigidas (MOURA, 2017; AMARAL, 2017). De acordo com Adrian e Westerweel (2011), um procedimento muito usual para remover as distorções é dado pela aplicação das funções de mapeamento às imagens. Tais funções são encarregadas de transformar as imagens a partir de funções polinomiais de modo que todos os pontos da imagem de calibração estejam alinhados com as posições relativas destes pontos no espaço físico, dado por um padrão geométrico conhecido.

Quanto à etapa de pré-processamento, atribui-se a ela o objetivo de eliminar os ruídos remanescentes da etapa de gravação (podem ser entendidos como tudo aquilo que não é visto como imagem de partícula), de modo a diminuir a probabilidade de detecção de um pico de deslocamento aleatório, ou seja, aumentar o sinal de correlação. Deste modo, além da remoção de ruído, a melhoria de contraste e as eventuais correções de brilho são os tópicos que devem ser executados nesta etapa. Vale destacar que, a título de correlação, o sinal de correlação é função do contraste que existe entre as imagens de partículas e a iluminação de fundo, sendo a condição ideal aquela em que persiste uma distribuição homogênea de intensidades dentro da janela de interrogação. Para tanto, o uso de rotinas que contemplem a aplicação de filtros espaciais nas imagens primárias é recomendado, uma vez que ambos são capazes de atuar sobre a distribuição de intensidades de uma imagem, assim como eliminar os ruídos atrelados à iluminação de fundo. Vale salientar que o alcance do destaque das partículas traçadoras frente às demais regiões presentes na imagem pode ser conseguido através das ferramentas de processamento digital de imagens, tais como a filtragem espacial, a filtragem temporal, a segmentação e as operações morfológicas. Tais ferramentas compreendem um conjunto de técnicas que possibilitam trabalhar com a imagem de modo a alterar apenas as 
características de interesse presentes na mesma, com resultado significativo com relação ao que se busca obter (RAFFEL et al., 2007; ADRIAN E WESTERWEEL, 2011; MOURA, 2017; AMARAL, 2017; SCHARNOWSKI, SCIACCHITANO e KÄHLER, 2019). Para o leitor interessado em se aprofundar no estudo de processamento de imagens, recomenda-se visitar as obras de Gonzalez e Woods (2010) e a de Solomon e Breckon (2011).

De acordo com o manual de boas práticas em PIV proposto pela ITTC (2014), um procedimento muito comum de ser realizado na etapa de pré-processamento é a remoção de ruído atrelado à iluminação de fundo (subtraction background em inglês). Segundo os membros que elaboraram este guia, tal operação consiste em remover parte do ruído da imagem primária através da subtração desta por uma imagem média, obtida sem a presença de traçadores. Com isso, estabelece-se como objetivo desta técnica melhorar o contraste entre o plano de fundo e as imagens de partículas geradas pelos traçadores sem elevados custos computacionais, melhorando a relação sinal-ruído da imagem préprocessada, sem garantir a alta qualidade na imagem final. Vale destacar que o procedimento mencionado pode ser utilizado como tratamento de imagens tanto para escoamentos monofásicos como para multifásicos.

A Figura 2.15 mostra um exemplo de resultado da aplicação do procedimento de remoção de background a um escoamento monofásico, apresentado pela Dantec Dynamics (2015). Solidária à apresentação da técnica de remoção de background, a ITTC (2014) expõe a ferramenta de normalização como um procedimento muito eficaz para produzir a homogeneização de intensidade, aspecto determinante da qualidade do sinal de correlação. Segundo Amaral et al. (2014), a operação de normalização é conhecida como alargamento de contraste e é utilizada para prover ao um determinado conjunto de imagens a mesma escala de intensidade. Alternativamente, há a possibilidade de normalizar individualmente uma determinada imagem, considerando os valores máximos e mínimos de intensidade presentes na matriz de pixels. A Figura 2.16 mostra um exemplo de uma aplicação da operação de normalização em uma imagem sem a presença de ruído de fundo. 
Figura 2.15 - Exemplo de uma aplicação da técnica de remoção de ruído de fundo. A imagem à esquerda é a imagem primária, enquanto à direita, a imagem pré-processada.
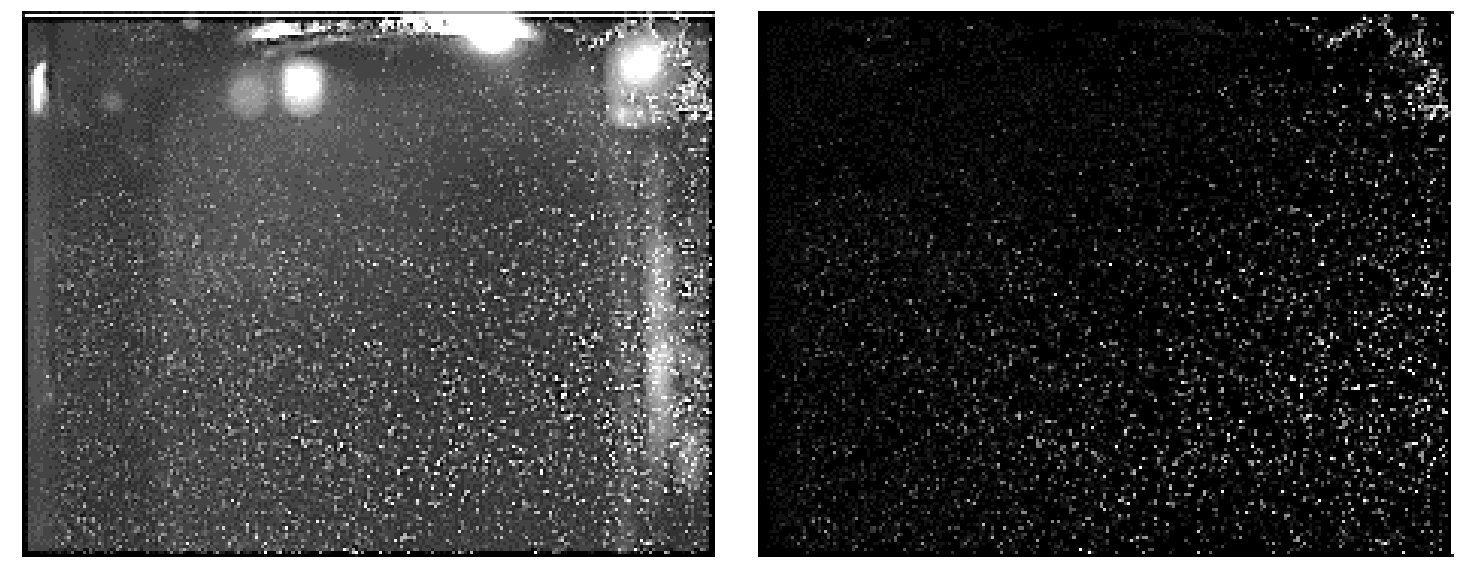

Fonte: Dantec Dynamics (2015).

Figura 2.16 - Exemplo de uma aplicação da técnica de normalização. A imagem à esquerda é a imagem primária pré-processada por filtros de remoção de background, enquanto à direita é apresentado o resultado da aplicação da normalização.
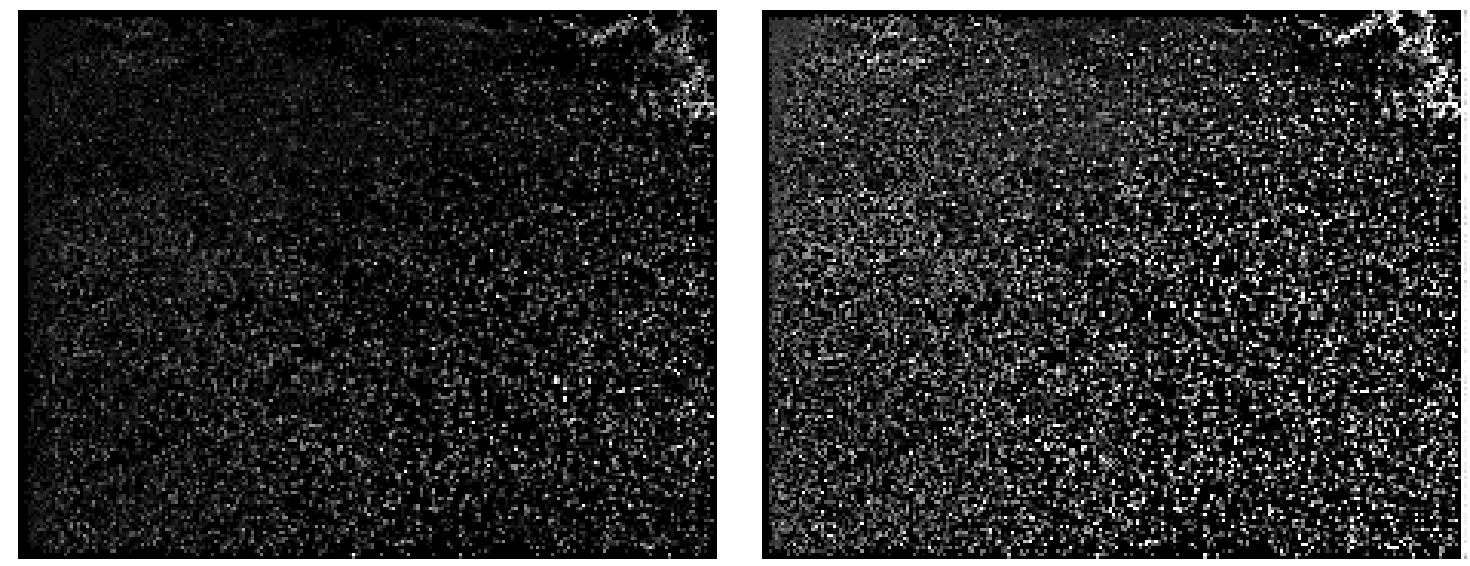

Fonte: Dantec Dynamics (2015).

Adicionalmente, Moura (2017) aponta três filtros que podem ser utilizados como elementos contribuintes à etapa de pré-processamento, uma vez que oferecem aumento de contraste e/ou promovem a remoção de background. O primeiro é o filtro gaussiano, adotado com o intuito de suavizar o formato da imagem de partícula, sem a responsabilidade de promover a remoção do ruído de fundo com eficiência. O segundo consiste no filtro SSM (sigla de Subtract Sliding Minimum), este capaz de remover a iluminação de fundo, propiciando, em contrapartida, elevada diferença de intensidade entre a população de imagens de partículas. Segundo Shavit, Lowe e Steinbuck (2007), este fato pode comprometer a homogeneidade da distribuição de intensidade e produzir 
erros de correlação, a menos do estabelecimento de um limite de intensidade (threshould, em inglês). Por fim, o último filtro discutido pelo autor é o filtro RMS (sigla de Root Mean Square), o qual tem a capacidade de oferecer ótima eficiência de remoção de ruído de fundo, além de alterar a forma do pico de correlação para uma configuração mais planificada. A Figura 2.17 apresenta o efeito que cada um dos três filtros citados por Moura (2017) oferece a uma imagem de partícula.

Figura 2.17 - Distribuição de intensidade de uma única imagem de partícula (a) original e préprocessada por um filtro (b) Gaussiano $3 \times 3$ pixels, (c) SSM $3 \times 3$ pixels e (d) RMS 3x3 pixels.
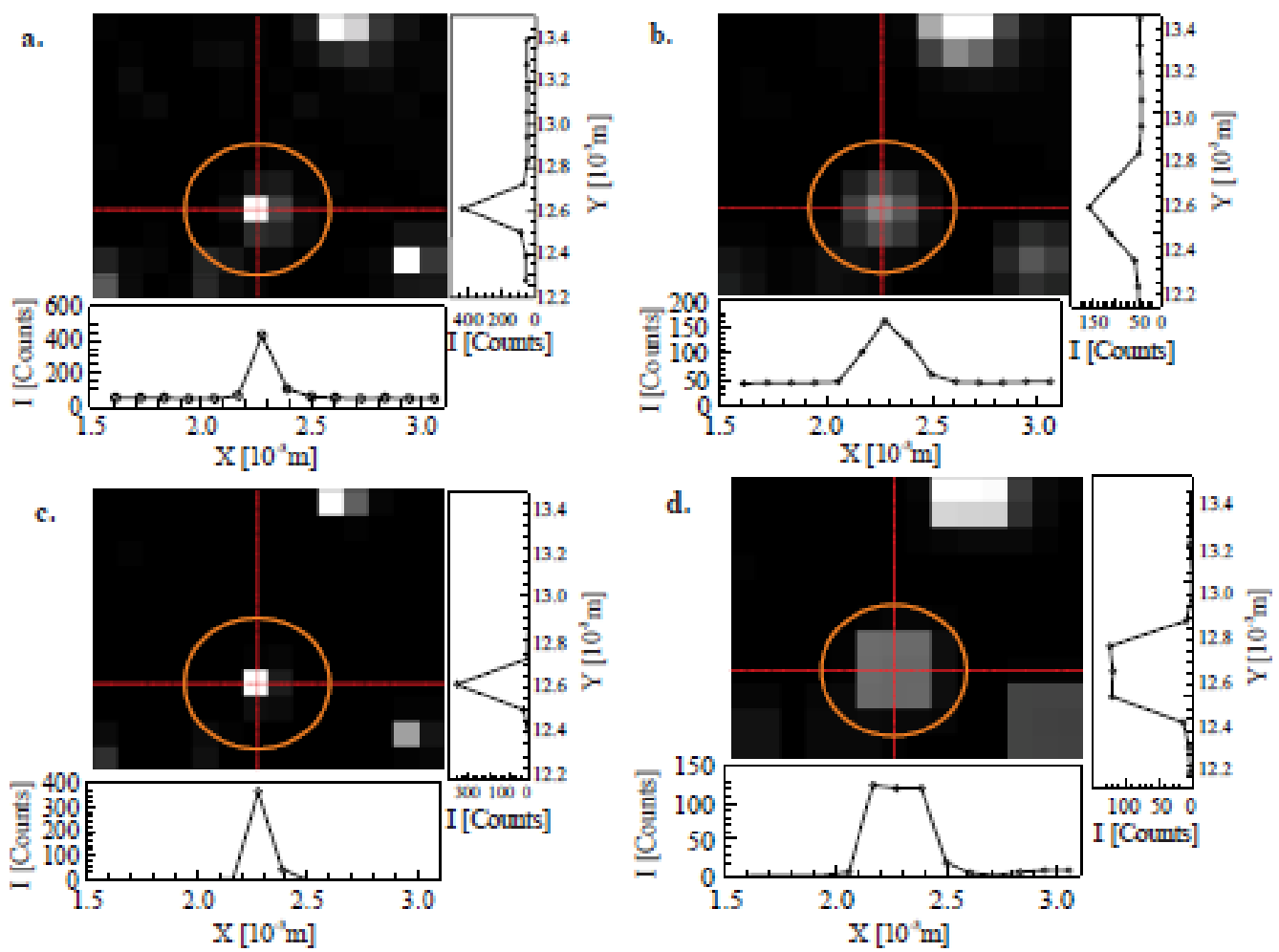

Fonte: Adaptado de Moura (2017)

Ainda no tocante às estruturas capazes de comporem a etapa de préprocessamento da técnica de $P I V$, é importante frisar que existe uma variável muito importante e que influencia significativamente o resultado da aplicação de filtros espaciais: o tamanho do filtro ou kernel. Kiger e Pan (2000), Khalitov e Longmire (2002) e Honkanen e Nobach, (2005) recomendam que os filtros sejam aplicados às imagens de partículas com tamanho maior do que o próprio traçador, principalmente nos casos em que escoamentos bifásicos tipo gás-liquido estão sendo estudados com o aporte da técnica de PIV. De acordo com a conclusão dos autores, a não observância desse aspecto pode levar ao realce de contraste, apenas. Os trabalhos desenvolvidos por Khalitov e Longmire 
(2002) e por Deen et al. (2010) são indicados ao leitor interessado em estudar estratégias de pré-processamento $P I V$ aplicado à escoamentos bifásicos tipo gás-líquido.

Cumprida a etapa de pré-processamento, a partir da hipótese de que a imagem final representa adequadamente as posições dos traçadores que marcam o escoamento em análise, cabe à estratégia de processamento a responsabilidade de estimar o campo de velocidades. Para tanto, o algoritmo padrão de correlação cruzada (Standard Cross Correlation - SCC, em inglês) é o método mais utilizado para estimar o deslocamento médio do conjunto de partículas presente em uma janela de interrogação. O método consiste em determinar o vetor velocidade a partir da aplicação do algoritmo de correlação cruzada em todas as janelas de interrogação, o qual emprega a Transformada de Fourier como ferramenta (em detrimento à convolução). Deste modo, as distribuições locais de intensidade são convertidas para o domínio da frequência. Logo, por meio da multiplicação das partes real e imaginária das duas imagens referentes à uma mesma janela de interrogação, obtém-se o mapa de correlação no domínio da frequência. Utilizando a transformada inversa de Fourier, o mapa de correlação é convertido para o domínio espacial. Com o novo mapa, o valor atrelado aos pixels traduz a boa ou a inadequada correspondência entre ambas as imagens, considerando que exista um deslocamento do conjunto de partículas incluído nas duas janelas. Finalmente, o vetor velocidade é obtido (idealmente a partir da correlação de duas imagens idênticas, porém deslocadas) a partir do produto do vetor deslocamento (produzido pelas coordenadas do centro da janela de interrogação e do maior pico de correlação) pelo escalar formado pelo inverso do produto da magnificação (ou fator de escala) com o intervalo de tempo entre as imagens (tempo inter-frame). A Figura 2.18 mostra um diagrama de fluxo que descreve o método de cálculo utilizado pelo método em alusão. A Equação 2.1 refere-se à obtenção do mapa de correlação cruzada entre as imagens primárias sugerido pela técnica $S C C$, onde $\mathfrak{J}$ é operador da transformada de Fourier das imagens $I_{1}$ e $I_{2}$ e o complexo conjugado é simbolizado pelo asterisco. É importante destacar que a utilização da transformada de Fourier assume que os sinais são periódicos, o que não necessariamente acontece. Então, erros de aliasing são pronunciados nos casos em que a periodicidade não é observada.

$$
C(x, y)=\mathfrak{J}^{-1}\left\{\mathfrak{I}\left[I_{1}(x, y)\right] \cdot \mathfrak{I}\left[I_{2}(x, y)\right]^{*}\right\}
$$

Para mensurar a precisão do método de determinação do vetor de deslocamento médio, indicadores de qualidade são utilizados. Um indicador frequentemente adotado é 
a relação sinal-ruído ( $S N R$, sigla em inglês), o qual é definido para o método $S C C$ pela Equação 2.2. Além deste, a razão entre o primeiro e o segundo picos mais altos (peak height) e o coeficiente de correlação são considerados parâmetros de qualidade da correlação (Adrian e Westerweel, 2011; Xue et al., 2014; Berti, 2018).

$$
S N R=\frac{\max (C)-\bar{C}}{\sqrt{\left(\frac{1}{N}\right) \sum_{i=1}^{N}\left(C_{i}-\bar{C}\right)^{2}}}
$$

De acordo com Xue et al. (2014), campos vetoriais podem ser classificados como confiáveis se o $S N R$ e o coeficiente de correlação forem superiores a 2,0 e 0,50, respectivamente. Alternativamente, a fim de aumentar a precisão da magnitude do vetor de deslocamento médio, uma função gaussiana pode ser ajustada ao pico de correlação para que a velocidade seja determinada com precisão sub-pixel, segundo Moura (2017). Por conta disso, tal procedimento é dito interpolação sub-pixel. A Figura 2.18 apresenta o diagrama de fluxo que descreve o método de cálculo realizado quando do uso da técnica $S C C$.

Figura 2.18 - Diagrama de fluxo do algoritmo SCC.

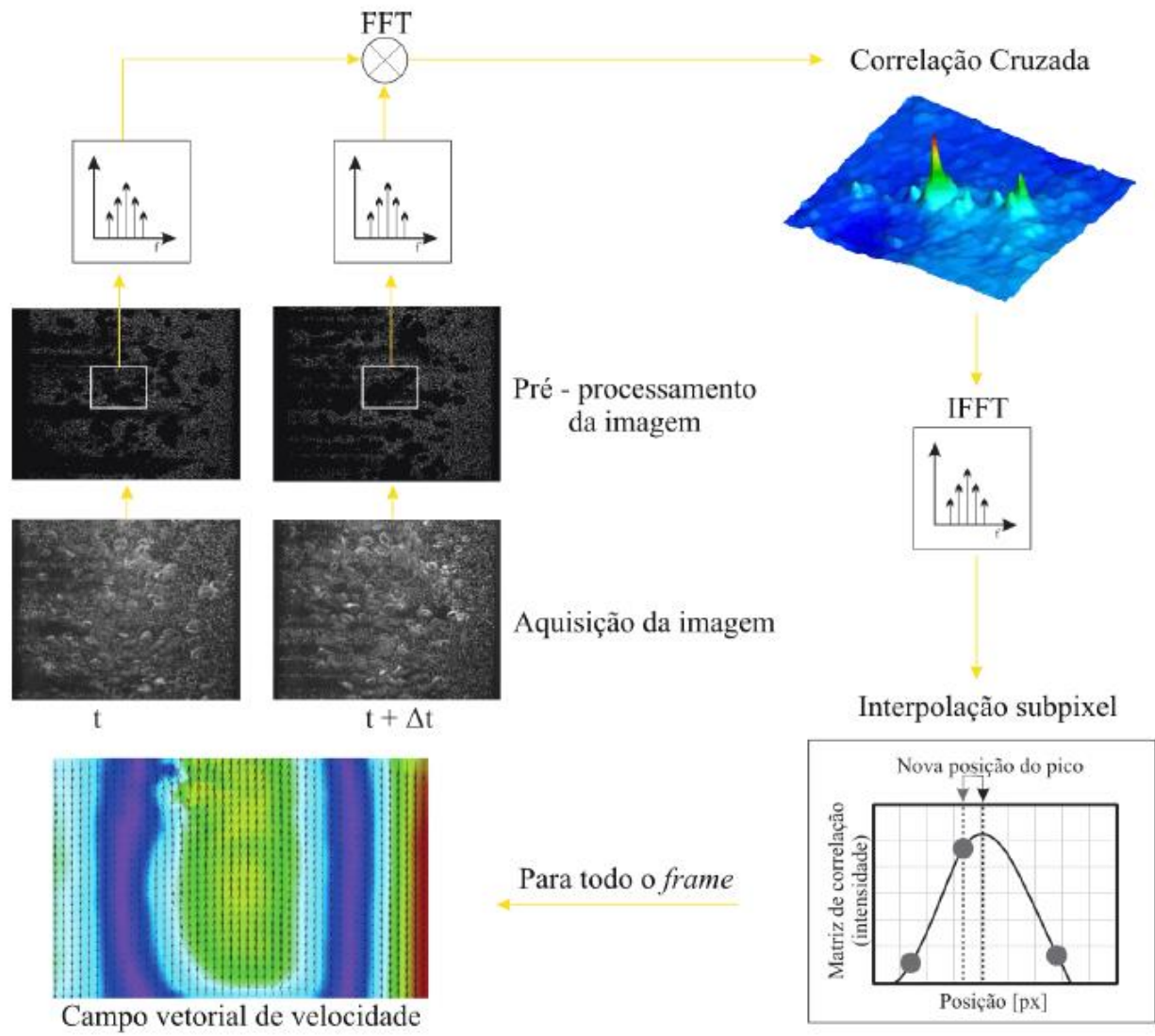

Fonte: Moura (2017). 
Ademais, um algoritmo interessante de ser utilizado para correlacionar as imagens gravadas é a correlação de fases robusta (Robust Phase Correlation - RPC, em inglês), apresentada por Eckstein e Vlachos (2009). Embora seja uma vertente da SCC, a RPC não considera necessária a proposição de métodos de pré-processamento para ser aplicada, uma vez que o algoritmo implementa técnicas de janelamento (windowing, em inglês) e filtros de suavização aos planos de correlação com o compromisso de atenuar a influência de qualquer ruído presente nas imagens primárias e maximizar a probabilidade de detecção confiável do pico principal da função de correlação. Contudo, os autores destacam que o modelo proposto por eles não garante bons resultados para os casos em que os diâmetros das imagens de partículas sejam muito pequenos. Os pesquisadores comentam, ainda, que o custo computacional despendido para correlacionar as imagens com o método $R P C$ é superior ao custo com o processamento de dados quando utilizado o método SCC. Informações detalhadas sobre o método podem ser encontradas no trabalho de Eckstein e Vlachos (2009). Vale destacar que, além das técnicas de processamento mencionadas, existem outros algoritmos capazes de realizar a correlação entre as imagens PIV, entretanto todos eles são modelados com base na SCC.

Concluída a etapa de definição do algoritmo de correlação, cabe ao pósprocessamento, passo posterior à determinação do campo de velocidades, melhorar a representatividade do campo vetorial obtido. Sendo assim, o pós-processamento consiste na exclusão dos possíveis falsos vetores (vetores espúrios ou outliers), isto é, aqueles que não representam adequadamente o escoamento em análise, pelo fato de não apresentarem coerência espacial e/ou temporal com a sua vizinhança. De acordo com Raffel et al. (2007), a presença de vetores espúrios culmina em inconsistências que alteram a visualização fidedigna da distribuição de velocidades e, consequentemente, a predição das quantidades derivativas da velocidade, tais como a vorticidade e a tensão de cisalhamento, por exemplo. Além disso, prejuízos frente à realidade são obtidos quando tais vetores são considerados sob a ótica da turbulência. Sendo assim, algoritmos de pósprocessamento têm aplicação justificada e deve ser proposta antes de qualquer análise de informações oferecidas pela técnica de PIV, segundo Raffel et al. (2007) e Garcia (2011). Essencialmente, o pós-processamento consiste na consecução de três etapas: (i) detecção de vetores falsos e/ou valores anômalos; (ii) substituição dos valores incorretos ou faltantes; (iii) suavização espacial dos dados. 
Considerando as referências recentes, as técnicas de validação PIV amplamente empregadas nos trabalhos que envolvem velocimetria por imagens de partículas são:

- normalized median test, - desenvolvido por Westerweel e Sacarno (2005) como uma ferramenta mais robusta face à tradicional filtragem por mediana (frequentemente percebida nos trabalhos atuais destinados ao estudo da interação ar-spray, referenciados na seção 2.3);

- método de detecção de outliers para dados não estruturados - proposto por Duncan et al. (2010), na tentativa de oferecer, via um método ponderado, a melhoria da descrição de um vetor velocidade quando comparado à sua vizinhança.

Embora as técnicas supracitadas têm grande relevância no cenário $P I V$ atual, os pesquisadores Masullo e Theunissen (2016) apontam que ambas são dependentes da uma comparação espacial de cada vetor com a sua respectiva vizinhança e que o desempenho não é adequado quando da presença de aglomerados de vetores falsos (outliers clusters). Diante do exposto, motivados por tal problemática, os autores apresentam um método mais robusto que consiste, essencialmente, em uma validação vetorial adaptativa, cuja sigla em inglês é AWAMT. Analogamente, os trabalhos de Liang, Jiang e Li (2003) e de Pun, Susanto e Dabiri (2007) oferecem métodos alternativos como forma de validação de campos vetoriais provenientes do método de PIV, sendo o primeiro baseado em redes neurais, enquanto o segundo é inspirado em reamostragem estatística. Garcia (2011) destaca em seu trabalho que, embora as técnicas desenvolvidas por Liang, Jiang e Li (2003) e por Pun, Susanto e Dabiri (2007) sejam efetivas, as mesmas têm alto custo computacional e são pouco utilizadas. Ademais, outras metodologias de pósprocessamento podem ser encontradas na obra escrita por Raffel et al. (2007) e por Adrian e Westerweel (2011).

Uma vez estando os outiliers identificados e removidos do campo vetorial processado, os vetores ausentes devem ser substituídos por dados interpolados. Segundo Raffel et al. (2007), técnicas de interpolação por vizinhança 3 x 3 e de interpolação bidimensional linear são corriqueiramente utilizadas para compor a segunda etapa do pósprocessamento. Vale destacar que nos casos que for percebido que muitos vetores foram excluídos em uma dada região, a interpolação tenderá para a média da velocidade das vizinhanças (NOGUEIRA, LECUONA e RODRIGUEZ, 1997). 
Para finalizar, a última etapa do pós-processamento é responsável por reduzir a possível permanência de ruídos no campo vetorial final a partir da aplicação de algoritmos de suavização de dados. Raffel et al. (2007) sugerem realizar uma estratégia de convolução dos dados, enquanto Garcia (2010) propõe um método mais avançado que utiliza o Método dos Mínimos Quadrados para alcançar a suavização dos dados. Alternativamente, Gunes e Rist (2007) apoiam que a suavização seja realizada com base nos métodos de intepolação Kriging (Kriging interpolation methods em inglês).

Vale ressaltar que diversos estudos têm mostrado que a primeira etapa do pósprocessamento é o processo mais crítico dentre aqueles desenvolvidos pelas demais etapas. Os trabalhos realizados por Hart (2000); Liang, Jiang e Li (2003); Shinneeb, Bugg e Balachandar (2004); Westerweel e Scarano (2005); Pun, Susanto e Dabiri (2007); Liu et al. (2008); Garcia (2011); Masullo e Theunissen (2016) evidenciam esta conclusão.

\subsubsection{BOAS PRÁTICAS PARA A APLICAÇÃO DO MÉTODO PIV}

Atualmente, a técnica de velocimetria por imagens de partículas é capaz de fornecer campos de velocidade confiáveis, mesmo com a presença de infortúnios típicos como a perda de pares por movimento dentro e fora do plano de luz, além de elevados gradientes de movimento. Entretanto, a confiabilidade que está atrelada ao método é função do ruído que é processado junto às imagens de partículas, e consequentemente, da forma com a qual o pico de correlação é estabelecido e com a magnitude com que propagam-se as incertezas associadas à velocidade. Na expectativa de buscar os melhores resultados possíveis com a aplicação do método de PIV, Keane e Adrian (1992) mostraram que o pico de correlação é formado convenientemente e é bem detectável se a quantidade de imagens de partículas, $N_{I}$, for superior a seis. No entanto, os autores destacam que a resolução espacial é prejudicada se houver uma quantidade muito grande de imagens de partículas abrigadas pelas janelas de interrogação. Por conta disso, o tamanho da janela de interrogação e a concentração de imagens de partículas devem ser estabelecidas a partir de uma solução de compromisso entre a resolução espacial e a alta probabilidade de detecção do pico de correlação adequado. Contudo, a fim de considerar todos os efeitos que controlam a obtenção confiável dos vetores deslocamento, parâmetros como a magnificação, a concentração de traçador, a espessura do plano de luz laser e o tamanho da janela de interrogação devem ser escolhidos de modo que os 
movimentos para dentro e para fora do plano, somados aos gradientes de deslocamento não prejudiquem a boa qualidade dos resultados. Uma forma de alcançar seguramente este objetivo é garantir que o número efetivo de partículas, $N$, presente em uma imagem gravada, seja superior a sete (RAFFEL, WILLERT, et al., 2007; ADRIAN e WESTERWEEL, 2011; SCHARNOWSKI e KÄHLER, 2016a; SCHARNOWSKI, SCIACCHITANO e KÄHLER, 2019). A Equação 2.3 apresenta a relação que define o referido parâmetro, onde $N_{I}$ é a quantidade de partículas abrigada pela janela de interrogação, $F_{I}$ e $F_{O}$ são os fatores atrelados às perdas de correlação devido a movimentos dentro e fora do plano de luz, respectivamente, e $F_{\Delta}$ refere-se ao fator atrelado à influência de gradientes de movimento da população de partículas.

$$
N=N_{I} \cdot F_{I} \cdot F_{O} \cdot F_{\Delta}
$$

No tocante à otimização dos fatores $F_{\Delta}$ e $F_{I}$, a regra do um-quarto (one-quarter rule, em inglês) proposta por Keane e Adrian (1990) propicia bons resultados se combinada ao método da interrogação por múltiplos passos (multi-pass em inglês) utilizado junto às técnicas de deformação de janelas de interrogação descritas por Scarano (2001) e à técnica de deslocamento de janela (window shifting em inglês) apresentada por Willert (1996). Já a otimização de $F_{O}$ acontece com a escolha cuidadosa do intervalo de tempo de gravação entre as imagens que serão correlacionadas, de modo a encontrar um trade-off entre a faixa dinâmica de velocidade e a perda de pares de imagens de partículas, de acordo com Scharnowski e Kähler (2016a). Ademais, tais considerações podem ser entendidas como premissas para alcançar resultados mais fidedignos à realidade. Consequentemente, tanto o experimento com PIV como o processamento de dados provenientes da aplicação do método de velocimetria por imagens de partículas podem ser tratados iterativamente, de modo que a solução de compromisso que abrange todas as premissas de forma otimizada seja tal que promova a maior probabilidade de detecção dos picos de correlação para todas as janelas de interrogação propostas na etapa de estratégia de interrogação e processamento.

Uma vez alcançada a maior probabilidade de detecção do pico de correlação possível via otimização dos parâmetros da Equação 2.3, uma boa prática para avaliar a precisão dos resultados é a proposição de uma estratégia confiável de quantificação da incerteza dos resultados. Diversos parâmetros motivam a presença de incertezas nos campos vetoriais provenientes do processamento $P I V$, sendo o tamanho das partículas 
traçadoras, a concentração do seeding, a intensidade de turbulência do escoamento, o nível de ruído nas imagens primárias, os gradientes de deslocamento no plano e o tamanho da janela de interrogação os parâmetros mais apontados na literatura como fontes capazes de afetar a magnitude das incertezas. Tais informações são oriundas das conclusões dos trabalhos apresentados pelos pesquisadores Timmins et al. (2012), Sciacchitano, Wieneke e Scarano (2013), Charonko e Vlachos (2013), Xue et al. (2014, 2015), Neal et al. (2015) e Wieneke (2015), os quais estudaram os métodos capazes de predizer quantitativa e qualitativamente a incerteza associada a cada campo vetorial obtido com a aplicação do método PIV.

De modo geral, a sumarização das discussões propostas pelos autores mencionados no parágrafo acima converge para dois tipos de estratégia de análise de incerteza. O primeiro, consiste em identificar todos os parâmetros que influenciam a produção de incerteza e, então, determinar o efeito que cada um oferece à incerteza global à partir da magnitude de cada um deles. O segundo, reduz-se à uma análise voltada à inspeção de variáveis dependentes da correlação e é justificada pelo fato de a forma da função de correlação reunir todas as contribuições dos parâmetros que produzem ou não incertezas associadas à predição de um vetor velocidade. Vale destacar que ambos têm o objetivo de discorrer sobre os aspectos qualitativos que definem a fonte geratriz do erro intrínseco à técnica, além de computar a magnitude da incerteza que cada variável imprime ao resultado final, para que o usuário da técnica de PIV possa atuar sobre o experimento, otimizando-o quanto à minimização de erros. O trabalho escrito por Boomsma et al. (2015) apresenta uma discussão que aponta para a classificação dos métodos capazes de avaliar a incerteza associada às medidas $P I V$, segundo as estratégias supracitadas, em três categorias: (i) métodos de superfície de incerteza; (ii) métodos de correspondência de imagens; (iii) métodos de plano de correlação.

Os métodos de superfície de incerteza utilizam a resposta a alguma variável entendida como fonte de erro para prever a magnitude da incerteza. Nesse tipo de método, algumas fontes de erro podem ser selecionadas, tendo cada uma delas o efeito mensurado a partir de simulações Monte Carlo. Definido o erro para cada vetor velocidade, uma superfície de incerteza é gerada a partir do confronto entre os resultados obtidos para cada fonte de erro selecionada. O trabalho de Timmins et al. (2012) apresenta uma investigação do tamanho da imagem de partícula, da concentração de seeding e do deslocamento de 
partículas como prováveis fontes de erro. Para o leitor interessado no estudo deste método, recomenda-se as referências escritas por Timmins et al. (2010, 2012).

Os métodos de correspondência de imagens compreendem o cálculo da incerteza de medição PIV com base em cada partícula presente em uma janela de interrogação mantida fixa entre duas imagens consecutivas (gravação tipo quadro-duplo). Em tais métodos, um vetor de disparidade é obtido por meio da comparação entre o deslocamento de cada imagem de partícula combinada e a velocidade medida para o conjunto de partículas. Deste modo, um campo de vetores de disparidade é obtido e, via estatística, a magnitude da incerteza associada à medição é determinada. Uma vertente deste método é a técnica de estatística de correlação, desenvolvida por Wieneke (2015). Tal técnica utiliza todas as imagens de partículas presentes em uma janela de interrogação e estima a incerteza das medições $P I V$ comparando o campo vetorial original a um campo produzido por adição sintética de deslocamentos tais que produzam um pico de correlação simétrico. Vale destacar que esses métodos apenas são aplicáveis após o processamento vetorial, mediante a condição de o campo de velocidades ser convergente. Mais informações sobre o conjunto de métodos de correspondência de imagens podem ser encontradas nos trabalhos de Sciacchitano et al. (2013), Wieneke (2015), Boomsma et al. (2015) e Neal et al. (2015).

Os métodos de plano de correlação utilizam, essencialmente, o plano de correlação como fonte provedora de informações pertinentes à estimativa da incerteza associada a cada vetor velocidade. Considerando a literatura atual, os trabalhos desenvolvidos por Charonko e Vlachos $(2013)$ e Xue et al. $(2014,2015)$ são exemplos de aplicações de métodos de plano de correlação. Charonko e Vlachos (2013), baseados em imagens sintéticas e na proposição de duas estratégias de processamento ( $S C C$ e $R P C$ ), relatam que a magnitude do erro de deslocamento é inversamente proporcional à altura do pico primário (maior pico de correlação) ou à relação entre as alturas dos dois maiores picos de correlação. Adicionalmente, os autores propuseram uma função que modela o erro a partir da consideração da altura do pico primário como variável independente. Vale destacar que, de acordo com Scharnowski e Kähler (2016a, 2016b), o uso de imagens sintéticas pode auxiliar na condução do estudo acerca das fontes produtoras de erros. Como complemento às conclusões de Charonko e Vlachos (2013), Xue et al. (2014) apresentaram uma relação matemática entre a relação sinal-ruído e o erro de deslocamento, admitindo que o erro não seja adequadamente modelado por uma 
distribuição normal. A Equação 2.4 refere-se ao modelo de ajuste proposto por Xue et al. (2014), onde U é a incerteza da velocidade, $\phi$ é o $S N R$ e A, B, C, M, N e S são parâmetros de ajuste.

$$
U^{2}=\left\{M \exp \left[-\frac{1}{2}\left(\frac{(\phi-N)}{S}\right)^{2}\right]\right\}^{2}+\left(A \phi^{-B}\right)^{2}+C^{2}
$$

Alternativamente, Xue et al. (2015) trouxeram uma métrica de quantificação da incerteza utilizando uma estratégia denominada por Informação Mútua, a qual refere-se ao quociente entre o pico de correlação cruzada e o pico da função de auto correlação. Segundo Xue et al. (2015), quão maior for o referido quociente, mais elevada é a quantidade de partículas se correlacionam dentro da janela de interrogação, de modo que menor será a incerteza associada ao valor de velocidade medido. Utilizando a estratégia oferecida pela Informação Mútua, os pesquisadores propuseram um método robusto para estimar a incerteza dos dados PIV.

Finda a apresentação acerca dos métodos de quantificação e de análise de incertezas PIV, é conveniente destacar que Neal et al. (2015) disponibilizaram à comunidade científica um conjunto de dados experimentais referentes à diversos tipos de escoamento. Para que toda e qualquer metodologia de investigação das incertezas advindas da aplicação do processamento $P I V$ seja realizada admitindo que todas as fontes de erros têm influência minimizada, as condições experimentais de todos os ensaios realizados foram minunciosamente controladas. Considerando a discussão oferecida pelos autores, o objetivo secundário à execução de procedimentos experimentais cuidadosos e com boa precisão é justificado pela necessidade de realizar um experimento em que a velocidade seja medida junto ao seu verdadeiro valor. Deste modo, no caso de impossibilidade do último, o experimento traduz-se na obtenção de vetores velocidade que podem ser entendidos como referências. Para tanto, além da técnica de $P I V$, a técnica de anemometria por fio quente ( $H W A$, sigla em inglês) foi utilizada. Vale destacar que esse tipo de dados é interessante a estudos que visem comparar diferentes métodos de processamento ou pós-processamento, desde que não haja partículas no escoamento ( situação que inviabiliza o uso do $H W A$ ).

Visto que o efeito de diversos parâmetros intrínsecos ao método de PIV na produção de incertezas é desejável para identificar as principais fontes de erros e, 
consequentemente, para alcançar as otimizações do experimento e do processamento, um parâmetro não poderia deixar de estar contido no conjunto de variáveis independentes da qualidade dos resultados obtidos com PIV: o nível de ruído remanescente do método de pré-processamento (ou da imagem primária, no caso da não proposição de algoritmos de tratamento de imagem). De acordo com Scharnowski e Kähler (2016a), o processo de geração de ruído na imagem é definido da seguinte forma:

“O ruído da imagem é gerado principalmente por processos estatísticos durante a gravação dos fótons, a geração de fotoelétrons e durante a leitura e amplificação dos sinais produzidos pelos elétrons no sensor da câmera. O ruído do fóton é caracterizado por uma distribuição de Poisson, e o ruído da leitura e amplificação pode ser aproximado pelo ruído Gaussiano. "

Motivados pela definição de ruído de imagem e pela grande influência que qualidade da imagem tem sobre a detecção adequada do pico de correlação, Scharnowski e Kähler (2016a) apresentam dados quantitativos que permitem compreender melhor as recomendações dadas por Raffel et al. (2007), Adrian e Westerweel (2011) e pela ITTC (2014) no tocante à necessidade de tratar a imagem primária com o propósito de eliminar ao máximo o ruído remanescente do processo de gravação. Utilizando imagens sintéticas, os autores estimaram a incerteza associada ao deslocamento médio, $\Delta X_{R M S}$, provocada pela intensidade de ruído, $\sigma_{N}$, presente em imagens com máxima intensidade dada por $I_{0}$ e com concentração de imagens de partículas por pixel (ou quantidade de imagens de partículas por pixel), $N_{P P P}$, as quais têm diâmetro constante e igual a 3,0 pixels. O resultado da análise é apresentado na Figura 2.19, a qual revela que o nível de ruído da imagem afeta significativamente a magnitude da incerteza atrelada ao deslocamento. Além disso, nota-se que para as menores concentrações de imagens de partículas testadas, os valores de incerteza são os maiores dentre todos os encontrados. Por fim, percebe-se que o efeito que o $N_{P P P}$ exerce sobre a variável $\Delta X_{R M S}$ torna-se mais pronunciado com o aumento de $\sigma_{N}$.

Graças à ausência de um método que quantifique o nível de ruído gerado em uma imagem primária, e solidário à respectiva influência que o mesmo tem sobre a determinação dos vetores deslocamento médio, Scharnowski e Kähler (2016a) 
propuseram um método para estimar a perda de correlação devido ao ruído de imagem. O método é baseado na função de autocorrelação da matriz de pixels e fornece uma definição de um $S N R$ voltado à análise da qualidade das imagens primárias ou prétratadas. O método oferece uma solução analítica que permite quantificar a influência do ruído na perda de correlação como uma função do $S N R$ da imagem, trazendo conclusões que versem apenas sobre a participação do ruído na imagem, excluindo do cálculo as participações de $F_{I}, F_{O}$ e $F_{\Delta}$.

Figura 2.19 - Incerteza do deslocamento determinada para imagens sintéticas como uma função do nível de ruído $\sigma_{N} / I_{0}$ para diferentes concentrações de imagens de partículas, $N_{P P P}$. O diâmetro das imagens de partículas escolhido é de 3,0 pixels e a janela de interrogação mede $32 \times 32$ pixels.

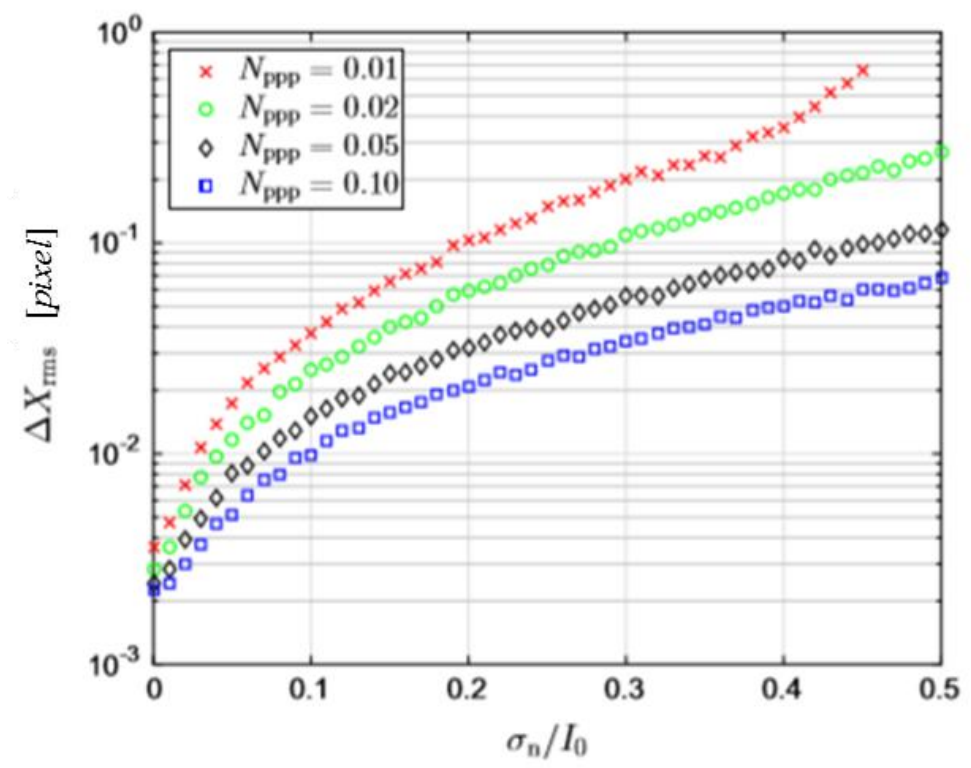

Fonte: Scharnowski e Kähler (2016a).

A Equação 2.5 apresenta o modelo da perda de correlação por ruído de imagem, $F_{\sigma}$, como uma função do desvio padrão das intensidades dos pixels das imagens que serão correlacionadas, $\sigma_{A}$ e $\sigma_{B}$. Adicionalmente, a Equação 2.6 refere-se à relação descoberta pelos pesquisadores entre o $S N R$ da imagem e o $F_{\sigma}$, a qual fora verificada experimentalmente, conforme mostra a Figura 2.20. Ainda sobre $F_{\sigma}$, a Figura 2.21 mostra a relação de dependência entre a incerteza do deslocamento e a perda de correlação devido ao ruído de imagem para diferentes janelas de interrogação. Conforme pode ser visto, o erro médio atrelado ao deslocamento médio do conjunto de partículas é fortemente afetado pelo ruído da imagem. Além disso, no caso em análise, a tentativa de aumento de 
resolução espacial configura aumento da incerteza de medição quando fixado um nível de ruído.

$$
\begin{gathered}
F_{\sigma}=\frac{\sigma_{A} \cdot \sigma_{B}}{\sqrt{\sigma_{A}^{2}+\sigma_{N}^{2}} \cdot \sqrt{\sigma_{B}^{2}+\sigma_{N}^{2}}} \\
F_{\sigma}=\left(1+\frac{1}{S N R^{2}}\right)^{-1}
\end{gathered}
$$

Figura 2.20 - Perda de correlação por ruído de imagem como uma função da relação sinal-ruído, definida na Equação (2.6). Cada símbolo refere-se à uma combinação de diâmetro e de concentração de imagens de partículas, atrelada à uma combinação de intensidade de ruído $\sigma_{N} / I_{0}$.

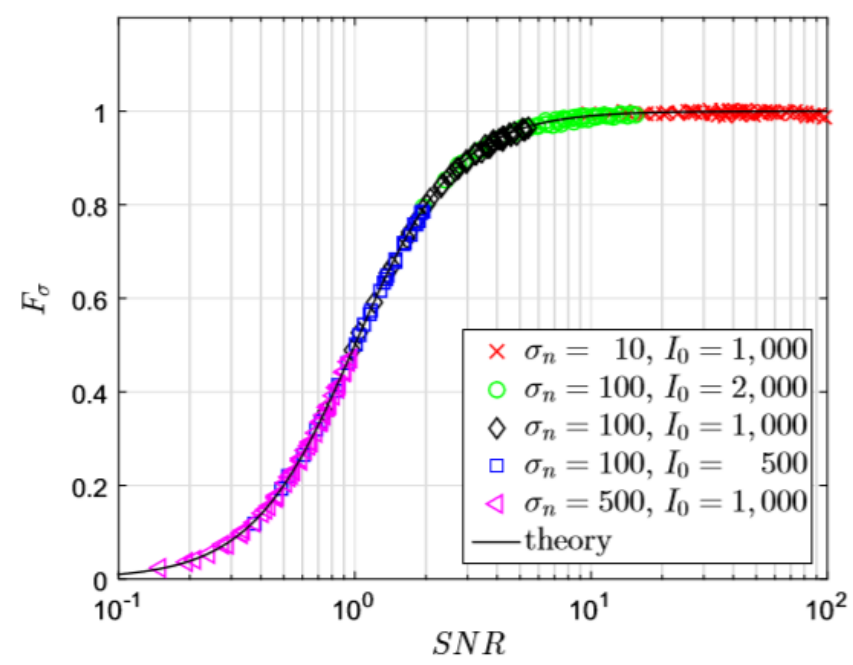

Fonte: Scharnowski e Kähler (2016a).

Figura 2.21 - Incerteza do deslocamento determinada para imagens sintéticas como uma função do fator Fo e do tamanho da janela de interrogação.

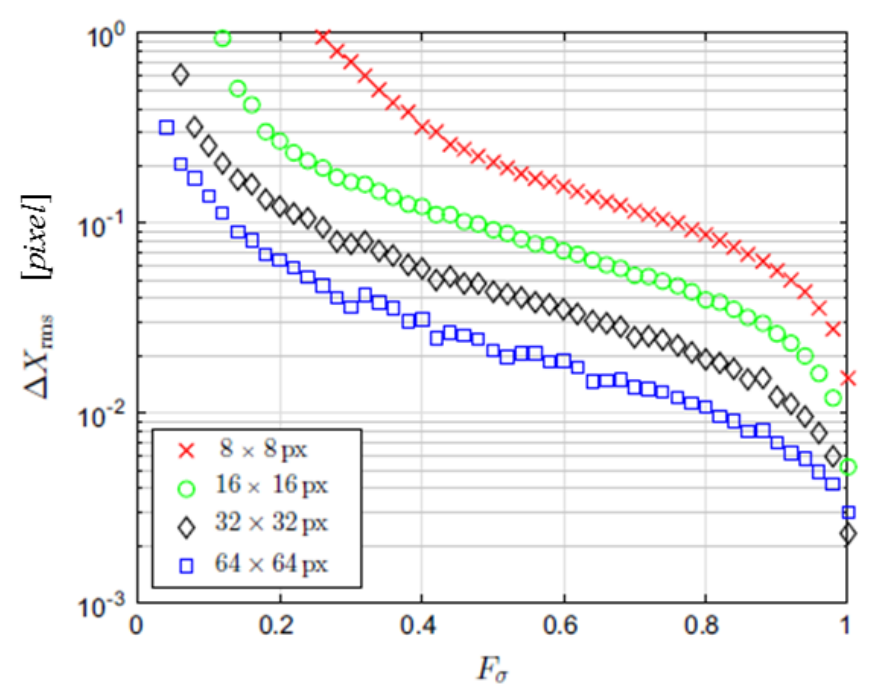

Fonte: Scharnowski e Kähler (2016a). 
Portanto, fica evidenciado que as conclusões obtidas por Raffel et al. (2007) e por Adrian e Westerweel (2011) são corroboradas pelos resultados mostrados por Scharnowski e Kähler (2016a), uma vez que a qualidade da imagem gravada e processada é, de fato, uma variável determinante da probabilidade de detecção do pico de correlação no mapa de correlação. Por conta disso, Scharnowski e Kähler (2016a) sugerem incluir o fator de perda de correlação por ruído de imagem no cálculo do número efetivo de partículas, apresentado pela Equação 2.3, na tentativa de manter os falsos vetores em uma quantidade cada vez mais irrisória. Consequentemente, com a inclusão de $F_{\sigma}$, o número efetivo de partículas passa a ser mais complexo de ser determinado, uma vez que uma nova variável o compõe. Adicionalmente, vale destacar que não existem métodos para a predição de perdas de pares para medições realizadas com $P I V 2 D$, o que torna ainda mais desafiador julgar a adequabilidade de um processamento PIV.

\subsubsection{DESAFIOS DA APLICAÇÃO DA TÉCNICA DE VELOCIMETRIA POR IMAGENS DE PARTÍCULAS PARA CARACTERIZAR SPRAYS DE COMBUSTÍVEL DENSOS}

Para o estudo de escoamentos bifásicos, uma extensão da técnica de PIV é amplamente aplicada e conhecida como velocimetria por imagens de partículas bifásica (Two-Phase PIV ou Two-Color PIV em inglês). Para que as fases sejam discernidas entre si, o emprego de traçadores fluorescentes como dopantes em uma das fases é adotado de forma tal que ambas podem ser visualizadas de forma independente. Isso ocorre graças à emissão de luz em diferentes comprimentos de onda por parte dos traçadores fluorescentes, se comparado à luz proveniente da fonte luminosa e à luz espalhada pelas partículas não fluorescentes que traçam a outra fase. Devido à essa peculiaridade, filtros ópticos são acopladas às câmeras para que os comprimentos de onda característicos de cada traçador sejam percebidos e, então, as fases sejam gravadas em imagens distintas. Consequentemente, duas câmeras, cada qual com o conjunto óptico conveniente à fase que será registrada, são utilizadas em aplicações de PIV bifásico. No caso da utilização de uma câmera para registrar os dois sinais, é necessária a inclusão de um dispositivo conhecido como duplicador de imagens (image doubler, em inglês). A partir do desacoplamento de ambas as fases, o método PIV é utilizado para determinar o movimento dos traçadores (fluorescentes e convencionais) e definir o respectivo campo 
de velocidades de ambos os escoamentos. No entanto, a sobreposição de ambas as imagens deve representar, no espaço de imagem, a interação entre ambas as fases. A Figura 2.22 mostra um exemplo de espectro de absorção e de emissão de luz de uma partícula fluorescente, no caso a Rhodamina B. De acordo com a figura, é possível notar que o pico de absorção de luz acontece no comprimento de onda de $545 \mathrm{~nm}$, aproximadamente, enquanto o pico de emissão de luz ocorre nas proximidades de $570 \mathrm{~nm}$.

Figura 2.22 - Espectro de absorção (linha pontilhada) e de emissão (linha cheia) da RhodaminaB.

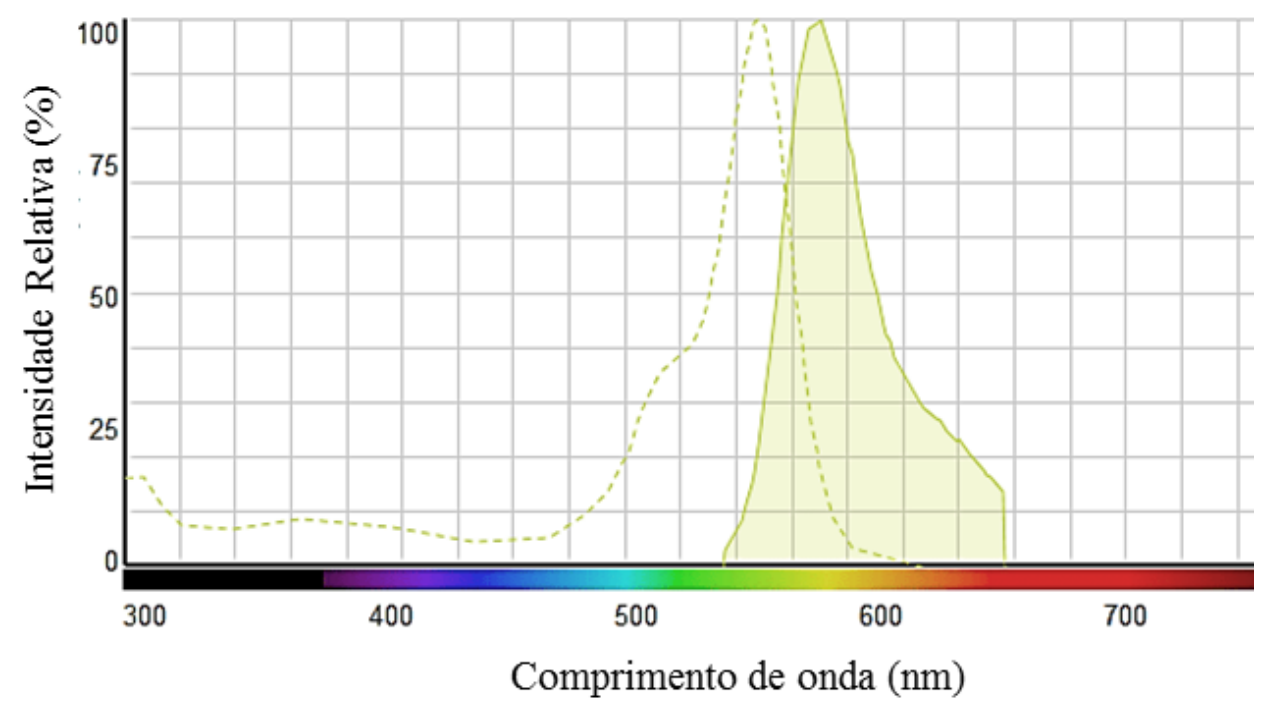

Fonte: Adaptado de Silvério, Cardoso e Moreira (2016).

Vale destacar que, de acordo com a literatura, o comportamento de variáveis atreladas à cinemática do escoamento ar-spray é comumente estudado a partir da técnica de PIV bifásico. Ao adotá-la, a separação entre as fases é promovida através da inserção de traçadores fluorescentes na fase gasosa, uma vez que as próprias gotículas de combustível se comportam como traçadores do fluido atomizado (BERTI, 2018). Então, no estudo de sprays por PIV bifásico, uma câmera é a responsável por gravar as imagens de fluorescência, enquanto a outra grava, simultaneamente, o espalhamento elástico das gotas de combustível. A Figura 2.23 mostra uma representação do princípio de separação das fases de um escoamento bifásico ar-spray, utilizando a técnica Two-Phase PIV. 
Figura 2.23 - Ilustração da aquisição individual típica das imagens do espalhamento-Mie e do sinal de fluorescência de um escoamento bifásico gás-spray utilizando a técnica de PIV bifásico.

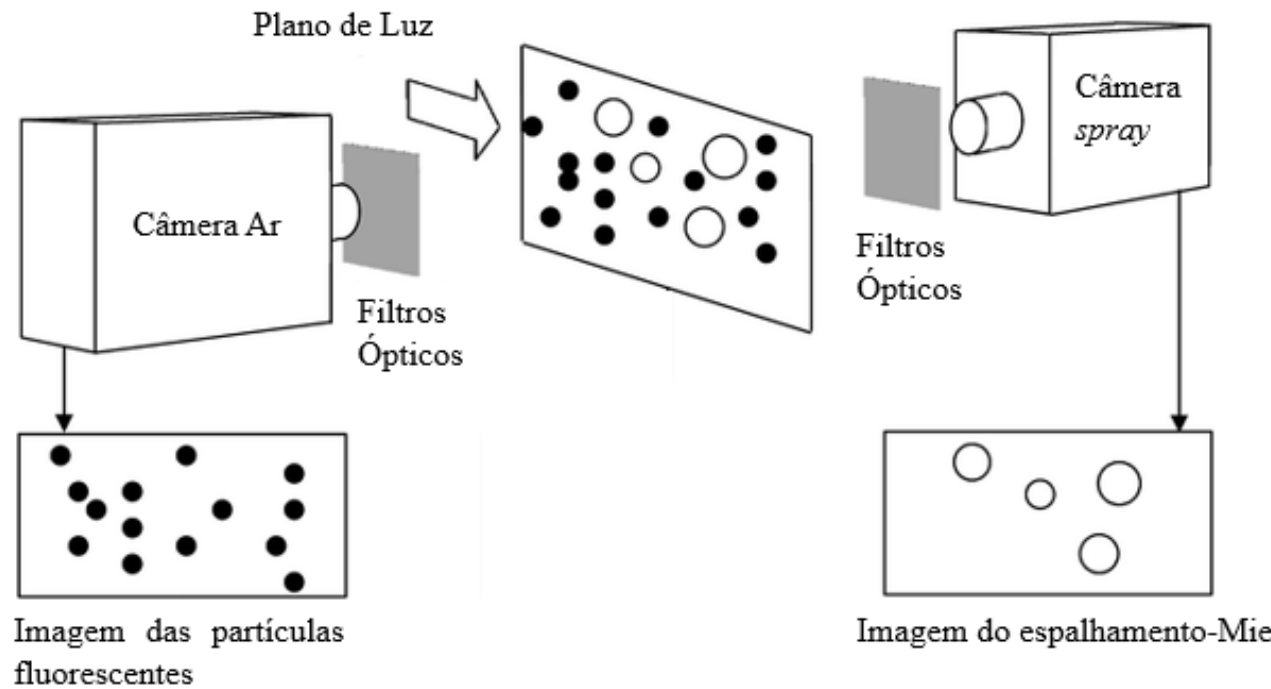

Fonte: Adaptado de Kosiwczuk, Cessou, Trinité e Lecordier (2005).

No âmbito da aplicação da técnica de velocimetria por imagens de partículas bifásica a sprays de combustível densos (produzidos por injetores de motores ciclo diesel e de motores equipados com injeção direta), dois aspectos a torna desafiadora, segundo Berti (2018) e Towers, Towers e Reeves (1999): a densidade do spray e a eficiência de fluorescência das partículas traçadoras do ar. De acordo com os autores, o primeiro fator está atrelado à produção de sprays compactos e com alta velocidade de penetração na atmosfera gasosa circundante, os quais oferecem alta concentração de gotas em toda a parte. Deste modo, quando os sprays são submetidos à iluminação laser, a energia incidente é espalhada com alta intensidade no volume de controle. Já o segundo fator refere-se à baixa parcela de energia dissipada pelas partículas fluorescentes frente à quantidade de energia dispendida pelo espalhamento-Mie. Tal parcela é cerca de sessenta vezes inferior a energia liberada pelo espalhamento-Mie. Contudo, tratando-se da contribuição de ambos os fatores à qualidade da imagem primária, é importante salientar que fortes ruídos podem ser percebidos nas gravações dos sinais de fluorescência. Isso se deve ao fato de o forte espalhamento de luz proveniente das gotículas de combustível influenciar a iluminação local com excesso de luminosidade, produzindo, assim, sinais de fluorescência que não são representativos dos traçadores.

Um exemplo dos fortes sinais que um spray denso e com alta velocidade de penetração oferecem às câmeras é mostrado na Figura 2.24a, enquanto Figura 2.24b 
apresenta os sinais de fluorescência das partículas traçadoras do gás circundante ao spray, ambas extraídas do trabalho de Dankers et al. (2008). Ao analisar a Figura 2.24a, nota-se um típico sinal de espalhamento elástico de luz, no entanto com forte intensidade à direita (lado de incidência do laser, segundo os autores). Já a Figura 2.24b, mostra um intenso sinal de fluorescência que pode ser atribuído não tão somente à elevada concentração de traçadores, mas também pela fluorescência induzida pelo espalhamento de luz advindo do spray. Ao analisar a Figura 2.24b, torna-se perceptível que as imagens de partículas não estão claramente definidas em relação ao fundo e que a presença do spray gera uma fonte de ruído que deveria ter sido evitada. No entanto, embora os autores defendem que a forte iluminação não interfere na qualidade dos resultados, Amaral et al. (2014) e Moura (2017) destacam que a iluminação desigual em uma imagem primária deve ser adequadamente tratada para evitar que o comportamento percebido seja entendido como ruído de imagem. Além disso, para as imagens de fluorescência, cabe à etapa de préprocessamento tratar a imagem de modo a eliminar este comportamento e homogeneizar a iluminação, de acordo com as definições fornecidas no início da seção 2.2. Já para a gravação da fluorescência, cabe à mesma etapa propor um aumento de contraste entre o fundo e as imagens de partículas, além de eliminar a presença do spray da imagem primária. Tais recomendações devem ser seguidas para produzir resultados mais confiáveis, evitando resultados mascarados por intensa aplicação de filtros no pósprocessamento.

Figura 2.24 - Exemplo de uma gravação do (a) espalhamento-Mie de um spray produzido por um injetor típico de motores de injeção direta e do (b) sinal de fluorescência fornecido pelos traçadores fluorescentes.

a.

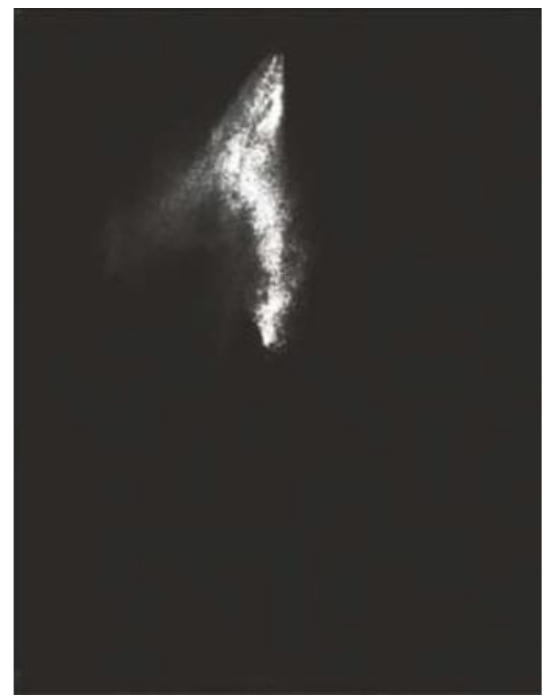

b.

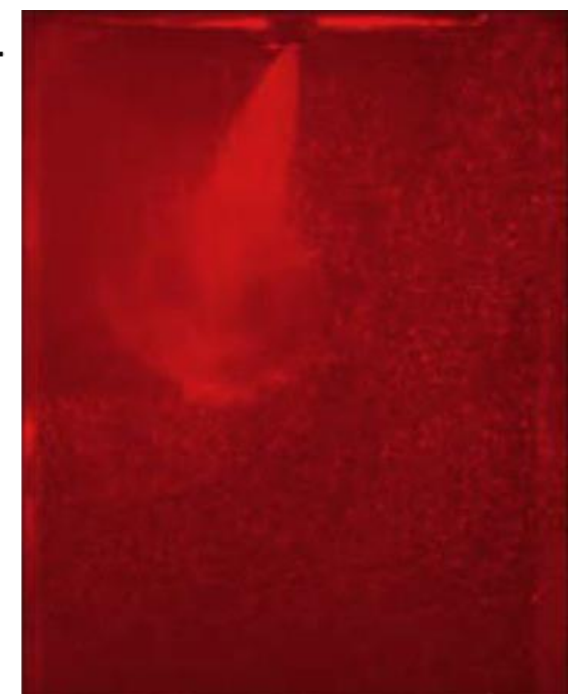

Fonte: Adaptado de Dankers et al. (2008). 
Portanto, para estudar o desenvolvimento do escoamento ar-spray utilizando a técnica de PIV bifásico, uma solução de compromisso entre a intensidade da luz laser, a concentração de traçadores e a abertura da câmera deve ser encontrada. A combinação deve ser tal que permita energia suficiente para excitar os sensores da câmera de fluorescência, simultaneamente ao fato de propiciar níveis seguros de iluminação para a câmera que registra o espalhamento elástico de luz por parte do spray. Para conseguir encontrar a solução de compromisso necessária à obtenção ideal de imagens primárias, filtros ópticos com alta performance devem ser utilizados, especialmente os filtros de passagem longa (longpass, em inglês) para atenuar os intensos sinais de espalhamento (BERTI, 2018). Um exemplo de montagem de um conjunto óptico que atendeu adequadamente às restrições impostas pelo forte espalhamento de luz é encontrado no trabalho de Berti (2018) e tem parte mostrada na Figura 2.25. O autor propôs uma combinação de filtros de passagem longa, de absorção e dicroicos que possibilitou gravar as imagens dos traçadores do ar segura e adequadamente. Para gravar as imagens do espalhamento-Mie, uma combinação de filtros passa-baixa com filtros de densidade neutra foi empregada.

Figura 2.25 - Ilustração da montagem dos filtros ópticos utilizada durante a gravação das imagens de fluorescência.

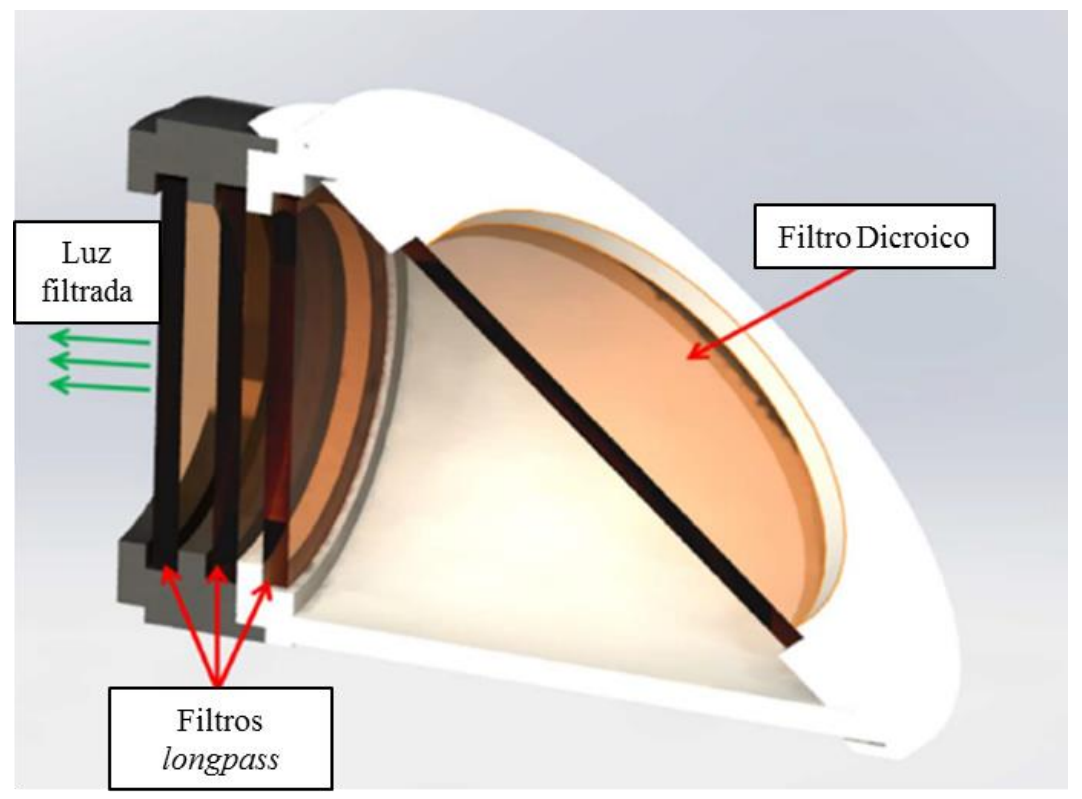

Fonte: Adaptado de Berti (2018). 


\subsection{ESTRATÉGIAS PIV UTILIZADAS PARA CARACTERIZAR SPRAYS DENSOS APLICADOS EM MOTORES DE COMBUSTÃO INTERNA EQUIPADOS COM SISTEMA DE INJEÇÃO DIRETA}

Soid e Zainal (2011) apresentam um levantamento detalhado sobre as técnicas existentes atualmente que permitem caracterizar sprays de combustíveis utilizados em motores de combustão interna. Considerando cinquenta trabalhos, a síntese realizada pelos pesquisadores converge para uma descrição qualitativa das técnicas a partir da seguinte classificação: métodos de análise macro e microscópicos. A primeira refere-se à análise visual da penetração e do formato do spray - embora ambas as variáveis possam ser medidas experimentalmente; a segunda resume-se à obtenção de informações como densidade e diâmetro de gotas, distribuição de tamanho de gotas, além da caracterização cinemática do escoamento. Dentre as técnicas discutidas por Soid e Zainal para compor os métodos microscópicos, o método de velocimetria por imagens de partículas é destacado como uma técnica capaz de ser aplicada quando o objetivo for caracterizar o escoamento desenvolvido por sprays (de baixa densidade, preferencialmente) através de grandezas que dependam de informações atreladas aos campos de velocidade instantânea. Diante desta consideração, fica evidenciado que a confiabilidade da caracterização de sprays a partir de dados experimentais provenientes do campo de velocidades obtido por meio da aplicação de $P I V$ é função da qualidade com a qual são desenvolvidas todas as etapas que compõe o método, conforme foi discutido na Seção 2.2.

Em concordância às conclusões obtidas por Soid e Zainal (2011), vale destacar que os trabalhos citados no presente tópico desta revisão bibliográfica utilizam a técnica PIV para caracterizar sprays de diversos combustíveis por meio do campo de velocidades. Entretanto, pode-se notar que, embora o conhecimento sobre a forte influência que a qualidade das imagens primárias tem sobre o resultado final, diversos estudos não consideram, com a importância devida, esse aspecto durante as análises. Tal fato é percebido graças à ausência de análises de sensibilidade aos métodos de préprocessamento destinados às imagens do escoamento ar-spray. Além disso, pode-se verificar que alguns estudos apresentam métodos superficiais no que tange a análise da influência que as etapas de processamento e pós-processamento oferecem ao campo vetorial final. Tais referências, mesmo propondo certa profundidade nos objetivos e nas discussões dos resultados obtidos, não apresentam nenhuma estratégia de préprocessamento das imagens primárias e não se mostram inclinados a verificar a 
confiabilidade dos resultados obtidos quanto à qualidade da correlação. $\mathrm{O}$ trabalho desenvolvido por Moon et al. (2010) é um exemplo da ausência completa de informações sobre as estratégias utilizadas em cada passo da técnica de PIV. Os autores apresentam um estudo criterioso e comparativo sobre a dinâmica do escoamento de sprays de óleo diesel, provenientes de dois injetores típicos utilizados em MCIs equipados com injeção direta, utilizando a técnica PIV. Com relação ao emprego da técnica, o estudo divulga apenas que as imagens do espalhamento-Mie e das partículas traçadoras foram obtidas e processadas por um determinado sistema de análise integrada. Sendo assim, não são descritos pelos autores como o sistema utilizado por eles trabalha com os métodos de pré e pós-processamento e como é desenvolvida a estratégia de interrogação e de processamento das imagens. Tão pouco a verificação da confiabilidade dos resultados obtidos é mostrada.

Quanto à ausência de métodos de pré-processamento, pode-se citar os estudos realizados por Moyne et al. (2007) e Zhang et al. (2014). Em ambos, a estratégia de interrogação e de processamento é apresentada e os autores consideram o tratamento do campo vetorial final por meio de uma técnica de pós-processamento. Deste modo, todos os resultados obtidos são provenientes das imagens primárias. Moyne et al. (2007) investigaram a distribuição do tamanho de gotas e o fenômeno de arrastamento do ar a partir de um spray de gasolina oriundo de um injetor tipo mecânico-centrífugo, utilizando a técnica PIV bifásico. No estudo apresentado pelos autores, a configuração experimental adotada é mostrada e consiste, essencialmente, em um arranjo típico da referida técnica. O experimento conta com duas fontes de luz laser e com duas câmeras acopladas a filtros ópticos passa-alta (para gravar as imagens do ar) e de interferência (para gravar as imagens do spray). Filtros dicroicos também são utilizados. O método de processamento das imagens proposto é particular de cada fase do escoamento e tem o objetivo de capturar elevados gradientes de velocidade. Para obter o campo de velocidades do spray, o método utilizado é a correlação cruzada solidária à metodologia de múltiplos passos (multipass em inglês). Inicialmente, as janelas de interrogação estipuladas pelos autores têm tamanho de 256 x 256 pixels e são reduzidas a 32 x 32 pixels, considerando sobreposição com intensidade igual a 75\%. Para as medições de velocidade do gás circundante, o procedimento é idêntico, no entanto a sobreposição igual a $50 \%$ foi adotada. Como método de pós-processamento, foi escolhida a filtragem por mediana. 
Zhang et al. (2014) desenvolveram um método de medição simultânea do escoamento do ar e do spray de combustível, utilizando a técnica de PIV bifásico, a partir da proposição de uma estratégia temporal que permite gravar as imagens do ar e do spray com melhor qualidade e em instantes diferentes. $\mathrm{O}$ experimento desenvolvido empregou uma fonte de luz laser para iluminar o escoamento ar-spray e uma câmera de alta velocidade, na qual foram acoplados filtros passa-alta e passa-baixa, além de lentes específicas e de um duplicador de imagens. Para obter os campos de velocidade de ambas as fases, os autores utilizaram a estratégia de múltiplos passos com tamanho final da janela de interrogação igual a 32 x 32 pixels. Nenhum processamento de imagem foi proposto, possivelmente devido ao processo de gravação das imagens ter suprimido a necessidade de tratá-las digitalmente. No entanto, embora os autores possam ter entendido que era desnecessário avaliar a qualidade das imagens primárias, eles verificaram a coerência dos resultados obtidos com o método PIV comparando-os aos resultados provenientes da aplicação da técnica de $L D V$. A comparação feita pelos pesquisadores pode confirmar que os resultados de velocidade obtidos com PIV bifásico e com $L D V$ eram consistentes, exceto na região de interface entre o ar e o spray.

De acordo com o manual de boas práticas em PIV proposto pela ITTC (2014), um procedimento muito comum de ser realizado na etapa de pré-processamento é a remoção de ruído de fundo (background em inglês), cuja definição é apresentada na seção 2.2. No âmbito da aplicação da técnica PIV para caracterizar sprays de combustíveis utilizado em MCIs, a técnica de remoção de background é utilizada como método de préprocessamento de imagens primárias do escoamento ar-spray nos trabalhos de Driscoll, Sick e Gray (2003) e de Dankers et al. (2008) para promover as análises do escoamento do gás circundante, enquanto Berti (2018) adota tal técnica em um procedimento particular para tratar as imagens de ambas as fases.

O estudo desenvolvido por Driscoll, Sick e Gray (2003) apresenta um método que possibilita realizar a medição instantânea do campo de velocidades do escoamento bifásico ar-spray, considerando a melhor resolução espacial possível. O spray analisado pelos autores é do tipo cone-sólido e o combustível é o iso-octano. O método proposto é capaz de otimizar a resolução da velocidade a partir da magnitude dos vetores velocidade que definem cada fase. Para tanto, Driscoll, Sick e Gray (2003) utilizaram um arranjo experimental típico, com duas fontes de luz laser e com duas câmeras equipadas com filtros ópticos tipo passa-banda e com um filtro de interferência. A câmera equipada com 
filtro passa-baixa foi utilizada para gravar as imagens da fluorescência, ao passo que o espalhamento foi registrado pela câmera com filtro de interferência instalado. Um conjunto de lentes foi proposto para definir a geometria dos feixes de luz. Para obter os campos de velocidade referentes ao gás circundante e às gotas de iso-octano, o método de remoção de ruído de fundo foi utilizado como pré-processamento. A estratégia de interrogação utilizada é a de múltiplos passos, de modo que o tamanho final das janelas de interrogação foi de $32 \times 32$ pixels. A sobreposição de janela foi considerada igual a $50 \%$. Uma estratégia de pós-processamento foi citada para remover os falsos vetores, porém esta não foi apresentada pelos autores.

Dankers et al. (2008) apresentam um esforço dedicado à busca por melhoria de eficiência de conversão energética em motores de combustão, a qual permita que as emissões de poluentes e o consumo de combustível atinjam uma condição minimizada. Para tanto, o estudo realizado pelos autores consiste em analisar a interação arcombustível desenvolvida por um injetor multi-furos utilizado em um motor de combustão equipado com injeção direta. Dankers et al. (2008) analisaram a referida interação a partir da análise do escoamento de ambas as fases, combustível e gás circundante, utilizando a técnica de $P I V$ bifásico. A análise foi feita a partir da investigação dos campos de velocidade do gás circundante e do spray de combustível, ambos obtidos com o aporte de uma câmara de volume constante. $\mathrm{O}$ experimento proposto pelos pesquisadores emprega duas câmeras para gravar as imagens do ar e do spray, separadamente, de modo que o escoamento de ar visualizado por uma delas é identificado pela fluorescência de partículas traçadoras compostas por carbonato de propileno, enquanto as gravações do combustível revelam o espalhamento de luz, apenas. Nenhum filtro óptico foi instalado nas câmeras. Os sinais de espalhamento e fluorescência foram obtidos perpendicularmente ao feixe de luz laser $\mathrm{Nd}: \mathrm{YAG}$, de altura aproximadamente igual a $100 \mathrm{~mm}$, que era incidido na câmara pela direita. Para aplicar o método PIV para ambas as fases, os autores adotaram como pré-processamento a subtração de background, apenas. A etapa de processamento escolhida foi a correlação cruzada aplicada junto à metodologia de múltiplos passos, considerando a diminuição das janelas de interrogação de 128 x 128 pixel para 32 x 32 pixel ou 16 x 16 pixel, e sobreposição de $25 \%$ ou $50 \%$ para a análise do espalhamento, enquanto para processar as imagens da fluorescência utilizou-se a mesma estratégia de sobreposição para janelas de interrogação que tinham valor final dado por uma região de 64 x 64 pixel ou 32 x 32 pixel. 
O filtro de mediana foi adotado como procedimento de pós-processamento. Nenhuma análise sobre a fidelidade dos resultados obtidos pelo método PIV proposto em relação à realidade foi apresentada pelos autores.

Com o mesmo objetivo da remoção de ruído de fundo, o manual da ITTC (2014) oferece como alternativa os procedimentos de normalização da imagem e aplicação de filtragem espacial, no entanto é destacado que tais operações são mais complexas e podem ser mais efetivas ao processo de eliminação de background. Embora seja sugerido pelo manual, o procedimento de tratamento de imagem por normalização não é notado nos trabalhos referentes à caracterização de sprays por meio da técnica de velocimetria por imagens de partículas contidos na literatura. Uma metodologia similar é encontrada no pré-processamento desenvolvido por Berti (2018). Conquanto, o efeito positivo deste filtro pode ser visto no trabalho de Amaral et al. (2014), que utiliza a técnica de normalização como um dos procedimentos incluídos na etapa de pré-processamento de imagens destinadas ao estudo da dinâmica do escoamento de uma coluna de bolhas. Além disso, vale ressaltar que diversas ferramentas de filtragem espacial, não necessariamente destinadas a aplicações voltadas à técnica $P I V$, são apresentadas por Gonzales e Woods (2010).

Considerando a literatura atual, foram encontrados dois trabalhos capazes de oferecer metodologias complexas de pré e pós-processamento, assim como de escolha da estratégia de interrogação e de processamento, embutidas em um mesmo estudo: Rottenkolber et al. (2002) e Berti (2018).

Rottenkolber et al. (2002) apresentam um estudo voltado à caracterização do escoamento ar-spray por meio da aplicação da técnica PIV bifásico. Para tanto, os autores propuseram um arranjo experimental que continha uma câmara pressurizada (mantinha nitrogênio como gás ambiente com o intuito de controlar a pressão interna e de homogeneizar o escoamento dos traçadores). Os ensaios foram realizados com temperatura igual a $20^{\circ} \mathrm{C}$ e pressões de $0,1 \mathrm{MPa}$ e $1,0 \mathrm{MPa}$. Gasolina tipo Euro-Super foi atomizada por um injetor típico utilizado em motores de combustão interna equipados com injeção direta, o qual foi montado no topo da câmara e possui as medidas nominais de ângulo de cone e de vazão iguais a $90^{\circ}$ e $15 \mathrm{~cm}^{3} / \mathrm{s}$, respectivamente. O dopante fluorescente DCM e carbonato de propileno foram utilizados como traçador do ar e a mistura de ambos foi pulverizada na câmara por meio de um aerossol. Um feixe de luz 
laser Nd:YAG (duplo-pulso) foi utilizado para iluminar o escoamento e uma câmera CCD de 12 bits foi empregada para gravar as imagens das fases iluminadas pela referida fonte de luz. Os sinais de espalhamento e fluorescência foram obtidos perpendicularmente ao feixe de luz laser Nd:YAG, o qual foi incidido na câmara pela direita e teve a duração de exposição travada em $5 \mathrm{~ns}$ com taxa de repetição igual a $10 \mathrm{~Hz}$ e foi emitido com $50 \mathrm{~mJ}$. As imagens foram gravadas com resolução de 640 x 512 pixels para garantir alta taxa de aquisição e maior sensibilidade (maior pixel binning). Filtros ópticos foram utilizados solidariamente à câmera para ajustar a intensidade da luz espalhada pelo spray e para separar os sinais de espalhamento-Mie dos sinais fluorescentes.

Como forma de obter os campos vetoriais das fases ar e combustível com maior confiabilidade, os autores oferecem duas metodologias para separar as contribuições de cada uma das fases nas imagens primárias: a técnica de mascaramento e o método de separação por picos de correlação. A técnica de mascaramento é baseada na contribuição de cada fase à distribuição global dos níveis de cinza presentes nas imagens primárias. Por meio de histogramas acumulativos de nível de cinza, duas análises são sugeridas. A primeira, refere-se à interpretação dos histogramas das imagens dos traçadores do ar e do spray, separadamente, ambas obtidas com o aporte dos filtros ópticos. A segunda, consiste em avaliar o perfil do histograma de uma imagem primária que apresenta ambas as contribuições. A partir da interpretação conjunta de ambos os histogramas, define-se um threshold, o qual servirá de referência para a definição de uma máscara. Vale destacar que ambas as curvas propostas evidenciam, quando comparadas, formatos diferentes, conforme pode ser visto na Figura 2.26. A Figura 2.26 (a) mostra um exemplo de histograma acumulativo do nível de cinza oriundos de imagens primárias do ar e do spray, enquanto a Figura 2.26 (b) apresenta o histograma da imagem primária que contempla as contribuições do ar e do combustível, simultaneamente. A seta presente na parte inferior direita da Figura 2.26 (b) indica uma característica dos histogramas de imagens primárias que não apresentam discernidas as fases ar e combustível. 
Figura 2.26 - Exemplos de histogramas acumulativos da distribuição dos níveis de cinza de imagens (a) de cada fase de um escoamento ar-spray e (b) com ambas as fases presentes.

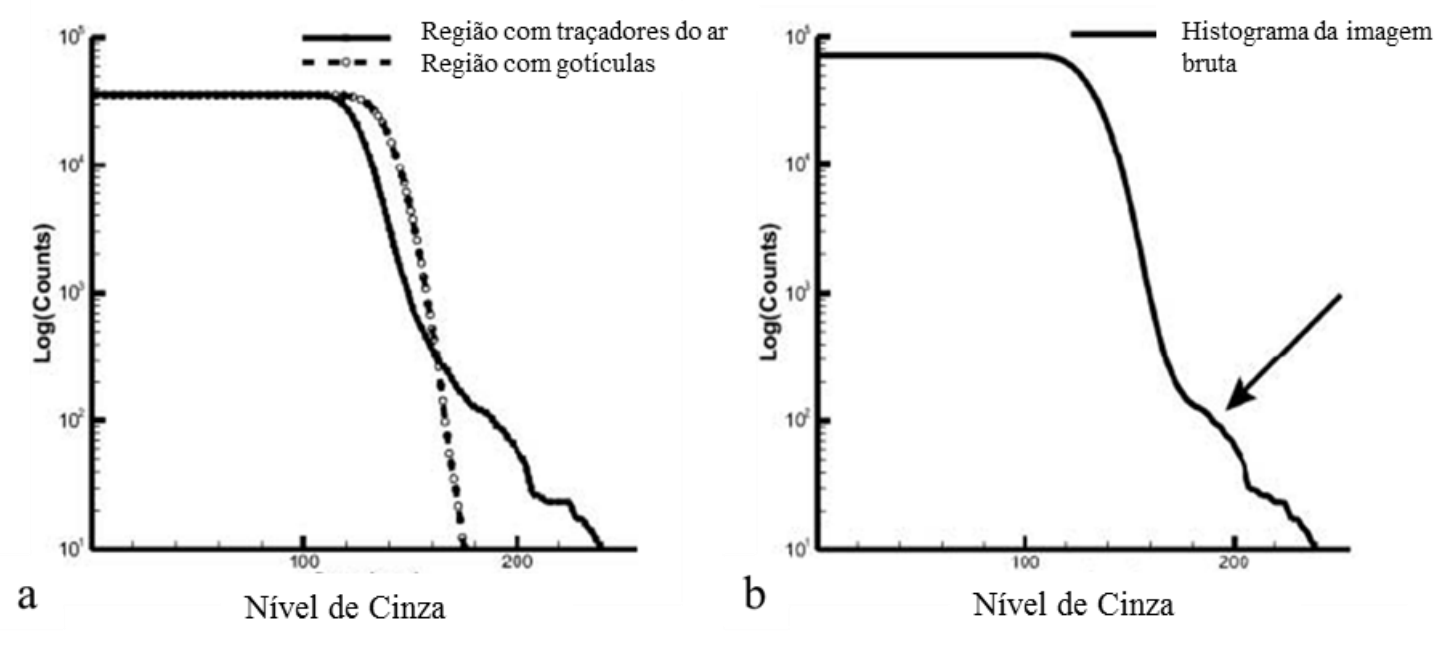

Fonte: Adaptado de Rottenkolber et al. (2002).

Terminadas as etapas de análise dos histogramas, Rottenkolber et al. (2002) obtiveram as imagens dos traçadores do ar a partir da binarização das imagens primárias. Considerando o limiar definido por meio da análise dos histogramas, a imagem foi formada por todos os pixels que tinham magnitude superior ou igual ao valor entendido como limite. Desta forma, máscaras representativas do escoamento de gás circundante foram obtidas adicionando o valor unitário aos pixels que possuíam valor maior que o threshold e zero aos demais. Os pixels que foram descartados da imagem mascarada foram responsáveis por compor a imagem da segunda fase. A Figura 2.27 mostra um exemplo de máscara obtida para representar as partículas traçadoras do gás circundante.

Os pesquisadores encerram a descrição do método proposto destacando que o mesmo pode ser aplicado em regiões menores definidas na imagem, de modo tal que a máscara possa ser definida a partir de toda imagem primária em sua totalidade ou puntualmente (considerando regiões com tamanho da ordem da janela de interrogação utilizada no processamento). Contudo, vale ressaltar que o método de mascaramento não é indicado para os casos em que há iluminação desigual por parte das partículas traçadoras e do espalhamento-Mie. Isto é, deve haver uma contribuição mínima de cada fase na mesma imagem primária para que a técnica consiga garantir resultados confiáveis. 
Figura 2.27 - Exemplo de uma máscara obtida para representar o escoamento de gás circundante.

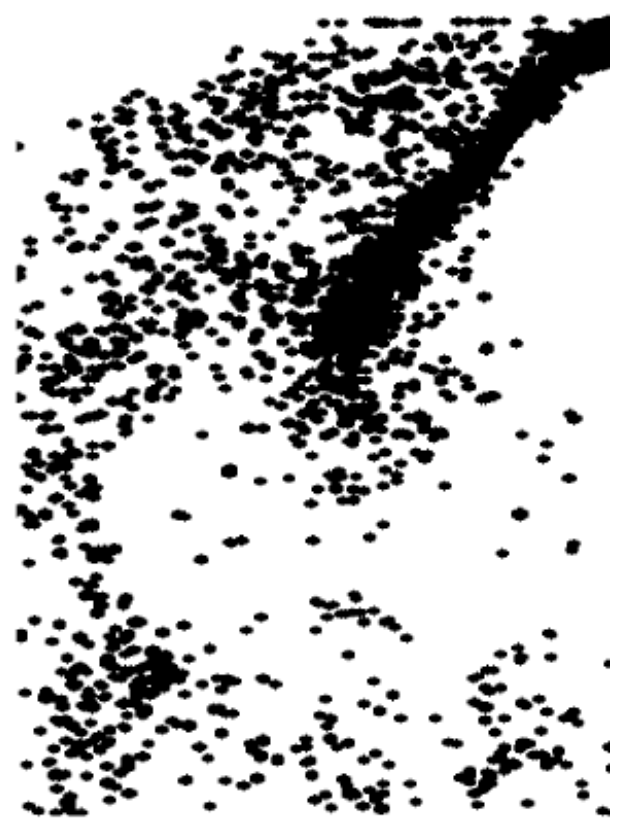

Fonte: Adaptado de Rottenkolber et al. (2002).

Motivados pela desvantagem que o método de mascaramento propicia em casos de diferentes contribuições de cada fase na iluminação da imagem, Rottenkolber et al. (2002) aplicaram, alternativamente, a técnica de separação dos picos em uma região de interface entre as fases. De acordo com Brucker (2000) e Rottenkolber et al. (2002), a técnica de separação consiste em identificar as regiões da imagem em que há a presença de traçadores do ar, gotas de combustível e de coexistência de ambos a partir da forma do pico de correlação. Brucker (2000) e Rottenkolber et al. (2002) destacam ainda que a referida técnica pode ser aplicada de forma segura quando há altos gradientes de velocidade entre as duas fases, se ambas estiverem presentes em uma mesma janela de interrogação. Consequentemente, os autores citam que tal técnica promove bons resultados nos instantes iniciais de penetração do spray no ambiente que o circunda, instantes nos quais há elevados gradientes de velocidade e intensa troca de quantidade de movimento entre as gotas de combustível e o gás.

A Figura 2.28 mostra o exemplo apresentado por Rottenkolber et al. (2002) como resultado da aplicação da técnica de separação por picos na mesma imagem primária utilizada para produzir a máscara apresentada na Figura 2.27. A imagem utilizada é mostrada pela Figura 2.28 (a), enquanto os campos de correlação obtidos para janelas de interrogação iguais a 160 x 128 pixels são apresentados pela Figura 2.28 (b). Analisando 
a Figura 2.28 (b), nota-se que há considerável diferença entre os formatos dos picos de correlação referentes às imagens de partícula e o espalhamento-Mie. De acordo com a imagem, o nível de ruído na região de presença única de traçadores (áreas 1, 2, 3, 5, 6 e 9) é muito maior que na região de presença única do spray (áreas 8, 11, 12, 15 e 16), graças ao baixo contraste que existe na primeira região mencionada. Consequentemente, nota-se que os picos de correlação são melhores definidos e mais pronunciados na última região, graças à menor influência de ruídos (devido ao maior contraste). No entanto, segundo os autores, embora estejam mais pronunciados, os picos de correlação apresentam-se com uma forte ampliação multidirecional (broadening). Esse fato decorre da presença de gotas grandes de combustível ou de coalescência, além do possível gradiente de velocidade entre as gotas que pertencem a uma mesma janela de interrogação. Por fim, a presença de duplos picos de correlação é notada (áreas 4, 7, 13 e 14) e indica que traçadores e gotas de combustível estão coexistindo em uma mesma janela de interrogação. Adicionalmente, os pesquisadores oferecem uma estratégia que utiliza histogramas para encontrar regiões com diferentes características de pico de correlação em uma mesma imagem. Todo o procedimento proposto é apresentado pelos autores e objetiva caracterizar o ruído através das alturas máxima e média dos picos de correlação.

Figura 2.28 - Exemplo da aplicação da técnica de separação por picos de correlação em uma região de interface ar-spray.
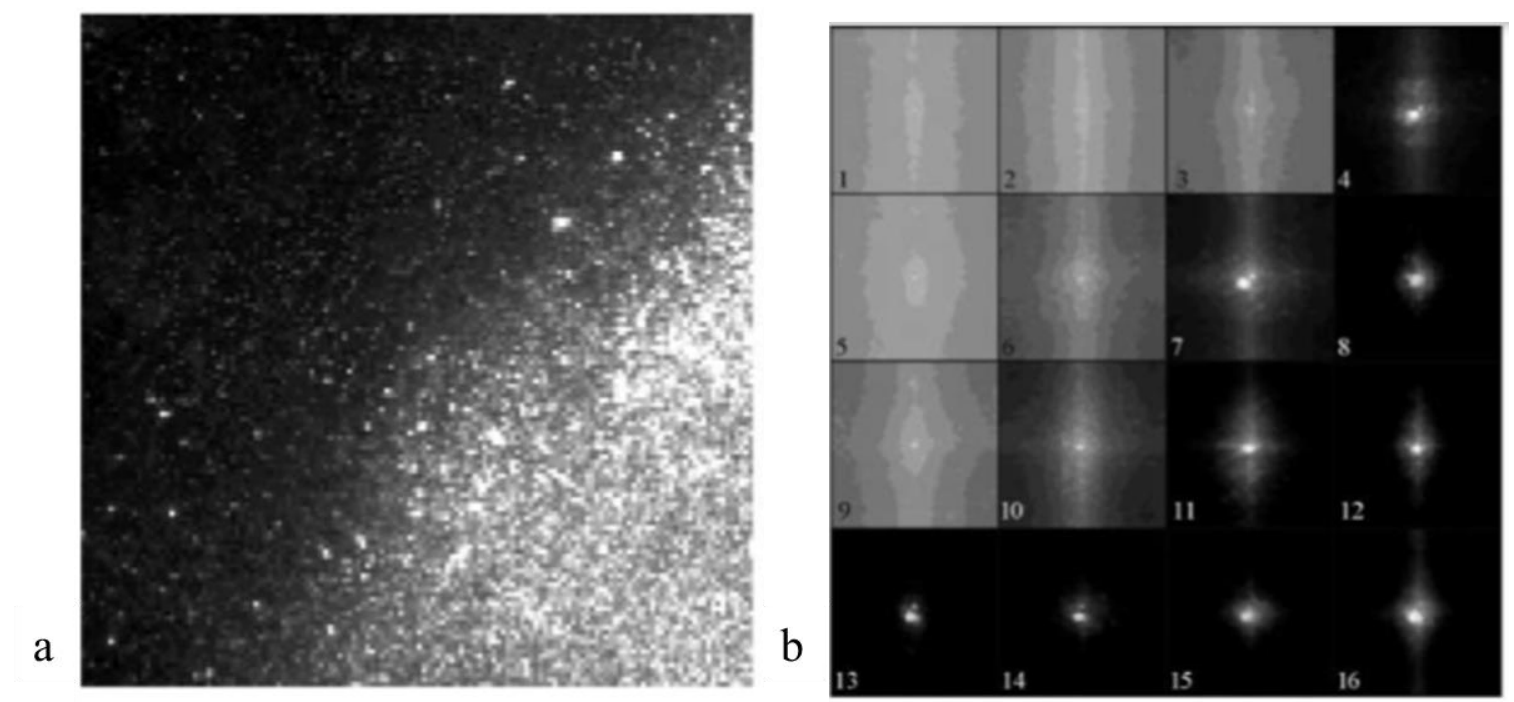

Fonte: Adaptado de Rottenkolber et al. (2002). 
O trabalho desenvolvido por Berti (2018) apresenta uma metodologia de pré-processamento mais robusta frente às propostas por Driscoll, Sick e Gray (2003) e por Dankers et al. (2008), no que tange o uso da estratégia de remoção de ruído de fundo das imagens primárias. Sendo o objetivo do autor alcançar uma melhor e mais detalhada caracterização da evolução de sprays de etanol oriundo de injetores utilizando em MCIs equipados como injeção direta, a técnica de PIV bifásica resolvida no tempo (TimeResolved Two-Phase PIV em inglês) foi utilizada. Neste trabalho, a influência que a turbulência do gás circundante exerce sobre o desenvolvimento da interação arcombustível pode ser avaliada. O procedimento experimental proposto por Berti (2018) é sumarizado na seção 3.1 e amplamente discutido no trabalho escrito pelo autor. A estratégia de pré-processamento utilizada consiste em gerar as imagens representativas do escoamento de ar a partir das imagens primárias dos traçadores e do spray de etanol. Para as imagens referentes ao ar, a estratégia de remoção de ruído de fundo foi utilizada e a referência adotada como plano de fundo das imagens foi tida a partir da média temporal das imagens que não detinham a presença do spray. $\mathrm{O}$ mesmo procedimento foi realizado para as imagens primárias do spray, no entanto a média temporal considerada foi composta por todas as imagens que continham o etanol atomizado. Após este passo, pequenos desvios entre as imagens primárias referentes ao spray e ao ar foram corrigidos por uma operação de deslocamento de coordenadas, dita shift, por Berti. Feito isso, foi aplicada a técnica de limiar de imagem (image threshold, em inglês) nas imagens de fluorescência com o propósito de eliminar possíveis ruídos provenientes do espalhamento-Mie. Tais ruídos (gotas de etanol) poderiam ser entendidos como sinais (partículas traçadoras), o que propiciaria falsos vetores no campo de velocidades final. Por fim, as imagens do spray tratadas pela remoção de background foram subtraídas das imagens do ar já processadas. A Figura 2.29 apresenta um esquema do método de préprocessamento mencionado, enquanto a Figura 2.30 mostra um exemplo do resultado obtido com a subtração das imagens. Concluída a etapa de subtração das imagens, o autor finaliza o pré-processamento com a realização das operações de balanceamento de sinal (com o objetivo de uniformizar a intensidade das imagens de partículas) e de mascaramento (com o propósito de remover as regiões próximas ao injetor da etapa de interrogação e processamento). Vale destacar que o pré-processamento das imagens realizado por Berti foi efetuado com o auxílio de um software comercial, o Dynamic Studio®, desenvolvido pela empresa Dantec Dynamics. A imagem pré-processada final não foi mostrada pelo autor. 
Figura 2.29 - Sequência das etapas propostas por Berti (2018) como método de pré-processamento das imagens.

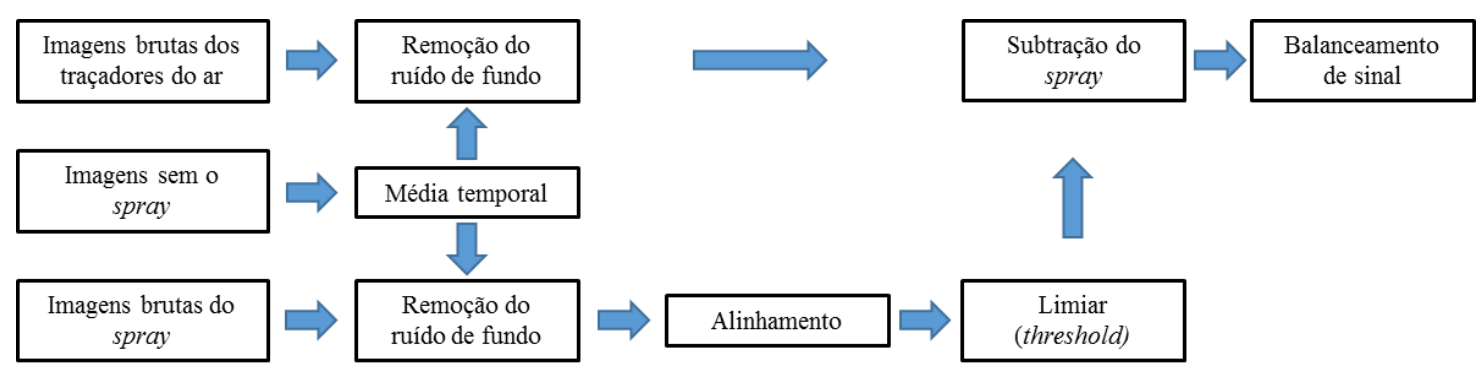

Fonte: Adaptado de Berti (2018).

Figura 2.30 - Exemplo de uma imagem pré-processada na etapa de subtração do spray de etanol.

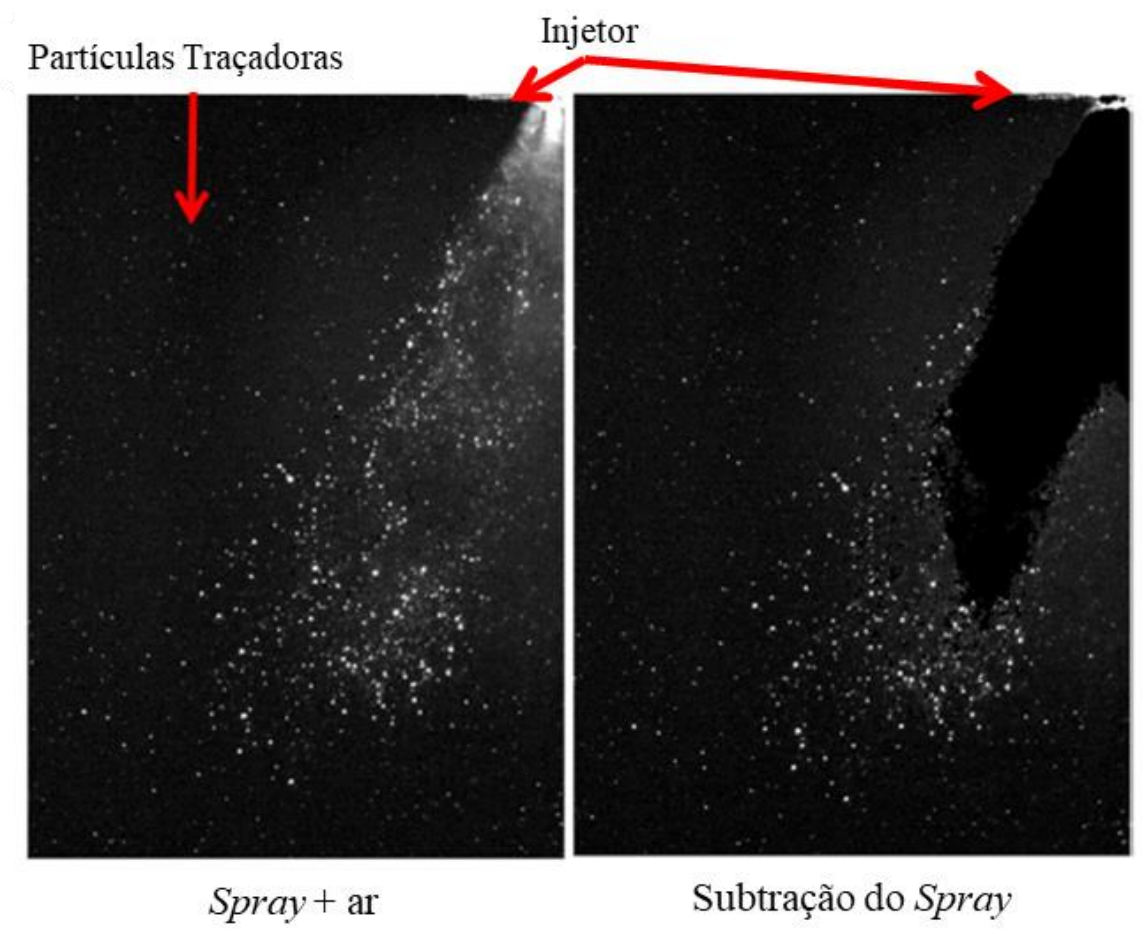

Fonte: Adaptado de Berti (2018).

Para compor a estratégia de interrogação e realizar a etapa de processamento das imagens, o método PIV adaptativo (adaptive PIV, em inglês) foi utilizado por Berti (2018). Segundo o autor, tal método foi escolhido para garantir maiores resoluções espaciais e maior relação sinal-ruído. É importante destacar que o método adaptativo trabalha de forma iterativa com o tamanho e com o formato das janelas de interrogação, parâmetros estes avaliados como uma função da densidade de partículas e do gradiente de velocidade. Como parâmetros de qualidade do processamento, foi considerado um valor mínimo para o $S N R$ igual a 6, simultaneamente ao quociente entre as alturas do 
primeiro e do segundo pico de correlação ser superior a 1.2. Como método de pósprocessamento, o algoritmo universal de detecção de falsos vetores (universal outlier dectection algorithm em inglês) foi adotado, considerando vizinhança $5 \times 5$ pixels, valor limite igual a 2,0 e valor de flutuabilidade igual a 0,1 .

Maior detalhamento sobre o método PIV adaptativo é encontrado no trabalho de Berti (2018) e a descrição sobre o método de pós-processamento escolhido pelo pesquisador é feita por Westerweel e Scarano (2005). Um trabalho com metodologia similar à apresentada por Berti (2018) é apresentado por Berti et al. (2017). 


\section{METODOLOGIA}

Este capítulo está dividido em três partes: estudo de caso; método de otimização $P I V$ e análise da interação bifásica gás-spray. A primeira apresenta uma síntese do experimento desenvolvido para gravar as imagens utilizadas no presente trabalho, desenvolvido por Berti (2018). Essencialmente, essa parte sumariza os principais tópicos sobre a estrutura e a metodologia experimentais adotadas para gravar as imagens do spray e do gás circundante, no caso ar atmosférico, considerando o emprego da técnica de PIV bifásico. A segunda parte apresenta a metodologia PIV proposta para atingir os objetivos prometidos, no tocante à otimização dos passos que compõem a aplicação da técnica de $P I V$. A última consiste na apresentação dos parâmetros utilizados para investigar a interação ar-spray a partir da melhor estratégia PIV obtida na segunda etapa. Todos os procedimentos propostos nas três etapas da presente metodologia foram realizados utilizando, exclusivamente, o software MATLAB®.

\subsection{ESTUDO DE CASO}

\subsubsection{ARRANJO EXPERIMENTAL}

No trabalho realizado por Berti (2018), a técnica de PIV bifásico foi utilizada e a separação óptica entre o ar e o as gotículas de combustível foi promovida através do traçador fluorescente Rhodamina B, dissolvido em carbonato de propileno - um óleo. Utilizando um bocal nebulizador tipo Laskin, a mistura entre ambos foi responsável pela geração das partículas traçadoras utilizadas para visualizar o escoamento de ar. Experimentos prévios revelaram, por meio da aplicação de $P D I$, que a distribuição de tamanho do seeding era adequadamente modelada por uma distribuição log-normal com Diâmetro Médio de Sauter $\left(D_{3,2}\right)$ próximo a $3 \mu \mathrm{m}$. Para iluminar o escoamento, foi utilizado um feixe de laser gerado por uma fonte modelo LDY302 com dupla cavidade e tecnologia Nd:YLF, do fabricante Litron Inc., com comprimento de onda de $527 \mathrm{~nm}$ e energia de $15 \mathrm{~mJ}$ por pulso a $1 \mathrm{kHz}$. O gerador de laser permaneceu acoplado a um conjunto óptico capaz de converter o feixe circular de luz proveniente da fonte em uma folha plana com largura de $50 \mathrm{~mm}$ e espessura que pode variar entre $5 \mu \mathrm{m}$ e $50 \mu \mathrm{m}$, aproximadamente. Durante os experimentos, a folha de luz laser foi posicionada na seção meridiana de um dos cinco sprays produzidos por um injetor multi-furos de alta pressão, 
do fabricante Delphi Powertrains Systems e destinado a uso em motores equipados com sistema de injeção direta.

No arranjo experimental proposto por Berti (2018), duas câmeras foram utilizadas. Uma delas foi responsável por receber o espalhamento de luz proveniente das gotículas com o mesmo comprimento de onda do laser - enquanto a outra registrava, simultaneamente, a fluorescência da Rhodamina B. Ambas foram posicionadas ortogonalmente ao feixe de luz. As câmeras utilizadas foram fabricadas pela Vision Research Inc., cujo modelo é o Phanton v3.11 de 16GB de memória interna (até 16 mil imagens consecutivas), o qual agrega sensor CMOS de 1280 x 800 pixels - pixel pitch igual a $20 \mu \mathrm{m}$ - com 12 bits de resolução. A frequência de aquisição de cada unidade é de até $500.000 \mathrm{fps}$ e o par é equipado com o conjunto Planar 1.4/50 ZF (distância focal igual a $50 \mathrm{~mm}$ e $f_{n}$ igual a 1,4 ), do fabricante Carl Zeiss. Para gerenciar os eventos de injeção e sincronizá-los com as câmeras, um amplo sistema de controle foi desenvolvido.

Uma vez definidas as condições e a estrutura disponível para realizar os ensaios, vale lembrar que a qualidade dos resultados que serão obtidos com a aplicação da técnica de $P I V$ é função da qualidade da gravação das imagens primárias, a qual depende da solução de compromisso proposta entre a intensidade do laser, a concentração de traçador e aspectos atrelados à abertura da câmera para registrar a posição das partículas. Esta combinação deve ser tal que uma determinada quantidade de energia seja, simultaneamente, suficiente para registrar as partículas fluorescentes e o espalhamentoMie do spray sem comprometer o funcionamento da câmera e a qualidade das imagens (Cf. Seção 2.2.2). Deste modo, considerando os referidos aspectos e a percepção de que os sinais luminosos da fluorescência têm comprimento de onda distintos ao do laser, Berti (2018) utilizou filtros ópticos na tentativa de gravar, da melhor maneira possível, as imagens de cada uma das fases registradas. Para gravar as imagens do espalhamento-Mie, um filtro de banda $(527 \pm 5 \mathrm{~nm})$ foi acoplado a uma das câmeras. Para registrar as partículas traçadoras do ar, um conjunto de filtros ópticos contendo filtros de passagem longa (longpass, em inglês), de absorção e um dicroico foram utilizados, como mostra a Figura 2.25. Em ambas as câmeras, filtros de densidade neutra foram acoplados para atenuar sinais com alta luminosidade e preservar os sensores. Uma discussão mais aprofundada sobre todos os aspectos citados neste tópico é encontrada no trabalho de Berti (2018). 
Para estudar a interação entre o gás circundante e o spray de etanol, os eventos de injeção foram pronunciados no interior de uma câmara de fluxo contínuo e visualizados a partir de janelas de acesso óptico presentes na própria estrutura, a qual foi construída e configurada por Berti (2018) e nomeada como Câmara de Spray de Etanol Isotérmica (IESC, sigla em inglês). A IESC é dividida em duas seções: (i) preparação da mistura do ar ambiente com o traçador e (ii) disposição da janela de visualização dos eventos de injeção.

A primeira seção consiste em um cilindro com $100 \mathrm{~mm}$ de diâmetro e $500 \mathrm{~mm}$ de comprimento, disposto verticalmente, que recebe ar no topo e dispersa os traçadores na linha de centro desse cilindro a uma distância tal que a mistura entre o ar e as partículas seja homogênea. $\mathrm{O}$ ar inserido na câmara é proveniente de um sistema que admite ar atmosférico e o pressuriza por meio de um soprador controlado por um inversor de frequência, responsável por definir a vazão do fluido que é inserido na IESC. Ao final dessa seção, são dispostas duas placas perfuradas radialmente com orifícios de 4,0 mm igualmente espaçados, a fim limitar os níveis de turbulência a um comprimento de escala integral semelhante ao que se encontra no interior de cilindros de motores de combustão interna. Solidário às placas perfuradas, por meio de um invólucro e disposto na linha de centro da câmara, um injetor automotivo multi-furos GDI Delphi é alocado para promover a atomização do etanol em gotas com diâmetro compreendido entre 10 e $43 \mu \mathrm{m}$.

A última seção da IESC é composta por quatro janelas de quartzo com dimensões $85 \times 136 \mathrm{~mm}$ e com espessura igual e 3,14 mm, responsáveis por formar uma câmara de acesso óptico com seção transversal quadrada que permite a visualização da interação entre os fluidos. As esquadrias que fixam estas janelas receberam tratamento químico para reduzir o espalhamento de luz por reflexão. A Figura 3.1 e a Figura 3.2 mostram as seções supracitadas a partir de uma vista em corte da IESC e o arranjo das placas perfuradas que permite a fixação do injetor junto à câmara, respectivamente. Após as janelas de visualização, há um filtro que separa o dopante e o etanol misturados com o ar atmosférico para que impurezas não sejam lançadas ao ambiente. Por fim, a Figura 3.3 ilustra o arranjo experimental proposto para obter as imagens primárias dos traçadores do ar e do espalhamento-Mie. 
Figura 3.1 - Seções e componentes principais da IESC.

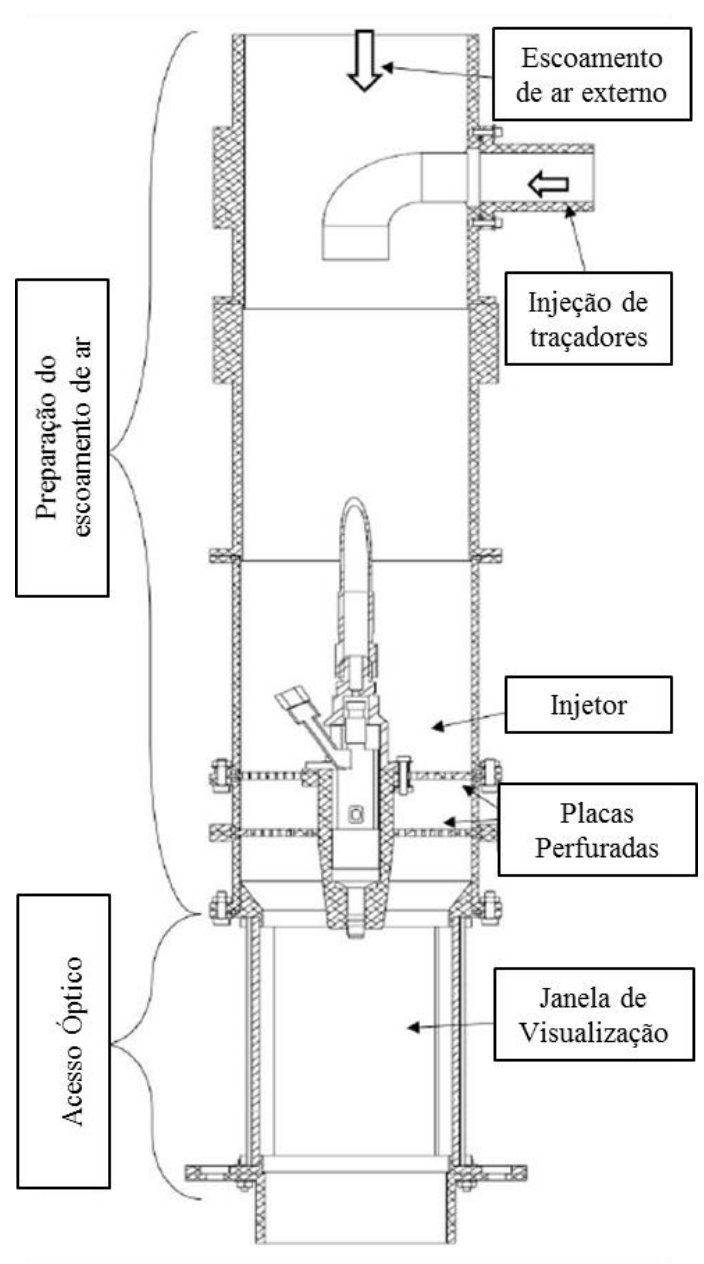

Fonte: Adaptado de Berti (2018).

Figura 3.2 - Disposição geométrica do injetor e das placas perfuradas proposta à IESC.

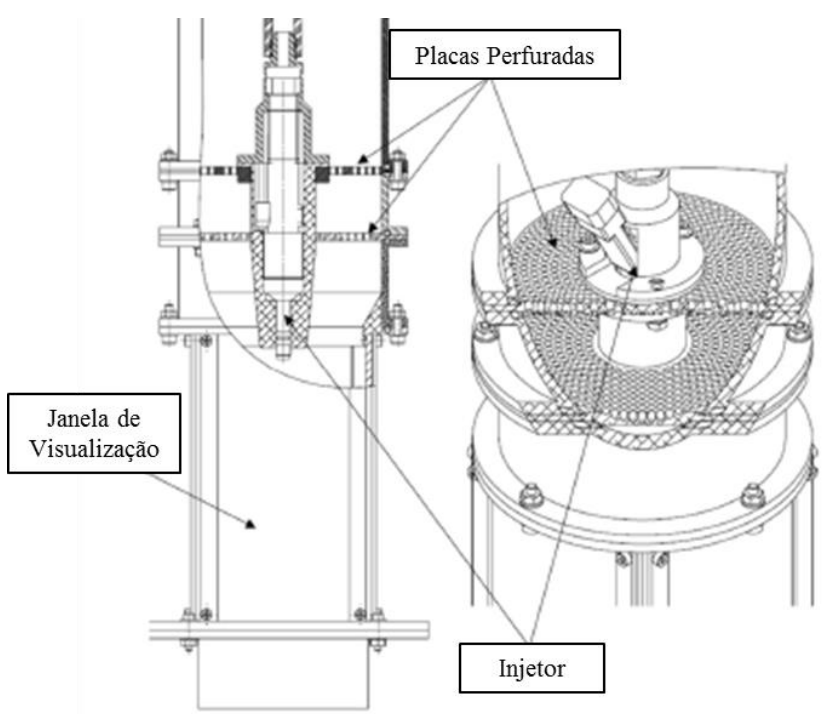

Fonte: Adaptado de Berti (2018). 
Figura 3.3 - Arranjo experimental utilizado na gravação das imagens de espalhamento-Mie e de fluorescência.

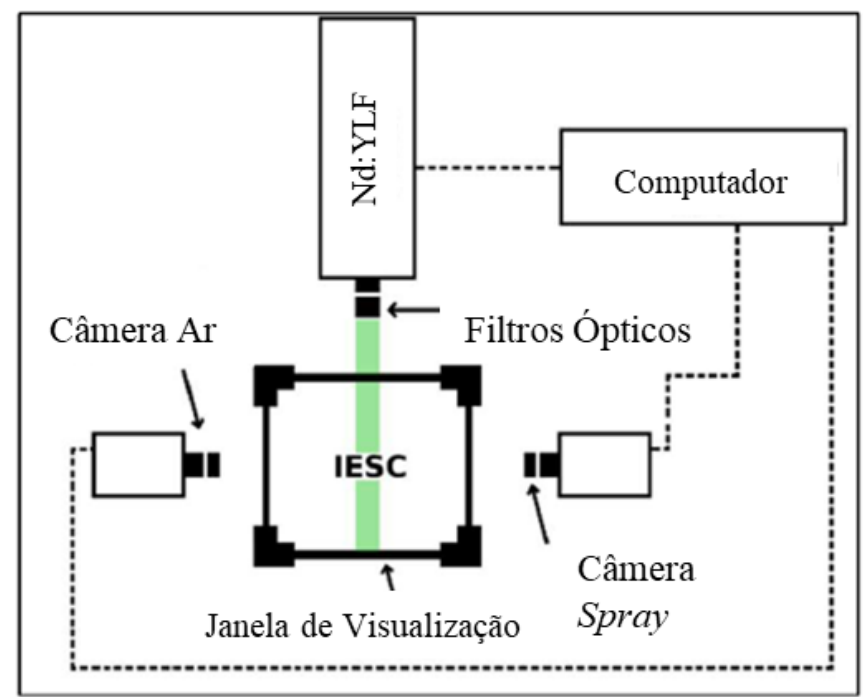

Fonte: Adaptado de Berti (2018).

\subsubsection{CASOS SELECIONADOS PARA ANÁLISE DA INTERAÇÃO AR-SPRAY}

Para estudar o mecanismo de interação entre o ar e o spray de etanol, duas configurações experimentais testadas por Berti (2018) foram escolhidas para investigar o escoamento bifásico. Cada configuração é definida pela pressão de injeção do combustível, pela vazão de ar que entra na câmara de fluxo contínuo e pelo diâmetro médio dos orifícios das placas instaladas na IESC. Dentre todas as combinações disponíveis propostas por Berti (2018), as duas configurações escolhidas são apresentadas na Tabela 3.1, onde são descritas como CASO 1 e CASO 2. A diferenciação entre ambos os casos consiste apenas na pressão de injeção (60 bar e 100 bar), haja vista que a vazão média de ar e o diâmetro médio dos orifícios são constantes e iguais a 0,066 kg/s (vazão mássica tida como referência para análises em ambiente quiescente) e 4,0 mm, respectivamente. Segundo Berti (2018), o comprimento de escala integral era de 3,5 $\mathrm{mm}$ e o número de Reynolds, com base no diâmetro hidráulico da IESC, era de $4,23 \cdot 10^{4}$. O autor também destaca que todos os parâmetros que definem as configurações experimentais foram controlados de forma adequada e independente. 
Tabela 3.1 - Configurações experimentais escolhidas para análise da interação ar-spray.

\begin{tabular}{cccc}
\hline & $\begin{array}{c}\text { Pressão de injeção } \\
{[\text { bar] }}\end{array}$ & $\begin{array}{c}\text { Vazão mássica de ar } \\
{[\mathbf{k g} / \mathbf{s}]}\end{array}$ & $\begin{array}{c}\text { Diâmetro médio } \\
\text { dos orifícios [mm] }\end{array}$ \\
\hline CASO 1 & 100 & 0,066 & 4,0 \\
CASO 2 & 60 & 0,066 & 4,0 \\
\hline
\end{tabular}

Fonte: Autor.

Em todos os casos estudados, a taxa de aquisição das imagens foi de $8000 \mathrm{~Hz}$ e o tempo interframe foi igual a $20 \mu$ s, segundo Berti (2018). Para cada caso, foram gravadas 17 sequências com 15 eventos de injeção cada, o que totaliza 255 ciclos de sprays mantidos na mesma condição e 14001 imagens de cada fase em cada sequência de eventos de injeção. Do total de ciclos gravados por Berti (2018), 34 eventos foram disponibilizados para permitir o desenvolvimento do presente trabalho, o que resultou na seleção de 2652 de imagens, as quais não contemplam os registros do longo período de estabilização do escoamento entre as injeções e foram previamente separadas em três categorias: pré-injeção (de $t=0,267 \mathrm{~ms}$ BSOI a $t=0,133 \mathrm{~ms}$ ASOI); injeção (de $t=0,267 \mathrm{~ms}$ ASOI a $t=3,333 \mathrm{~ms}$ ASOI) e pós-injeção (de $t=3,467 \mathrm{~ms}$ ASOI a $t=4,400 \mathrm{~ms}$ ASOI). Todas as imagens foram gravadas considerando uma matriz de pixels reduzida para $360 \times 512$ pixels, responsável por gerar imagens com campo de visão de 20,4 $x 29 \mathrm{~mm}$. A resolução espacial do sistema de imagem foi de $59 \mu \mathrm{m} /$ pixel. O campo de visão adotado consiste na região à esquerda do eixo de simetria do spray contido no plano de luz - e abaixo da ponta do injetor, conforme ilustra a Figura 3.4. Todos os casos foram gravados com imagens definidas em tons de cinza, com 12 bits.

Figura 3.4 - Campo de visão escolhido para observar o escoamento ar-spray desenvolvido na IESC.

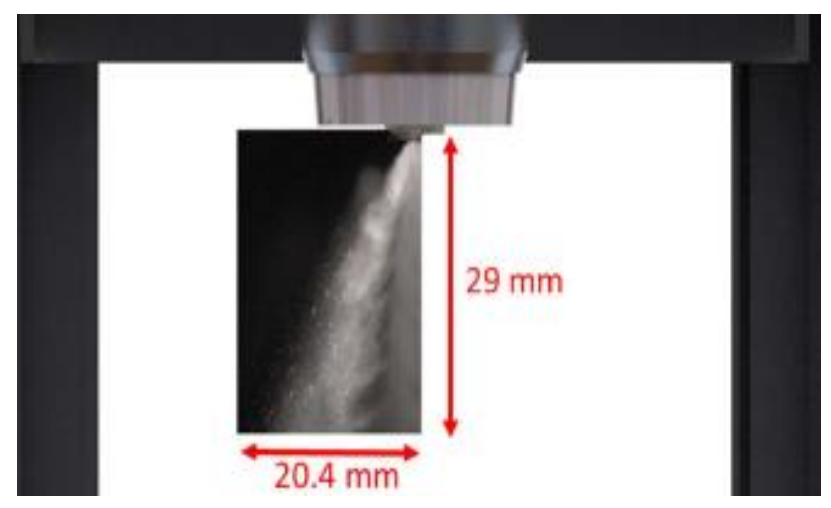

Fonte: Adaptado de Berti (2018). 


\subsection{MÉTODO DE OTIMIZAÇÃO PIV}

A metodologia que será apresentada nesta seção segue a sequência padrão utilizada em análises com PIV, conforme é apresentado na Seção 2.2: (i) préprocessamento; (ii) estratégia de interrogação e processamento; (iii) pós-processamento. O método proposto é estruturado a partir de análises de sensibilidade do campo vetorial pós-processado às estratégias de pré-processamento, interrogação e processamento. Tais análises são propostas com o intuito de verificar a influência que o tratamento da imagem primária e as escolhas realizadas na etapa de processamento exercem sobre a representatividade do escoamento a partir do campo de deslocamentos e de parâmetros cinemáticos importantes. Para realizar os procedimentos presentes na metodologia proposta, utilizou-se o software MATLAB®. No presente trabalho, apenas as imagens instantâneas dos traçadores do gás circundante são pré-processadas com o intuito de obter a otimização do método de $P I V$ prometida.

Análises prévias ao desenvolvimento da metodologia apresentada mostraram que, mesmo com o uso consistente dos filtros ópticos selecionados por Berti (2018), os pares de imagens gravadas da fase gasosa possuem uma distribuição de intensidade heterogênea. Tal aspecto pode ser notado em ambos os frames mostrados na Figura 3.5, a qual apresenta um par de imagens primárias como um exemplo capaz de evidenciar a presença de ruídos de imagem provenientes do intenso espalhamento de luz provocado pelo spray. Adicionalmente, a Figura 3.6 apresenta os histogramas de intensidade dos pixels, os quais evidenciam a heterogeneidade observada e, consequentemente, a caráter ruidoso encontrado nas imagens PIV gravadas por Berti (2018). Devido ao intenso ruído evidenciado pelas imagens, o desenvolvimento de uma metodologia de préprocessamento robusta foi motivado e é justificado pela tentativa de encontrar um método que, quando aplicado, garanta boa qualidade de sinal às imagens primárias préprocessadas. Vale lembrar que a referida qualidade consiste na percepção por alto contraste das imagens de partículas frente ao fundo, as quais devem preencher o domínio espacial com intensidades distribuídas de forma homogênea a fim de garantir níveis adequados de $S N R$ ao campo vetorial primário. De forma aditiva, é importante destacar que o atendimento a esse objetivo reflete positivamente nos campos vetoriais pósprocessados, uma vez que a qualidade e a coerência dos resultados oriundos da estratégia de interrogação e do método de processamento são dependentes da qualidade da imagem 
tratada (RAFFEL, WILLERT, et al., 2007; ADRIAN e WESTERWEEL, 2011; SCHARNOWSKI e KÄHLER, 2016a; MOURA, 2017; BERTI, 2018).

Figura 3.5 - Par de imagens primárias da fase gasosa em um instante de injeção do spray com pressão de 100 bar. O primeiro frame é apresentado à esquerda, enquanto o segundo, à direita.
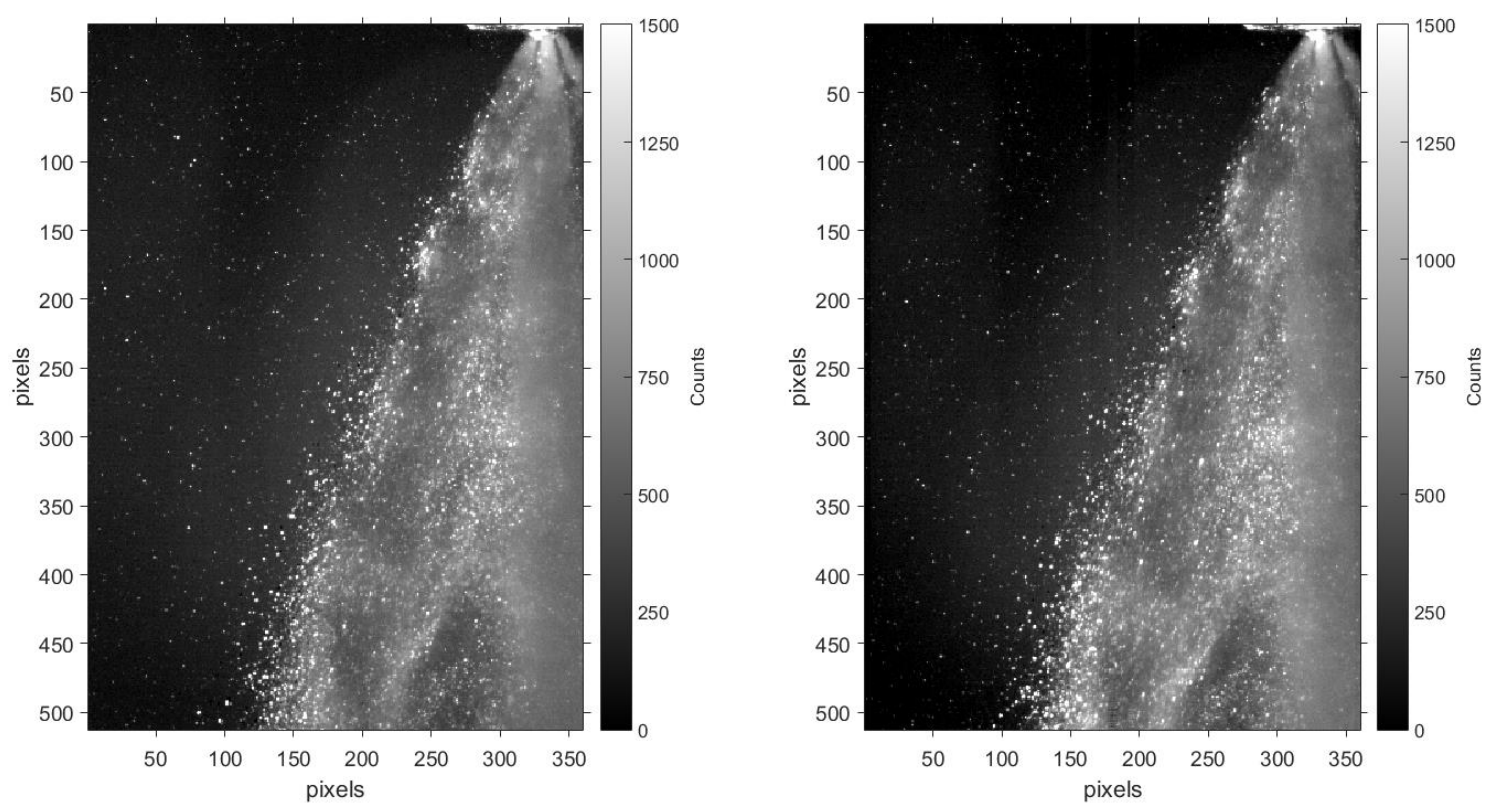

Fonte: Autor.

Figura 3.6 - Histogramas de nível de cinza das imagens primárias da fase gasosa em um instante de injeção do spray com pressão de 100 bar. O histograma do primeiro e do segundo frame é apresentado à esquerda e à direita, respectivamente.
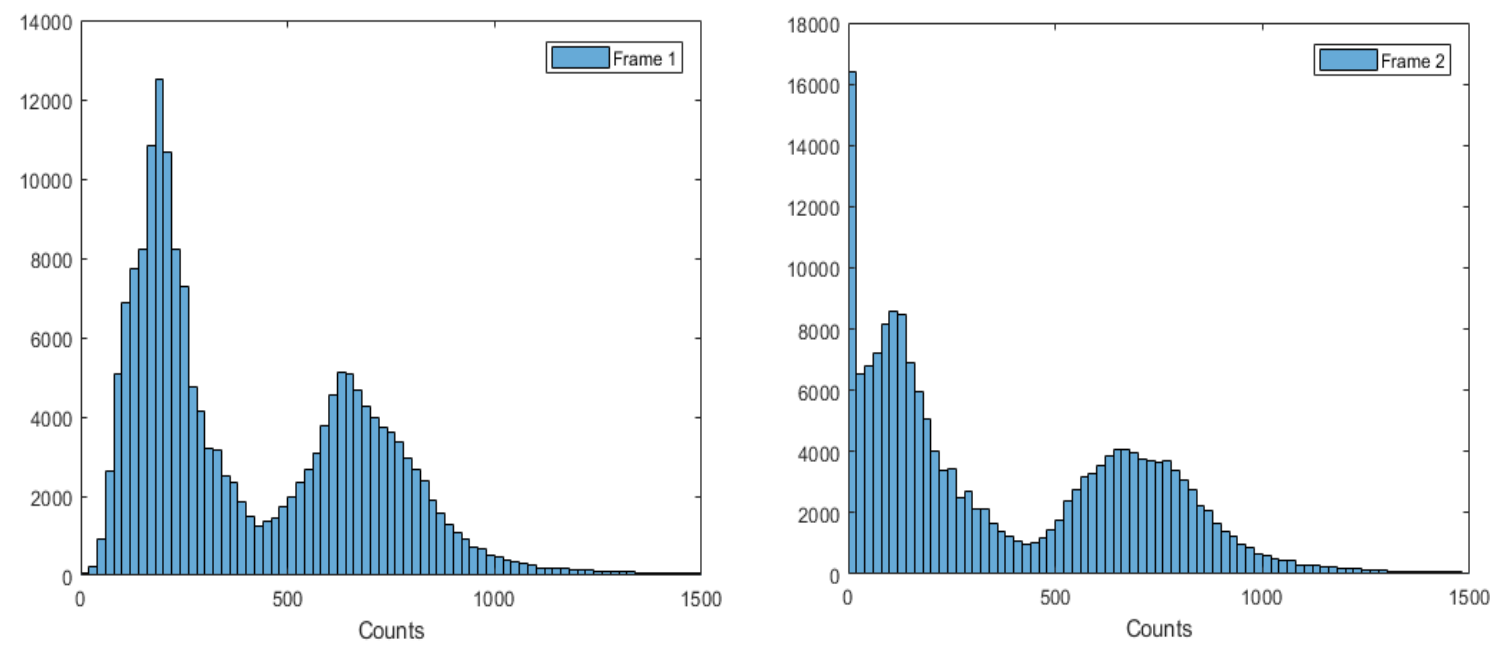

Fonte: Autor.

Além do ruído de imagem, a baixa concentração de traçadores nas imagens de fluorescência também foi percebida, o que torna a estratégia de interrogação primordial à fidelidade dos resultados em relação à realidade e entrega um desafio adicional à referida 
etapa: verificar a adequabilidade da aplicação da técnica de $P I V$ para analisar as imagens e, consequentemente, se o escoamento pode ser representado pelos resultados obtidos com o auxílio da técnica de velocimetria por imagens de partículas (SCHARNOWSKI e KÄHLER, 2016a). A Figura 3.7 apresenta a média-temporal da distribuição da concentração de imagem de partícula por pixel $\left(N_{P P P}\right)$ de todas as sequências de imagens citadas na Seção 3.1.2. A partir dela, nota-se que a menos da região ruidosa próxima e sobre o spray (nas vizinhanças e à direita da linha azul pontilhada), a desigualdade $N_{P P P}<0,025$ referencia a concentração por pixel que prevalece em todo o domínio espacial. Tal consideração, atrelada ao desconhecimento dos fatores $F_{I}, F_{O}$ e $F_{\Delta}$ que compõem a Equação 2.3, aponta para um cenário em que o tamanho da janela de interrogação é absolutamente determinante para a coerência dos resultados, uma vez que a quantidade de imagens de partículas por pixel é pequena. Consequentemente, o método de processamento deve ser escolhido de modo a maximizar a confiabilidade com a qual os vetores velocidade são obtidos.

Figura 3.7 - Média-temporal da concentração de imagem de partícula por pixel.

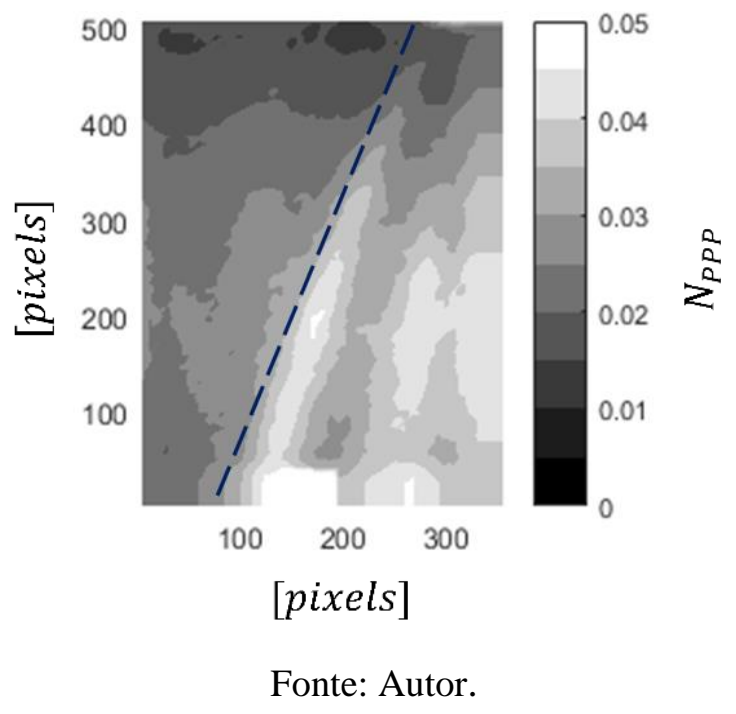

\subsubsection{PRÉ-PROCESSAMENTO}

A etapa de pré-processamento é composta por duas estratégias de tratamento das imagens primárias, as quais são despretensiosamente nomeadas por: Pré-processamento Alfa e Pré-processamento Beta. Ambas têm o propósito de melhor caracterizar as imagens de partículas que representam o escoamento de ar, eliminando, ao máximo possível, o ruído presente nas gravações. As estratégias não são utilizadas simultaneamente e não 
interferem uma à outra, pois configuram apenas duas possibilidades de melhorar a qualidade da imagem primária, com o objetivo de pôr à prova qual método de interrogação e processamento é capaz de representar melhor um par de imagens tratadas a partir de um campo vetorial pós-processado. Contudo, é importante ressaltar que desde as mais simples até as mais rebuscadas ferramentas de processamento digital de imagens, existem limitações que definem a sua eficácia. Deste modo, evidentemente, tais limitações devem ser entendidas como intrínsecas à natureza da técnica de processamento e, portanto, devem ser ponderadas (GONZALEZ e WOODS, 2010). Algumas sugestões de metodologia de tratamento de imagens PIV são propostas por Khalitov e Longmire (2002) e por Deen et al. (2010), autores que recomendam procedimentos de préprocessamento aplicados a escoamentos mono e bifásicos.

\subsubsection{PRÉ-PROCESSAMENTO ALFA}

Tendo em vista o forte ruído proveniente do espalhamento de luz e presente nas imagens de fluorescência gravadas nos instantes em que o spray está contido no espaço de imagem, o Pré-processamento Alfa foi desenvolvido com a premissa de eliminar o ruído de fundo provocado pelo spray, buscando maximizar o contraste dos traçadores simultaneamente à minimização da perda de informação pelo processamento digital da imagem. A Figura 3.8 sumariza a sequência de operações de filtragem proposta para o Pré-processamento Alfa.

Figura 3.8 - Visão global do Pré-processamento Alfa.

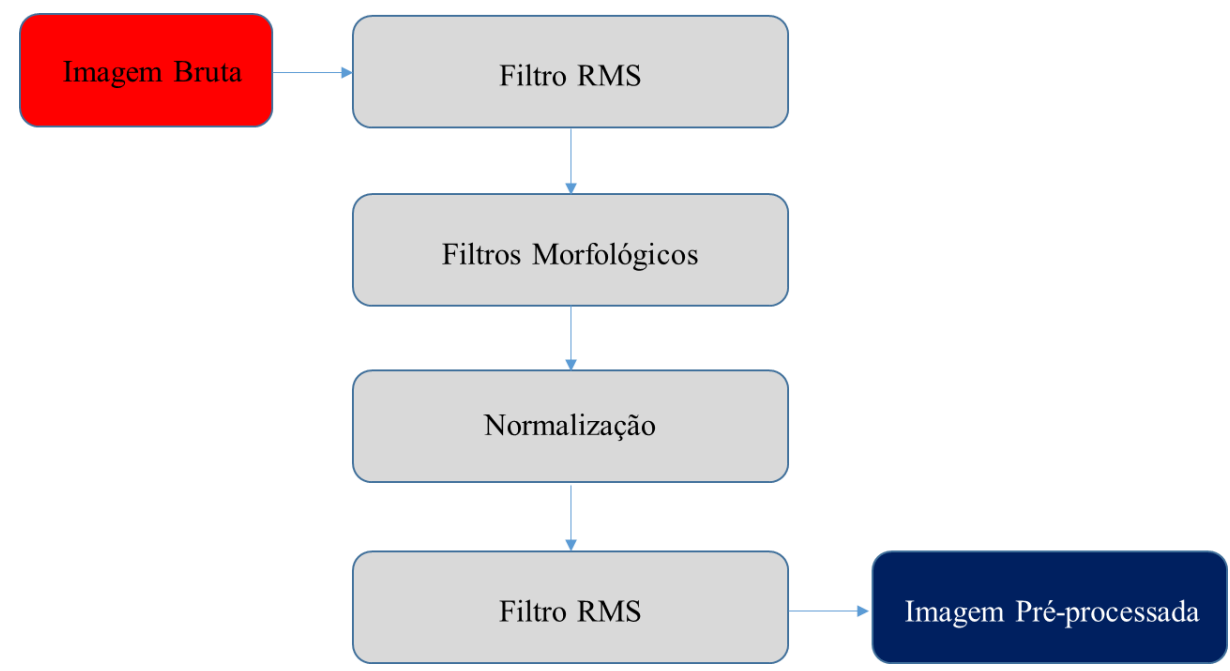

Fonte: Autor. 
Conforme pode ser visto na Figura 3.5 e na Figura 3.6, a distribuição heterogênea de intensidade luminosa é uma das principais fontes de ruído das imagens primárias. Por conta desse aspecto, o Pré-processamento Alfa tem início marcado pela aplicação do filtro espacial $R M S$, pelo fato de apresentar eficácia significativa no que tange à homogeneização da luminosidade e à eliminação de ruído de fundo (AMARAL, COSTA, et al., 2014; AMARAL, 2017; MOURA, 2017). Ao aplicá-lo em uma imagem, o valor do pixel alvo $I(i, j)$ é substituído pelo valor de $R M S(i, j)$, calculado a partir de uma vizinhança delimitada por uma matriz de ordem $N($ kernel $N \times N$ ), de acordo com a Equação 3.1.

$$
R M S(i, j)=\sqrt{\left.\frac{1}{N^{2}} \sum \mid I(i \pm k, j \pm k)\right)\left.\right|^{2}}
$$

Na presente etapa da metodologia, o filtro $R M S$ foi aposto aos pares de imagens primárias considerando vizinhança- 8 em todo o espaço de imagem, isto é, foi aplicado em toda a matriz de intensidade luminosa por meio de um kernel $3 \times 3$. A Figura 3.9 mostra um par de imagens resultante da aplicação da filtragem por $R M S$. Nela, é perceptível a ausência das regiões que se assemelham aos "clarões" que podiam ser vistos nas imagens apresentadas na Figura 3.5, além da maior homogeneidade do plano de fundo dos registros fotográficos percebida graças à diminuição da iluminação de fundo. Tais comportamentos são corroborados pelos histogramas das imagens pré-processadas apresentados na Figura 3.14 e na Figura 3.15. Vale destacar que, de acordo com o os trabalhos de Breckon e Solomon (2016) e de Gonzalez e Woods (2010), pode-se inferir que o processo de filtragem por RMS é baseado em conectividade de vizinhança. Um exemplo sobre a eficácia da filtragem RMS para remoção de background de imagens reais pode ser visto no trabalho de Amaral et al. (2014), onde foi aplicado com o objetivo de remover a iluminação de fundo em imagens PIV aplicadas à coluna de bolhas. 
Figura 3.9 - Par de imagens da fase gasosa pré-processadas por filtragem RMS em um instante de injeção do spray com pressão de 100 bar. O primeiro frame é apresentado à esquerda, enquanto o segundo, à direita.
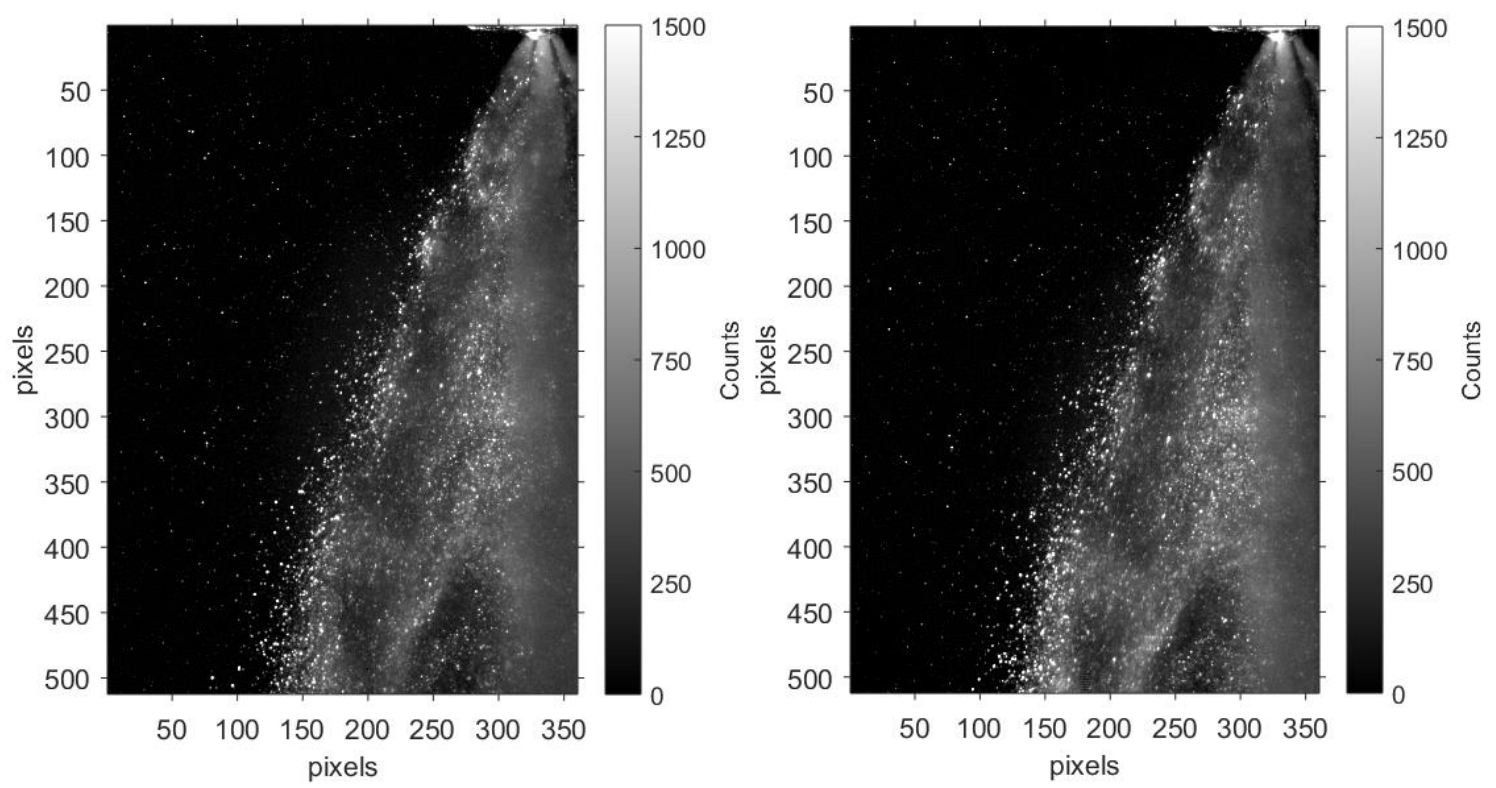

Fonte: Autor.

Após a filtragem por $R M S$, operações com filtros morfológicos foram realizadas para remover as regiões marcadas pelo forte ruído proveniente do espalhamento-Mie e com alta concentração de gotas de combustível, as quais que podem ser identificadas erroneamente como traçadores do ar. Por conseguinte, a utilização de filtros morfológicos foi idealizada como uma ferramenta capaz de eliminar a presença da intensidade acentuada do spray remanescente nas imagens primárias do ar circundante. Deste modo, o objetivo da aplicação de recursos da filtragem morfológica é suprimir a presença do spray, de modo a visualizar apenas as partículas traçadoras que representem o escoamento de ar.

Para iniciar a etapa de aplicação dos filtros morfológicos, os fatores necessários para executar o processamento da imagem, e então, produzir uma máscara adequada, foram definidos. A imagem considerada foi a matriz de intensidade luminosa dos pixels obtida após a aplicação do filtro $R M S$. Os filtros de erosão e dilatação foram utilizados, nessa ordem e em sequência, para compor o tipo de operação morfológica. O elemento estrutural escolhido foi o círculo de raio unitário. A escolha do elemento estrutural foi feita de modo a garantir que a imagem de partícula fosse preservada ao máximo. Vale destacar que o objetivo da escolha destes parâmetros é obter uma imagem que, quando subtraída da imagem filtrada por $R M S$, não contenha mais as regiões brilhantes que 
definem o spray e mantenha o restante da imagem inalterado. Essencialmente, para assegurar esta condição, o procedimento morfológico escolhido e supracitado foi estabelecido iterativamente. Uma breve introdução à filtragem morfológica, aos filtros de erosão e dilatação, bem como ao tratamento matemático empregado no Pré-processamento Alfa, é encontrada no APÊNDICE A - FILTROS MORFOLÓGICOS. Explanações mais detalhadas e específicas sobre a lógica morfológica, bem como os filtros que a compõem, são descritas por Gonzalez e Woods (2010) e por Breckon e Solomon (2016).

Fundamentalmente, o procedimento proposto consiste em erodir a imagem primária tratada pelo filtro $R M S$, e então, dilatá-la. Em seguida, a matriz de pixels obtida, chamada simbolicamente de máscara morfológica, é subtraída da imagem filtrada por $R M S$. Sendo assim, tal operação pode ser entendida como um procedimento de mascaramento e possibilita a supressão da forma e da iluminação excessiva do spray das imagens primárias do ar. A Figura 3.10 mostra um esquema voltado à apresentação das etapas do procedimento mencionado para tratar a imagem com os filtros morfológicos. A Figura 3.11 apresenta o resultado da aplicação dos filtros morfológicos ao par de imagens processadas por filtragem $R M S$, enquanto as consequências dessa aplicação às distribuições de intensidade luminosa das imagens podem ser vistas na Figura 3.14 e na Figura 3.15 por meio dos histogramas de nível de cinza.

Figura 3.10 - Esquema ilustrativo referente às etapa que compreende a aplicação dos filtros morfológicos.

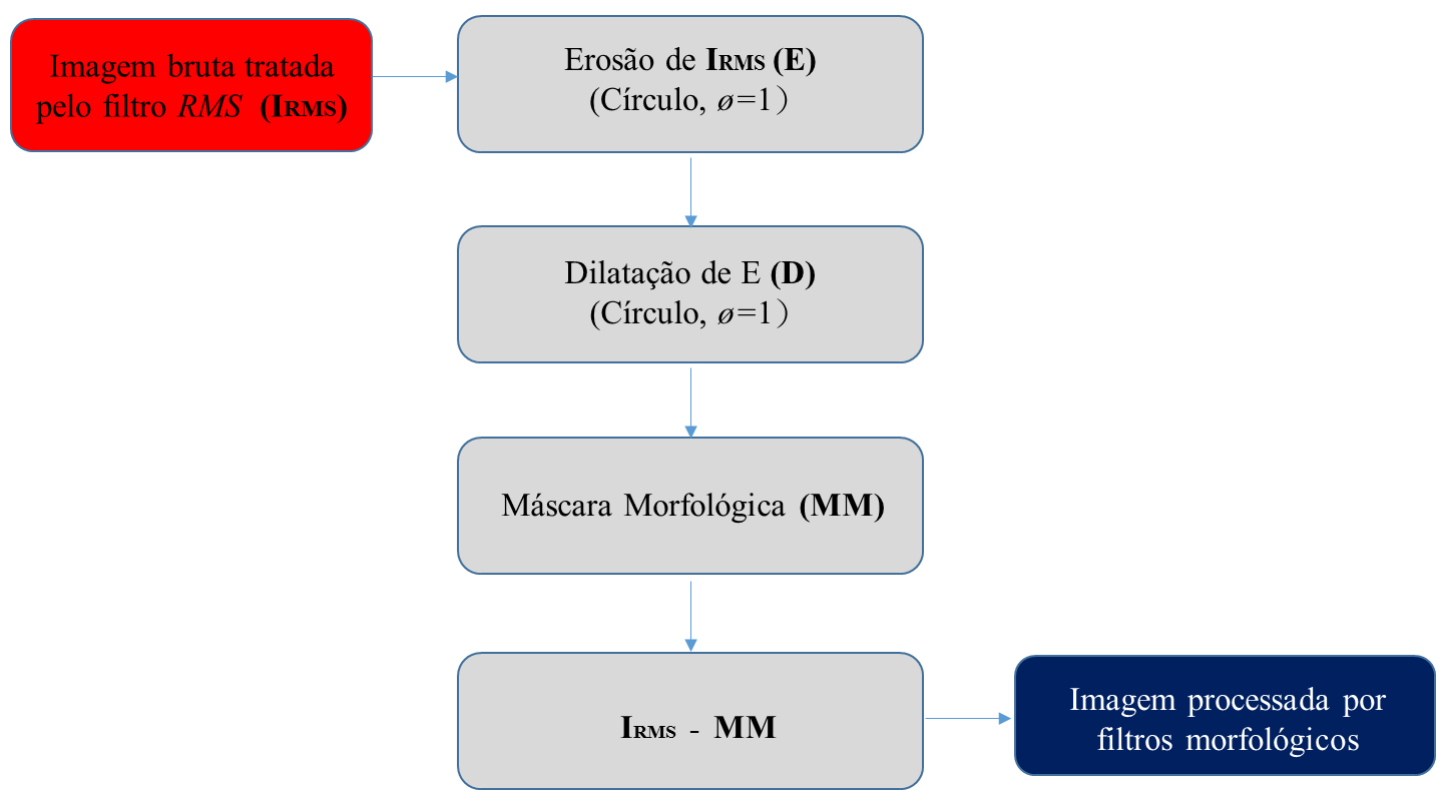

Fonte: Autor. 
Figura 3.11 - Par de imagens da fase gasosa pré-processadas pelos filtros morfológicos em um instante de injeção do spray com pressão de 100 bar. O primeiro frame é apresentado à esquerda, enquanto o segundo, à direita.
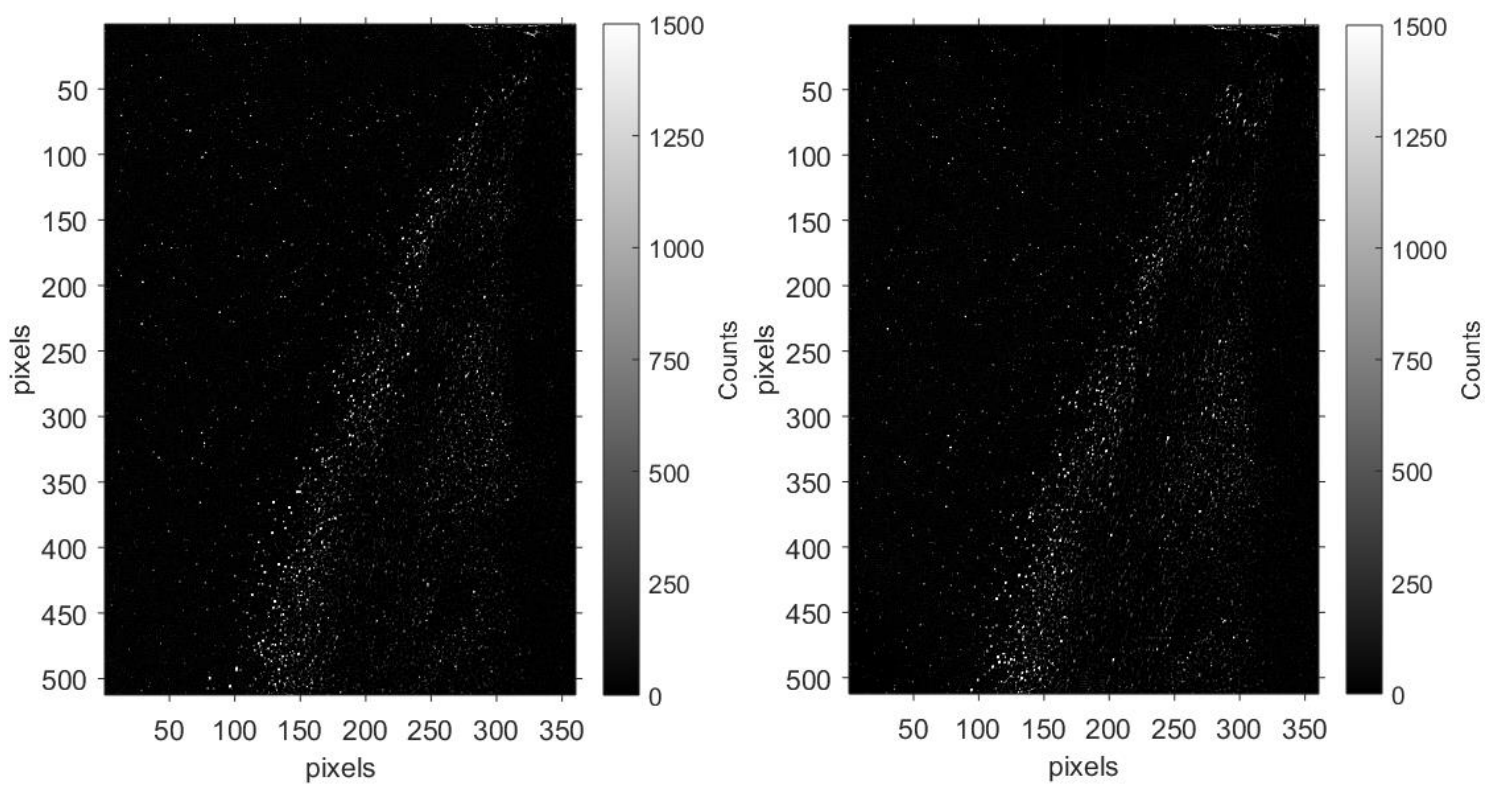

Fonte: Autor.

Ao comparar os resultados apresentados na Figura 3.9 e na Figura 3.11, percebese uma mudança expressiva na distribuição de intensidade luminosa das imagens devido à exclusão do spray. Através de análise visual das imagens tratadas, nota-se que as partículas que apresentavam brilho intenso na região próxima ao spray foram mantidas e que as demais imagens de traçadores fluorescentes não foram excluídas ou tiveram a forma alterada. Sendo assim, é importante destacar também que todas as imagens de partículas foram preservadas. Adicionalmente, por meio da Figura 3.14 e da Figura 3.15, percebe-se que, embora ambas as imagens têm iluminação homogênea entre si, o processamento das imagens com operadores morfológicos provocou um escurecimento acentuado em todo o espaço de imagem.

Após a filtragem morfológica, a operação de normalização da imagem foi proposta com o objetivo de trazer à tona as partículas que estavam com baixos níveis de cinza, quando comparados aos pixels de maior intensidade, além de procurar corrigir as regiões com imagens de partículas com diferentes intensidades. Deste modo, a normalização foi utilizada para homogeneizar todo o domínio espacial e, simultaneamente, realçar as imagens de partículas. Além disso, o método de filtragem por normalização foi utilizado devido à sua capacidade de promover o alargamento de contraste, conforme é mostrado por Amaral et al. (2014). 
Nesse âmbito, para corrigir as regiões de iluminação desigual, a normalização foi realizada com base na metodologia sugerida por Sage e Unser (2003), a qual utiliza filtros gaussiano e de média como ferramentas dedicadas ao tratamento da imagem. Através de tais ferramentas, a estratégia visa normalizar a imagem balizado na uniformidade da média e variância local, variáveis estas apresentadas por meio da Equação 3.2 e definidas em um kernel $N \times N$. Nela, $\operatorname{Norm}(i, j)$ é a intensidade luminosa do pixel resultante do processo de normalização local, $f(i, j)$ é a imagem local original, $m(i, j)$ é a média das intensidades locais da imagem e $\sigma(i, j)$ é o desvio padrão das intensidades locais. Um exemplo do efeito que esta aplicação causa à imagem pode ser visto na Figura 2.16.

No presente método, a normalização foi utilizada considerando kernel $5 \times 5$. Vale destacar que $\sigma(i, j)$ foi tido como o resultado da raiz quadrada da imagem $f(i, j)$ $m(i, j)$ processada com filtro gaussiano de $\sigma=5,0$ counts. Uma discussão detalhada acerca do método de normalização que motivou o desenvolvimento da presente etapa do Pré-processamento Alfa é encontrada no trabalho de Sage e Unser (2003). Uma breve síntese sobre o método de filtragem gaussiana é oferecida no APÊNDICE B - FILTRO GAUSSIANO.

$$
\operatorname{Norm}(i, j)=\frac{f(i, j)-m(i, j)}{\sigma(i, j)}
$$

A Figura 3.12 mostra o resultado da aplicação do filtro de normalização ao par de imagens obtidas após a filtragem morfológica. Ao analisá-la, nota-se que houve uma diminuição severa da intensidade luminosa em ambos os frames, conforme pode ser visto nas escalas de cinza presente na Figura 3.12 e nos histogramas apresentados na Figura 3.14 e na Figura 3.15. Todavia, percebe-se que há uma melhora expressiva na visualização das imagens de partículas, o que mostra, portanto, que o método está convergindo para atingir parte dos objetivos específicos prometidos. Vale destacar que nas imagens apresentadas na Figura 3.12, as partículas são majoritariamente representadas por 2 a 4 pixels, o que propicia ao método uma condição ótima de ser aplicado, segundo simulações PIV realizadas por Keane e Adrian (1990) e as considerações feitas por Raffel et al. (2007). 
Figura 3.12 - Par de imagens da fase gasosa pré-processadas com filtragem por normalização em um instante de injeção do spray com pressão de 100 bar. O primeiro frame é apresentado à esquerda, enquanto o segundo, à direita.
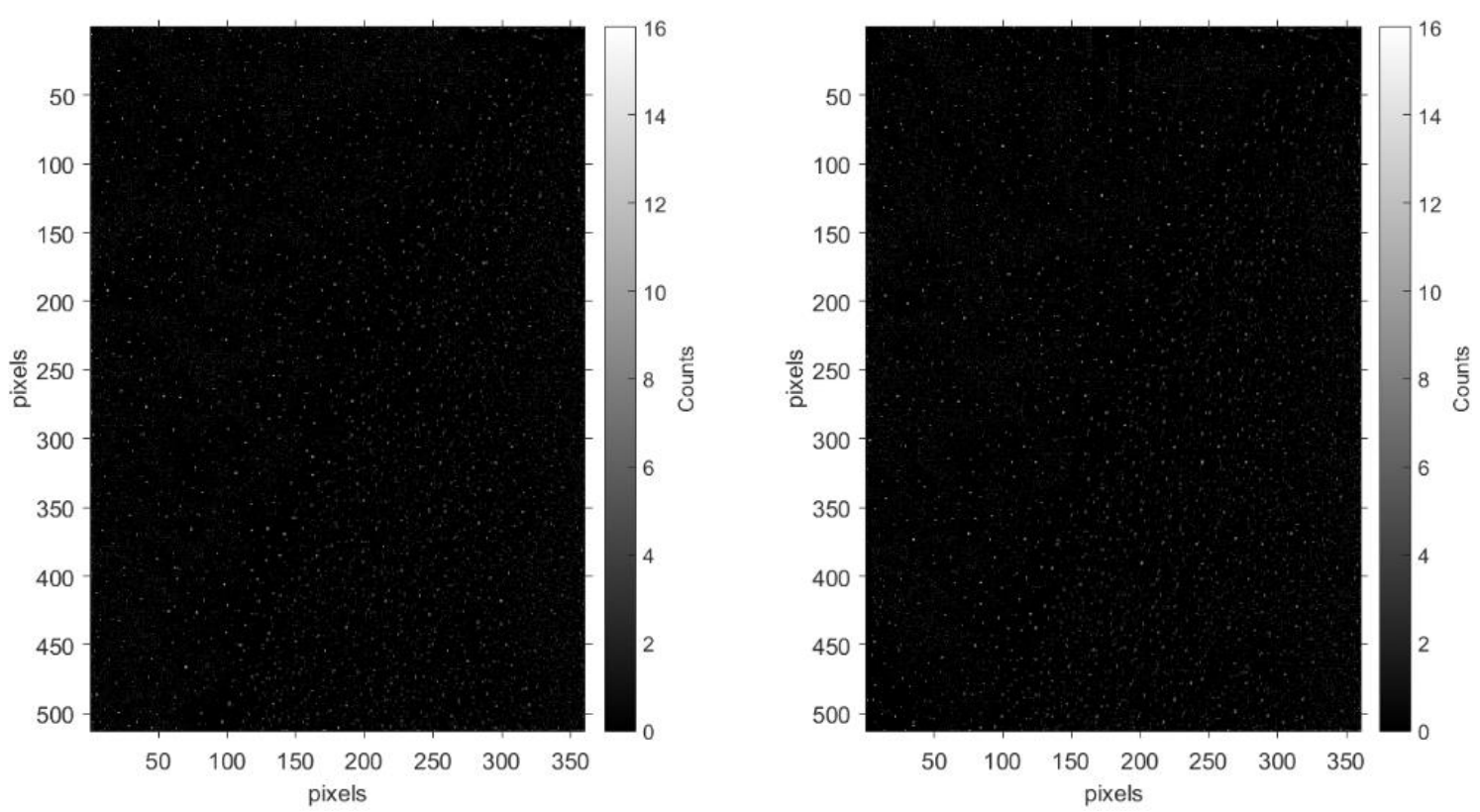

Fonte: Autor.

Por fim, devido à boa experiência adquirida com a aplicação do filtro $R M S$, o mesmo foi aplicado às imagens normalizadas com o objetivo de garantir o comportamento homogêneo da imagem final, sem qualquer ruído de fundo que possa ter sido gerado intrinsecamente pelos métodos de tratamento digital. O resultado é apresentado na Figura 3.13, a qual mostra que, embora as partículas estejam bem definidas, a intensidade luminosa resultante diminuiu em todo o espaço de imagem. Os histogramas de nível de cinza referentes ao par de imagens finais são apresentados na Figura 3.14 e na Figura 3.15. Caberá à etapa de Processamento PIV concluir sobre as consequências que este comportamento traz à correlação entre os frames. 
Figura 3.13 - Par de imagens da fase gasosa resultantes da aplicação completa do Préprocessamento Alfa em um instante de injeção do spray com pressão de 100 bar. O primeiro frame é apresentado à esquerda, enquanto o segundo, à direita.
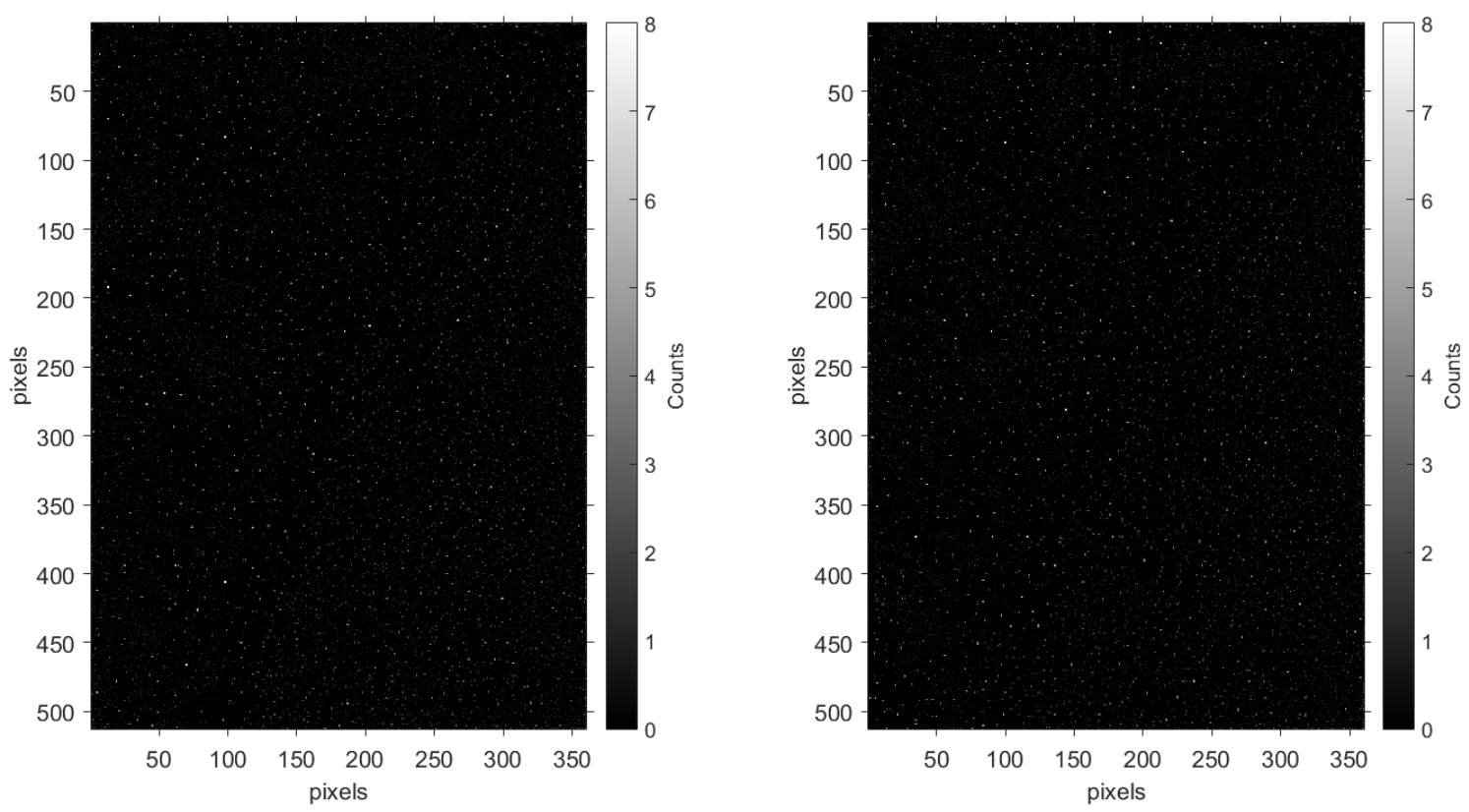

Figura 3.14 - Efeito das etapas do pré-processamento alfa sobre os histogramas de nível de cinza do primeiro frame processado. (a) refere-se à Imagem Primária; (b) à imagem filtrada por RMS; (c) à imagem filtrada com operadores morfológicos; (d) à imagem normalizada e (e) à última aplicação de filtragem espacial por RMS.
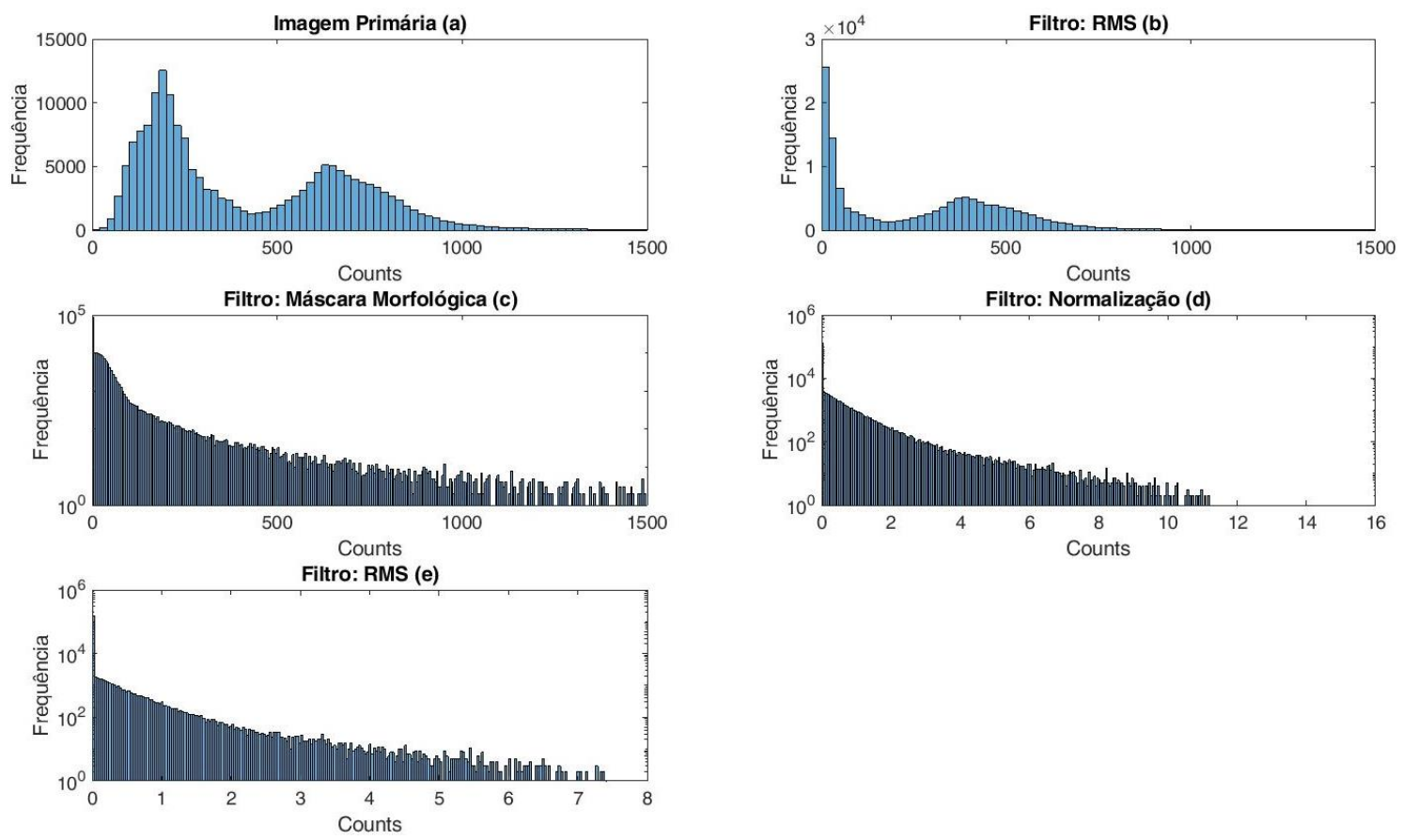

Fonte: Autor. 
Figura 3.15 - Efeito das etapas do pré-processamento alfa sobre os histogramas de nível de cinza do segundo frame processado. (a) refere-se à Imagem Primária; (b) à imagem filtrada por RMS; (c) à imagem filtrada com operadores morfológicos; (d) à imagem normalizada e (e) à última aplicação de filtragem espacial por RMS.
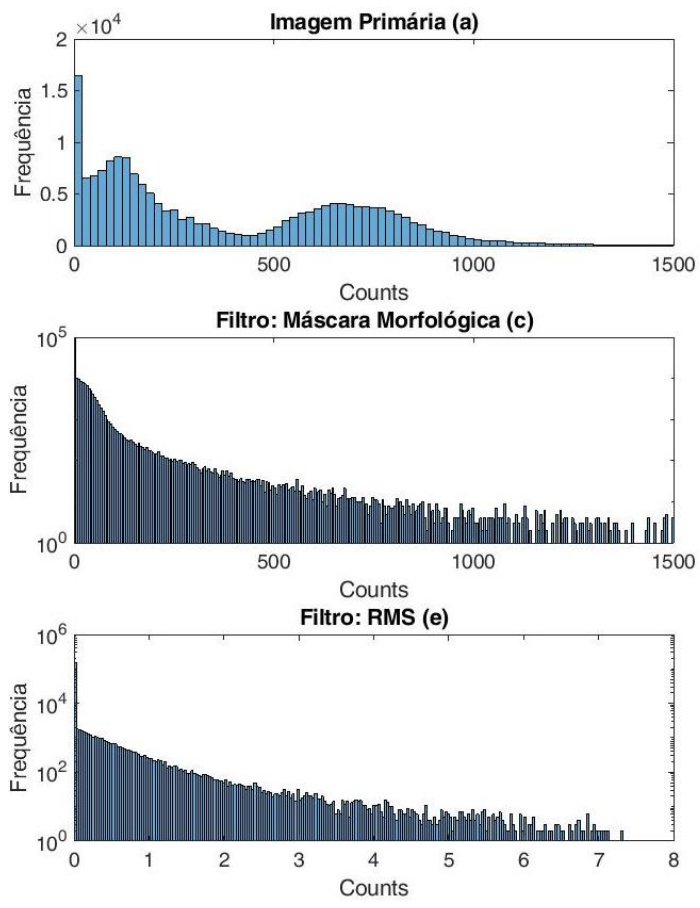
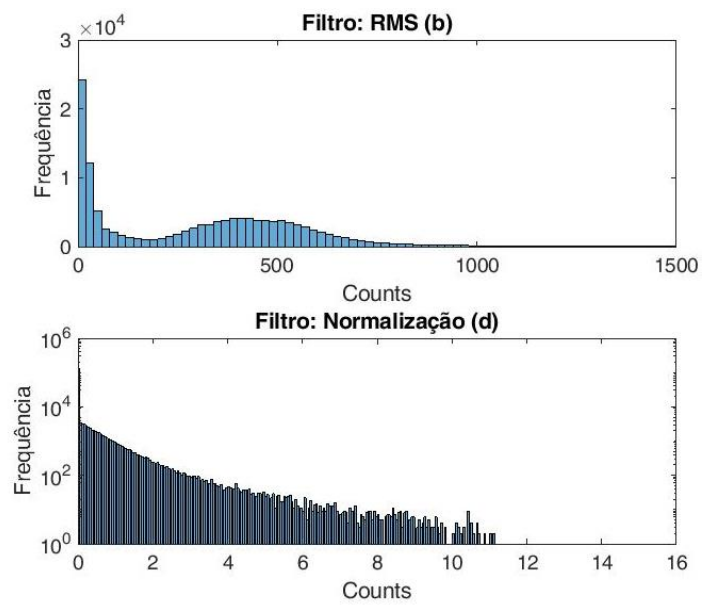

Fonte: Autor.

\subsubsection{PRÉ-PROCESSAMENTO BETA}

Considerando as mesmas premissas adotadas para elaborar o Pré-processamento Alfa, o Pré-processamento Beta foi desenvolvido. Entretanto, somente filtros espaciais típicos de estratégias de processamento de imagens PIV foram aplicados e um procedimento numérico mais simples foi considerado. A visão global da estratégia de préprocessamento proposto é mostrada esquematicamente na Figura 3.16 e o par de imagens primárias utilizado para verificar a influência das etapas desta metodologia é apresentado na Figura 3.5.

O Pré-processamento Beta tem início dado pela aplicação do filtro espacial $S T D$, com o objetivo de remover o ruído de fundo e, adicionalmente, eliminar as imagens de partículas com diâmetro inferior ao recomendado por Keane e Adrian $(1990,1991)$ para garantir melhor confiabilidade aos resultados provenientes da etapa de correlação. Dessa forma, a filtragem por $S T D$ pode ser entendida como uma filtragem espacial que utiliza como base a função desvio padrão, a qual foi aplicada em todo o domínio espacial das 
imagens primárias considerando kernel $3 \times 3$, segundo as recomendações de Amaral et al. (2014). O resultado pode ser visto na Figura 3.17 e a equação que governa as operações matemáticas realizadas é apresentada pela Equação 3.1.

Figura 3.16 - Visão global do Pré-processamento Beta.

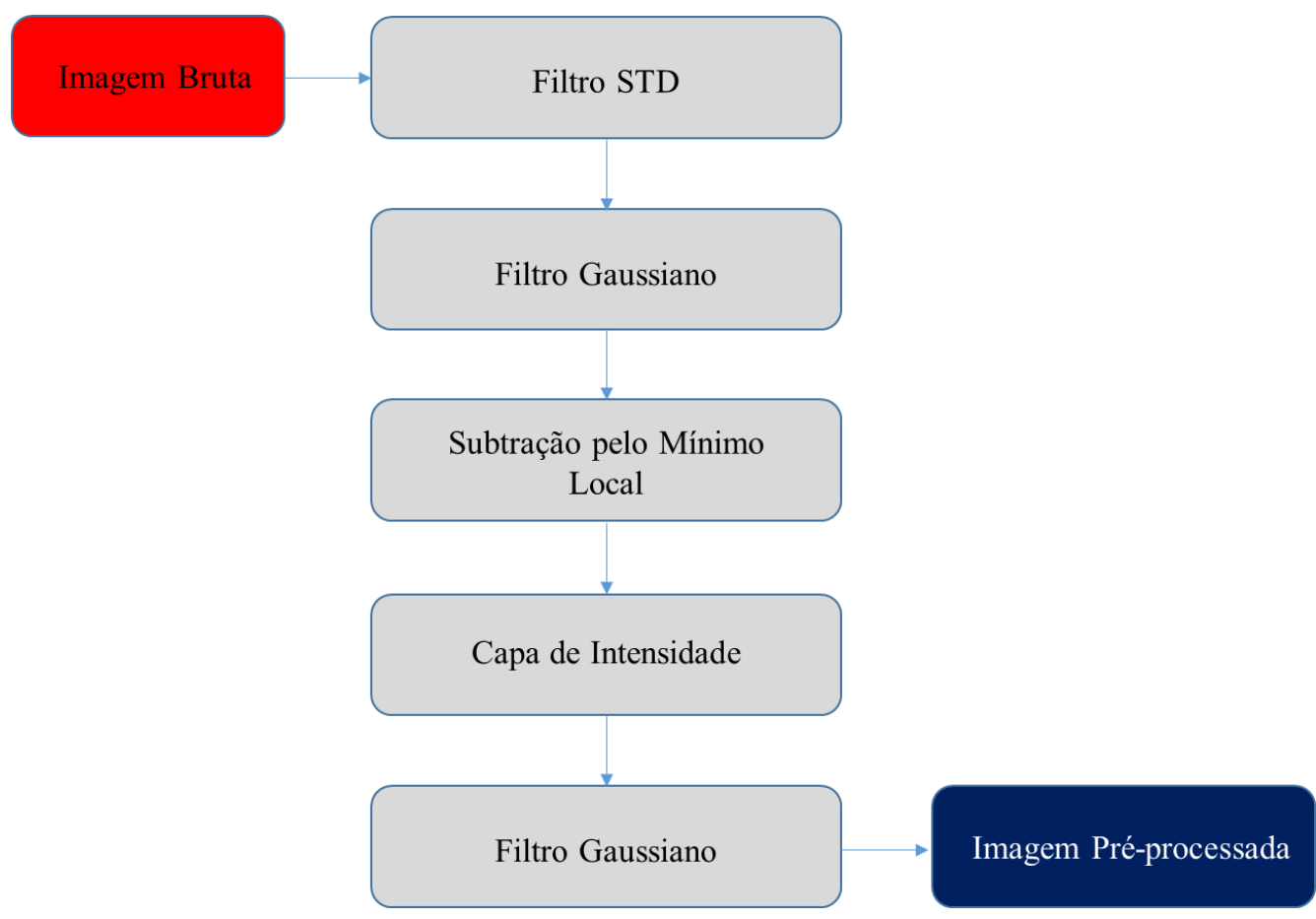

Fonte: Autor.

Após a filtragem por desvio padrão, um filtro gaussiano foi aplicado às imagens primárias com o propósito de melhorar a forma das imagens de partículas. Para tanto, aplicou-se o filtro mencionado considerando desvio padrão igual a 0,1 counts e kernel $3 \times 3$. Com essa operação, o traçador é identificado como uma imagem de partícula com núcleo de maior intensidade frente à borda. O resultado da aplicação do filttro gaussiano é mostrado na Figura 3.18. Maiores detalhes sobre o filtro Gaussiano são oferecidos no APÊNDICE B - FILTRO GAUSSIANO.

Inspirado nos resultados alcançados por Amaral et al. (2014) e nos apontamentos feitos por Moura (2017), após a aplicação do filtro gaussiano propôs-se aplicar a filtragem por Subtract Sliding Minimum para garantir o contraste das imagens de partículas frente ao fundo que as contêm. Para tanto, o método de SSM foi aplicado em todas as matrizes de pixels a partir de um kernel $50 \times 50$. O resultado da filtragem por SSM é apresentado 
na Figura 3.19 e uma breve revisão sobre o método encontra-se no APÊNDICE C -

\section{FILTRO SSM.}

Figura 3.17 - Par de imagens da fase gasosa pré-processadas pelo filtro STD em um instante de injeção do spray com pressão de 100 bar. O primeiro frame é apresentado à esquerda, enquanto o segundo, à direita.
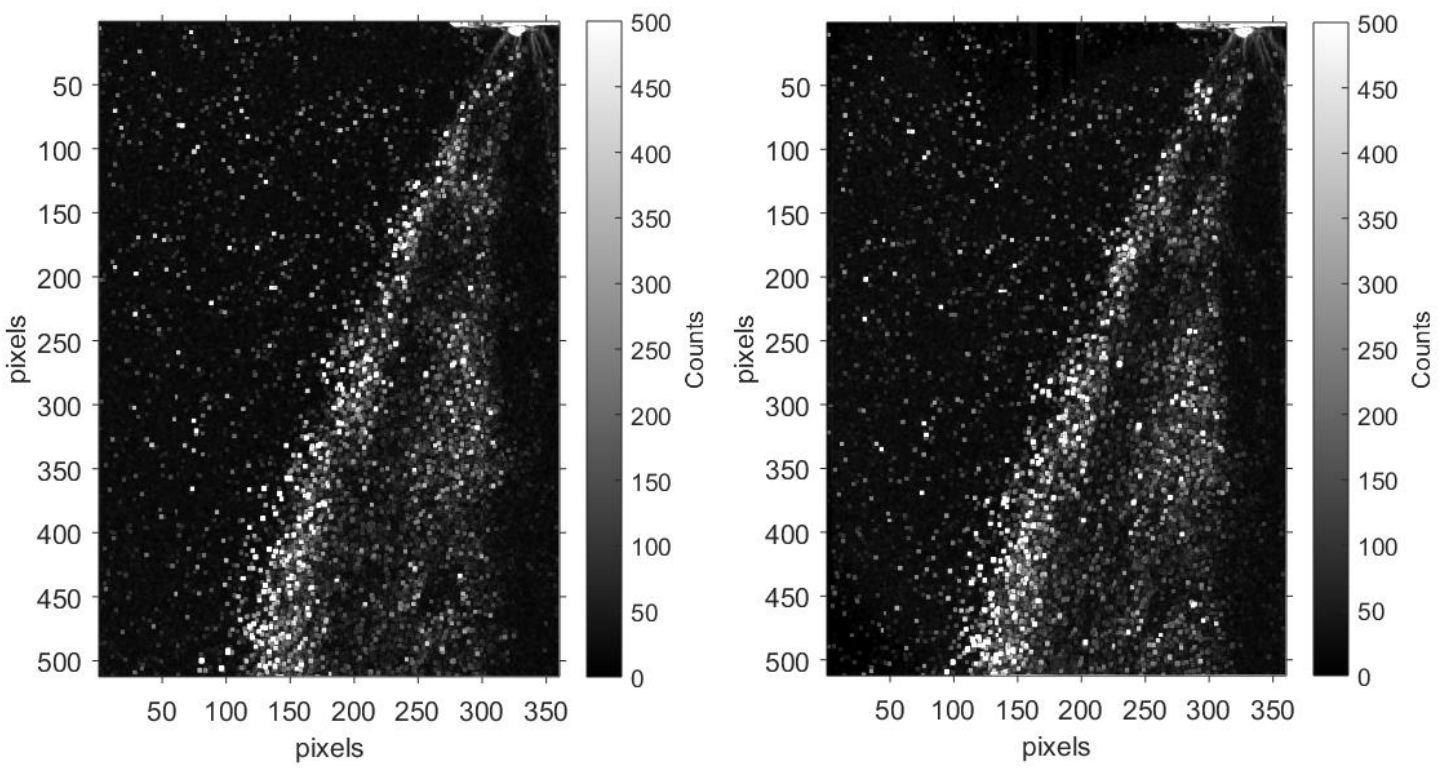

Fonte: Autor.

Figura 3.18 - Par de imagens da fase gasosa pré-processadas pelo filtro gaussiano com $\sigma=0,1$ em um instante de injeção do spray com pressão de 100 bar. O primeiro frame é apresentado à esquerda, enquanto o segundo, à direita.
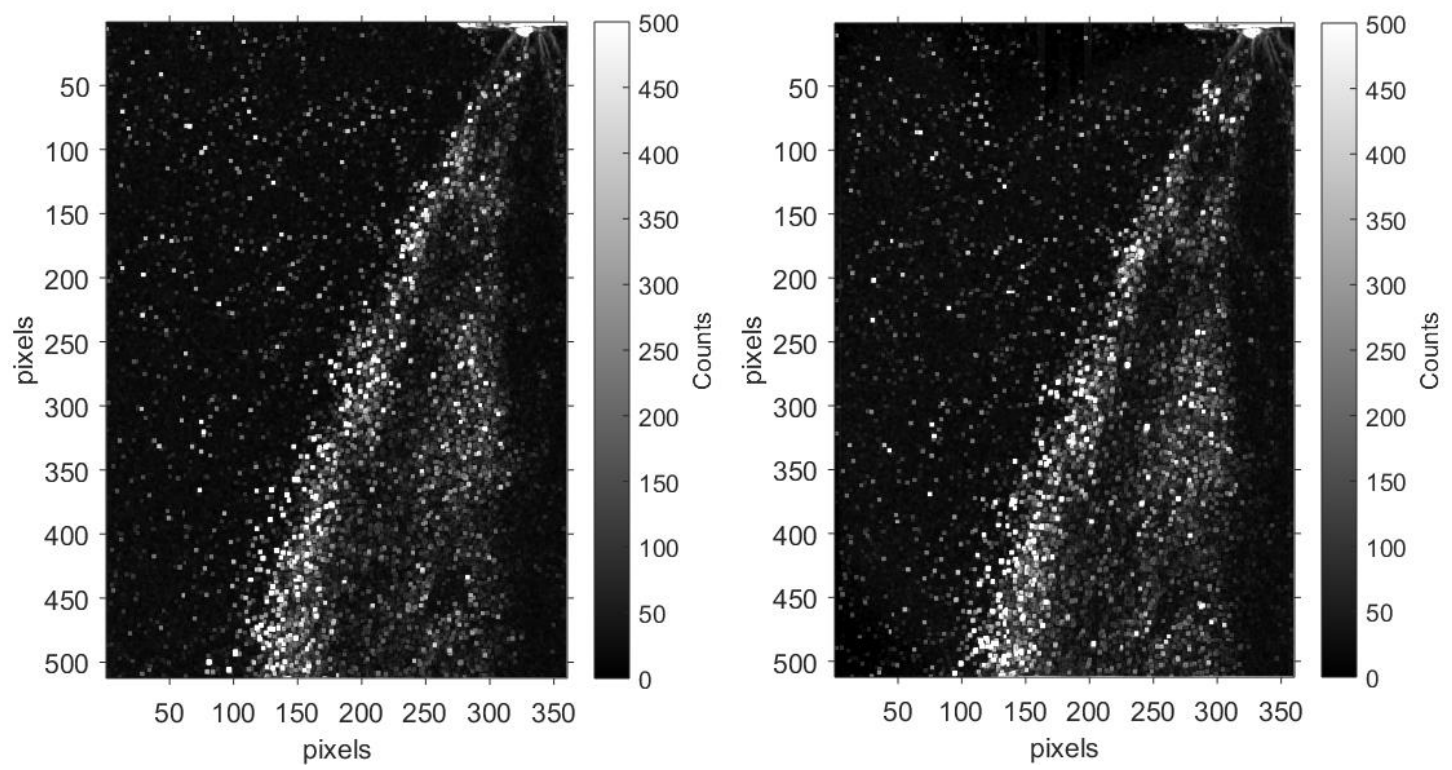

Fonte: Autor. 
Figura 3.19 - Par de imagens da fase gasosa pré-processadas pelo filtro SSM em um instante de injeção do spray com pressão de 100 bar. O primeiro frame é apresentado à esquerda, enquanto o segundo, à direita.
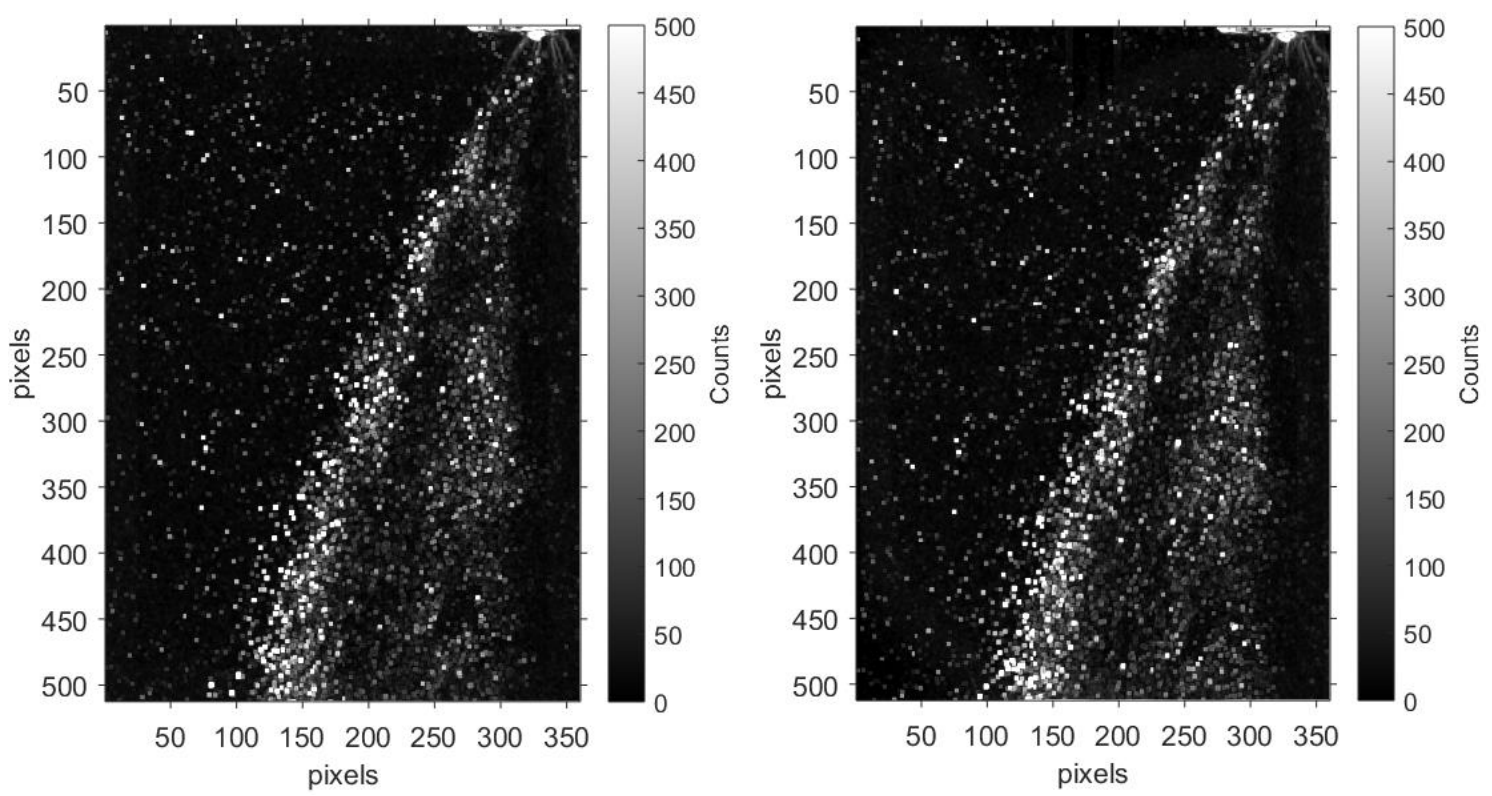

Fonte: Autor.

De forma complementar à operação de $S S M$, o método proposto por Shavit, Lowe e Steinbuck (2007) como Intensity Capping foi utilizado. O intuito de aplicá-lo foi de eliminar pontos ou conglomerados brilhantes nas imagens, a fim de evitar que o Número Efetivo de Partículas pudesse ser denegrido pela possível presença de bright spots. As imagens foram pré-processadas com a capa de intensidade considerando o fator $n$ igual a 2 e são mostradas na Figura 3.20. Mais informações sobre o método de Intensity Capping estão disponíveis no APÊNDICE D - O MÉTODO DA CAPA DE INTENSIDADE.

Por fim, o filtro Gaussiano foi novamente aplicado, com as mesmas dimensões e com a mesma finalidade de quando fora utilizado no início desta metodologia de préprocessamento. Todavia, o filtro foi aplicado considerando desvio padrão igual a 1 count. O par de imagens resultante da última aplicação do filtro gaussiano é apresentado na Figura 3.21. 
Figura 3.20 - Par de imagens da fase gasosa pré-processadas utilizando o algoritmo de Intensity Capping em um instante de injeção do spray com pressão de 100 bar. O primeiro frame é apresentado à esquerda, enquanto o segundo, à direita.
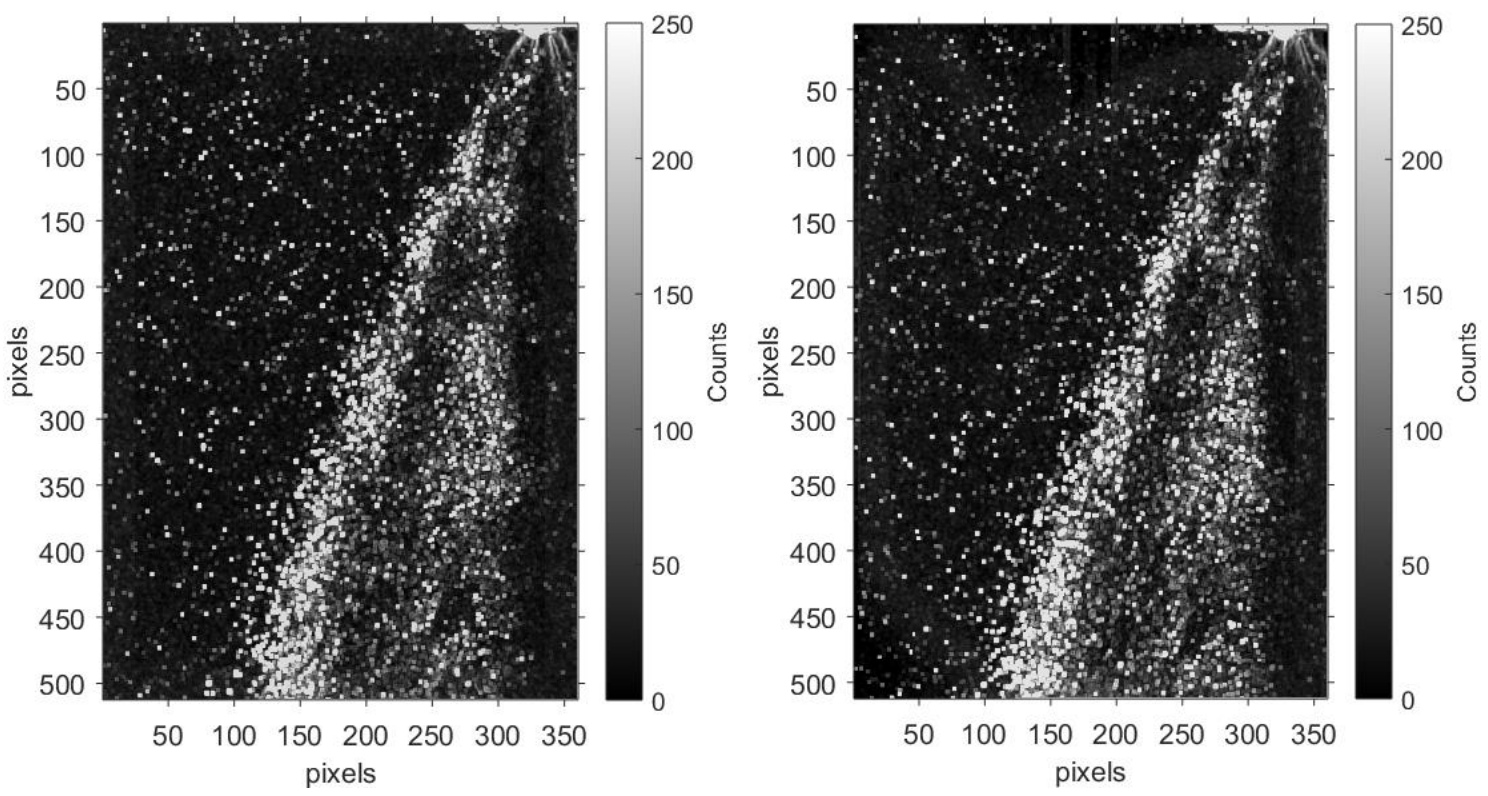

Fonte: Autor.

Figura 3.21 - Par de imagens da fase gasosa pré-processadas pelo filtro gaussiano com $\sigma=1 \mathrm{em}$ um instante de injeção do spray com pressão de 100 bar. O primeiro frame é apresentado à esquerda, enquanto o segundo, à direita.
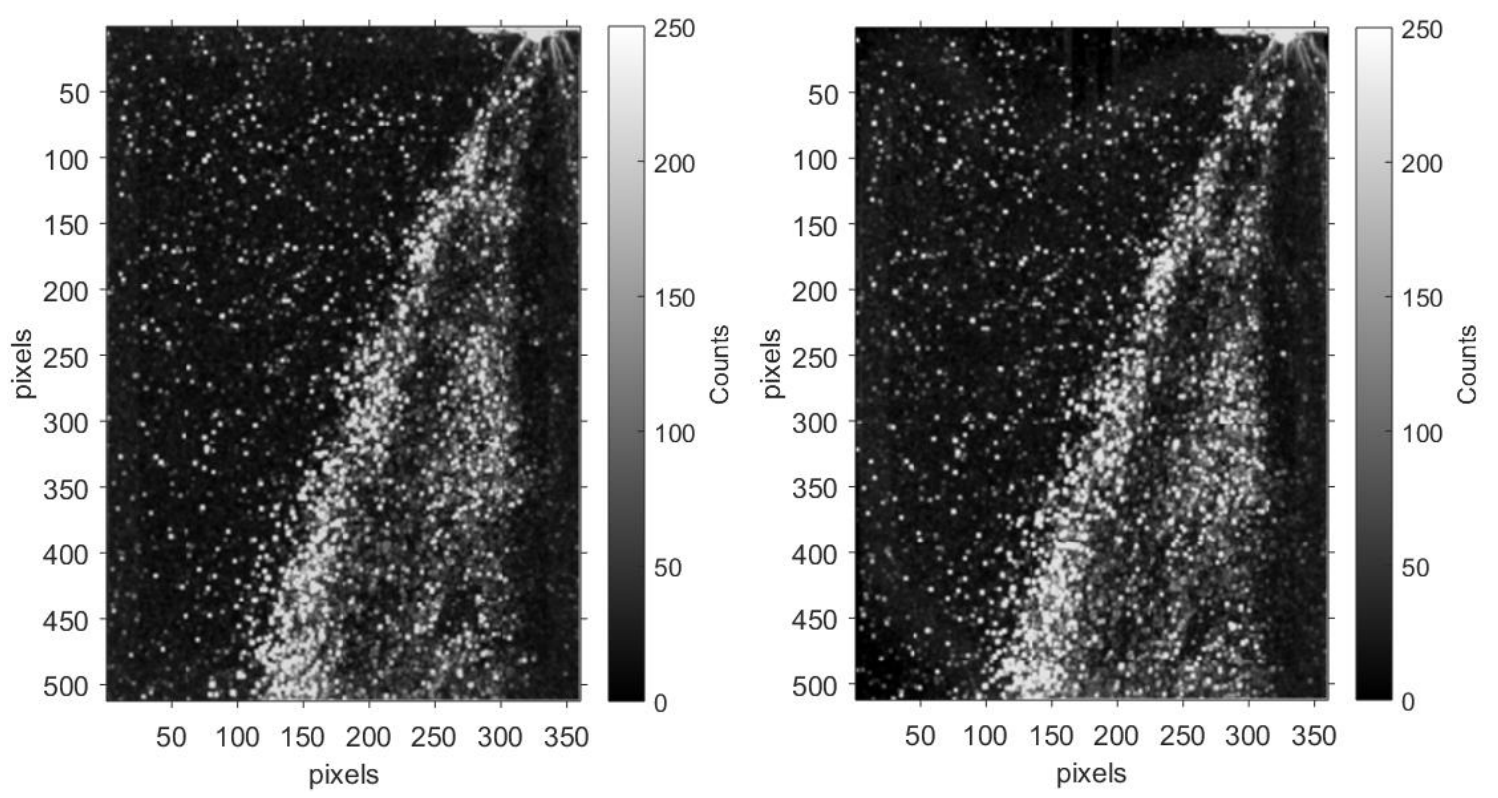

Fonte: Autor.

De forma análoga à realizada no Pré-processamento Alfa, os histogramas de nível de cinza obtidos em cada passo da metodologia Beta são mostrados na Figura 3.22 e na Figura 3.23. A Figura 3.22 refere-se ao primeiro frame, enquanto a Figura 3.23, ao segundo. Mediante a análise dos histogramas, nota-se que no decorrer do pré- 
processamento Beta houve redução da luminosidade das imagens de modo concomitante à melhoria de homogeneidade das intensidades de cada pixel, no entanto de forma menos pronunciada frente à percebida com o pré-processamento que utilizou filtragem morfológica. Além disso, vale destacar que a estratégia Beta não oferece mudanças bruscas de luminosidade entre as etapas que o descrevem devido à capacidade que as ferramentas de processamento digital utilizadas têm de atuarem mais sobre a forma da partícula do que na respectiva parcela de iluminação que destina a todo o domínio espacial. Todavia, é importante notar que a redução de ruído de fundo e a homogeneidade da iluminação das imagens aconteceram e foram propiciadas, principalmente, pela aplicação das filtragens $S T D$ e por $S S M$, estando a última atrelada a um limite de intensidade para evitar que a iluminação da imagem seja denegrida com a sua aplicação.

Figura 3.22 - Efeito das etapas do pré-processamento Beta sobre os histogramas de nível de cinza do primeiro frame processado. (a) refere-se à Imagem Primária; (b) à imagem filtrada por RMS; (c) à imagem tratada com filtro gaussiano; (d) à imagem resultante da aplicação da metodologia SSM; (e) à aplicação da capa de intensidade e (f) última aplicação da filtragem espacial com filtro gaussiano.
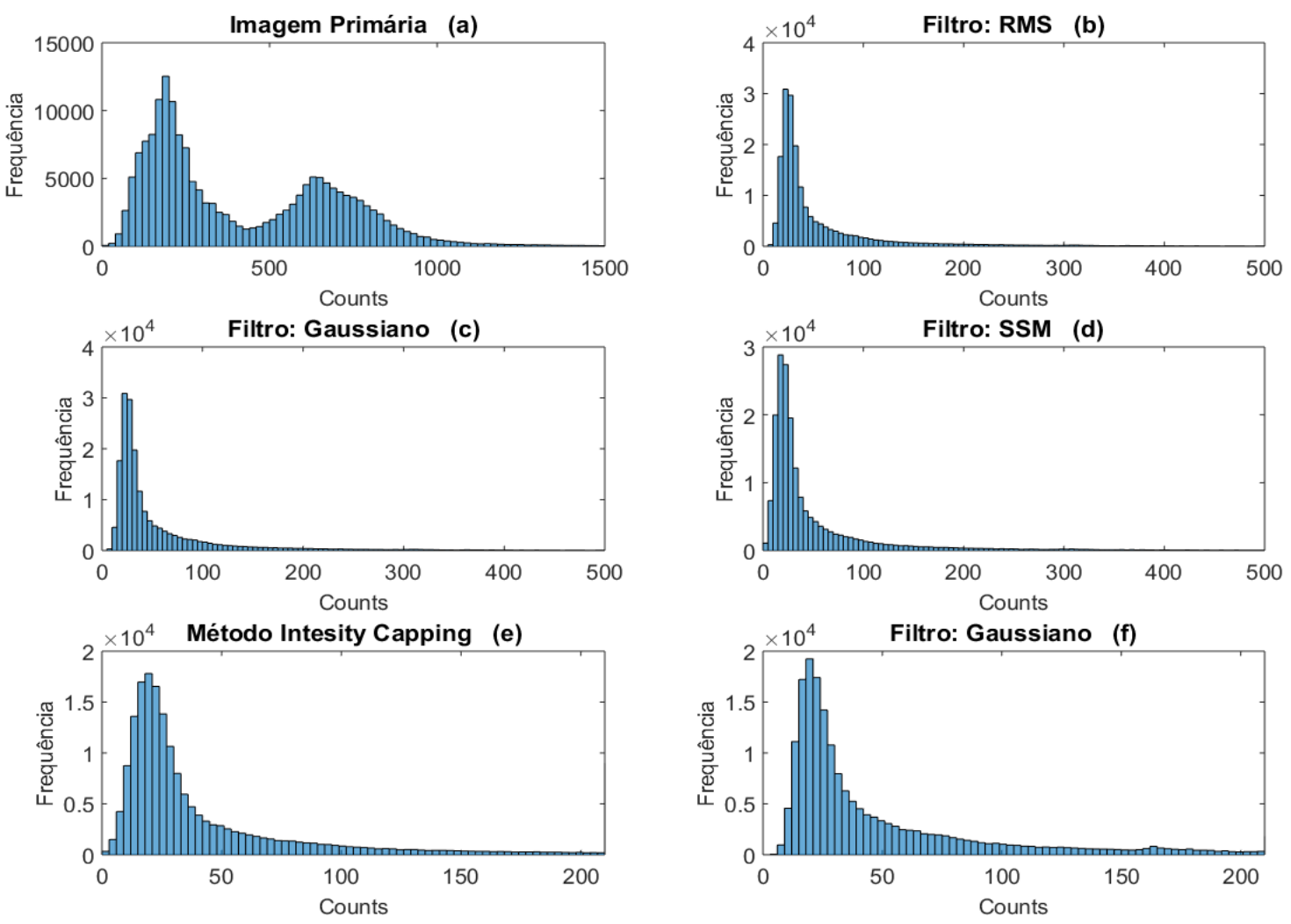

Fonte: Autor. 
Figura 3.23 - Efeito das etapas do pré-processamento Beta sobre os histogramas de nível de cinza do segundo frame processado. (a) refere-se à Imagem Primária; (b) à imagem filtrada por RMS; (c) à imagem tratada com filtro gaussiano; (d) à imagem resultante da aplicação da metodologia SSM; (e) à aplicação da capa de intensidade e (f) última aplicação da filtragem espacial com filtro gaussiano.
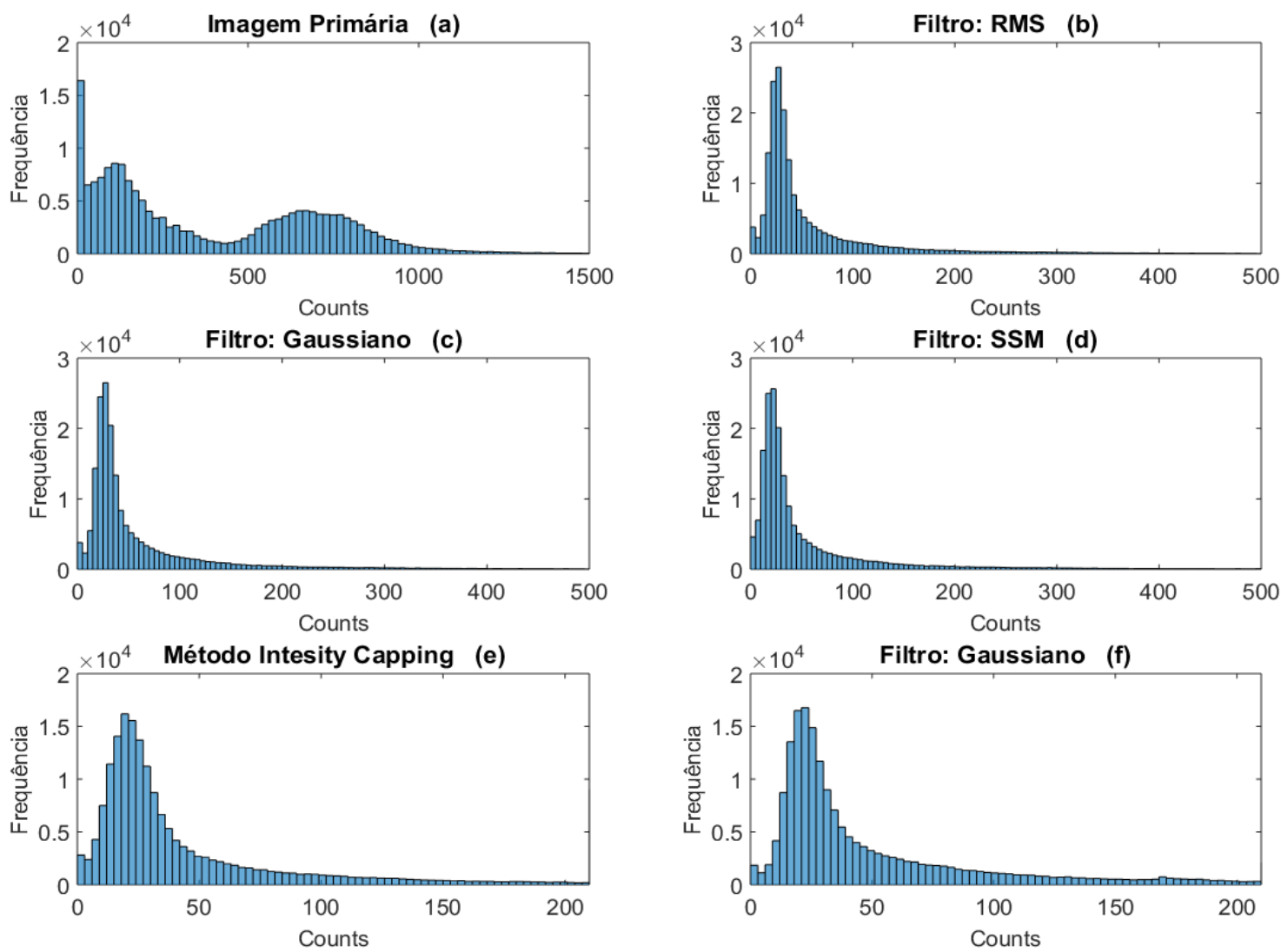

Fonte: Autor.

A partir da análise das imagens pré-processadas, nota-se que o pré-processamento Beta fornece imagens de partículas mais destacadas e com maiores diâmetros se comparado às imagens primárias. No entanto, ao examinar as imagens pré-processadas, verifica-se que o método não oferece boa qualidade na região de interface ar-spray, uma vez que produz um aglomerado de partículas nesta região que não são discerníveis quanto à classificação de imagem de partícula e gotículas de combustível, isto é, torna impraticável a distinção das fases com clareza. Tal comportamento, embora suavizado pela capa de intensidade, gera uma fonte de ruído adicional à correlação e pode interferir negativamente na qualidade dos campos vetoriais referentes ao escoamento de ar, uma vez que o movimento das gotículas será considerado como movimento das partículas traçadoras, gerando resultados incoerentes à realidade nestes casos. Por fim, percebe-se que a forma do spray é visivelmente preservada nas imagens pré-processadas pela metodologia Beta, contrário ao que foi observado nas imagens oriundas da aplicação do 
Pré-processamento Alfa. Maiores detalhes sobre o filtro Gaussiano, o método da capa de intensidade e o algoritmo de SSM são apresentados nos apêndices A - D.

\subsubsection{ESTRATÉGIA DE INTERROGAÇÃO E PROCESSAMENTO PIV}

Para avaliar o desempenho das metodologias de pré-processamento propostas, diferentes abordagens de janelamento e processamento PIV foram sugeridas. A estratégia adotada em todos os processamentos feitos no presente trabalho é a de múltiplas grades (abordagem multigrid, em inglês), a qual permite correlacionar pares de imagens em mais de uma etapa de correlação (abordagem multipass, em inglês) de modo tal que o tamanho da janela de interrogação é diminuído progressivamente durante as etapas de correlação, segundo uma porcentagem de sobreposição. Com o uso dessa metodologia, a restrição travada pela regra de um quarto é amenizada e surge a possibilidade de obter maiores resoluções espaciais. Para mais informações sobre a estratégia multigrid, sugere-se a leitura dos trabalhos de Scarano e Riethmuller (1999, 2000). Uma descrição objetiva sobre a estratégia de sobreposição de janelas de interrogação é encontrada no APÊNDICE E - ESTRATÉGIA DE SOBREPOSIÇÃO DE JANELAS DE INTERROGAÇÃO e uma síntese sobre a abordagem multipass é fornecida no APÊNDICE F - MÉTODO DE PROCESSAMENTO PIV POR MÚLTIPLOS PASSOS.

Utilizando a metodologia de processamento por múltiplas grades, duas estratégias de correlação foram utilizadas inicialmente para testar os resultados obtidos com a aplicação das metodologias de pré-processamento: a $S C C$ e a $R P C$. Não foram utilizadas técnicas de deformação da imagem durante os passos de correlação. Considerando todas as combinações possíveis entre pré-processamento e estratégia de correlação, doze configurações foram propostas e estão divididas em grupos (Casos A - C; D - F; G - I e J - L). Em todos os grupos o processamento foi feito com dois passos, a sobreposição de janela escolhida foi de $25 \%$ e três tamanhos iniciais de janela de interrogação foram considerados: 48, 32 e 21 pixels. A Tabela 3.2 resume em casos todos os parâmetros e as técnicas utilizadas para compor a estratégia inicial de interrogação e processamento $P I V$. 
Vale destacar que os tamanhos de janela de interrogação foram escolhidos baseados em uma análise hipotética que visou nortear a escolha do grid com base na máxima resolução espacial capaz de manter o número efetivo de partículas dentro do intervalo recomendado pela literatura $(N \leq 7)$. A análise considerou que todos os fatores que compõem o referido parâmetro de qualidade das medidas $P I V$ são iguais a 0,75 e adotou $N_{P P P}=0,025$, em respeito às conclusões extraídas da Figura 3.7. Sendo assim, foi pressuposto que o tamanho da janela de interrogação final mínimo, admitindo condição de janelamento não adaptativo, seria de 32 pixels.

Tabela 3.2 - Parâmetros de processamento PIV utilizados na abordagem multigrid.

\begin{tabular}{cccc}
\hline Casos & Correlação & Pré-processamento & $\begin{array}{c}\text { Tamanho Inicial da Janela } \\
\left(\mathbf{I W}_{\boldsymbol{i}}\right)[\text { pixels }]\end{array}$ \\
\hline Caso A & & 48 over $25 \%=36$ \\
Caso B & SCC & --- & 32 over $25 \%=24$ \\
Caso C & & 21 over $25 \%=16$ \\
\hline Caso D & & Beta & 48 over $25 \%=36$ \\
Caso E & SCC & & 32 over $25 \%=24$ \\
Caso F & & & 21 over $25 \%=16$ \\
\hline Caso G & & 48 over $25 \%=36$ \\
Caso H & SCC & Alfa & 32 over $25 \%=24$ \\
Caso I & & & 21 over $25 \%=16$ \\
\hline Caso J & & 48 over $25 \%=36$ \\
Caso K & RPC & 32 over $25 \%=24$ \\
Caso L & & -16 over $25 \%=16$ \\
\hline
\end{tabular}

Fonte: Autor.

\subsubsection{PÓS-PROCESSAMENTO}

A etapa de pós-processamento proposta para compor o método de otimização $P I V$ consiste na remoção de vetores espúrios mediante a aplicação conjunta de dois métodos. $\mathrm{O}$ primeiro refere-se à remoção de outliers com base em uma medida robusta de variabilidade de distribuições univariadas: o Desvio Absoluto Mediano (MAD, sigla em 
inglês). Quando aplicado, o $M A D$ foi encarregado de substituir os vetores falsos utilizando a estratégia de interpolação cúbica por spline (shape-preserving piecewise cubic spline interpolation), método sugerido por Fritsche e Carlson (1980) para garantir a preservação da forma das demais entidades vetoriais. Para aplicar esse método, definiuse por outlier o vetor que possui magnitude superior ao triplo da escala $M A D$, conforme sugere o trabalho de Miller (1991), sendo a escala $M A D$ definida a partir da média do desvio absoluto da mediana determinado dos valores contidos em um kernel $3 \times 3$.

O segundo dirige-se à exclusão de outliers restantes ou resultantes da aplicação do primeiro método de pós-processamento ora proposto. Para tanto, um algoritmo de filtragem por $S N R$ foi aplicado para remover dos resultados finais todas as regiões do campo vetorial e/ou dos diagramas de contornos que tivessem SNR inferiores a um valor determinado parametricamente. Para os casos em que foi necessário excluir outliers, a janela de interrogação onde o vetor fora excluído foi preenchida completamente pela cor branca.

Vale destacar que a presente estratégia de pós-processamento foi utilizada cautelosamente, a fim de evitar que os campos vetoriais finais e, consequentemente, todos os dados e conclusões que fossem dele extraídas, estivessem denegridos devido à exclusão demasiada de vetores coerentes ou representassem informações que não fossem confiáveis. À cautela, atribui-se a escolha da solução de compromisso utilizada durante a seleção do tamanho do kernel combinado à tolerância máxima permitida ao desvio absoluto mediado associado ao método de interpolação. Além disso, atribui-se também a eleição do $S N R$ como parâmetro de exclusão de vetores, quando utilizado.

\subsection{INVESTIGAÇÃO DA INTERAÇÃO AR-SPRAY}

De posse dos melhores resultados obtidos com a otimização $P I V$ proposta na seção 3.2, estudou-se o mecanismo de interação do spray de etanol no ambiente gasoso, limitado às condições experimentais escolhidas por Berti (2018). Para tanto, quando analisada a fase gasosa sem a presença do spray no espaço de imagem, considerou-se a média temporal das médias de fase dos campos pós-processados obtidos durante o período de estabilidade do escoamento. Já para as análises da interação gás-spray, considerou-se a evolução temporal das médias de fase dos campos pós-processados como 
estratégia inicial de estudo. Vale frisar que a escolha das abordagens supracitadas permite eliminar possíveis perturbações locais que podem denegrir o sinal no campo de correlação. Assim, busca-se sustentar a discussão física do escoamento com argumentos mais sólidos, eliminando do escopo possíveis estruturas provenientes da preservação de ruídos.

Para discorrer sobre a interação entre o ar circundante e o spray de etanol, as distribuições de norma dos vetores velocidades e das respectivas componentes estimadas em um sistema de eixos conveniente foram utilizadas. A escolha de tais variáveis foi inspirada na metodologia e na discussão oferecidas nos trabalhos de Rottenkolber et al. (2002) e Zhang et al. (2014), uma vez que os autores elegeram o módulo dos vetores velocidade com um dos parâmetros de referência para a proposição de análises qualitativas e quantitativas sobre o escoamento gás-spray. No entanto, especificamente à escolha das componentes dos vetores velocidade como parâmetro de análise, a abordagem escolhida por Zhang et al. (2014) se mostrou conveniente pelo fato de evidenciar a relação de dependência entre o ângulo dos vetores que compõem o campo de velocidades e as estruturas do escoamento, as quais foram avaliadas sob o aspecto de interação bifásica em regiões previamente elencadas pelos autores com base da direção dos vetores. Adicionalmente, o campo de vorticidade também foi escolhido para analisar o escoamento gás-spray. O parâmetro de análise ora proposto está baseado nos resultados de Jedelsky et al. (2018), uma vez que o autor propõe uma discussão sobre a interação bifásica do escoamento em questão, mantido em condições específicas, amplamente baseada em estruturas recirculantes. Uma síntese sobre as principais considerações de Rottenkolber et al. (2002), Zhang et al. (2014) e Jedelsky et al. (2018) é apresentada na seção 2.1.3. 


\section{RESULTADOS E DISCUSSÃO}

Este capítulo está dividido em três partes. A primeira trata sobre o efeito das metodologias de pré-processamento no campo vetorial primário, considerando, e não, a presença do spray no espaço de imagem. Nessa etapa, foi escolhida a melhor estratégia de pré-processamento para tratar as imagens primárias, com base em indicadores típicos. A segunda parte consiste na proposição da estratégia de otimização do processamento $P I V$, idealizada a partir do resultado obtido na etapa anterior. Por fim, a última trata sobre a investigação do escoamento ar-spray, estudado a partir dos resultados otimizados na etapa intermediária.

\subsection{ANÁLISE INICIAL DAS MEDIDAS PIV}

Com o propósito de obter a melhor descrição das estruturas do escoamento ar-spray investigado no presente trabalho, buscou-se a máxima resolução espacial capaz de representá-las sem que as medidas PIV fossem deterioradas. Nesse âmbito, a Figura 4.1 mostra o efeito que a diminuição do tamanho de janela de interrogação final, $I W_{f}$, exerce sobre a distribuição da média temporal do módulo da velocidade, $|\bar{U}|$, da relação Sinal-Ruído, $S N R$, e do $R M S$ do módulo da flutuação de velocidade, $|U|^{\prime}$, considerando a sequência de imagens registradas no período definido entre o instante em que ocorre a estabilização do escoamento e um instante anterior à injeção do spray. Para tanto, a abordagem SCC foi utilizada como referência para processar as imagens primárias gravadas na condição em que a pressão de injeção foi de 100 bar e a vazão de ar, 0,066 kg/s (CASO 1, Tabela 3.1): os Casos A - C, apresentados na Tabela 3.2. Na Figura 4.1(a), nota-se que o aumento da resolução espacial produziu um efeito negativo tanto na suavização dos contornos que definem a distribuição de $|\bar{U}|$ quanto nos valores de $S N R$. Adicionalmente, percebe-se que menores janelas de interrogação produziram distribuições de $R M S$ de $|U|^{\prime}$ com contornos mais segregados e menos suavizados, fato que evidencia perdas de coerência espacial e de qualidade de representação das medidas $P I V$. Vale destacar que a escolha do $R M S$ da flutuação de velocidade como um parâmetro de análise foi baseada na maior sensibilidade que as flutuações de velocidade têm em relação às fontes ruidosas e às manipulações algébricas. Deste modo, as distribuições $|U|_{R M S}^{\prime}$ foram utilizadas com o objetivo de refinar as análises comparativas pertinentes ao presente estudo. 
Figura 4.1 - Medidas do escoamento do ar sem o spray, para 100 bar e $0,066 \mathrm{~kg} / \mathrm{s}$ utilizando a abordagem $S C C$ a partir da imagem primária: (a) média temporal do módulo de velocidade; (b) distribuição da relação sinal-ruído; (c) root mean square da flutuação do módulo de velocidade.
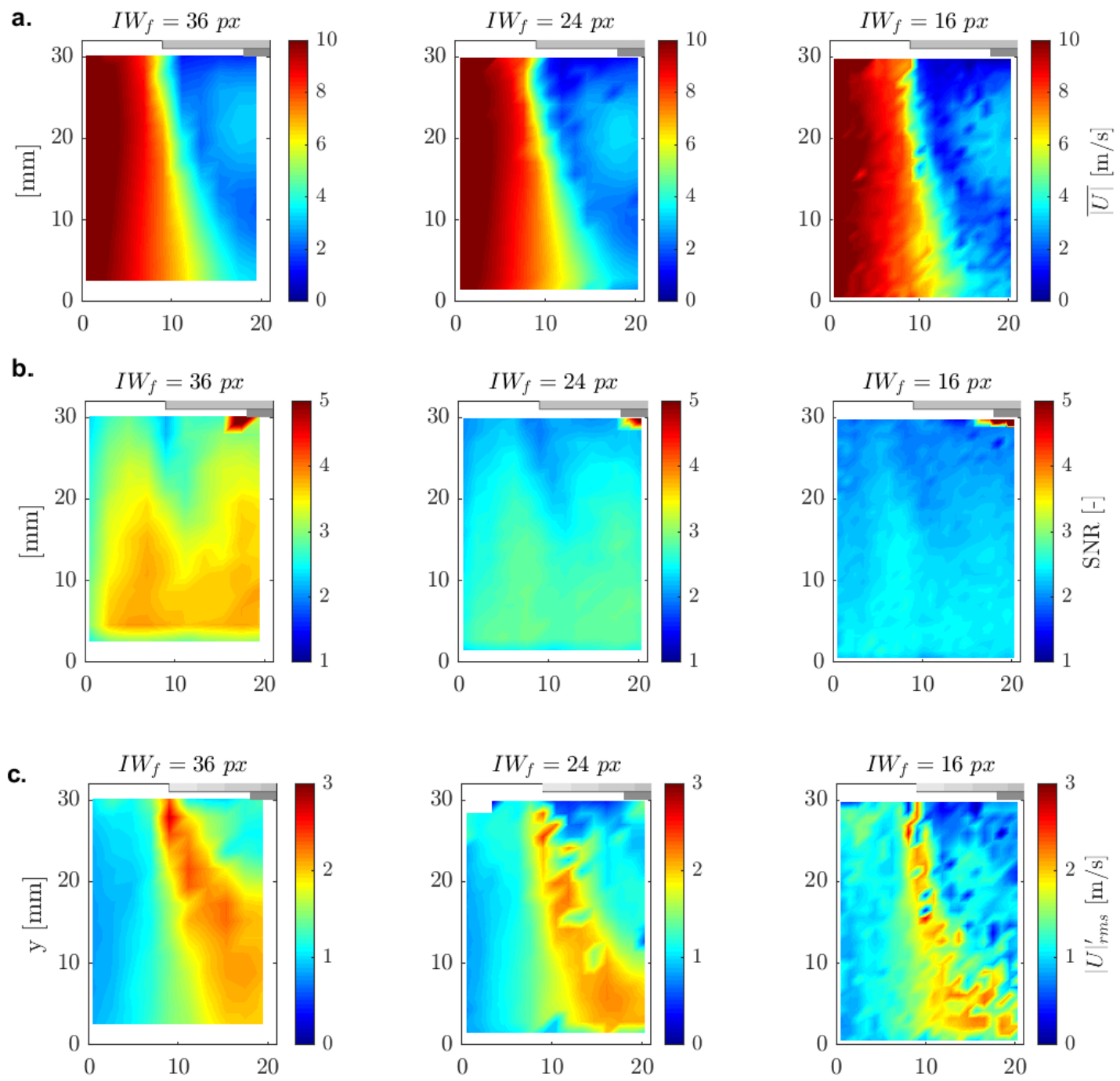

Fonte: Autor.

Para analisar detalhadamente o efeito da resolução espacial na suavização da distribuição dos parâmetros da Figura 4.1, a Incoerência das distribuições de $|\bar{U}|$ e de $|U|_{R M S}^{\prime}$ para 100 bar e $0,066 \mathrm{~kg} / \mathrm{s}$ foi estimada e os resultados são mostrados na Figura 4.2. A Incoerência está fundamentada na Coerência Local, indicador investigado por Nogueira, Lecuona e Rodríguez (1997) e nomeado originalmente como val. Tal parâmetro se refere a uma estratégia capaz de quantificar a coerência espacial das medidas oriundas de um determinado campo de deslocamento, indicando o grau de uniformidade que uma determinada vizinhança, $v_{i}$, tem com relação a uma velocidade da janela de interrogação alvo, $v_{0}$. De acordo com Nogueira, Lecuona e Rodríguez (1997), tão menor for o valor associados à val, maior é a coerência espacial e menor é a possibilidade de ter falsos vetores representando o escoamento. Analogamente, maiores valores de val 
remetem a maior incoerência e a maior chance de falsos vetores comporem o campo de velocidades. Logo, estendendo as definições propostas pelos autores, a Coerência Local pode ser entendida como um indicador da probabilidade de haver a presença de vetores espúrios nos campos vetoriais. No entanto, é importante destacar que a análise da val deve ser feita cautelosamente, a fim de evitar falsas conclusões quando da aplicação em escoamentos com elevados gradientes de velocidade.

A Equação 6.1 apresenta a relação matemática que permite calcular o valor de val, agora identificado pela variável Incoerência. No cálculo do referido parâmetro, considerase aplicação local com kernel $3 \times 3$ e cada uma das oito velocidades vizinhas à velocidade central, $v_{i}$. Vale destacar que durante a aplicação da Equação 6.1 não há aplicação de um critério de exclusão de outliers.

$$
\text { Incoerência }=\frac{\sum_{i}\left|v_{i}-v_{0}\right|}{\sum_{i}\left|v_{i}\right|}
$$

Figura 4.2 - Medidas do escoamento do ar sem o spray, para 100 bar e 0,066 kg/s utilizando a abordagem SCC a partir da imagem primária. Distribuição da incoerência da (a) média e do (b) RMS da flutuação do módulo de velocidade.
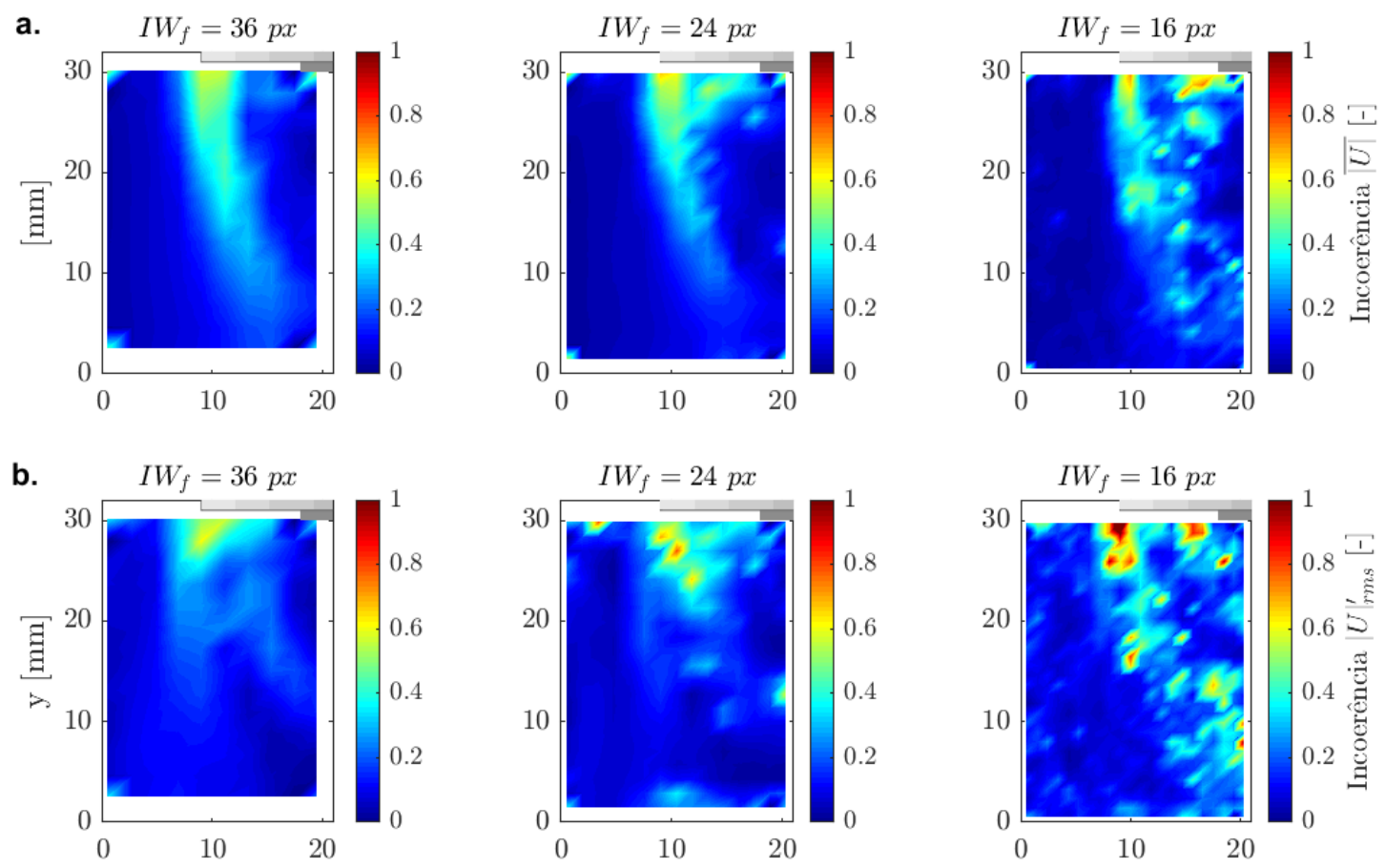

Fonte: Autor. 
Ao analisar a Figura 4.2, verifica-se que, de fato, a diminuição da janela de interrogação final promoveu a perda de coerência espacial prevista na Figura 4.1. Esse comportamento foi observado com maior intensidade na distribuição de $|U|_{R M S}^{\prime}$, a qual evidencia que as janelas de interrogação finais iguais a 24 e 16 pixels não são indicadas para representar as medidas do escoamento ar-spray. Vale salientar que o comportamento observado na Figura 4.1 e na Figura 4.2 pode estar atrelado à baixa concentração de imagens de partículas em todo o domínio espacial, uma vez que à medida em que o tamanho de janela de interrogação é diminuído, os efeitos atrelados à perda de correlação devido ao movimento dentro e fora do plano de luz $\left(F_{i}\right.$ e $\left.F_{O}\right)$ e ao gradiente de velocidade $\left(F_{\Delta}\right)$ tendem a ser mais pronunciados e a refletir na relação Sinal-Ruído. No entanto, ao considerar a maior incoerência e a diminuição generalizada do SNR obtidas com $I W_{f}=24$ pixels e $I W_{f}=16$ pixels, junto às observações tecidas para a Figura 3.7, fica evidenciado que a baixa concentração de partículas está refletindo na necessidade de manter menores resoluções espaciais como um compromisso com a representatividade das medidas PIV. Sendo assim, atribui-se à menor resolução espacial testada a melhor condição de ser utilizada para representar as medidas típicas do escoamento ar-spray.

Com base nas observações associadas à Figura 4.1 e à Figura 4.2, o efeito das estratégias de pré-processamento foi investigado considerando a janela de interrogação final igual a 36 pixels ( $I W_{i}=48$ pixels com $25 \%$ de sobreposição) e é mostrado na Figura 4.3. Com ela, verifica-se que os piores resultados foram obtidos com o Préprocessamento Alfa, baseado principalmente na distribuição de $R M S$ de $|U|^{\prime}$ e de sua respectiva incoerência. Além disso, o Pré-processamento Alfa propiciou baixos valores de $S N R$ quando comparado às demais combinações mostradas na Figura 4.3. A mesma figura evidencia também que as outras estratégias testadas não produziram diferenças significativas nas distribuições de $|U|_{R M S}^{\prime}$ e na coerência espacial do campo de velocidades. No entanto, percebe-se que os contornos de $|U|_{R M S}^{\prime}$ são ligeiramente mais suavizados frente aos demais e que maior confiabilidade pode ser esperada para os resultados gerados com a aplicação do Pré-processamento Beta junto à abordagem SCC.

Os mesmos efeitos encontrados com o aumento da resolução espacial foram observados em todas as outras combinações de estratégias de pré-processamento e processamento propostas na seção 3.2.2 (Casos D-L; Tabela 3.2). As Figuras G.1 - G.6 apresentam o efeito da diminuição do tamanho da janela de interrogação final à qualidade 
das medidas PIV, considerando as configurações dos Casos D - F, G - I e J - L aplicadas às imagens primárias obtidas a 100 bar e 0,066 kg/s (Caso 1; Tabela 3.1).

Figura 4.3 - Comparação entre o root mean square da flutuação do módulo de velocidade $\left(|U|_{R M S}^{\prime}\right)$, a incoerência na distribuição de $|U|^{\prime}{ }_{R M S}$ e a distribuição da relação sinal-ruído $(S N R)$ para diferentes estratégias de pré-processamento e processamento na condição de 100 bar e 0,066 $\mathrm{kg} / \mathrm{s}$ : (a) Imagem primária/SCC, (b) Imagem após o pré-processamento Beta/SCC; (c) Imagem após o pré-processamento Alfa/SCC; (d) Imagem primária /RPC.

a.

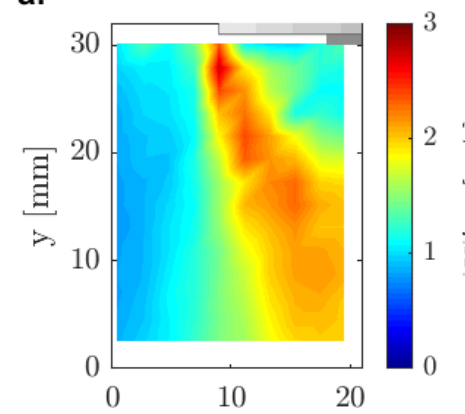

b.

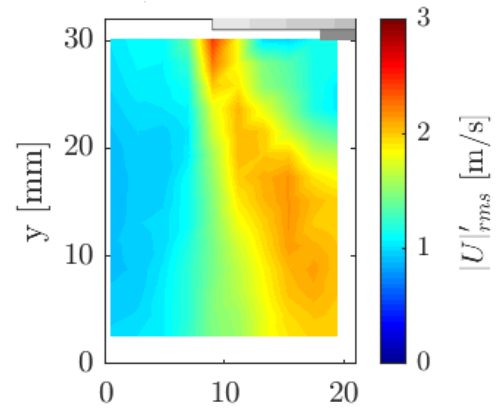

c.

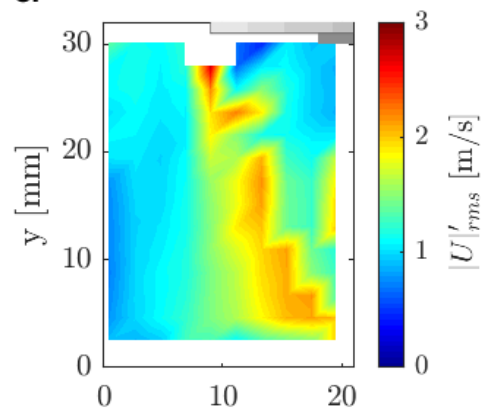

d.

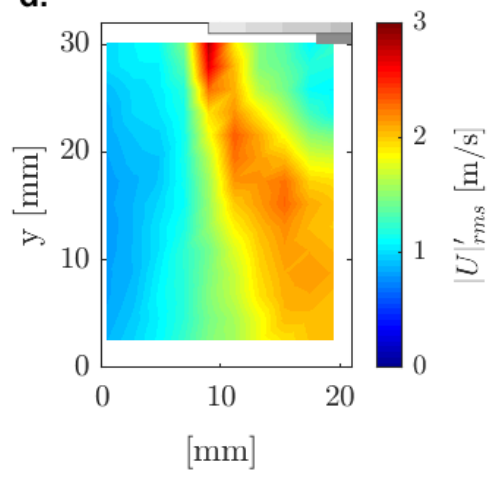

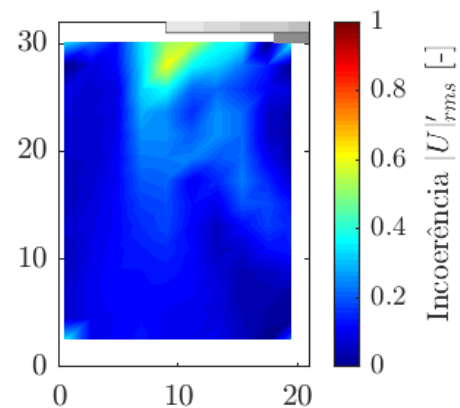
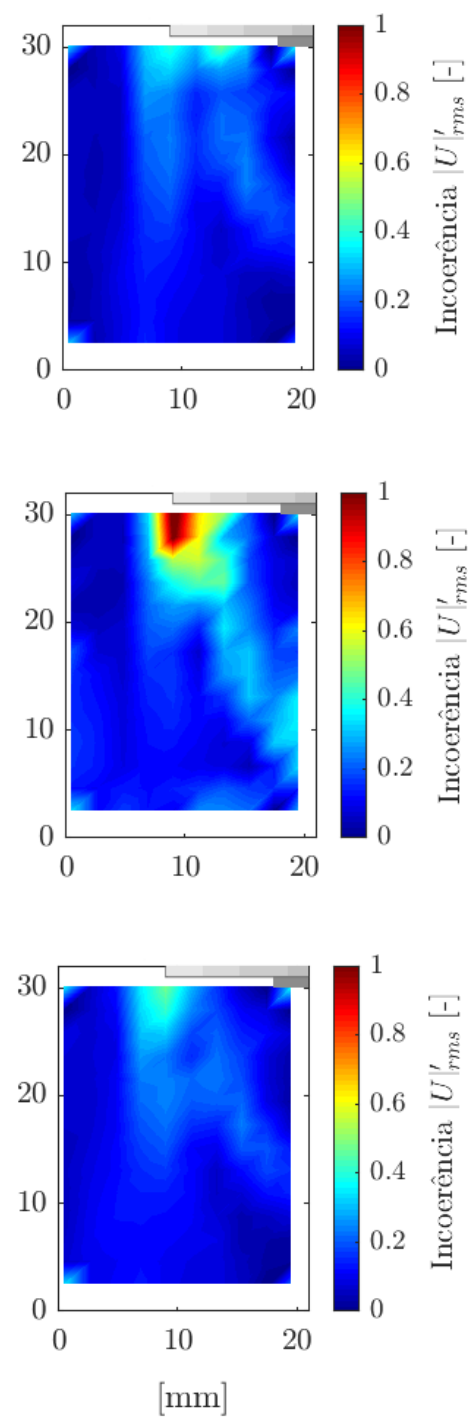
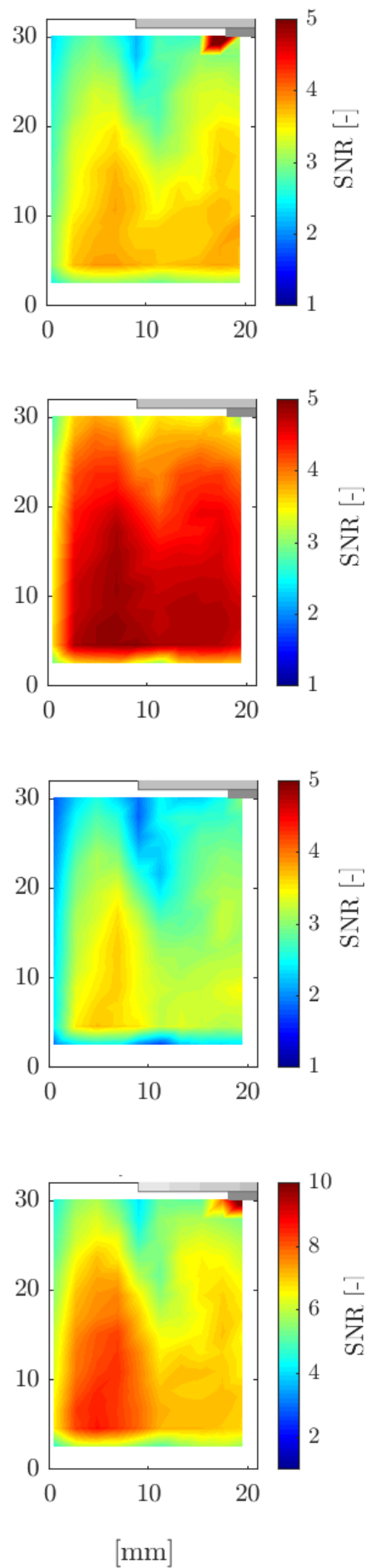

Fonte: Autor. 
Com o intuito de trazer à tona os efeitos que o pré-processamento e a estratégia de correlação propiciaram aos campos vetoriais obtidos a partir das imagens que contam com a presença do ruído associado ao spray, a Figura 4.4 apresenta o módulo da velocidade instantânea estimado em três momentos durante o evento de injeção do etanol.

Figura 4.4 - Comparação do módulo de velocidade instantâneo para imagem primária/SCC, imagem com o pré-processamento Beta/SCC e imagem primária/RPC em diferentes tempos de injeção do spray na condição de 100 bar e $0,066 \mathrm{~kg} / \mathrm{s}$ considerando $I W_{f}=36 p x$.
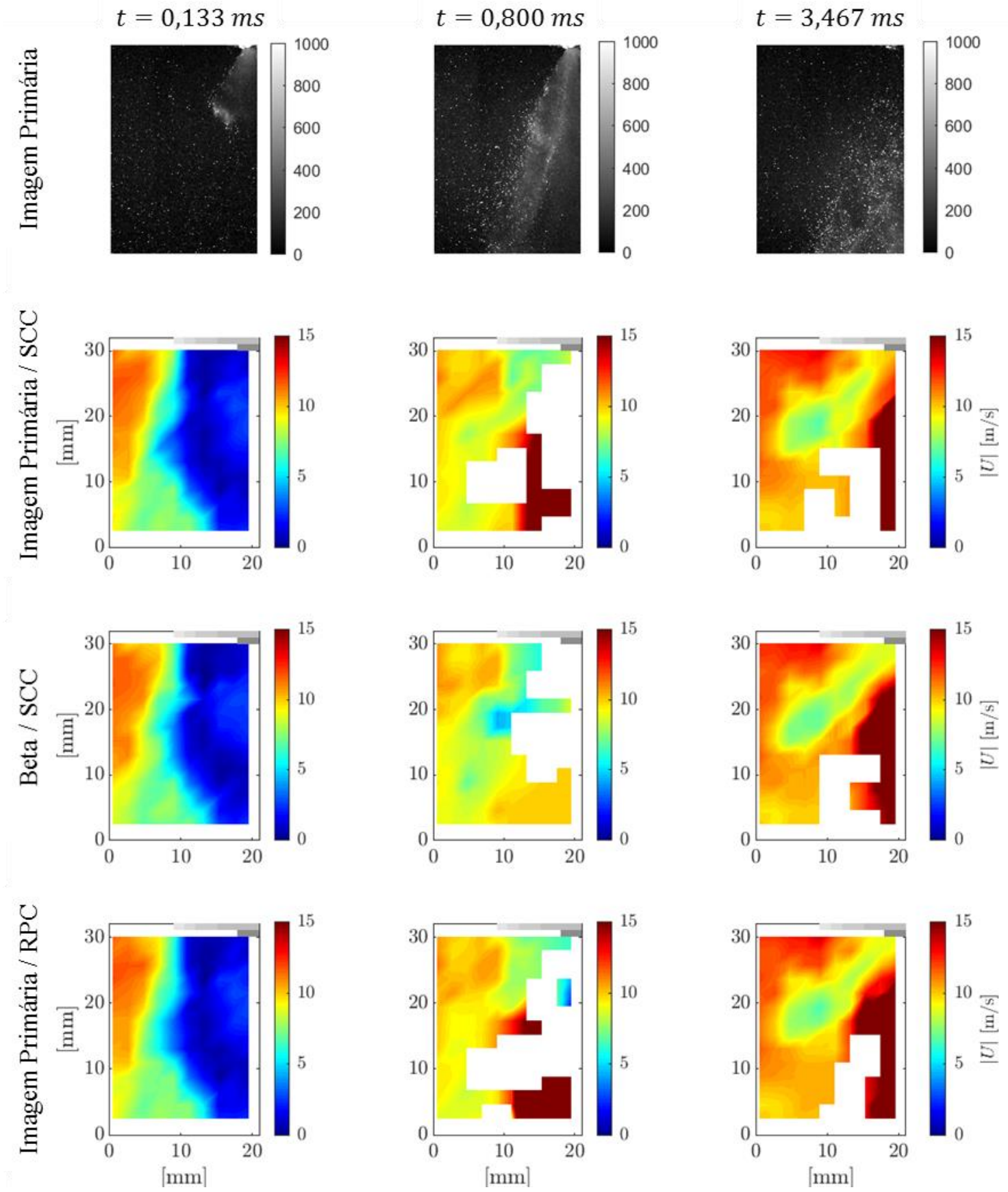

Fonte: Autor.
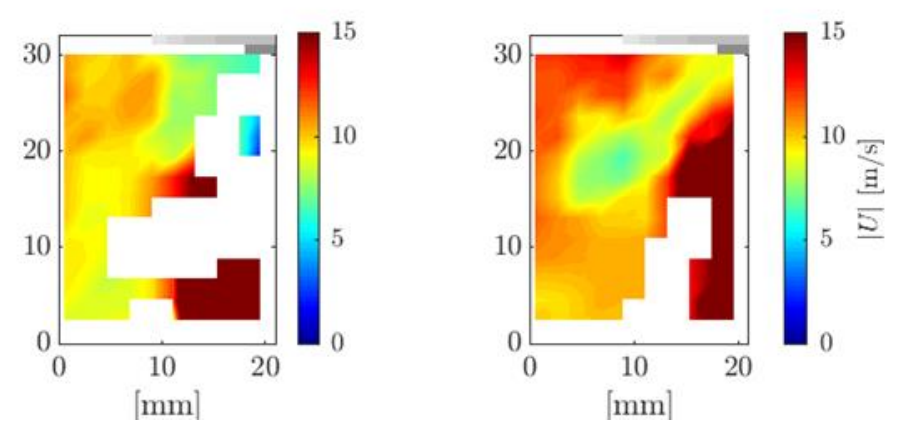
Adicionalmente, a Figura 4.4 mostra ainda os locais onde os resultados das distribuições de $|U|$ foram excluídos devido à falta de coerência espacial apresentada pelo campo vetorial, os quais são representados pelas regiões brancas. De acordo com um estudo paramétrico realizado à parte, percebeu-se que os resultados eram mais coerentes e com baixa influência de ruídos em regiões com $S N R \geq 1,3$. Deste modo, estabeleceuse a exclusão de todos os resultados obtidos em regiões que contavam com $S N R<1,3$ como um critério inicial de pós-processamento PIV.

Ao analisar a Figura 4.4 em $t=0,133 \mathrm{~ms}$, observa-se que não foram percebidas diferenças significativas nas regiões do campo em que as gotículas que formaram o spray se tornaram presentes no plano investigado. No entanto, nas regiões onde o spray contou com alta concentração de gotas de etanol, nota-se que a qualidade do sinal presente no campo de correlação diminuiu a ponto de produzir campos vetoriais com $S N R$ inferior a 2,0, valor mínimo sugerido por Xue et al. (2014) como critério de qualidade de medidas $P I V$, conforme mostra a Figura 4.5. Esse comportamento foi mais evidente no instantes em que o spray esteve plenamente desenvolvido $(t=0,800 \mathrm{~ms})$, ocupando quase metade de todo o espaço de imagem, e durante o seu decaimento $(t=3,467 \mathrm{~ms})$. Com base na discussão proposta na seção 2.2.2, a perda de sinal na região do spray pode estar associada à presença de gotas de combustível dentro das janelas de interrogação, de modo tal que o etanol seja confundido com o traçador da fase gasosa. Vale destacar que, a menos das regiões ainda tidas como ruidosas, os valores de SNR mostrados pela Figura 4.5 são maiores com a combinação Imagem Primária/RPC e Pré-processamento Beta/SCC.

Contudo, considerando os resultados mostrados pela Figura 4.4 e pela Figura 4.5, fica evidenciado que os campos resultantes são similares para as diferentes configurações de processamento PIV testadas, o que permite concluir que a ausência de traçadores é o principal fator determinante do ruído presente nos campos analisados. Além disso, fica evidenciado que a similaridade entre os resultados mostrados na Figura 4.4 implica na necessidade de utilizar outros caminhos para determinar, de fato, a estratégia de processamento e correlação que permite melhor descrever as estruturas do escoamento ar-spray. Para tanto, o aumento da resolução espacial por meio do incremento da sobreposição de janelas de interrogação foi adotado como uma nova estratégia. Logo, cabe à próxima etapa a otimização do método $P I V$ propriamente dita, uma vez que a melhor combinação entre a estratégia de pré-processamento, o janelamento e a abordagem de correlação deve ser encontrada. 
Figura 4.5 - Comparação do $S N R$ estimado instantaneamente para os casos imagem primária/SCC, imagem com o pré-processamento Beta/SCC e imagem primária/RPC em diferentes tempos de injeção do spray na condição de 100 bar e $0,066 \quad \mathrm{~kg} / \mathrm{s}$ considerando $I W_{f}=36 p x$.
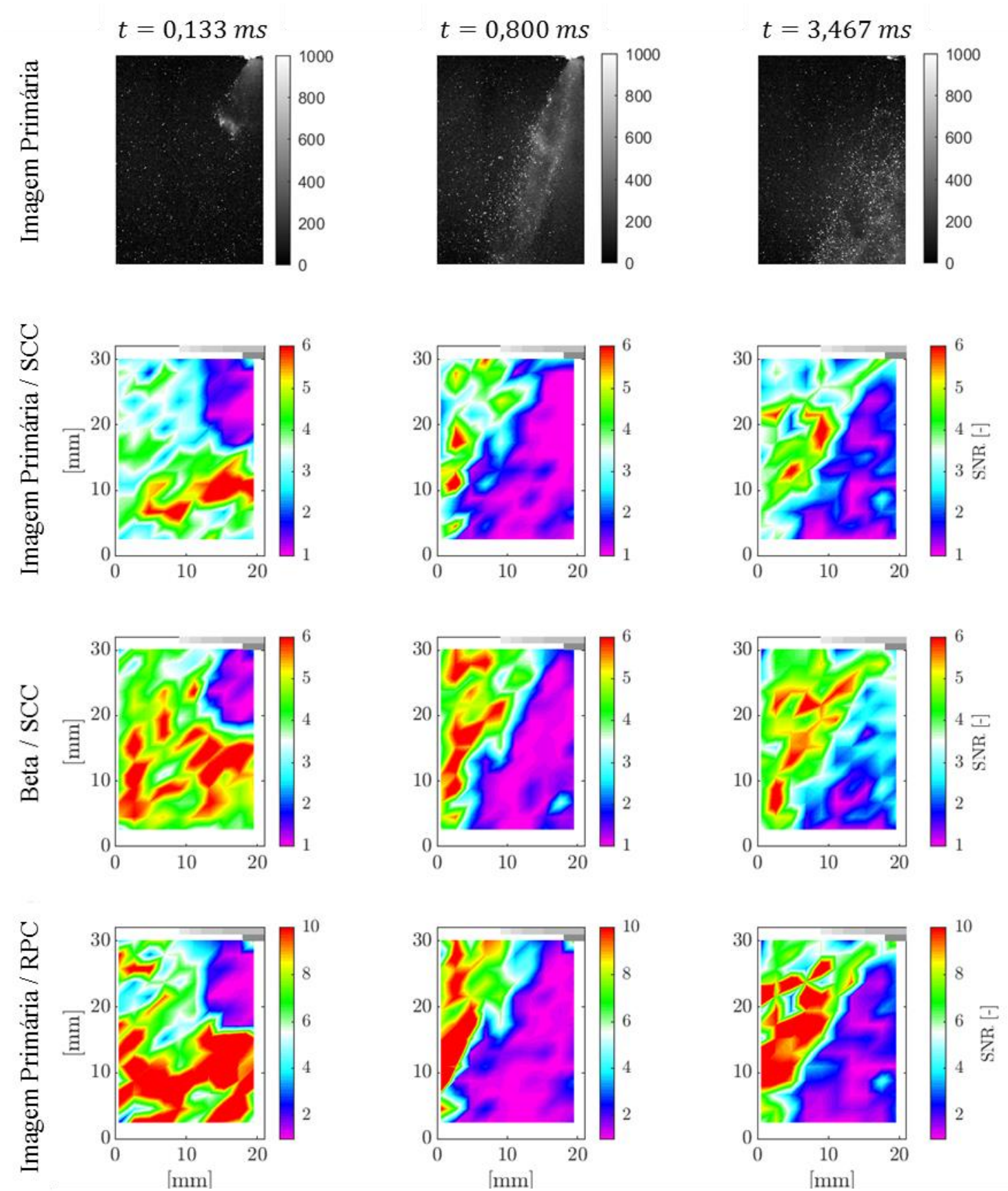

Fonte: Autor. 


\subsection{ANÁlise DAS MEDIDAS COM PSEUdO-ALTA RESOLUÇÃo ESPACIAL}

Devido à necessidade de encontrar o melhor meio capaz de descrever com qualidade a interação ar-spray, os resultados oriundos da combinação Pré-processamento Beta/SCC aplicada às imagens com e sem o spray foram comparados aos resultados provenientes da correlação das imagens primárias com $S C C$ e $R P C$ por meio da proposição de uma segunda estratégia de janelamento. Tal estratégia tem o intuito de obter medidas com maior resolução espacial sem diminuir a qualidade e a representatividade das medidas $P I V$. Para atingir estes objetivos, o tamanho da janela de interrogação inicial foi mantido constante e a abordagem multigrid foi utilizada com aumento progressivo da sobreposição de janela. Graças à esta estrutura, o resultado de cada passo tem resolução dependente da porcentagem de sobreposição imposta aos respectivos grids anteriores, o que justifica o fato da presente seção considerar a análise das medidas PIV com pseudo-alta resolução espacial. Vale destacar que esta estratégia de janelamento visa analisar as medidas $P I V$ com janelas de interrogação finais por vezes menores do que às consideradas na seção 4.1. No entanto, é importante frisar que o tamanho da janela de interrogação inicial necessário para obter bons resultados pode prejudicar a determinação de elevados gradientes de movimento. A Tabela 4.1 resume as configurações, estruturadas com seis passos, escolhidas para analisar as medidas PIV em questão.

Tabela 4.1 - Nova estratégia de janelamento multigrid baseada na variação da sobreposição em uma janela de interrogação inicial de 48 pixels.

\begin{tabular}{cccc}
\hline Passo & $\boldsymbol{I W}_{\boldsymbol{i}}[\boldsymbol{p x}]$ & Sobreposição [\%] & $\boldsymbol{I W}_{\boldsymbol{f}}[\boldsymbol{p x}]$ \\
\hline $\mathbf{1}$ & 48 & 0 & 48 \\
$\mathbf{2}$ & 48 & 25 & 36 \\
$\mathbf{3}$ & 48 & 50 & 24 \\
$\mathbf{4}$ & 48 & 66 & 16 \\
$\mathbf{5}$ & 48 & 75 & 12 \\
$\mathbf{6}$ & 48 & 80 & 10 \\
\hline
\end{tabular}

Fonte: Autor. 
Com o objetivo de evidenciar os efeitos que o pré-processamento e a nova estratégia de janelamento oferecem à qualidade de representação dos campos vetoriais, a Figura 4.6 apresenta o módulo da velocidade instantânea estimado nas mesmas condições da Figura 4.4, no entanto considerando as configurações apresentadas na Tabela 4.1. Analogamente, a Figura 4.7 mostra as distribuições de $S N R$ dos resultados apresentados na Figura 4.6. A menos do esperado refino das regiões com $S N R$ menor que 1,3 excluídas pelo pós-processamento inicial, as distribuições apresentadas na Figura 4.6 não têm diferenças significativas entre si. Observa-se ainda, a partir das Figuras 4.6 e Figura 4.7, que não houve depreciação dos resultados ao considerar $I W_{f}=10$ pixels, fato que motiva a permanência dessa configuração nas medidas subsequentes na expectativa de obter a melhor descrição das estruturas do escoamento ar-spray.

Ao avaliar a Figura 4.7, verifica-se também que as distribuições da relação sinalruído obtidas com a abordagem SCC a partir das imagens primárias e processadas pelo Pré-processamento Beta não tiveram diferenças expressivas entre si, embora os resultados oriundos das imagens com tratamento se sobressaíram em relação às imagens primárias. Além disso, vale destacar que o $S N R$ obtido com o uso da abordagem $R P C$ se mostrou superior em todo o plano de correlação, com mudanças positivas sutis à medida em que a resolução espacial final era aumentada. Contudo, verifica-se com a Figura 4.7 que a qualidade do sinal processado com os seis passos de correlação tem fraca dependência da porcentagem de sobreposição, uma vez que a diminuição do grid não interferiu significativamente na qualidade do sinal das medidas em cada combinação testada. 
Figura 4.6 - Comparação do módulo de velocidade instantâneo em $t=0,800 \mathrm{~ms}$ entre as combinações imagem primária/SCC, imagem com o Pré-processamento Beta/SCC e imagem primária/RPC para $I W_{f}$ iguais a 24 px, 16 px, 12 px e 10 px.
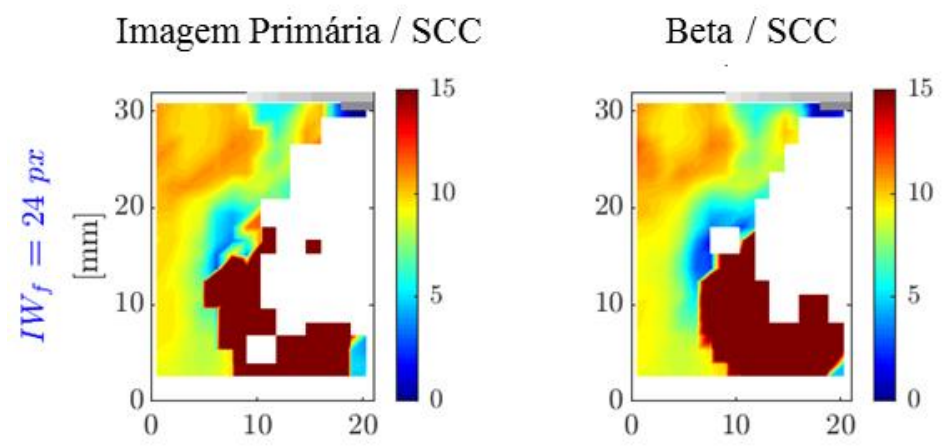

Imagem Primária / RPC
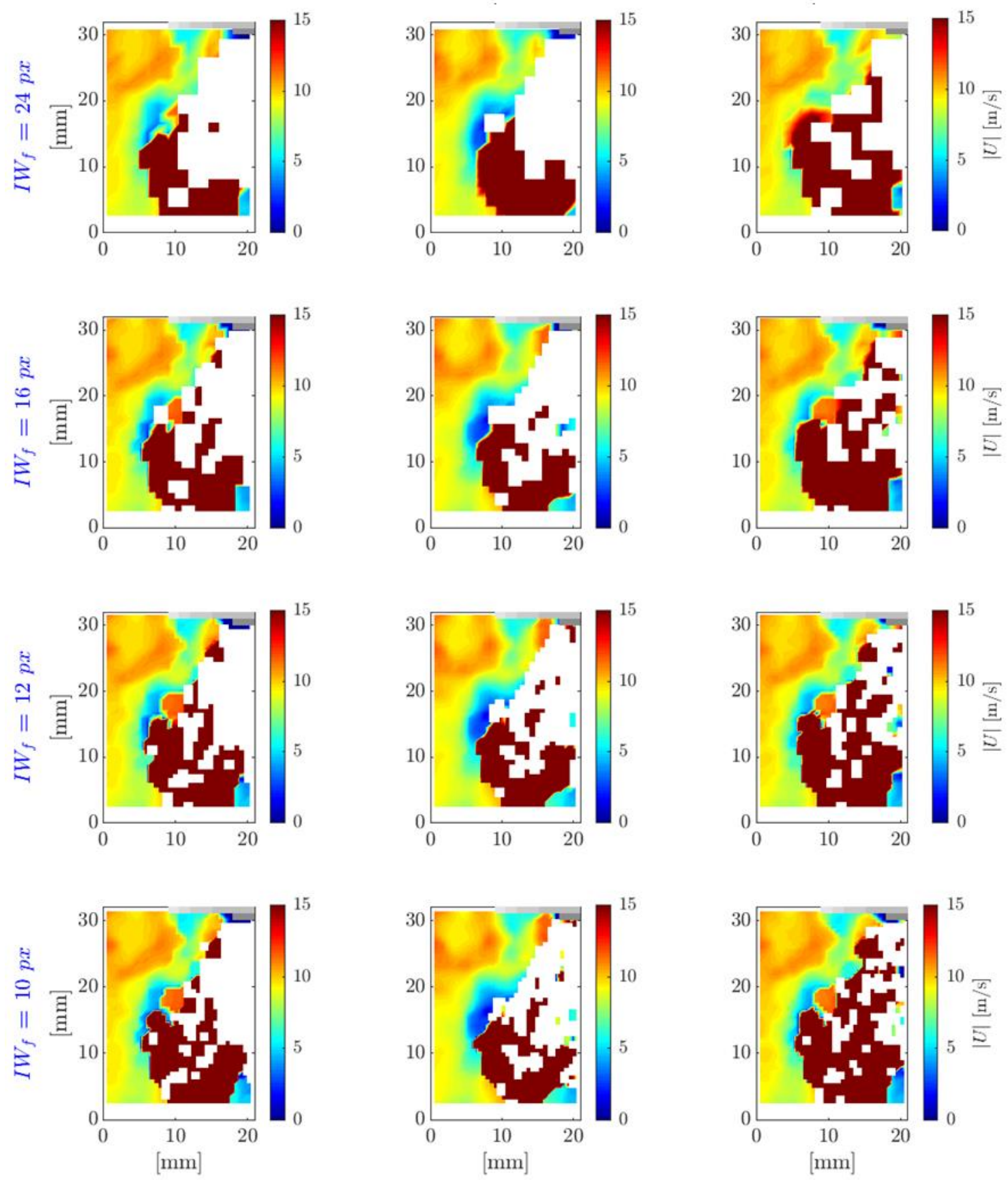

Fonte: Autor.

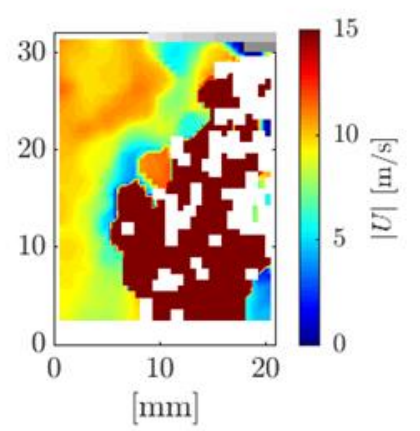


Figura 4.7 - Comparação do módulo de velocidade instantâneo em $t=0,800 \mathrm{~ms}$ entre as combinações imagem primária/SCC, imagem com o Pré-processamento Beta/SCC e imagem primária/RPC para $I W_{f}$ iguais a $24 p x, 16 p x, 12 p x$ e $10 p x$.
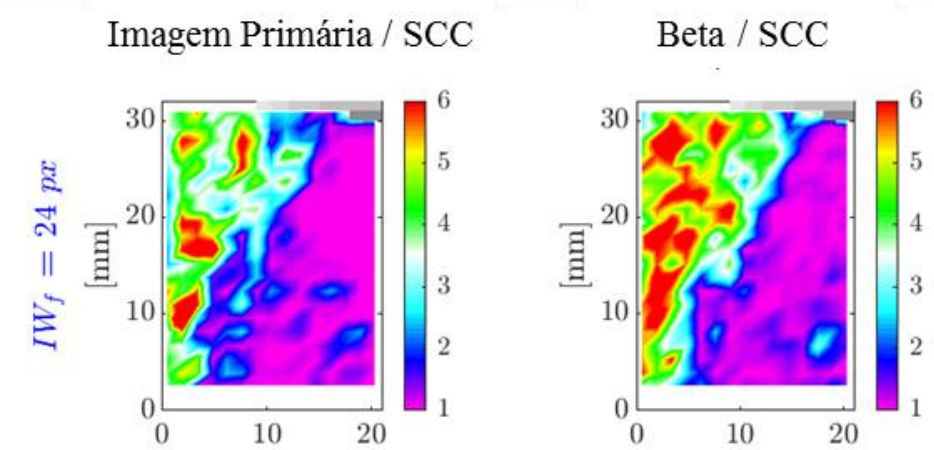

$$
\text { Imagem Primária / RPC }
$$
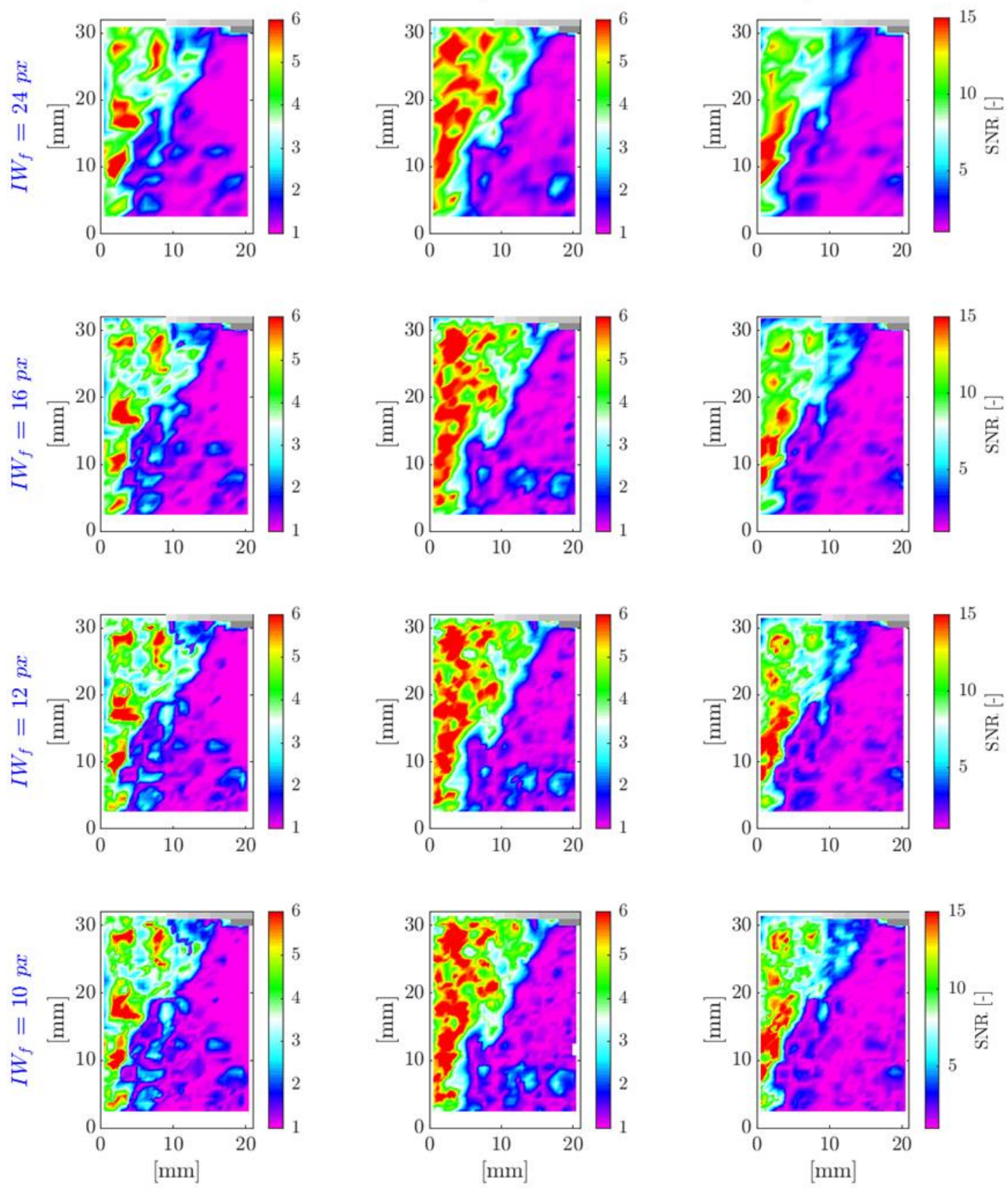

Fonte: Autor.

A Figura 4.8 e a Figura 4.9 comparam, nessa ordem, as distribuições de $|U|$ e de SNR resultantes do último passo de diminuição do tamanho das janelas de interrogação $\left(I W_{f}=10\right.$ pixels $)$ para os mesmos instantes considerados na Figura 4.4. Ao analisar a Figura 4.8, verifica-se que poucas diferenças foram percebidas nas distribuições obtidas 
para os três casos. Tais diferenças se pronunciaram na região de interação bifásica arspray, principalmente na condição $t=0,800 \mathrm{~ms}$. Adicionalmente, nota-se com a Figura 4.9 que a metodologia Pré-processamento Beta/SCC produziu resultados menos ruidosos frente ao obtido com a correlação das imagens primárias com $S C C$, ao passo que metodologia que utiliza a abordagem $R P C$ gerou campos vetoriais menos ruidosos na região de interface entre as fases.

Contudo, é importante destacar que, embora obtidas com o critério sugerido pelo pós-processamento inicial (velocidades excluídas em janelas onde $S N R<1,3$ ), as distribuições vistas na Figura 4.8 ainda apresentaram regiões que podem comprometer a fidelidade das medidas $P I V$. Tais partes referem-se às regiões que contam com a presença do spray e aquelas que são representadas por pequenos bolsões azuis, embora ainda não seja possível afirmar se as últimas são compostas por falsos vetores. Com o propósito de eliminar os vetores velocidade presentes nesses locais, além de toda e qualquer influência negativa remanescente do spray em todo o campo de deslocamento, verificou-se parametricamente que $S N R=2,5\left(S N R_{\text {limite }}\right)$ promete a melhor combinação possível entre os fatores ora mencionados, cujo resultado é mostrado na Figura 4.10. A partir dela, observou-se que, quando imposto o critério de supressão de vetores nas regiões onde $S N R<S N R_{\text {limite }}$, grande parte dos vetores incoerentes eram excluídos. Além disso, notou-se que houve a exclusão de medidas coerentes na fase representada pelos traçadores do ar obtida com a correlação das imagens primárias com SCC, fato que evidenciou a necessidade de desenvolver um método que possibilite preservar as regiões com medidas confiáveis quando da exclusão dos vetores com baixa representatividade. Vale ressaltar que valores maiores do que 2,5 provocaram a exclusão demasiada de vetores coerentes. 
Figura 4.8 - Comparação do módulo de velocidade instantâneo para imagem primária/SCC, imagem com o Pré-processamento Beta/SCC e imagem primária/RPC em diferentes tempos de injeção do spray na condição de 100 bar e $0,066 \mathrm{~kg} / \mathrm{s}$ considerando $I W_{f}=10 p x$ (Passo 6).
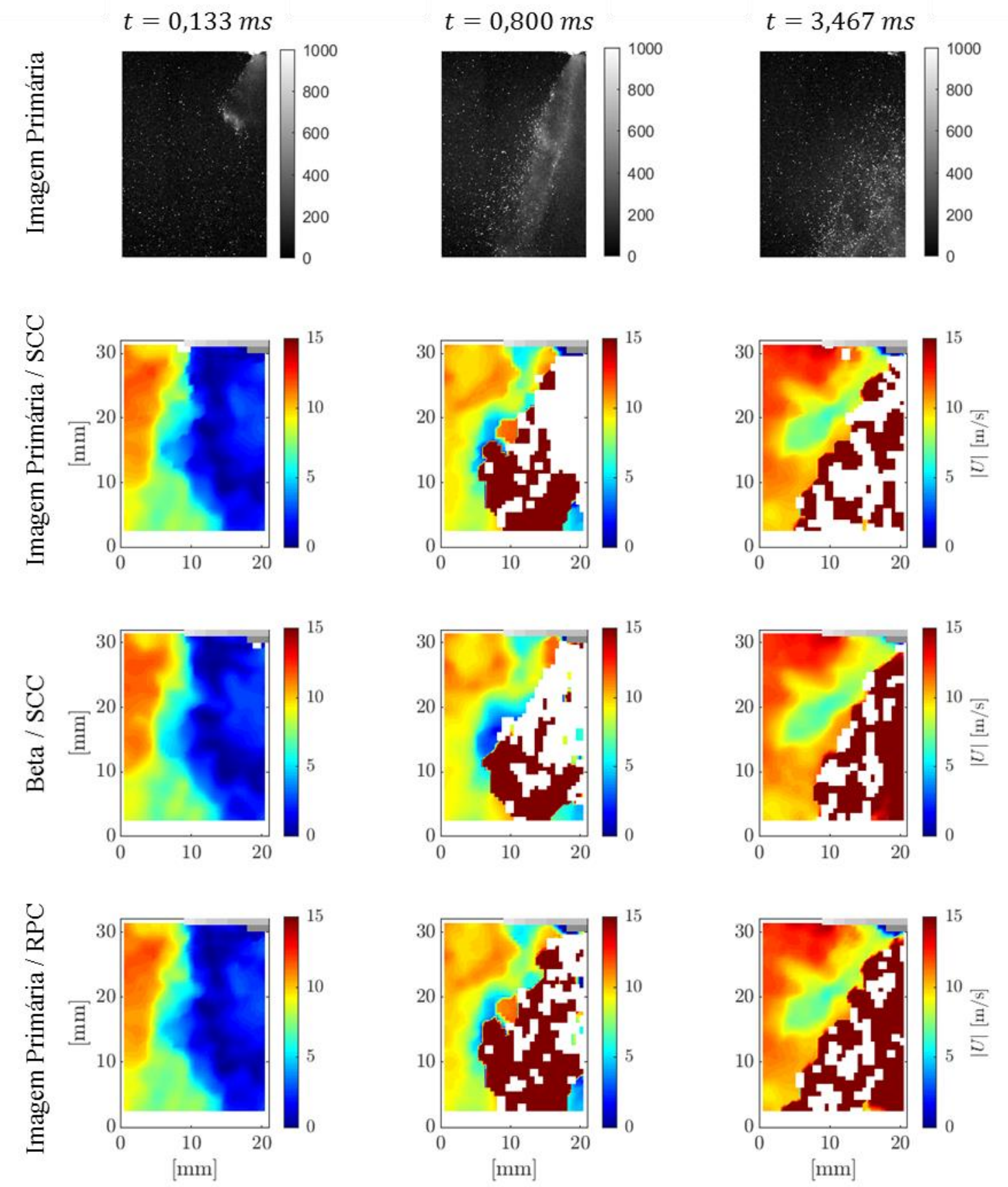

Fonte: Autor. 
Figura 4.9 - Comparação do SNR estimado instantaneamente para os casos imagem primária/SCC, imagem com o Pré-processamento Beta/SCC e imagem primária/RPC em diferentes tempos de injeção do spray na condição de 100 bar e $0,066 \mathrm{~kg} / \mathrm{s}$ considerando $I W_{f}=10 p x$ (Passo 6).
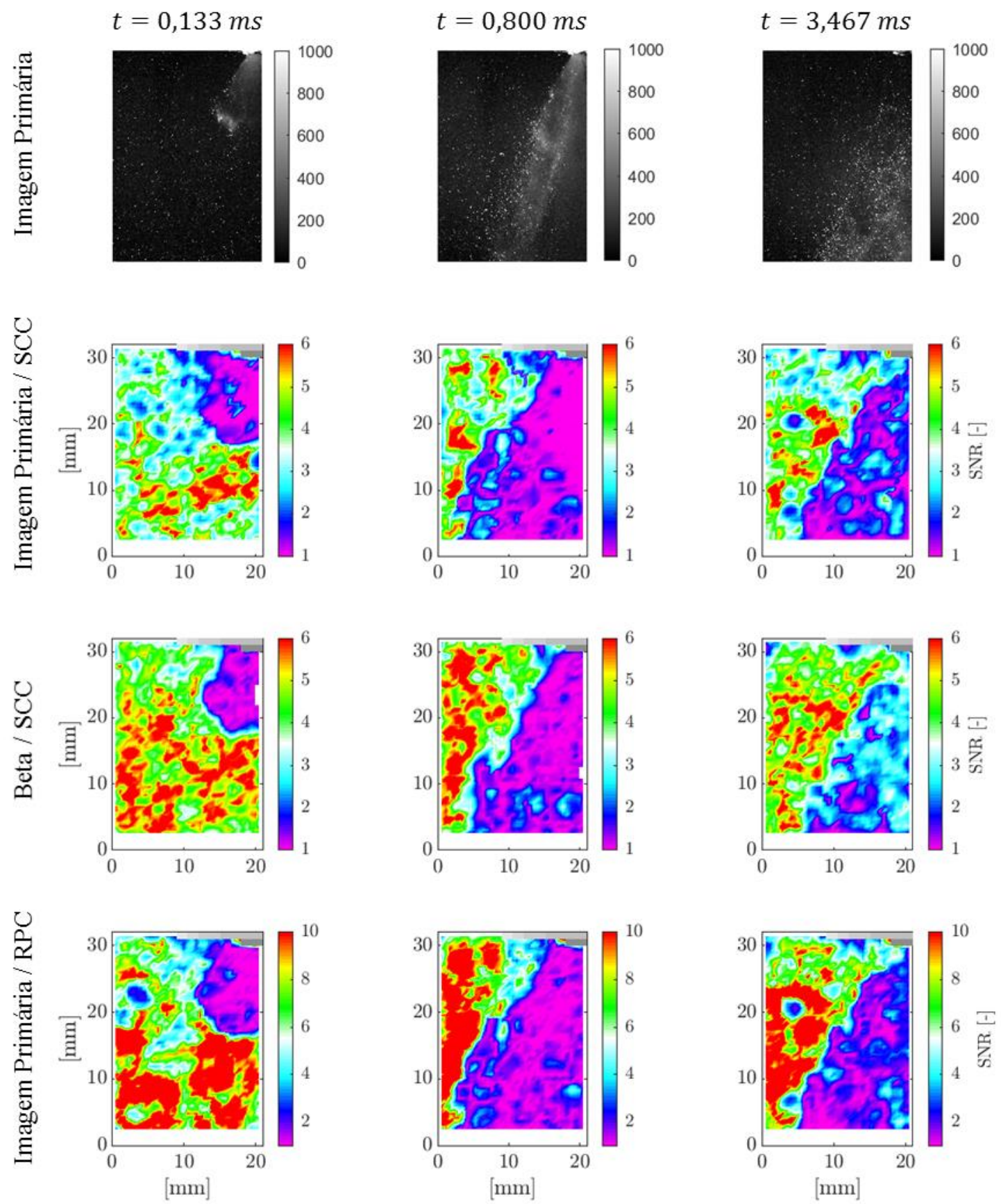

Fonte: Autor. 
Figura 4.10 - Comparação do módulo de velocidade instantâneo para imagem primária/SCC, imagem com o pré-processamento Beta/SCC e imagem primária/RPC em diferentes tempos de injeção do spray na condição de 100 bar e $0,066 \mathrm{~kg} / \mathrm{s}$ considerando $I W_{f}=10 p x$ e $S N R>2,5$.
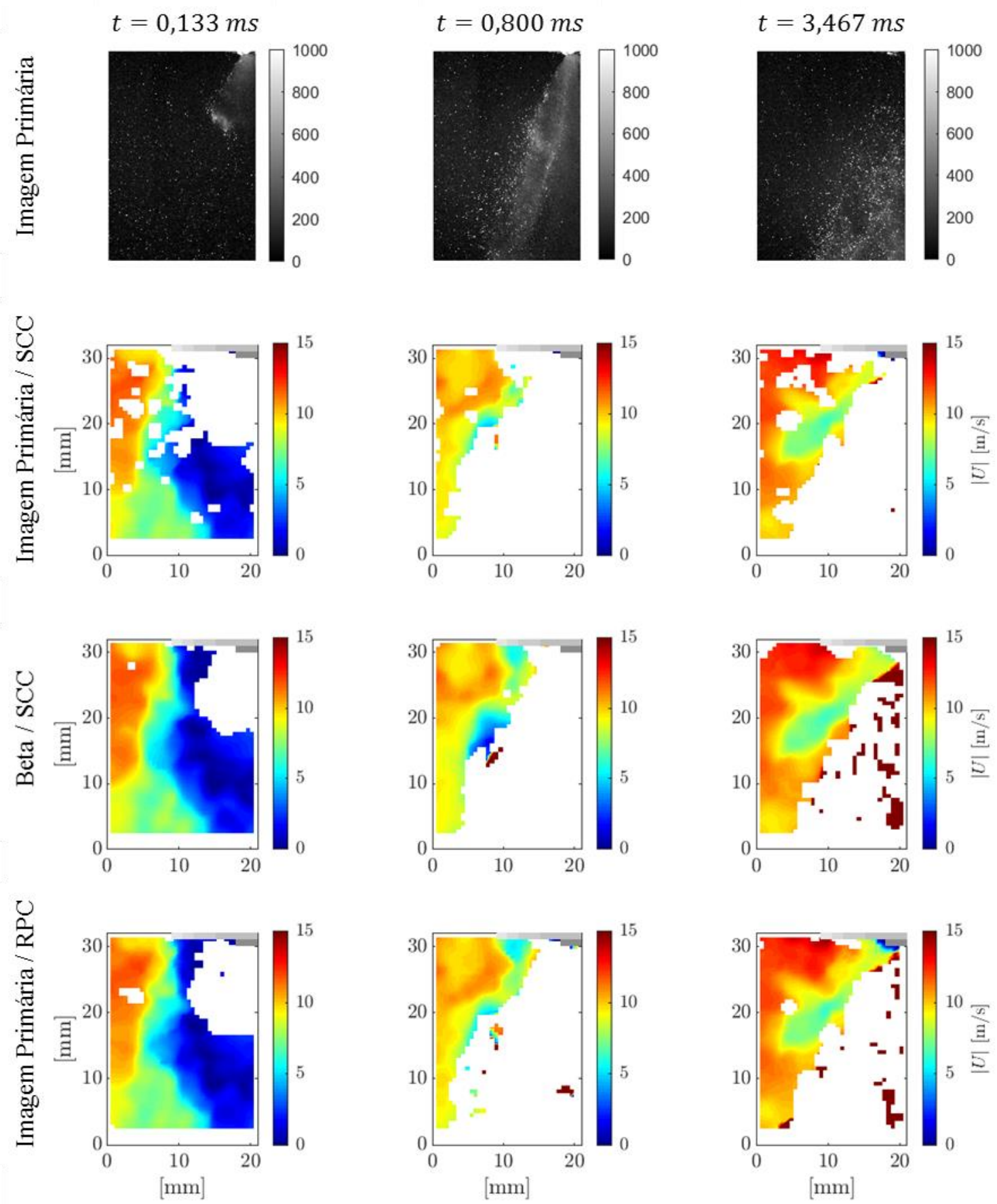

Fonte: Autor.

Devido à exclusão de medidas $P I V$ coerentes quando da aplicação da filtragem por $S N R$ e ao fato de os falsos vetores observados terem velocidades superiores à velocidade máxima válida no escoamento, uma Capa de Velocidade foi utilizada. A Capa de Velocidade propõe um limite superior aceitável de velocidade, $|U|_{\text {limite }}$. Caso o valor 
do módulo da velocidade em uma região do campo de velocidades seja maior que $|U|_{\text {limite }}$ o vetor é excluído. Inicialmente, o $S N R_{\text {limite }}$ é utilizado para separar o campo de velocidades entendido como referência em dois campos independentes: um menos ruidoso $\left(S N R \geq S N R_{\text {limite }}\right)$ e um mais ruidoso $\left(S N R<S N R_{\text {limite }}\right)$. Mediante tal separação, a média espacial de cada campo é calculada independentemente. Nesse caso, $|U|_{\text {limite }}$ é estimado através da média espacial do campo mais ruidoso. Entretanto, essa separação só acontece se a média espacial dos módulos dos vetores velocidade presentes no campo menos ruidoso, $N_{-}$, for inferior à média espacial do campo mais ruidoso, $N_{+}$. Esse procedimento torna automática a aplicação do filtro e a escolha de um $|U|_{\text {limite }}$ para cada instantâneo. $\mathrm{O}$ ajuste fino de $|U|_{\text {limite }}$ é realizado por meio de um parâmetro de sensibilidade, $s$, que é utilizado como um fator de multiplicação de $N_{-}$. Por sua vez, a medida será tratada como incoerente se a magnitude da velocidade superar o produto $s \cdot N_{-}$. Sendo assim, a medida é excluída do campo referência e todas as demais podem ser entendidas como medidas com boa qualidade. Para tanto, o parâmetro de sensibilidade que permite assegurar a máxima e adequada exclusão das medidas incoerentes deve ser determinado por meio de um estudo paramétrico. A Figura 4.11 apresenta uma ilustração do princípio de operação sugerido pela Capa de Velocidade.

Figura 4.11 - Ilustração das operações pertencentes ao algoritmo Capa de Velocidade.

Campo menos Ruidoso

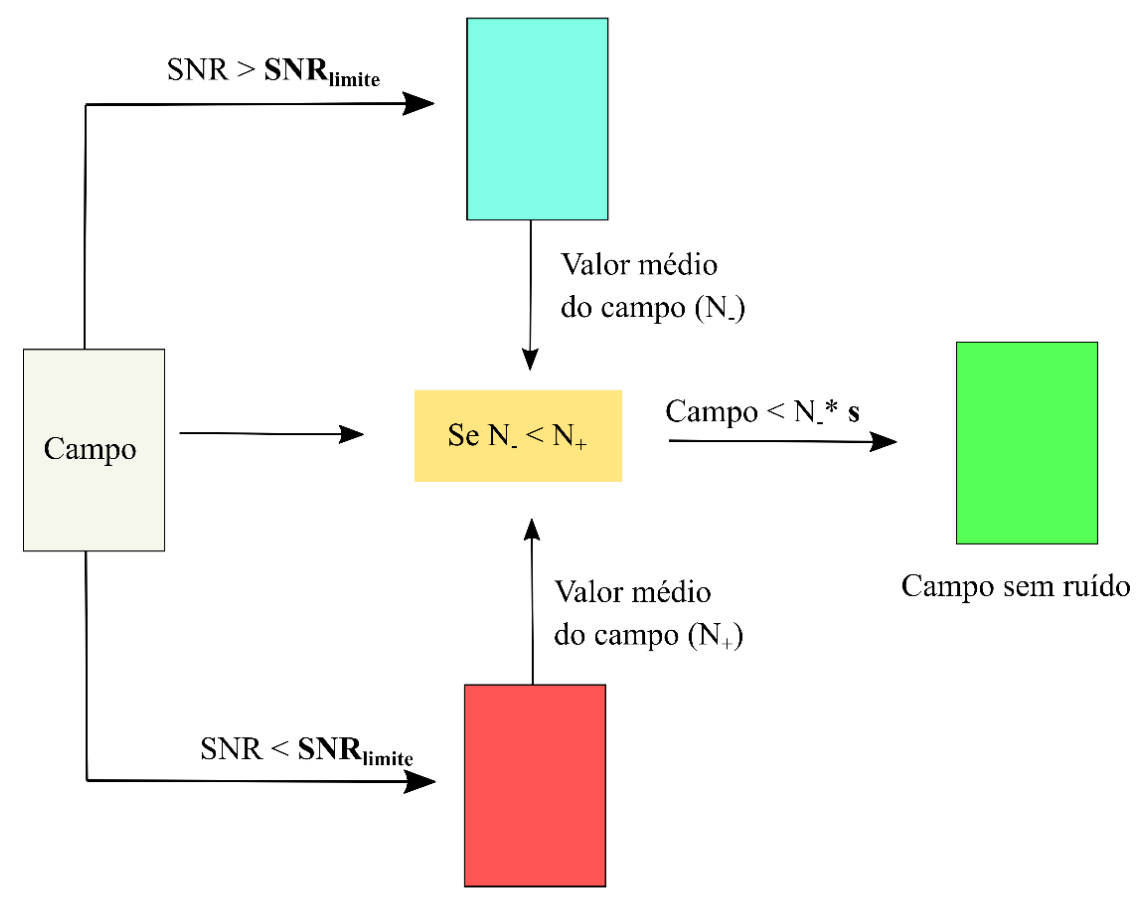

Campo mais Ruidoso

Fonte: Autor. 
A Figura 4.12 apresenta o resultado da aplicação da Capa de Velocidade nos campos apresentados na Figura 4.8, considerando $s=1,5$. Nota-se que os campos resultantes não contêm medidas influenciadas pela contribuição marcante do spray, percebidas na Figura 4.8, e que boa parte dos vetores excluídos na Figura 4.10 foram preservados, principalmente na região de predominância da fase gasosa. Desta forma, verifica-se em todos os instantes analisados que a Capa de Velocidade permitiu a exclusão majoritária dos vetores capazes de produzir medidas PIV de baixa qualidade, sem deteriorar o campo vetorial com a supressão demasiada de vetores representativos.

Figura 4.12 - Comparação do módulo de velocidade instantâneo para imagem com o Préprocessamento Beta/SCC e imagem primária/RPC em diferentes tempos de injeção do spray na condição de 100 bar e $0,066 \mathrm{~kg} / \mathrm{s}$, considerando $I W_{f}=10 p x, S N R_{\text {limite }}=2,5$ e $s=1,5$.

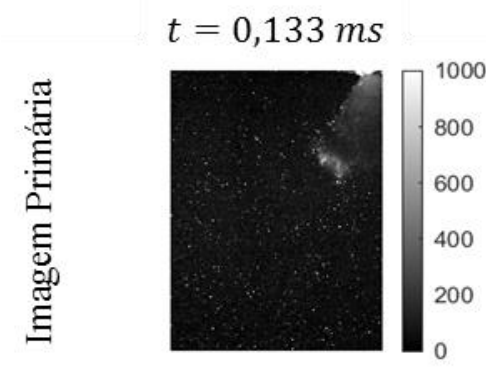

$t=0,800 \mathrm{~ms}$
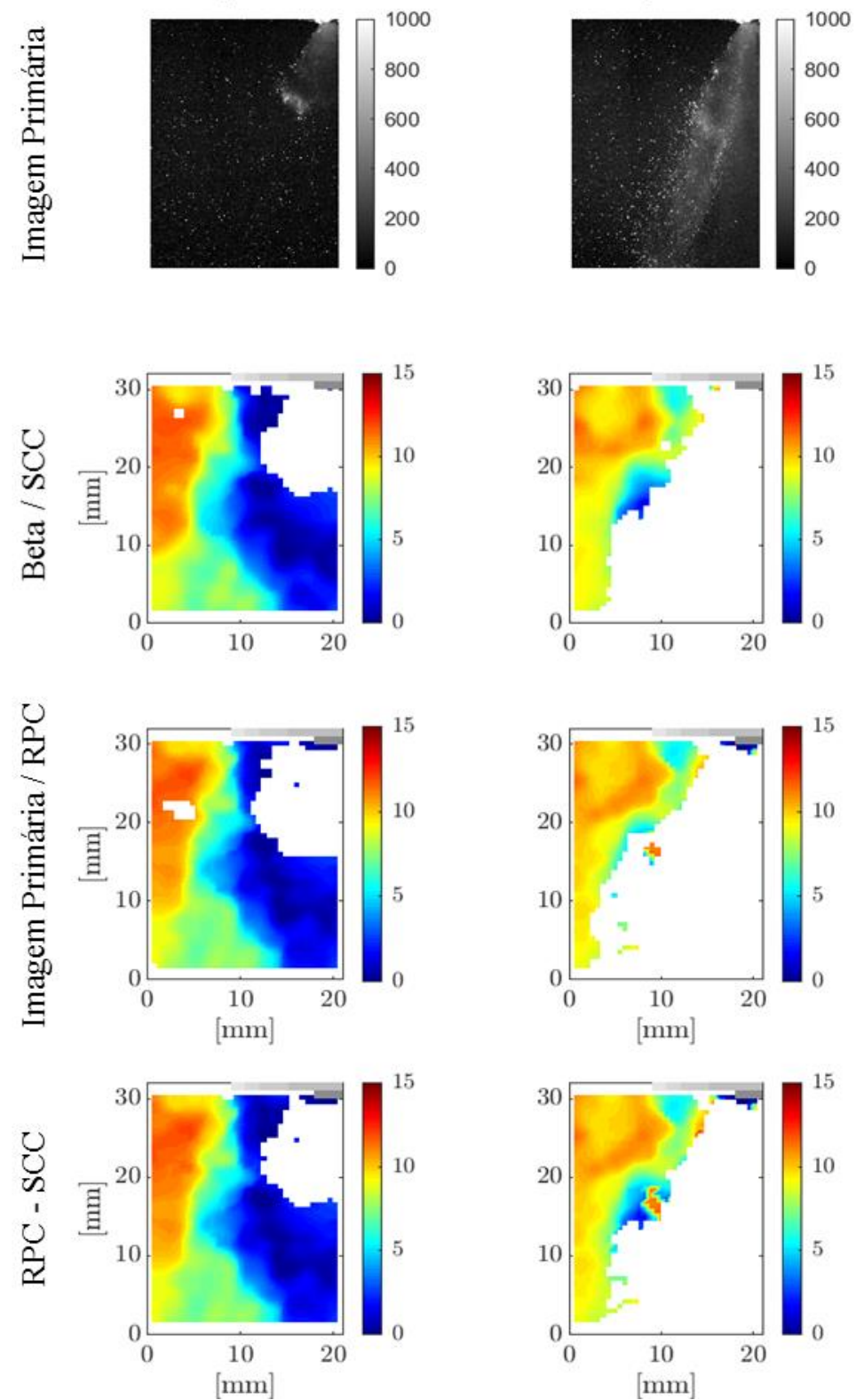

Fonte: Autor.
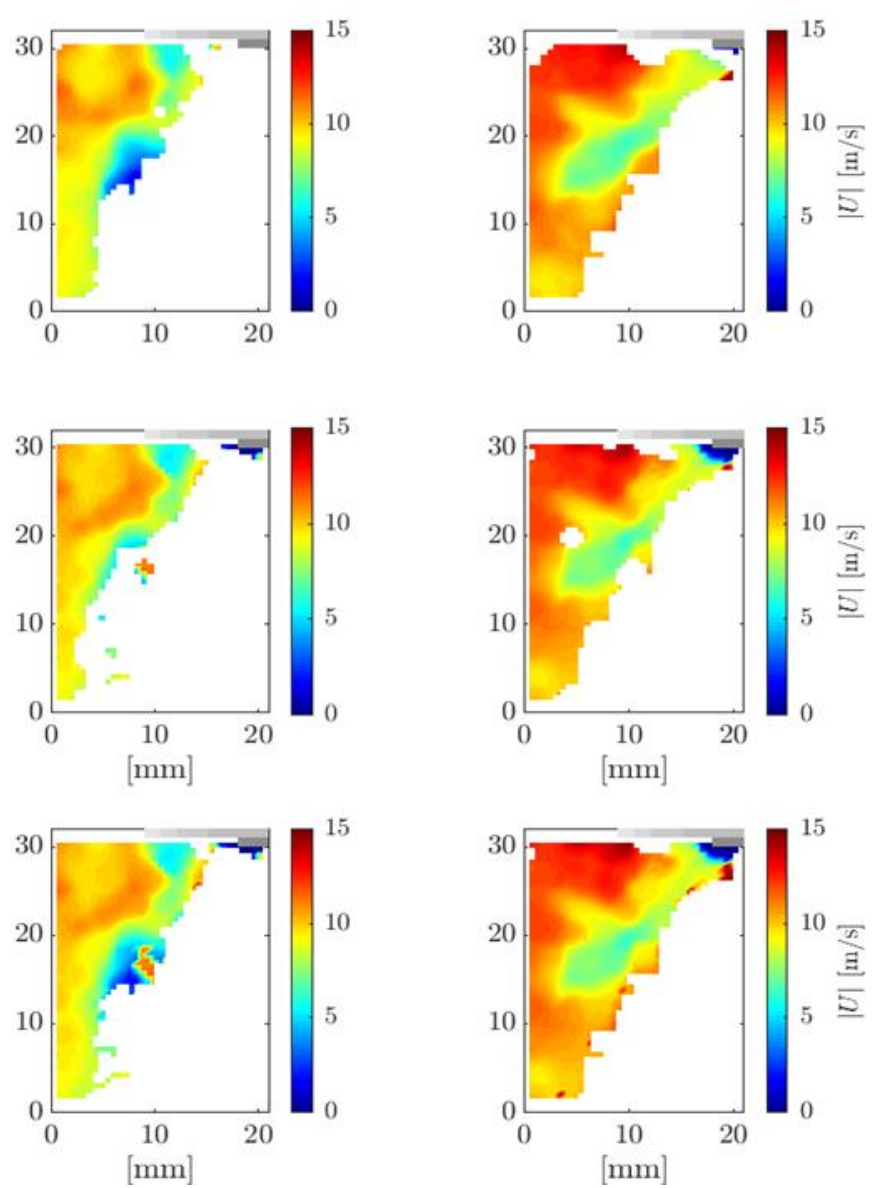
Adicionalmente, a Figura 4.12 apresenta o resultado da sobreposição dos campos vetoriais obtidos com as duas melhores combinações de metodologias de préprocessamento e processamento PIV, identificado como RPC-SCC. Os campos $R P C-S C C$ foram produzidos com a inserção dos vetores do campo Pré-processamento Beta/SCC nas regiões onde os vetores do campo processado com $R P C$ foram excluídos. Vale destacar que essa operação de substituição aconteceu somente para os casos em que os vetores do campo Pré-processamento Beta/SCC não tinham sido excluídos com a aplicação da Capa de Velocidade.

Contudo, a menos da falha na região definida pelos pontos $(5,15),(11,15),(5,20)$ e $(11,20)$, em $t=0,800 \mathrm{~ms}$, os campos $R P C$-SCC são os resultados principais do método de otimização $P I V$ proposto no presente trabalho, uma vez que consideram a melhor combinação entre os dois campos mais promissores aqui identificados, obtidos a partir da aplicação conjunta de técnicas baseadas em boas práticas de pós-aquisição de imagens $P I V$. Com o intuito de garantir ainda mais qualidade a todas as medidas calculadas a partir dos campos vetoriais $R P C$-SCC, o método de remoção de outliers utilizado em todos os campos processados no presente trabalho, descrito na seção 3.2.3, foi aplicado.

\subsection{ANÁLISE DA INTERAÇÃO BIFÁSICA AR-SPRAY}

A presente seção oferece uma análise do escoamento bifásico ar-spray em estudo e sugere uma discussão que objetiva comparar, sob a ótica da fenomenologia, os resultados obtidos a partir das duas condições experimentais previamente elencadas na Tabela 3.1: os Casos 1 e 2. Tais condições referem-se às configurações experimentais escolhidas para observar a relação existente entre a fluidodinâmica do escoamento gasoso e as propriedades do spray por meio dos efeitos associados à pressão de injeção de combustível no ambiente circundante, quiescente. Para tanto, durante os experimentos, a vazão mássica de ar circundante foi mantida constante em $0,066 \mathrm{~kg} / \mathrm{s}$ e duas pressões de injeção foram testadas: 100 bar (Caso 1) e 60 bar (Caso 2). Vale ressaltar que não há, por ora, a possibilidade de comparar efeitos atrelados à turbulência do escoamento, uma vez que os dados fornecidos para a execução do presente trabalho foram obtidos com o mesmo par de placas de orifícios (vide Figura 3.2). Para mais informações, sugere-se a leitura do trabalho de Berti (2018), o qual contempla uma ampla análise comparativa que 
envolve, dentre outros aspectos, a relação existente entre a intensidade de turbulência da fase gasosa e a interação entre as fases do escoamento ar-spray.

Todos os resultados aqui apresentados foram obtidos com base na evolução temporal dos campos médios de fase produzidos a partir dos 34 eventos sincronizados de injeção de etanol, com duração de 3,000 ms cada, processados individualmente segundo a metodologia $R P C$-SCC. É importante destacar que o uso da média de fase dos campos instantêneos como referência para a análise temporal do escoamento ar-spray permite eliminar possíveis perturbações locais capazes de denegrir o sinal, tornando a discussão física do escoamento mais consistente. Os campos de velocidade obtidos para os casos 1 e 2 foram otimizados utilizando $S N R_{\text {limite }}=2,5$ e $s=1,5$, seguindo os mesmos passos adotados para a obtenção da Figura 4.12. As regiões sem preenchimento foram suprimidas para evitar conclusões errôneas, conforme proposto na seção 4.2. Em todas as figuras mostradas na presente seção, a representação simbólica da ponta do injetor foi suprimida para que houvesse o melhor ajuste de escala entre as imagens primárias e as distribuições relacionadas aos respectivos instantes representados por cada frame. No entanto, vale salientar que a ponta do injetor está localizada no canto superior direito de todas as imagens primárias apresentadas.

A Figura 4.13 compara as evoluções temporais dos módulos dos vetores velocidades que compõem o escoamento de ar circundante nos instantes iniciais de injeção de etanol, enquanto a Figura 4.14 e a Figura 4.15 apresentam o comportamento das respectivas componentes dos vetores que descrevem o escoamento da fase gasosa nos mesmos instantes. Além disso, a Figura 4.16 mostra a evolução temporal do campo de vorticidade do escoamento considerando o mesmo período. Na presente seção, entendese por componente vertical o resultado da decomposição do vetor velocidade em relação à reta vertical que contém o bocal de saída do injetor (portanto, estabelece-se o eixo vertical); e por componente horizontal o resultado da decomposição do vetor velocidade em relação a sistema ortogonal ao vertical (analogamente, define-se o eixo horizontal). Os eixos vertical e horizontal estão orientados para baixo e para a direita, respectivamente.

A análise conjunta das Figuras 4.13 - 4.16, especificamente no instante - 0,267 ms (0,267 ms antes do início da injeção), revelou que o ambiente onde o spray foi injetado não era descrito por meio de uma distribuição uniforme de velocidade. Notou- 
se ainda que a distribuição de velocidade do gás era composta por duas regiões claramente distintas. A primeira, predominantemente delimitada por $X>11[\mathrm{~mm}]$, continha o gás descrevendo uma trajetória formada por estruturas recirculantes e composta por vetores velocidade de baixa magnitude. Já a segunda, definida em $X \leq 11[\mathrm{~mm}]$, descrevia um escoamento irrotacional, com vetores velocidade predominantemente orientados da direção vertical, com sentido para baixo e com módulos crescentes horizontalmente, considerando a origem contida no eixo de simetria teórico do spray (borda direita das imagens primárias). Vale ressaltar que a distribuição de velocidade assumiu tal configuração devido a estrutura do injetor permitir que regiões de baixa pressão sejam formadas logo abaixo dele, o que inclui a formação dos vórtices presentes na região delimitada por $8<X<10[\mathrm{~mm}]$ e $Y>20[\mathrm{~mm}]$.

No início da injeção do etanol, marcado nas Figuras 4.13 - 4.16 pelos instantes $0 \mathrm{~ms}$ e $0,133 \mathrm{~ms}$, o spray penetrou na primeira região citada no parágrafo anterior e interagiu com uma pequena quantidade de gás circundante. Mediante a análise das figuras, não foram percebidas alterações significativas na estrutura do escoamento gasoso quando da penetração do spray no ambiente quiescente. As pequenas mudanças localizadas próximo à ponta do spray (em $Y>20[\mathrm{~mm}]$ e $X>10[\mathrm{~mm}]$ ) não têm coerência espacial e temporal, o que leva ao entendimento de que tais estruturas devem ser tomadas como ruídos não tratados originados pela correlação entre gotas de combustível e traçadores. Já ao analisar a parte superior do campo de velocidades, especificamente em $Y>25[\mathrm{~mm}]$ no instante $0,133 \mathrm{~ms}$, observa-se um aumento do módulo da componente horizontal dos vetores velocidade, $u$, nas imediações da ponta do injetor. De acordo com a Figura 4.14, verificou-se que o aumento observado ocorreu de forma mais intensa no caso de maior pressão de injeção. Entretanto, o aumento de $u$ não trouxe consequências perceptíveis no módulo dos vetores velocidade, $|U|$, dado que no instante em questão a componente vertical domina a magnitude de $U$. De forma antitética, não foram observadas variações significativas na vorticidade do escoamento gasoso, tampouco na intensidade das componentes verticais de $U$ (a menos das regiões ruidosas representadas por $v>10\left[\frac{m}{s}\right]$ na distribuição referente ao Caso 2). 
Figura 4.13 - Comparação entre as evoluções temporais do módulo da velocidade do escoamento bifásico ar-spray em instantes associados ao início da injeção de etanol na IESC, considerando o efeito dominante da pressão de injeção.

CASO 1 - 100 bar | 0,066 kg/s
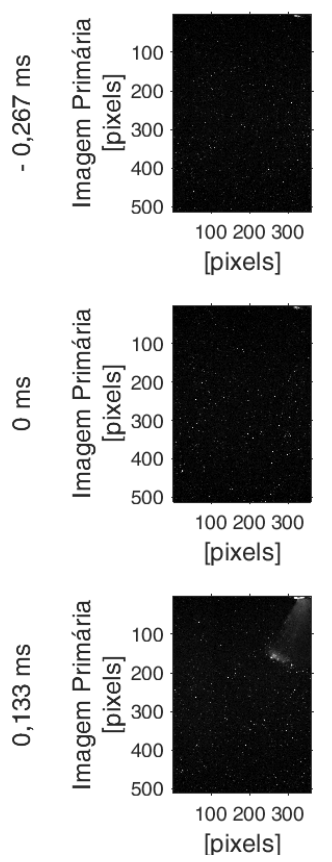
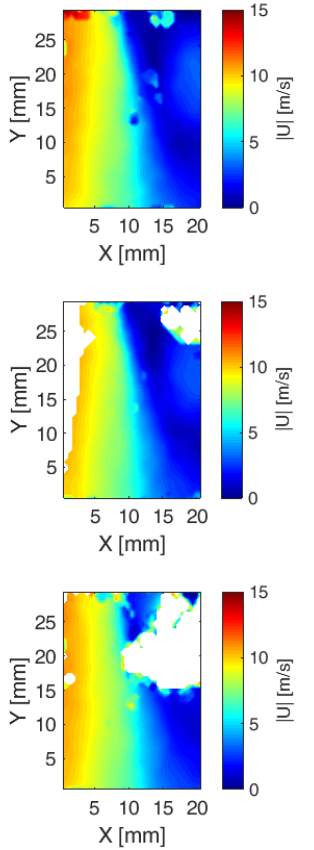

CASO 2 - 60 bar | 0,066 kg/s
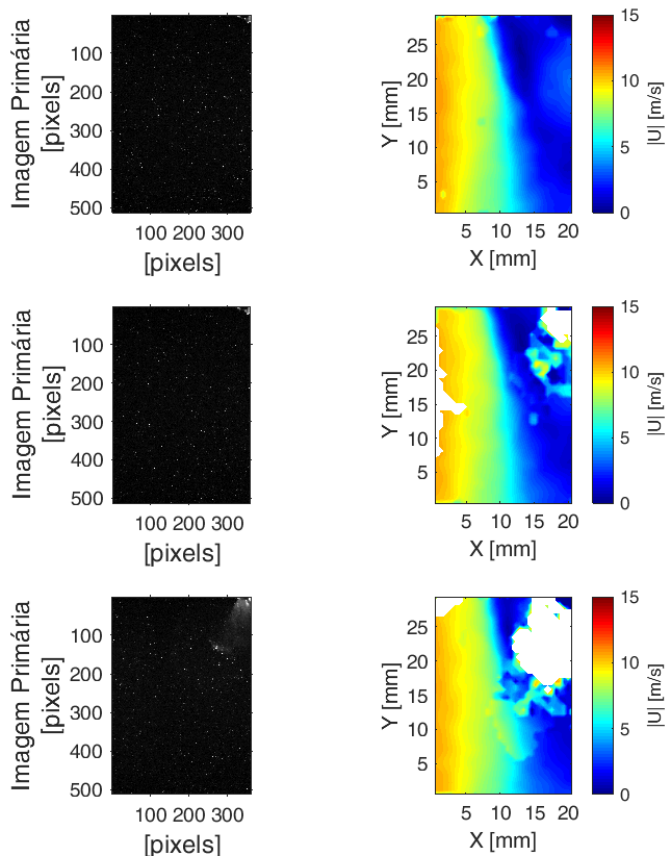

Fonte: Autor.

Figura 4.14 - Comparação entre as evoluções temporais da componente horizontal dos vetores velocidade do escoamento bifásico ar-spray registrados em instantes associados ao início da injeção de etanol na IESC, considerando o efeito dominante da pressão de injeção.
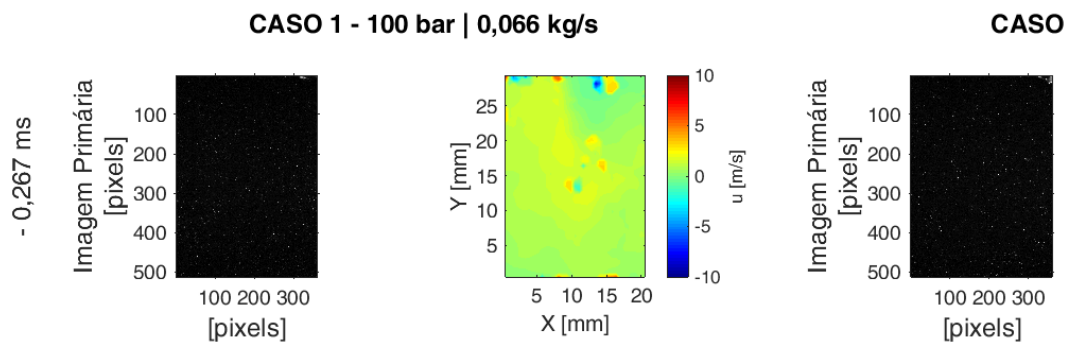

CASO 2 - 60 bar | 0,066 kg/s
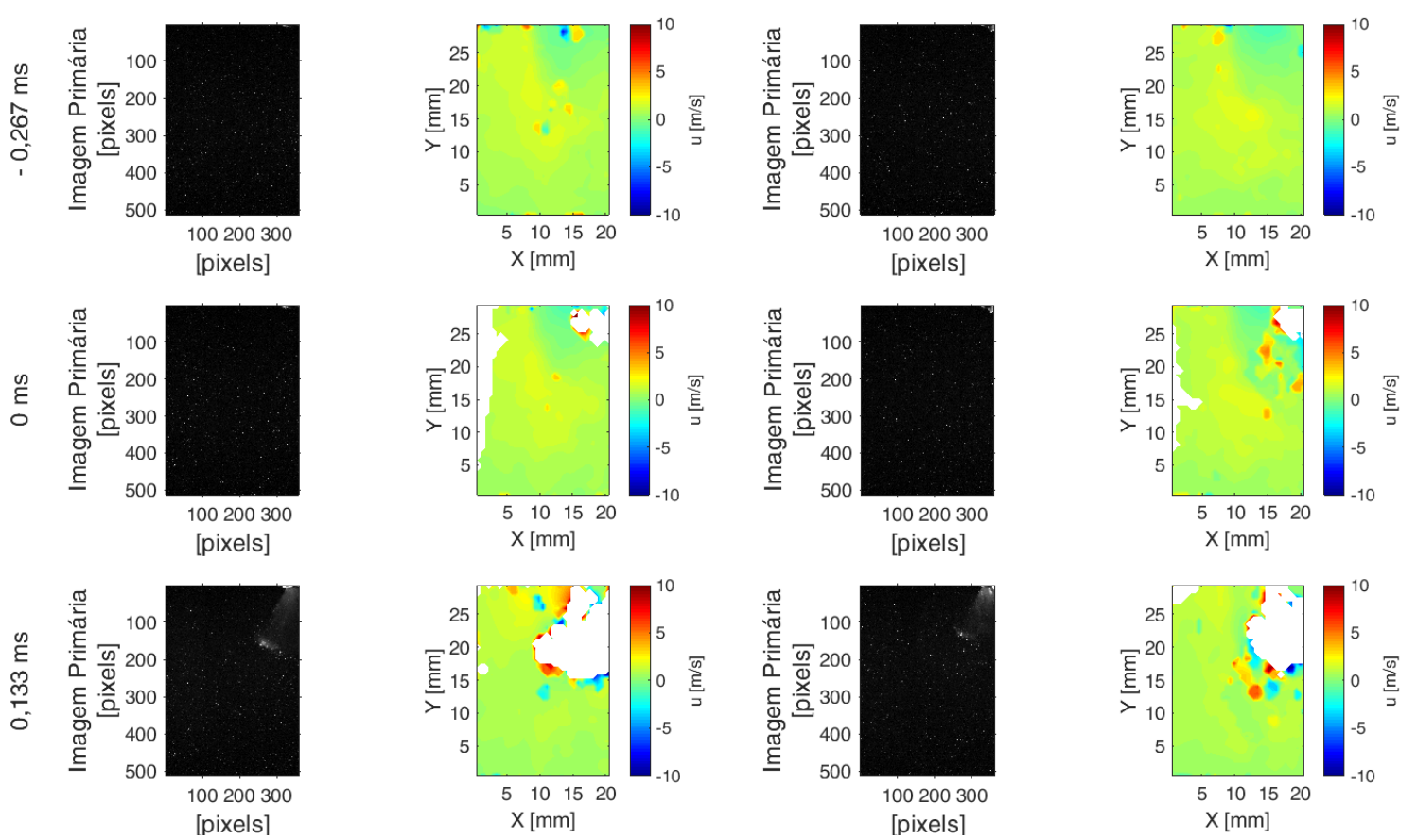

Fonte: Autor. 
Figura 4.15 - Comparação entre as evoluções temporais da componente vertical dos vetores velocidade do escoamento bifásico ar-spray registrados em instantes associados ao início da injeção de etanol na IESC, considerando o efeito dominante da pressão de injeção.
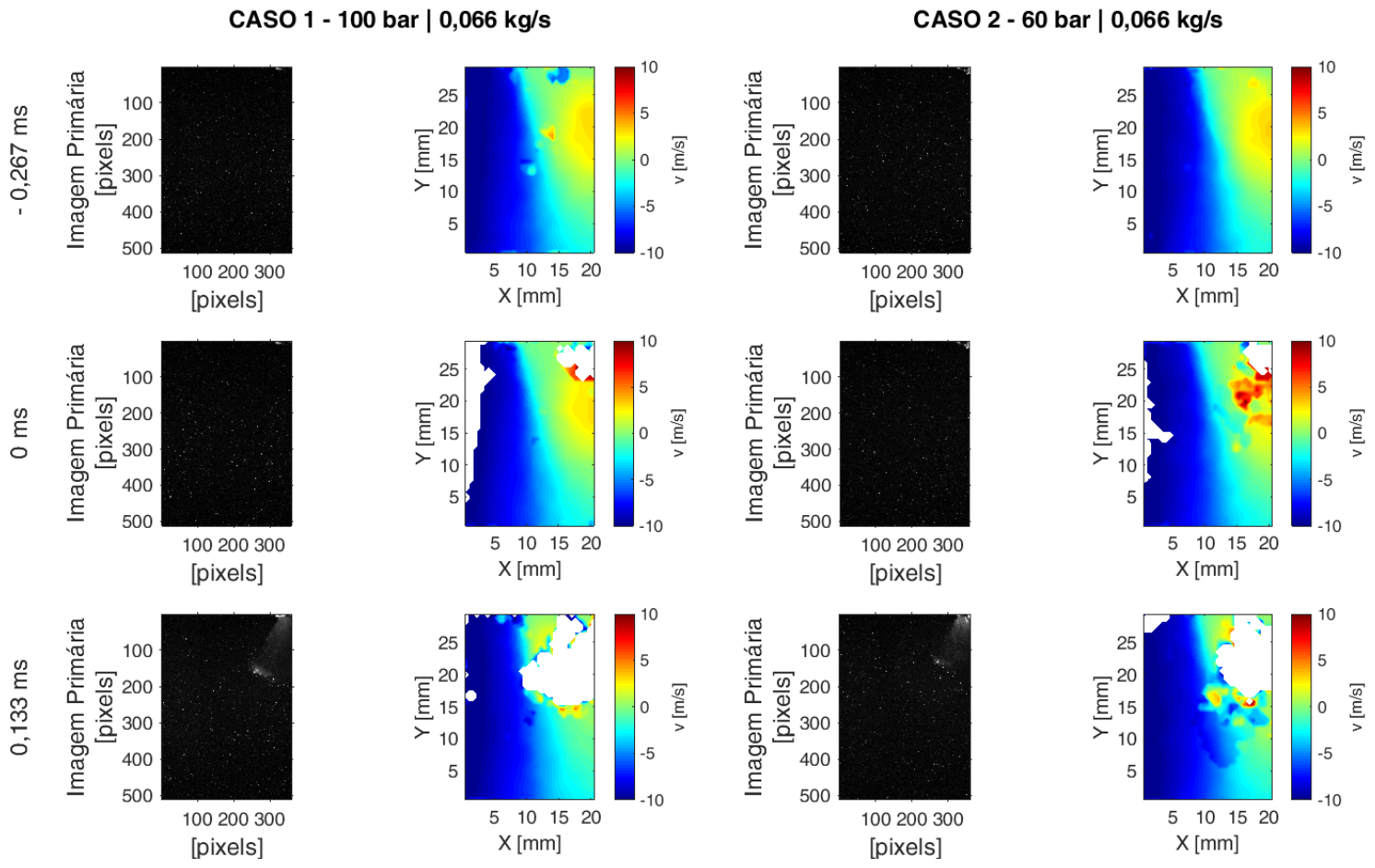

Fonte: Autor.

Figura 4.16 - Comparação entre os campos de vorticidade do escoamento bifásico ar-spray registrados em instantes associados ao início da injeção de etanol na IESC, considerando o efeito dominante da pressão de injeção.

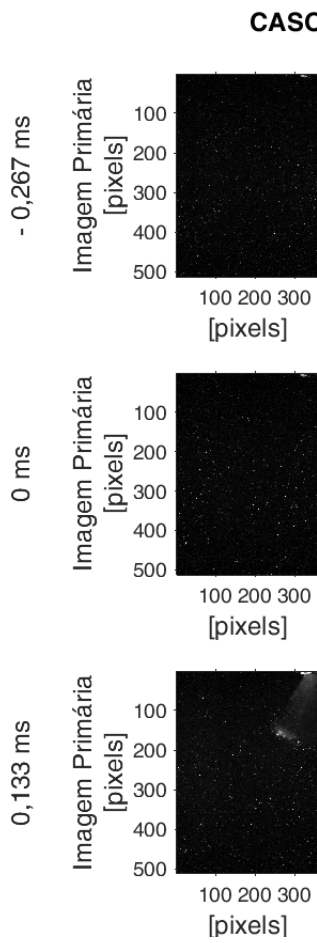

ASO 1 - 100 bar | 0,066 kg/s
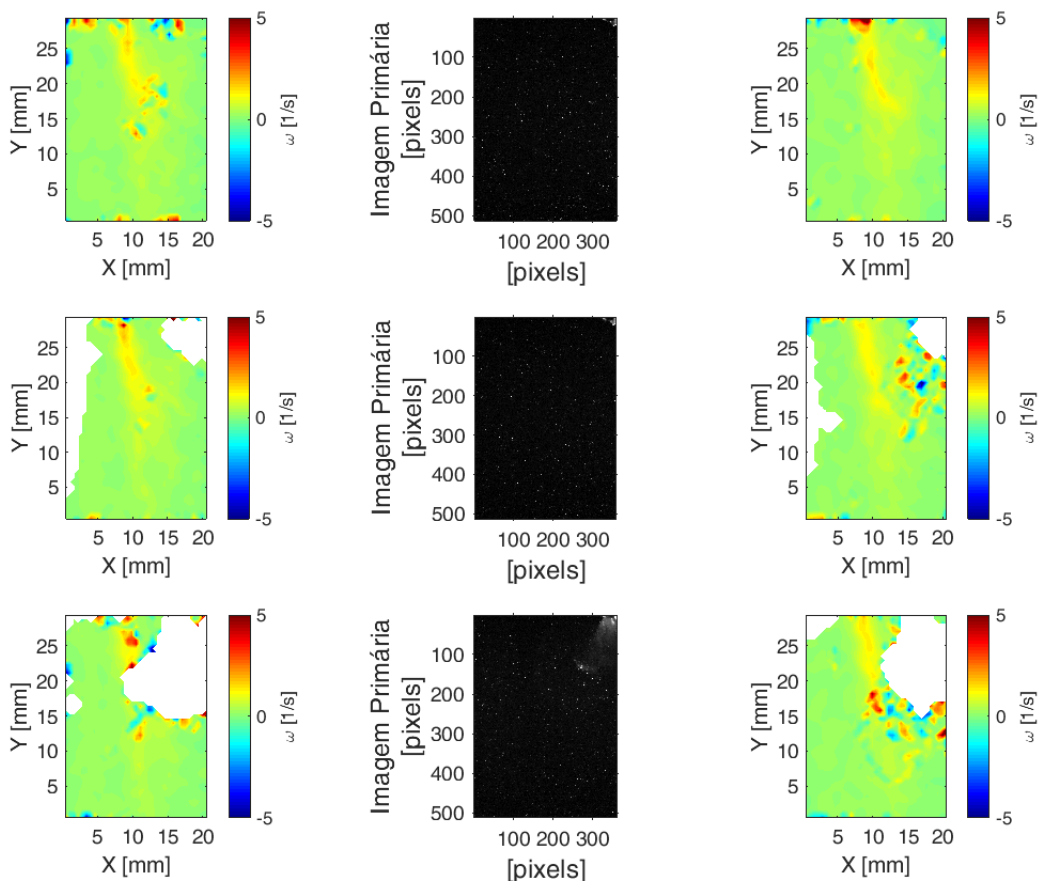

Fonte: Autor. 
Diante das evidências expostas pelas Figuras 4.13 - 4.16 e baseado nas referências bibliográficas utilizadas no presente trabalho, pode-se esperar que o aumento local e gradual da componente horizontal dos vetores velocidade represente o arraste de gás para regiões internas ao spray, indo em direção à ponta do injetor. No entanto, a partir dos resultados apresentados não foi possível visualizar as estruturas recirculantes que transportam o gás, as quais são discutidas por Zhang et al. (2014) e mostradas por Jedelsky et al. (2018). Além disso, por meio da Figura 4.17, verificou-se que o spray injetado a 100 bar teve maior comprimento de penetração e, sutilmente, menor ângulo de abertura em relação ao Caso 2, o que corrobora as observações de Moyne et al. (2007).

Figura 4.17 - Comparação entre sprays injetados com pressão 100 bar (Caso 1) e 60 bar (Caso 2) nos instantes $0,133 \mathrm{~ms} ; 0,267 \mathrm{~ms}$ e $0,400 \mathrm{~ms}$ ASOI.
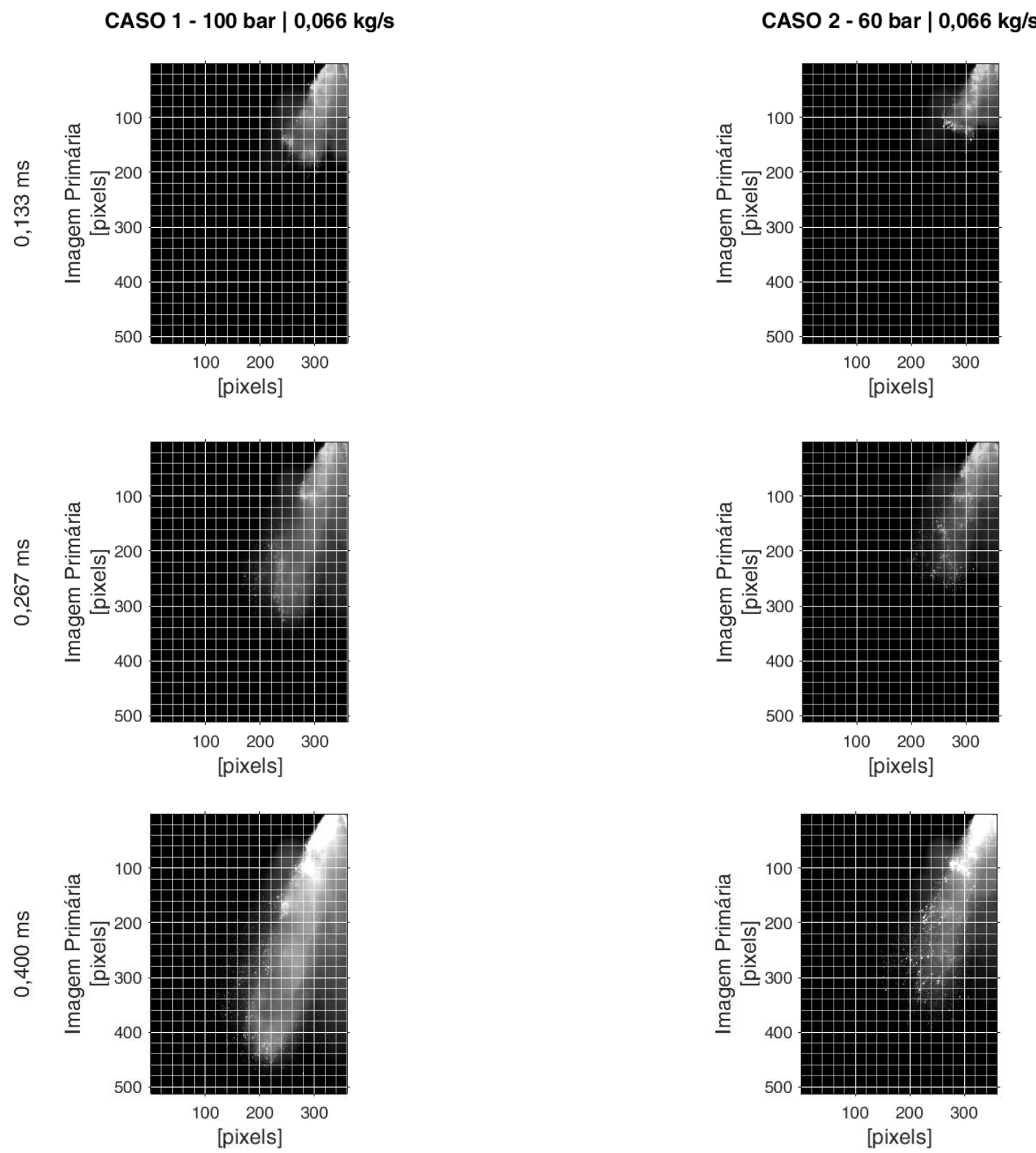

Fonte: Autor. 
As Figuras 4.18 - 4.20 revelam o comportamento do escoamento gasoso em quatro instantes pertencentes ao período de injeção do spray na IESC. Elas apresentam o módulo e as componentes dos vetores velocidade na mesma ordem utilizada nas Figuras 4.13 - 4.16. A Figura 4.21 apresenta a comparação entre os campos de vorticidade da fase gasosa do escoamento ar-spray nos instantes escolhidos para analisar o período de injeção de etanol. A análise conjunta das Figuras 4.18 - 4.21 indica uma circunstância de transição do escoamento inicialmente desenvolvido em regime transitório para uma condição próxima a um regime permanente: a fase quasi-steady (BERTI, 2018). No entanto, devido à escolha do campo de visão feita por Berti (2018) durante a gravação das imagens, não foi possível visualizar todo o spray durante a fase quasi-steady. Consequentemente, a ausência dos dados impede a discussão das estruturas do escoamento na região do escoamento mais afastada do injetor, limitando-nos, portanto, ao estudo da interação entre as fases apenas na região que contém a geratriz de referência teórica do cone, e não a sua base (região que contém em sua vizinhança as zonas de recirculação e pulverização, bem como apresenta intensa coalescência de gotas, segundo os dados de Moon et al. [2010], Zhu et al. [2011] e Zhang et al. [2014]).

Durante a evolução do spray, percebeu-se novamente que a magnitude da componente horizontal dos vetores localizados na parte superior do campo de velocidades $(Y>25[\mathrm{~mm}])$ era constantemente aumentada durante os instantes em que o injetor esteve aberto. Além disso, a Figura 4.18 revela o aumento de $|U|$ na mesma região onde foi notado o aumento da componente horizontal e na zona de interface entre as fases do escoamento ar-spray. Mediante a análise das Figuras 4.18 - 4.20, o aumento do módulo dos vetores foi dado pela elevação das componentes horizontais, predominantemente. Tal predominância é perceptível devido ao fato $u \geq v$ nas regiões mencionadas anteriormente. Vale salientar que tanto o aumento de $u$ quanto a elevação do módulo dos vetores ocorreram de forma mais pronunciada na condição de maior pressão de injeção.

Adicionalmente, durante a injeção de etanol, notou-se a dependência de $u$ em respeito ao tempo e crescente na direção contrária aos eixos $X$ e $Y$ conforme o avanço temporal. Sendo assim, torna-se razoável entender a componente horizontal de velocidade como um indicador do processo de arraste do ar para as cavidades internas do spray. 
Figura 4.18 - Comparação entre as evoluções temporais do módulo da velocidade do escoamento bifásico ar-spray em instantes associados ao desenvolvimento pleno do spray na IESC, considerando o efeito dominante da pressão de injeção.
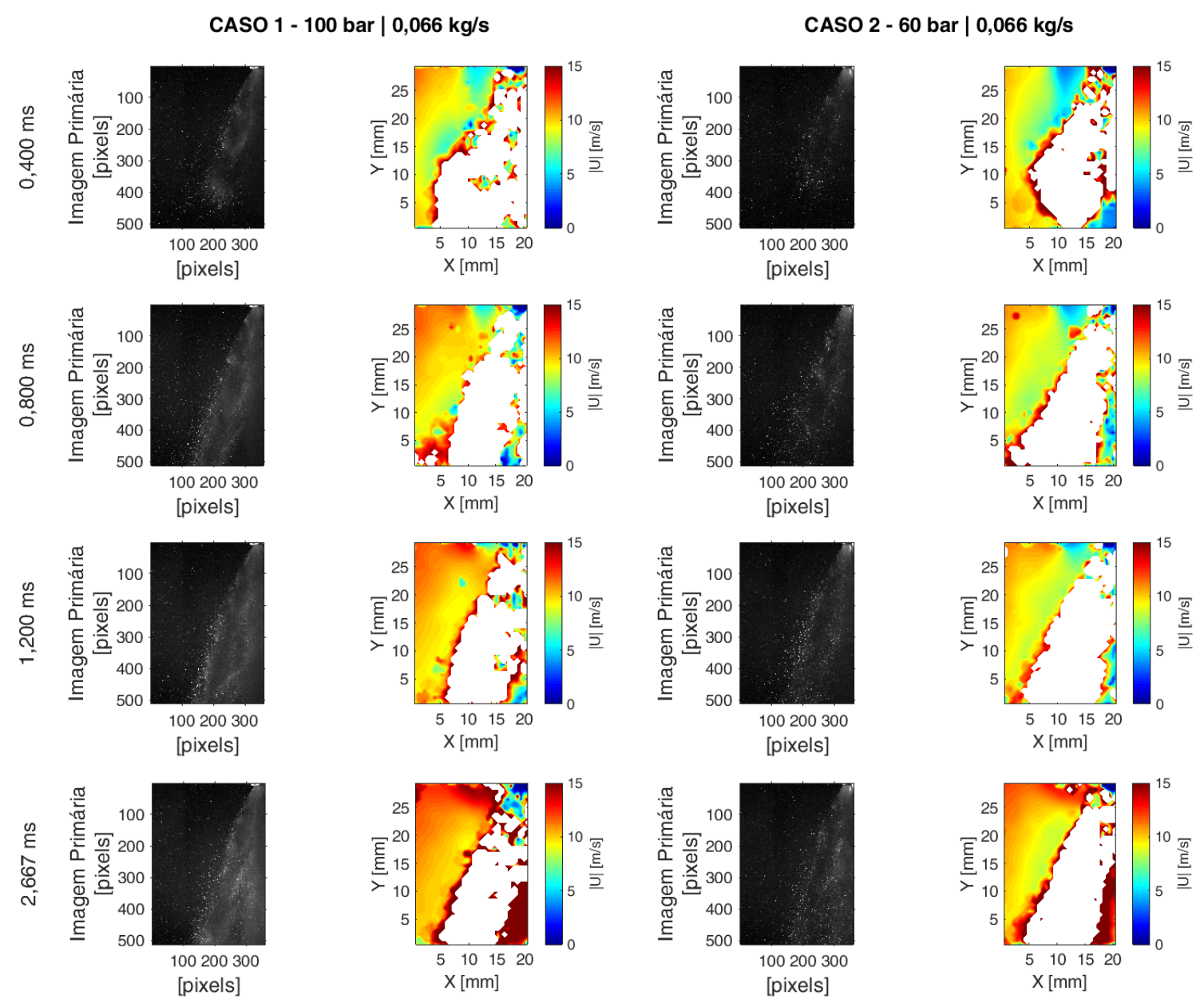

Fonte: Autor. 
Figura 4.19 - Comparação entre as evoluções temporais da componente horizontal dos vetores velocidade do escoamento bifásico ar-spray registrados em instantes associados ao desenvolvimento pleno do spray na IESC, considerando o efeito dominante da pressão de injeção.
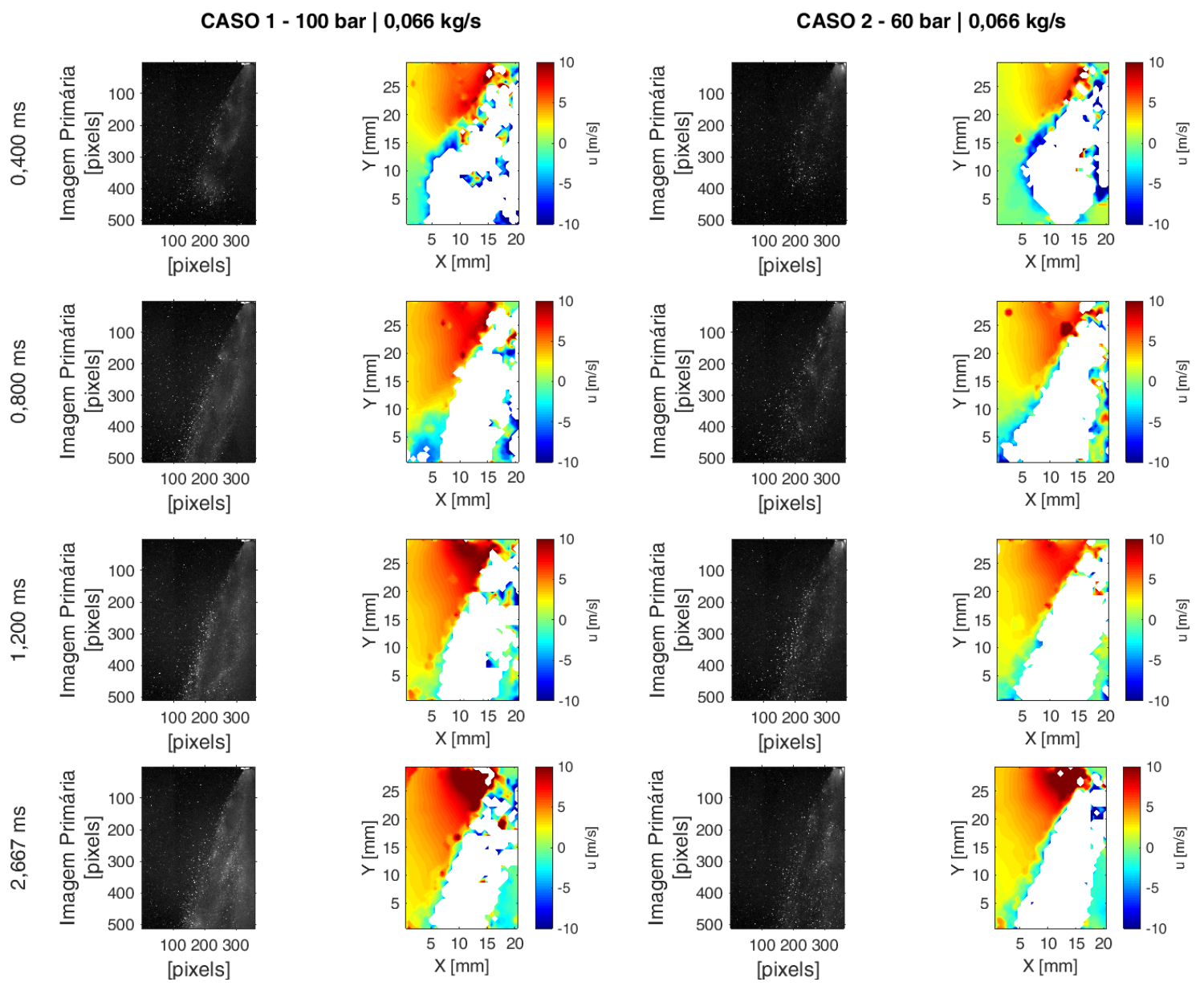

Fonte: Autor. 
Figura 4.20 - Comparação entre as evoluções temporais da componente vertical dos vetores velocidade do escoamento bifásico ar-spray registrados em instantes associados ao desenvolvimento pleno do spray na IESC, considerando o efeito dominante da pressão de injeção.
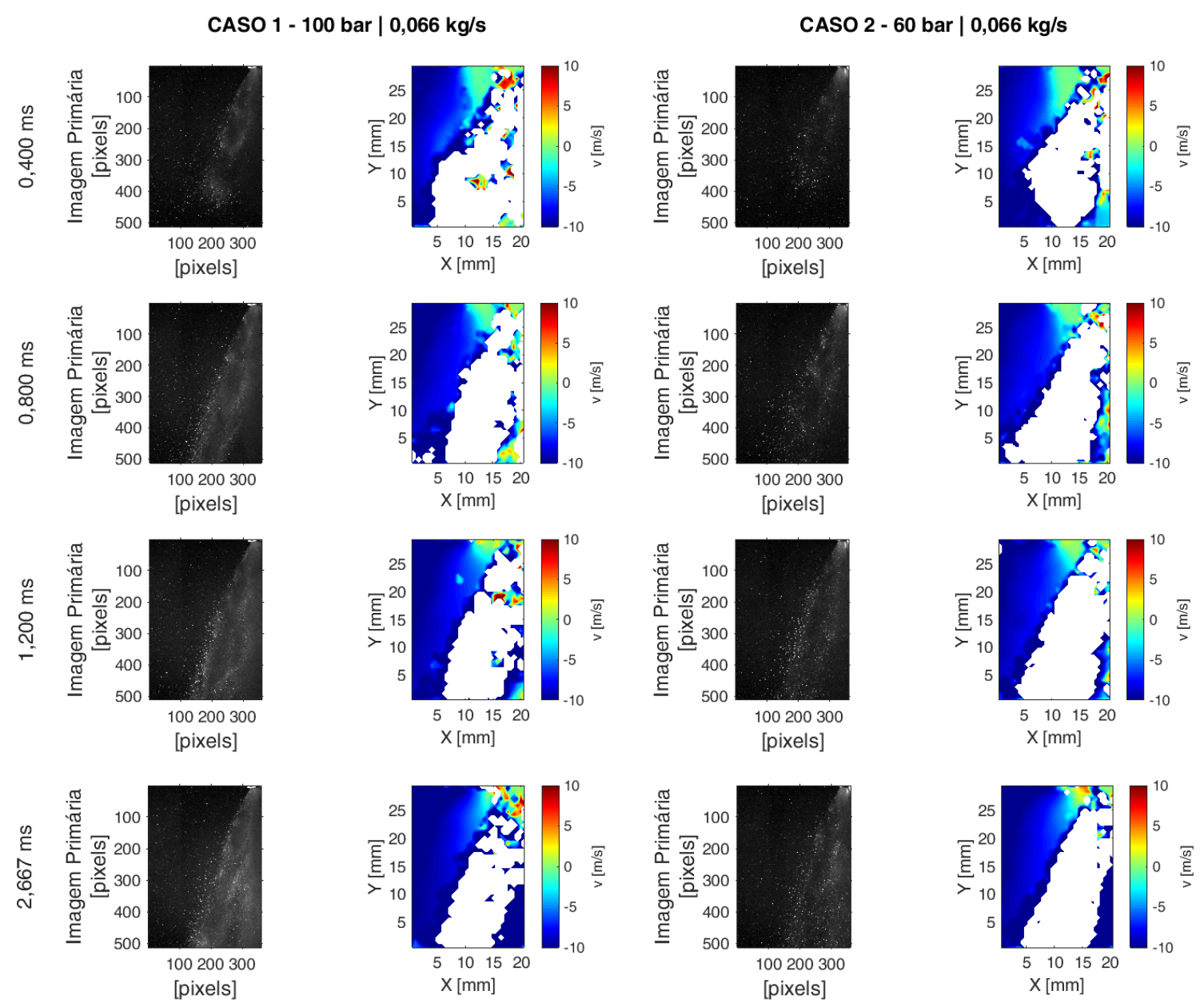

Fonte: Autor.

De modo contrário ao comportamento das componentes horizontais, a Figura 4.20 mostra que não foram observadas variações significativas nas componentes verticais dos vetores velocidade que descreviam o escoamento. Percebeu-se, ainda, que a direção e o sentido são parâmetros que também foram preservados e invariantes com relação à pressão de injeção. Além disso, é importante ressaltar que as estruturas recirculantes que estavam presentes no início da injeção do spray foram visualizadas em 0,400 ms e dissipadas durante a evolução do evento de pulverização do etanol, conforme mostra a Figura 4.21. Pelo fato de nenhuma outra estrutura recirculante com vorticidade significativa ter sido desenvolvida durante o evento de injeção, pode-se inferir que a penetração do spray no ambiente circundante pouco influenciou a vorticidade da fase gasosa do escoamento ar-spray. 
Figura 4.21 - Comparação entre os campos de vorticidade do escoamento bifásico ar-spray registrados em instantes associados ao desenvolvimento pleno do spray na IESC, considerando o efeito dominante da pressão de injeção.
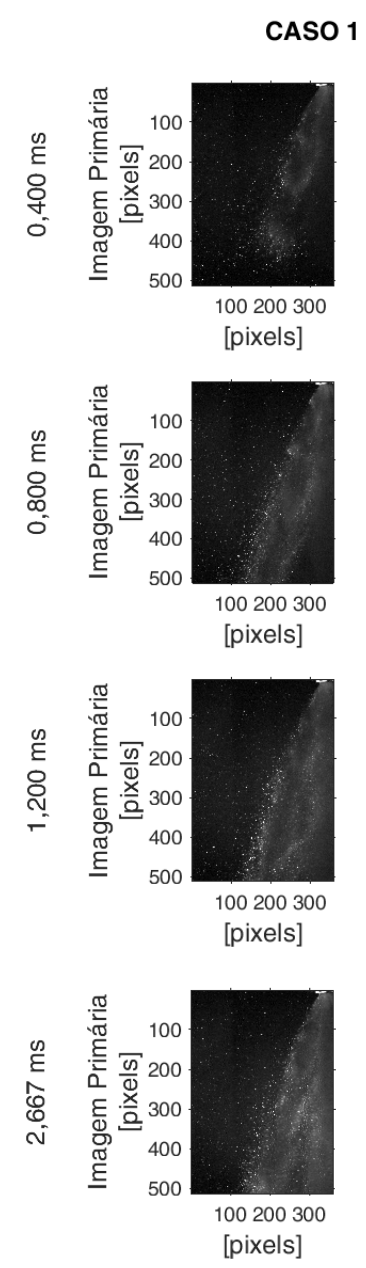
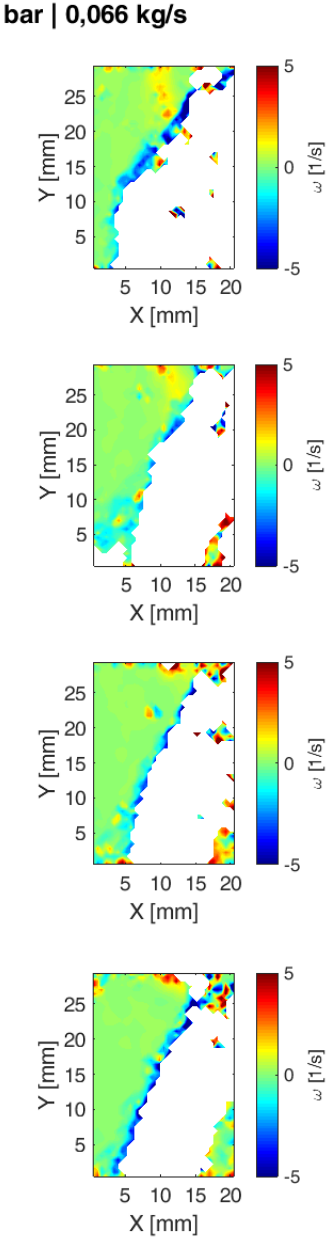
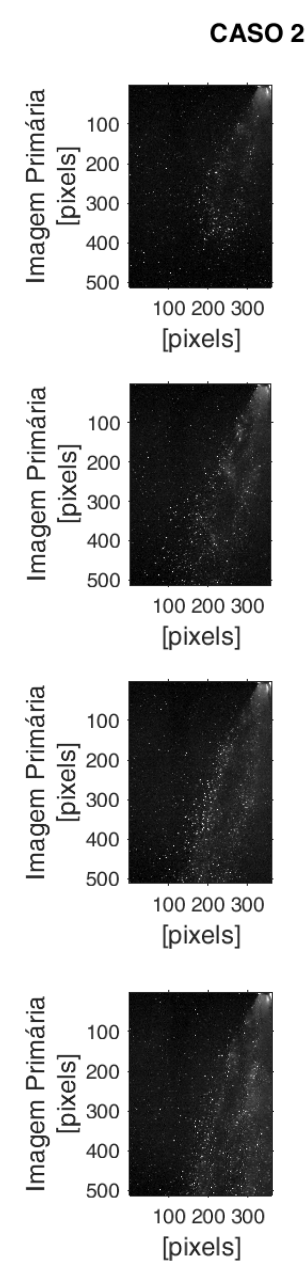
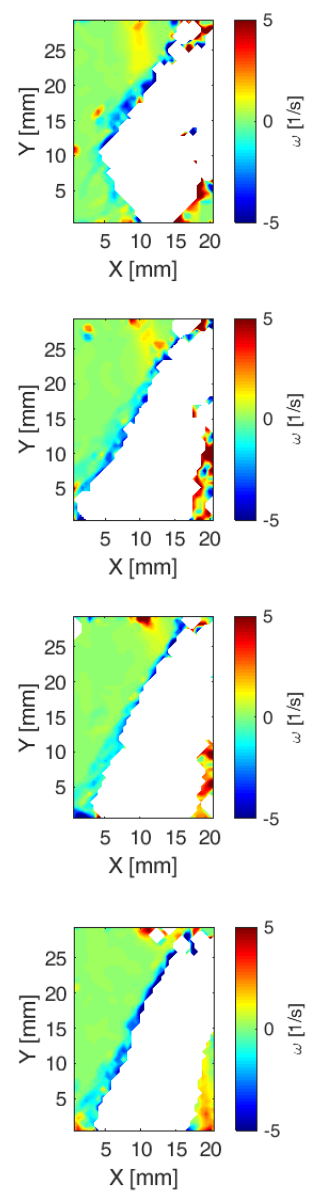

Fonte: Autor.

As Figuras 4.22 - 4.25 mostram o comportamento cinemático do escoamento gasoso instantes após o fim da injeção de etanol. No primeiro instante registrado após o fechamento da agulha, 3,467 $\mathrm{ms}$, observou-se que o arraste de ar estava acontecendo em toda a região de interface entre as fases, com maiores intensidades de $u$ nas vizinhanças do injetor, conforme sugere a Figura 4.23. No instante subsequente, 3,733 ms, notou-se que os vetores velocidade tinham magnitude tendendo a zero na região onde o injetor estava localizado, o que evidenciou a interrupção do arraste de ar no local. A partir de $3,733 \mathrm{~ms}$, verificou-se que as componentes horizontais de velocidade tendiam a decrescer generalizadamente, fato que indica a diminuição da intensidade com a qual o gás era arrastado em direção ao spray de etanol. 
Figura 4.22 - Comparação entre as evoluções temporais do módulo da velocidade do escoamento bifásico ar-spray em instantes posteriores ao fim da injeção de etanol na IESC, considerando o efeito dominante da pressão de injeção.

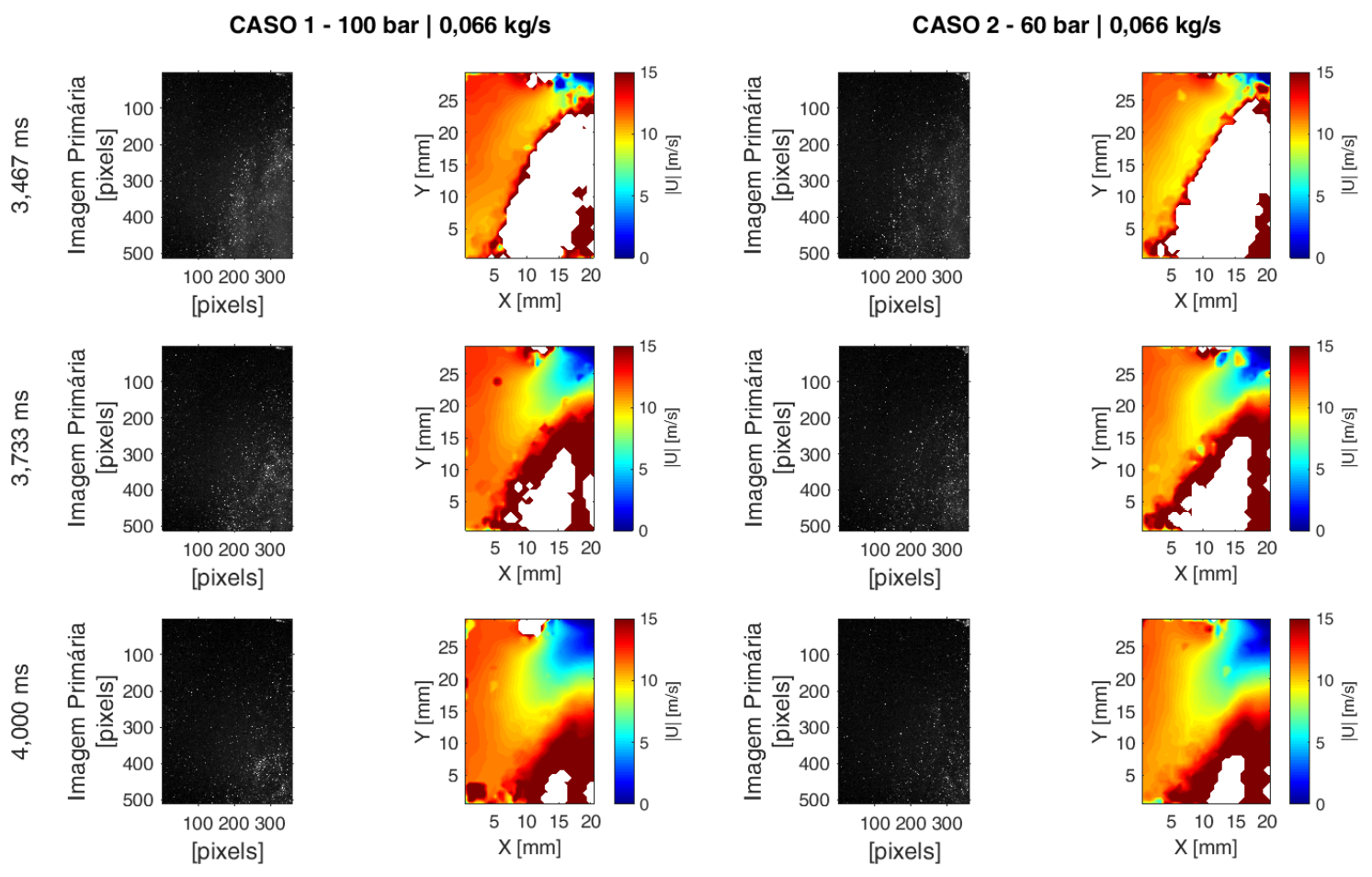

Fonte: Autor.

Figura 4.23 - Comparação entre as evoluções temporais da componente horizontal dos vetores velocidade do escoamento bifásico ar-spray registrados em instantes posteriores ao fim da injeção de etanol na IESC, considerando o efeito dominante da pressão de injeção.

CASO 1 - 100 bar | 0,066 kg/s
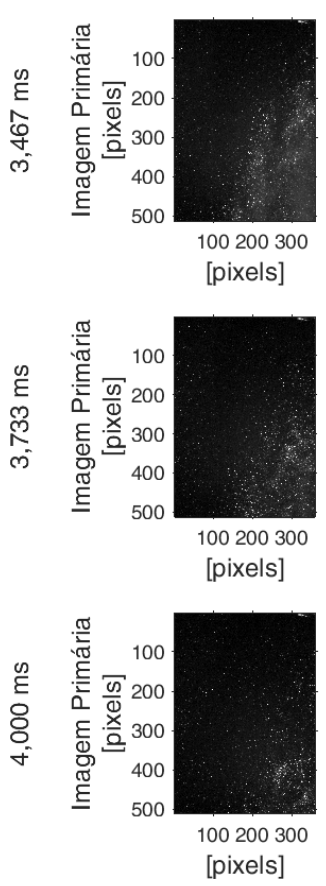
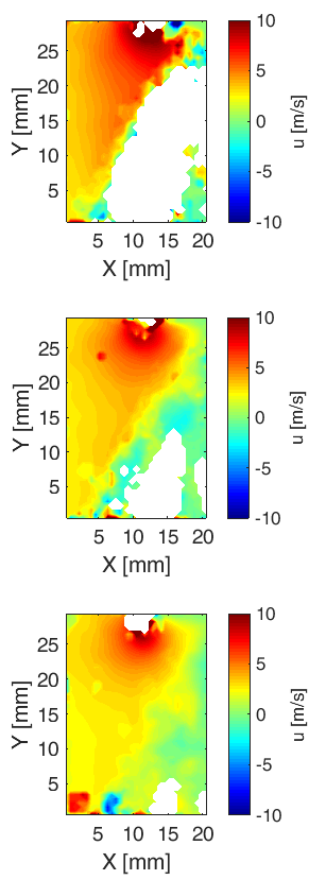

CASO 2 - 60 bar | 0,066 kg/s
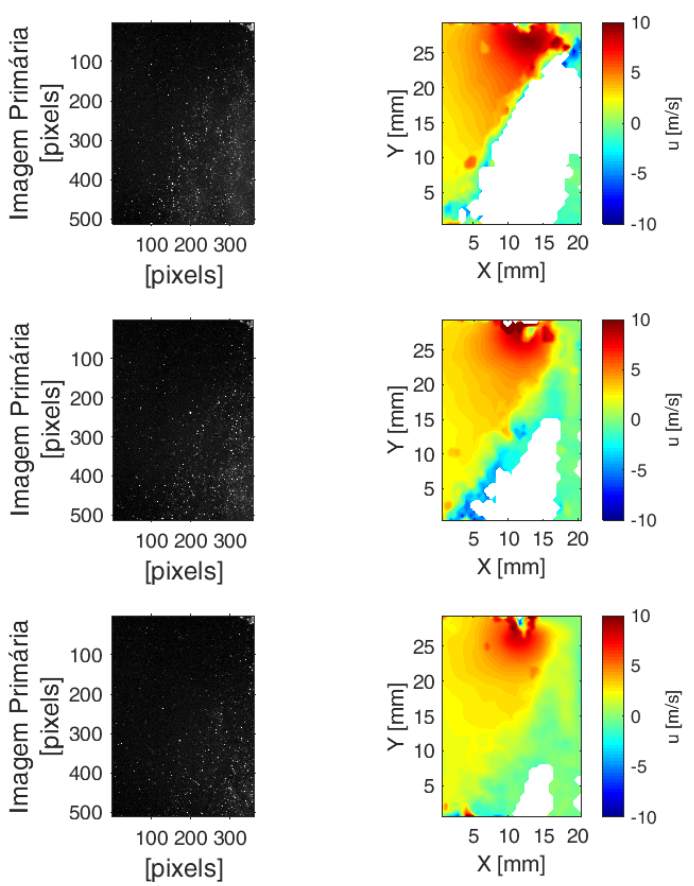

Fonte: Autor. 
Figura 4.24 - Comparação entre as evoluções temporais da componente vertical dos vetores velocidade do escoamento bifásico ar-spray registrados em instantes posteriores ao fim da injeção de etanol na IESC, considerando o efeito dominante da pressão de injeção.

CASO 1 - 100 bar | 0,066 kg/s
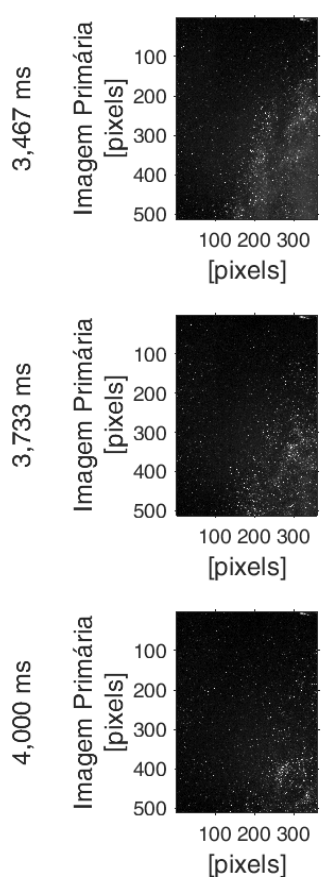
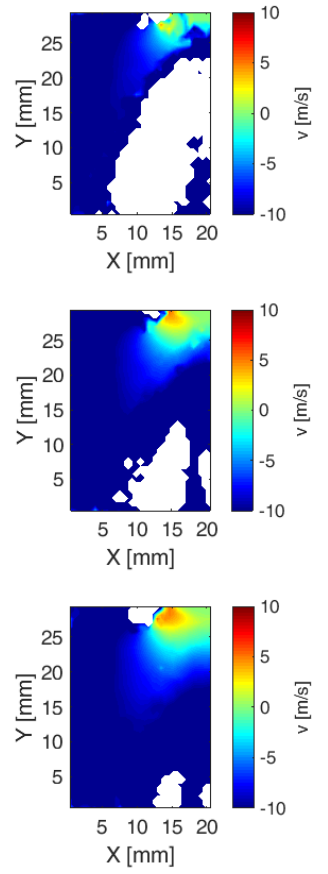

CASO 2 - 60 bar | 0,066 kg/s
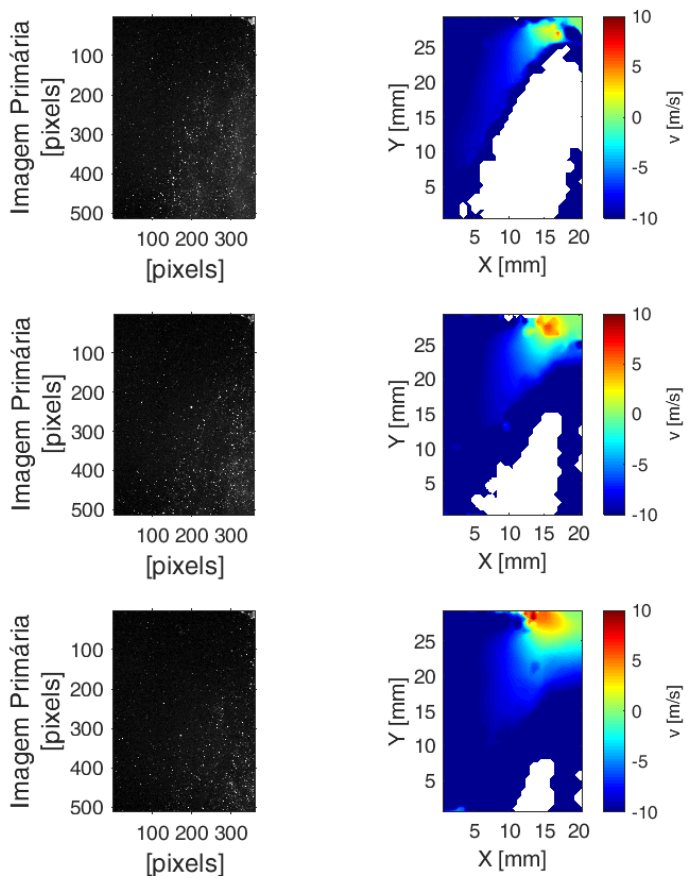

Fonte: Autor.

Figura 4.25 - Comparação entre os campos de vorticidade do escoamento bifásico ar-spray registrados em instantes posteriores ao fim da injeção de etanol na IESC, considerando o efeito dominante da pressão de injeção.

CASO 1 - $100 \mathrm{bar} \mid 0,066 \mathrm{~kg} / \mathrm{s}$
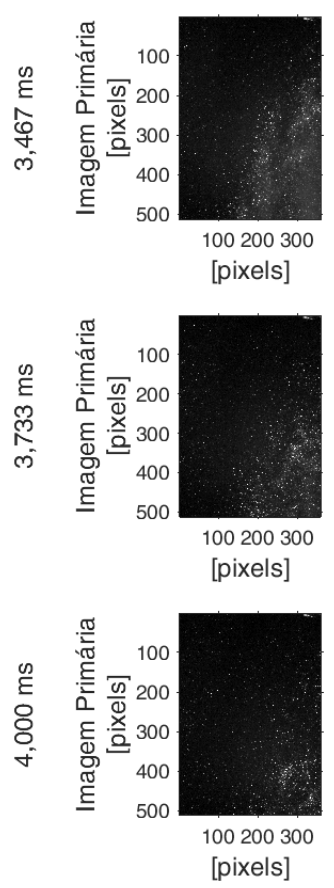
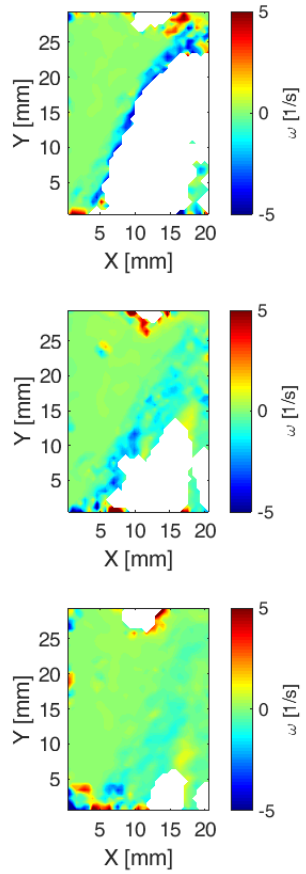

CASO 2 - 60 bar | 0,066 kg/s
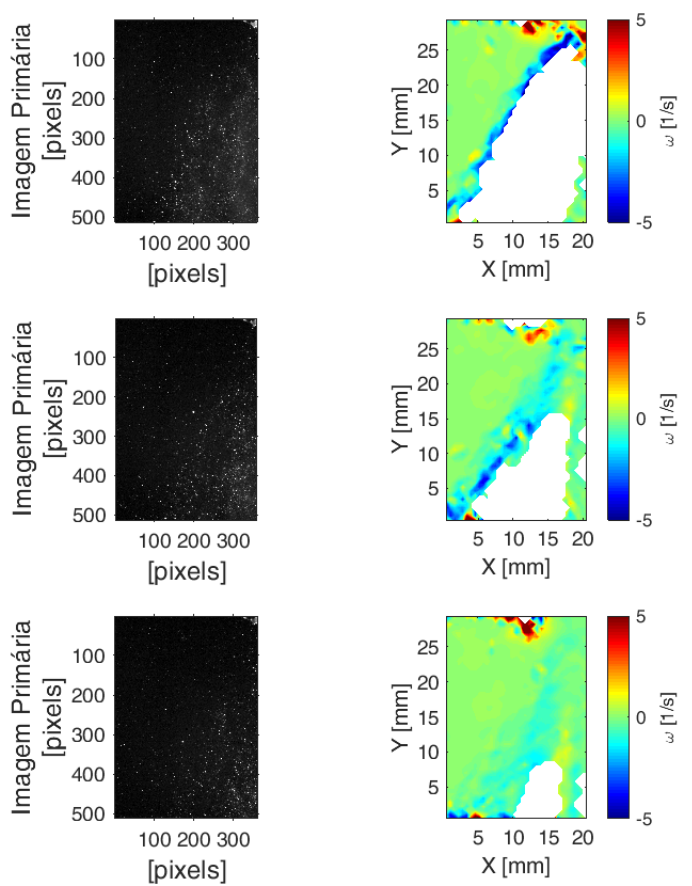

Fonte: Autor. 
Como esperado, a componente vertical de velocidade se mostrou com baixa influência no processo de retardamento do mecanismo de arraste de ar, enquanto a vorticidade foi praticamente inalterada quando do fechamento do injetor, segundo a Figura 4.24 e a Figura 4.25. Vale salientar que ao final do evento de injeção de combustível, embora o arraste de ar causado pela presença do spray estava sendo amenizado, há indícios de que a própria estrutura do injetor promoveu o arraste do ar remanescente. Tal arraste é esperado e se justifica devido ao efeito que a geometria da estrutura do injetor causa às estruturas do escoamento, conforme discutido durante a análise das Figuras 4.13 - 4.16.

Quanto aos resultados apresentados pelas Figuras 4.22 - 4.25, vale destacar que a ausência do filme líquido que compunha o spray durante a fase quasi-steady facilitou a correlação entre imagens de partículas e gotículas de etanol, assim como foi observado nos primeiros instantes da injeção de combustível. Deste modo, resultados sem coerência espacial e temporal foram obtidos e estão contidos nas regiões que apresentam dados com valores maiores que o limite superior das escalas de cores correspondentes. Adicionalmente, por meio das distribuições propostas para o instante 4,000 ms, é esperado o retorno das variáveis à condição quiescente com a mesmas formas e seguindo os mesmos contornos obtidos em $-0,267 \mathrm{~ms}$.

Mediante a análise conjunta das Figuras 4.13 - 4.25, é razoável concluir que, a menos das regiões com predominância de ruído, as grandezas selecionadas para avaliar o escoamento ar-spray sofreram alterações graduais e coerentes durante a evolução temporal do spray desenvolvido na IESC. Isso se sucede graças à manutenção da coerência espaço-temporal das representações cinemáticas que definiram a fase gasosa. Além disso, pode-se inferir que os vetores velocidade que definem a trajetória do gás apresentaram uma tendência de serem permanentemente orientados na direção da camada cisalhante, fato que pode levar ao entendimento de que o gás circundante interage de modo a coexistir com a fase líquida durante a pulverização do combustível. De modo complementar, vale destacar que, por se tratar de um injetor multi-furos, essa representação pode indicar uma interação tridimensional do gás com o spray de etanol, o que evidenciaria estruturas recirculantes que o envolvem em sua periferia. Vale destacar que, comparativamente, embora em ambos os casos o comportamento de preservação das formas e contornos das distribuições foi percebido, as normas de $U$ e a respectiva componente horizontal foram notoriamente superiores para o Caso 1, conforme mostra a 
Figura 4.26. Com a figura, nota-se, ainda, que o Caso 2 apresentou vetores com componentes verticais maiores, em módulo, frente às observadas no Caso 1.

Figura 4.26 - Comparação entre as evoluções temporais do módulo e das componentes dos vetores velocidade em dois pontos do campo de velocidades: $P_{1}=(11,68 ; 27,02)[\mathrm{mm}]$ (à esq.) e $P_{2}=$ $(11,68 ; 22,89)[\mathrm{mm}]$ (à dir.).
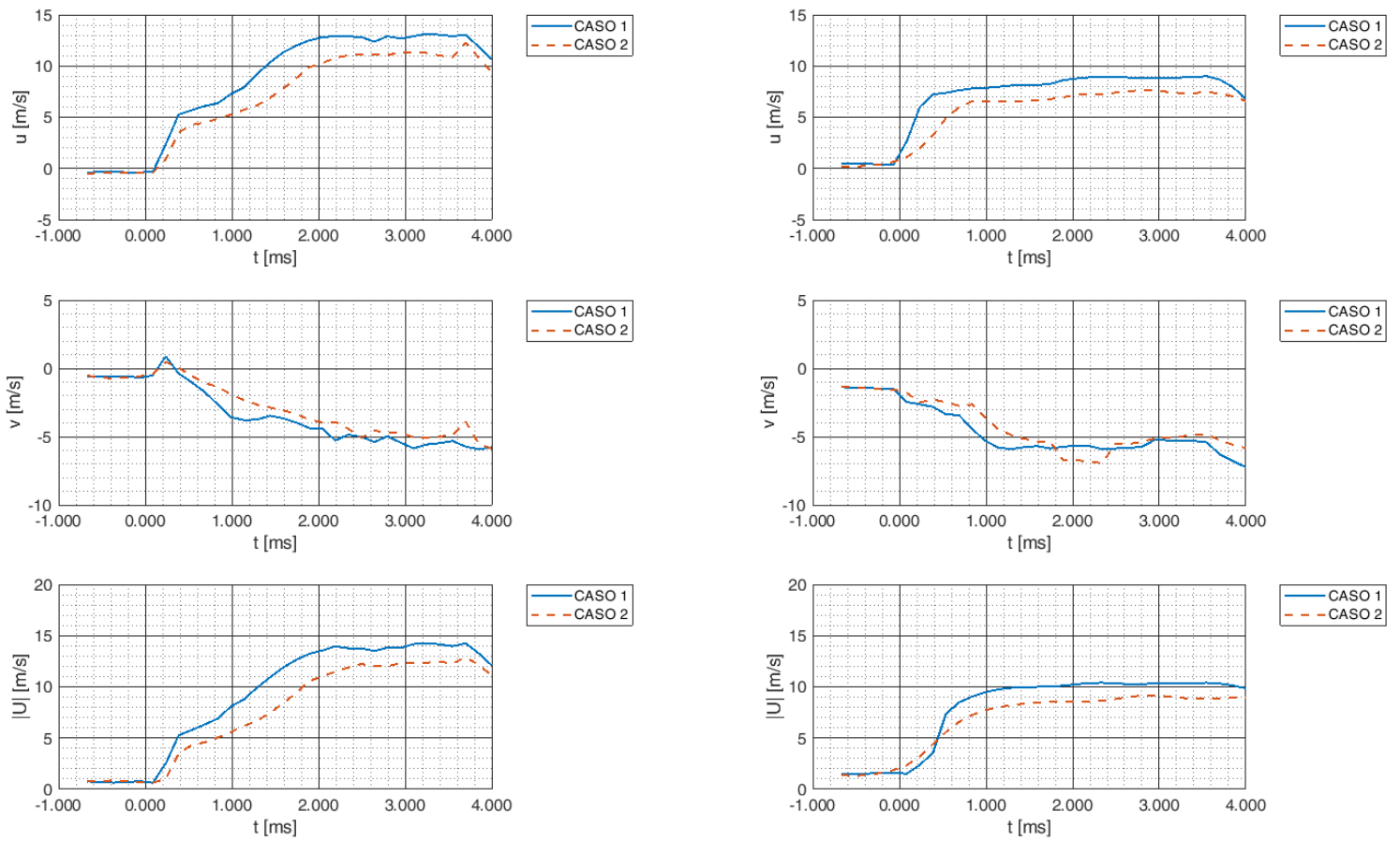

$-\mathrm{CASO} 1$
$--\mathrm{CASO} 2$

Fonte: Autor.

Ademais, uma constatação importante é o fato de a comparação entre os ângulos dos vetores velocidade para cada instante dos dois casos considerados revelar que as orientações destes são consideravelmente próximas entre si. Tal condição mostra a similaridade entre os campos vetoriais, a menos da norma dos vetores, obviamente. Sendo assim, a Figura 4.27 evidencia um aspecto relevante ao estudo da interação cisalhante ar-spray: desde que mantida uma vazão de gás circundante, as estruturas do escoamento são preservadas em forma e têm magnitudes definidas como função da pressão de injeção do combustível. 
Figura 4.27 - Comparação entre as evoluções temporais dos ângulos dos vetores velocidade do escoamento bifásico ar-spray registrados em diferentes instantes da injeção de etanol na IESC, considerando o efeito dominante da pressão de injeção.

CASO 1 - 100 bar | 0,066 kg/s
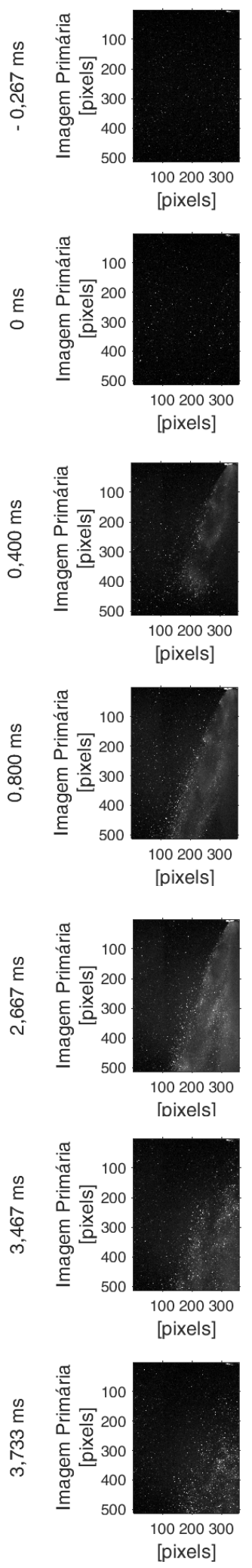
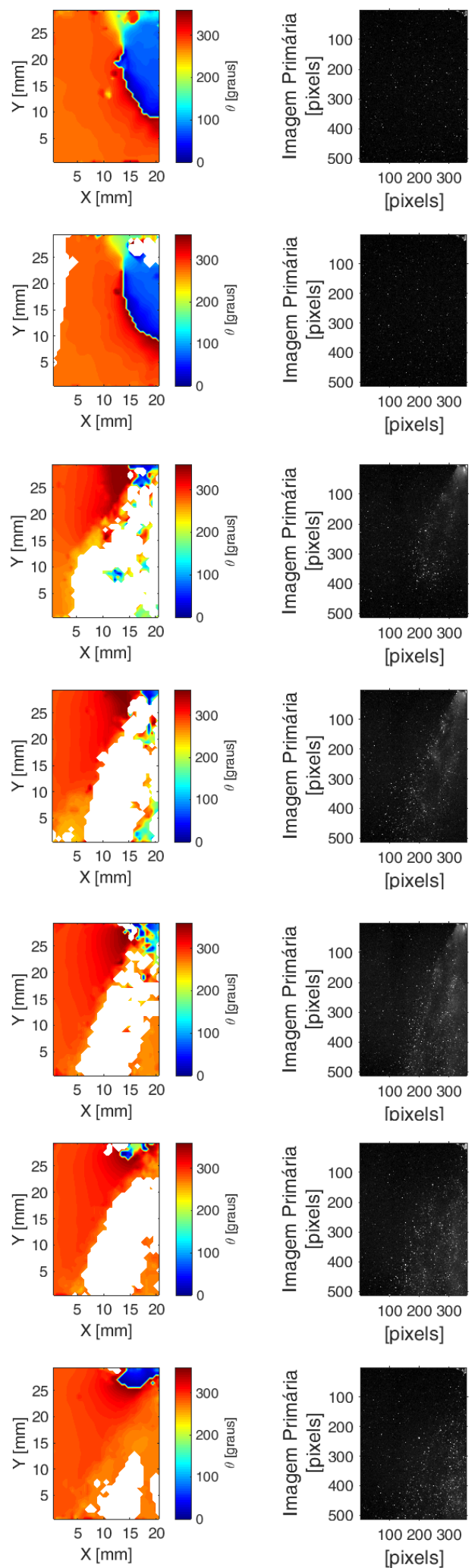

CASO 2 - 60 bar | 0,066 kg/s
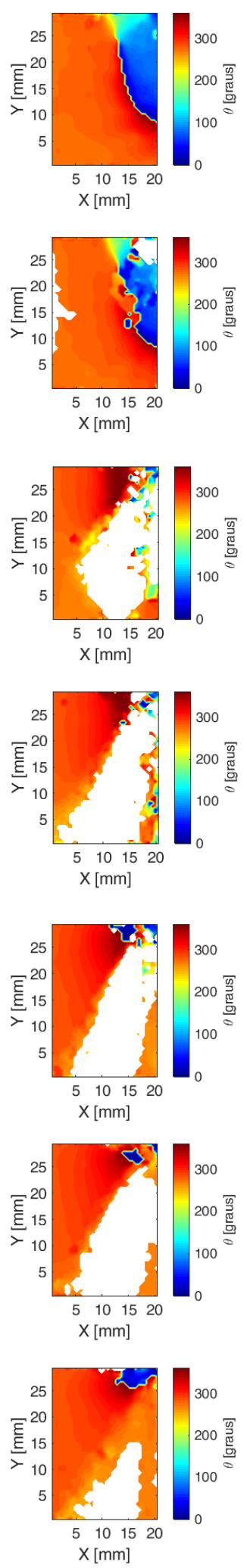

Fonte: Autor. 
Por fim, a Tabela 4.2 sumariza as principais observações reportadas na presente seção, quando da análise do escoamento ar-spray registrado parcialmente nas Figuras $4.13-4.25$.

Tabela 4.2 - Síntese das observações experimentais acerca do escoamento bifásico ar-spray, considerando o efeito dominante da pressão de injeção do etanol.

(continua)

\section{Período}

\section{Observações}

I. Ambiente gasoso com distribuição de velocidade não uniforme e dividido em duas regiões distintas, discernidas entre si por meio dos perfis de velocidade axial;

II. Interação puntual entre as fases líquida e gasosa, marcada pelo aumento local da magnitude das

Pré-Injeção

(Figuras $4.13-4.16)$ componentes horizontais dos vetores velocidade, mas ainda sem mudanças significativas no módulo;

III. Fraco efeito da presença do spray na componente vertical dos vetores velocidade e na vorticidade do escoamento gasoso;

IV. O comprimento de penetração do spray no ambiente circundante se comportou como variável dependente da pressão de injeção de combustível.

V. Aumento progressivo do módulo dos vetores velocidade localizados próximo à saída do injetor;

VI. Aumento progressivo das componentes horizontais dos vetores velocidade nas regiões próximas à

\section{Injeção}

(Figuras 4.18-4.21) interface entre as fases que dividem o escoamento ar-spray;

VII. O módulo das componentes horizontais, $u$, se comportou como função da pressão de injeção do injetor, ao contrário da componente vertical, que apresentou fraca relação com o parâmetro mencionado; 
Tabela 4.2 - Síntese das observações experimentais acerca do escoamento bifásico ar-spray, considerando o efeito dominante da pressão de injeção do etanol.

(conclusão)

\begin{tabular}{|c|c|c|}
\hline Período & & Observações \\
\hline $\begin{array}{c}\text { Injeção } \\
\text { (Figuras } 4.18-4.21)\end{array}$ & VIII. & $\begin{array}{l}\text { Indício da transição do escoamento ar-spray de uma } \\
\text { condição transiente para um cenário quasi-steady; } \\
\text { Fraco efeito da presença do spray na componente } \\
\text { vertical dos vetores velocidade e na vorticidade do } \\
\text { escoamento gasoso; }\end{array}$ \\
\hline \multirow{3}{*}{ (Figuras $4.22-4.25)$} & $X$ & $\begin{array}{l}\text { Atenuação gradual do arrastamento de ar, marcado } \\
\text { pela presença de vetores velocidade com intensidade } \\
\text { próxima a zero na região próxima à ponta do injetor e } \\
\text { indicado pela diminuição generalizada do módulo da } \\
\text { componente horizontal; }\end{array}$ \\
\hline & XI. & $\begin{array}{l}\text { Fraco efeito da interrupção da injeção do spray na } \\
\text { componente vertical dos vetores velocidade e na } \\
\text { vorticidade; }\end{array}$ \\
\hline & XII. & $\begin{array}{l}\text { Reestabelecimento cinemático do escoamento para o } \\
\text { estado quiescente. }\end{array}$ \\
\hline
\end{tabular}

Fonte: Autor. 


\section{CONCLUSÃO}

No trabalho apresentado foi proposta a investigação da interação entre as fases do escoamento ar-spray a partir de medidas PIV confiáveis, todas obtidas por meio da aplicação de um método de otimização das etapas pós-aquisição de imagens PIV. Para a etapa de pré-processamento, duas metodologias de tratamento digital de imagens foram testadas e a otimização consistiu na minimização do ruído de imagem e na melhor qualidade de representação das imagens de partículas, conforme pode ser visto no histograma apresentado pela Figura H.1. Nos casos analisados, o pré-processamento elaborado somente com filtragem espacial (beta) se sobressaiu frente à outra estratégia pelo fato de ter produzido campos vetoriais com relação sinal-ruído até $150 \%$ maior. Tal estratégia está sumarizada na forma de fluxograma na Figura H.3. Entretanto, notou-se que, para a região que abrigava o spray e a sua respectiva vizinhança, seria necessário oferecer um tratamento local e minucioso, ao qual a aplicação de operadores morfológicos é indicada. No tocante à otimização da etapa de processamento $P I V$, foi feita a escolha da estratégia de interrogação e de processamento que destinava aos campos vetoriais a simultaneidade entre a maximização do $S N R$ e a preservação das coerências espacial e temporal, considerando abordagens contidas na literatura.

Durante a fase de processamento $P I V$, a presença de ruídos associados à baixa concentração de imagens de partículas foi notada continuamente, fato que evidenciou que o escoamento deveria ser estudado com baixas resoluções espaciais para que os resultados tivessem boa qualidade. Por conta disso, uma segunda estratégia de interrogação e processamento $P I V$ foi sugerida, a qual permitiu estudar o escoamento ar-spray com uma pseudo-alta resolução espacial a partir de um campo híbrido de velocidades. Ao pósprocessamento, foi oferecida uma estratégia de tratamento dos vetores espúrios capaz de evitar falsas conclusões e discrepâncias referentes à coerência espaço-temporal. A estratégia contempla a aplicação de um método de detecção de outliers baseado na relação sinal ruído e na coerência espacial, o qual foi utilizado junto a um método de interpolação. Além disso, todos os campos híbridos foram otimizados pela aplicação de uma capa de velocidade, a qual considerou a exclusão de vetores velocidade com intensidade superior a uma velocidade limite, determinada por uma relação entre o $S N R$ e um parâmetro de sensibilidade. Ademais, diante das inferências supraditas, fica evidenciado que os objetivos principal e específicos às etapas pós-aquisição de imagens $P I V$ prometidos 
foram cumpridos. Todas as etapas descritas neste parágrafo estão sintetizadas nos fluxogramas apresentados pela Figura H.2 e pela Figura H.4.

De posse dos resultados otimizados, a investigação acerca da interação entre as fases líquida e gasosa foi analisada através do comportamento da evolução temporal de parâmetros associados à cinemática do escoamento bifásico, considerando duas pressões de injeção. Como resultado da investigação do escoamento ar-spray, inicialmente verificou-se que a fase gasosa tinha suas estruturas influenciadas pela geometria da estrutura do injetor de combustível, a quem atribuiu-se a produção de um ambiente quiescente formado por uma distribuição não uniforme de velocidade e com vorticidade particular. Além disso, os resultados permitiram afirmar que, para um escoamento arspray, a evolução temporal da componente horizontal dos vetores velocidade (definida ortogonalmente ao eixo vertical que contém orifício de saída do etanol) pode ser entendida como indicador do arraste de gás para regiões internas ao spray e que o mecanismo de arrastamento é intensificado até o fim do período de injeção de combustível. Adicionalmente, notou-se que tanto a vorticidade da fase gasosa quanto a componente vertical dos vetores velocidade (definida com base na reta vertical que contém o bocal de saída do injetor) foram minimamente influenciadas pela dinâmica do spray, bem como não se comportaram como função da pressão de injeção. No entanto, verificou-se que o módulo dos vetores velocidade descritores do ambiente circundante, assim como o comprimento de penetração e o ângulo de abertura do spray, são grandezas que se comportaram como função da pressão de injeção. Ao final, considerando o contexto em que o gás circundante estava sendo mantido a vazão constante, observou-se que, embora a pressão de injeção atuasse de forma a influenciar a magnitude dos vetores que definiam o escoamento bifásico ar-spray, as estruturas do escoamento eram preservadas e tinham formas invariantes com a pressão. Contudo, com base no conteúdo apresentado neste parágrafo, afirma-se que o objetivo secundário prometido ao presente trabalho foi atingido.

\subsection{SUGESTÕES PARA O DESENVOLVIMENTO DE TRABALHOS FUTUROS}

De acordo com os resultados obtidos no presente trabalho e com as respectivas conclusões acerca de cada etapa nele desenvolvida, sugere-se testar a sensibilidade do 
método de otimização $P I V$ proposto com relação a diferentes configurações experimentais. Isso inclui a eleição de uma nova sequência de experimentos para buscar a melhoria da aquisição das imagens de partículas, principalmente na concentração de traçadores e na atenuação dos ruídos típicos de imagens de fluorescência. Além disso, a com base nos campos híbridos produzidos a partir de imagens primárias menos ruidosas, sugere-se avaliar o efeito da vazão de gás circundante nas estruturas do escoamento arspray, bem como analisar os efeitos da vazão de gás circundante e da pressão de injeção no processo de transferência de energia entre as fases. 


\section{REFERÊNCIAS BIBLIOGRÁFICAS}

ADRIAN, R. J.. Particle-Imaging Techiniques for Experimental Fluid Mechanics. Annual Reviews Fluid Mechanics. [S.1.]: [s.n.]. 1991. p. 1-44.

ADRIAN, R. J.; WESTERWEEL, J. Particle Image Velocimetry. [S.1.]: Cambridge University Press, 2011. Acesso em: 2 jun. 2019.

AMARAL, R. L. QUALITY ANALYSIS OF 2D-2C AND 2D-3C F-PIV MEASUREMENTS OF THE LIQUID PHASE VELOCITY IN A BUBBLE COLUMN. UNICAMP. Campinas. 2017. Tese de Doutorado.

AMARAL, R. L. et al. EFEITO DO PRÉ-PROCESSAMENTO DE IMAGEM PIV NA VELOCIDADE DO LÍQUIDO EM UMA COLUNA DE BOLHAS COM EXPANSÃO DE DIÂMETRO. VIII CONGRESSO NACIONAL DE ENGENHARIA MECÂNICA. UBERLANDIA, MG: [s.n.]. 2014.

ANFAVEA. Estatísticas. ANFAVEA, 2019. Disponivel em: <www.anfavea.com.br/estatisticas.html>. Acesso em: 18 Fevereiro 2019.

BAUMGARTEN, C. Mixture formation in internal combustion engines. Berlin: Spring-Verlag Berlin Heidelberg, 2006.

BEER, J. M.; CHIGIER, N. A. Combustion Aerodynamics. Nova York: Halsted Press Division John Wiley \& Sons, 1972.

BERTI, R. C. R. et al. TURBULENCE CHARACTERIZATION OF A FLOW AROUND A DI INJECTOR BY MEANS OF TR-PIV. Naples: [s.n.]. 2017.

BERTI, R. D. C. R. Interaction of turbulent structures with ethanol sprays in mixture formation processes in a constant-flow chamber. Universidade de São Paulo. São Paulo, p. 154. 2018. Tese de Doutorado.

BOOMSMA, A. et al. PIV Uncertainty: Experimental Evaluation of Uncertainty Methods. 11th International symposium on particle image velocimetry. anta Barbara,: [s.n.]. 2015. 
BRUCKER, C. PIV in two-phase flows. Particle Image Velocimetry and associated techniques, 2000.

BRUSSTAR, M.; BAKENHUS, M. EPA - Transportation and Air Quality. Economical. High-Efficiency Engine Technologies for Alcohol Fuels., 2010. Disponivel em: 〈>. Acesso em: 16 fevereiro 2019.

CHARONKO, J. J.; VLACHOS, P. P. Estimation of uncertainty bounds for individual particle image velocimetry measurements from cross-correlation peak ratio. Measurement Science and Tecnology, v. 24, p. 65301, 2013.

DANKERS, S. et al. Two-Phase PIV: Fuel-Spray Interaction with Surrounding Air. Springer-Verlag, Berlin, 2008. 333-343.

DANTEC DYNAMICS S/A. DynamicStudio User's Guide. Skovlunde: [s.n.]. 2015.

DEEN, N. G. et al. On image pre-processing for PIV of single- and two-phase flows over reflecting objects. Experiment in Fluids, 2010. ISSN DOI 10.1007/s00348010-0827-y.

DIAS, R. F.; DE CARVALHO, C. A. A. Bioeconomia no Brasil e no Mundo: Panorama Atual e. Rev. Virtual Quim., p. 410-430, Setembro 2017.

DIKSHIT, S. et al. Experimental investigations of performance parameters of pressure swirl atomizer for kerosene type fuel. Proceedings of ASME Turbo Expo 2009, Orlando, p. 61-77, 2009.

DOMANN, R.; HARDALUPAS, Y. Planar droplet sizing for quantification of spray unsteadiness. 18th ILASS - Europe. [S.1.]: [s.n.]. 2002.

DRISCOLL, K. D.; SICK, V.; GRAY, C. Simultaneous air/fuel-phase PIV measurements in a dense fuel spray. Experiments in Fluids, v. 35, p. 112-115, 2003. ISSN DOI 10.1007/s00348-003-0647-4.

DUARTE, A. EXPERIMENTAL AND NUMERICAL ANALYSES OF WATER-PUMP INTAKES. University of Hannover. [S.1.], p. 138. 2005. 
DUNCAN, J. et al. Universal outlier detection for particle image velocimetry (PIV) and particle tracking velocimetry (PTV) data. Measurement Science and Technology, p. 57002, 2010.

ECKSTEIN, A.; VLACHOS, P. P. Digital particle image velocimetry (DPIV) robust phase correlation. Measurement Science and Technology, 2009.

FRITSCHE, F. N.; CARLSON, R. E. Monotone Piecewise Cubic Interpolation. SIAM Journal on Numerical Analysis, v. 17, p. 238-246, 1980.

GARCIA, D. Robust smoothing of gridded data in one and higher dimensions with missing values. Computational Statistics \& Data Analysis, 2010. 1167-1178.

GARCIA, D. A fast-all-in-one method for automated post-processing of PIV data. Experiments in Fluids, p. 1247-1259, 2011.

GONZALEZ, R. C.; WOODS, R. E. Processamento Digital de Imagens. $3^{\text {a }}$ Edição. ed. [S.1.]: [s.n.], 2010.

GUNES, H.; RIST, U. Spatial resolution enhancement/smoothing of stereoparticle-image-velocimetry data using proper-orthogonal-decomposition-based and Kriging interpolation methods. Physics of Fluids, p. 64101, 2007.

GUZZEllA, L.; SCIARRETTA, A. Vehicle Propulsion Systems. Berlin: Springer, 2007. ISBN 9783540746911.

HART, D. P. PIV error correction. Experiments in Fluids, p. 13-22, 2000.

HONKANEN, M.; NOBACH, H. Background extraction from double-frame PIV images. Experiments in Fluids, p. 348-362, 2005.

INTERNATIONAL TOWING TANK CONFERENCE - ITTC. Guideline on Best Practices for the Application of PIV/SPIV in Towing Tanks and Cavitation Tunnels. Flow Measurement Techniques of the 27th ITTC. [S.1.]: [s.n.]. 2014.

JEDELSKY, J. et al. Air-liquid interactions in a pressure-swirl spray. International Journal of Heat and Mass Transfer, p. 788-804, Março 2018. 
KEANE, R. D.; ADRIAN, R. J. Optimization of particle image velocimetry. Part I: double pulsed systems. Measurement ans Science Tecnology, p. 1202-1215, 1990. ISSN DOI: 10.1088/0957-0233/1/11/013.

KEANE, R. D.; ADRIAN, R. J. Theory of cross-correlation analysis of PIV images. Applied Scientific Research, v. 49, p. 191-215, 1992.

KHALITOV, D. A.; LONGMIRE, E. K. Simultaneous two-phase PIV by twoparameter phase discrimination. Experiments in Fluids, p. 252-268, 2002.

KIGER, K. T.; PAN, C. Technique for the Simultaneous Measurement of Dilute Two-Phase Flows. Journal of Fluids Engineering, p. 811, 2000.

KOSIWCZUK, W. et al. Simultaneous velocity field measurements in two-phase flows for turbulent mixing of sprays by means of two-phase PIV. Experiments in Fluids, v. 39, p. 895-908, Novembro 2005.

LAVISION. Flow Master. Gottingen, p. 174. 2017.

LEFEBVRE, A. H. Atomization and Sprays. Indiana: Taylor \& Francis, 1989.

LEFEBVRE, A. H.; MCDONELL, V. G. Atomization and Sprays. Nova York: CRC Press, 2017.

LI, T.; NISHIDA, K.; HIROYASU, H. Droplet size distribution and evaporization characteristics of fuel spray by type atomizer, 90, 2011. 2367-2376.

LI, X. et al. Combustion and emission characteristics of a two stroke diesel engine opeating on alcohol. Renewable Energy, v. 30, p. 1952-1964, 2005.

LIANG, D.; JIANG, C.; LI, Y. Cellular neural network to detect spurious vectors in PIV data. Experiments in Fluids, p. 52-62, 2003.

LIU, Z. et al. Flow-adaptive data validation scheme in PIV. Chemical Engineering Science, p. 1-11, 2008.

MARQUES, O. Practical Image and Video Processing Using MATLAB. Canada: John Wiley \& Sons, 2011. 
MASULLO, A.; THEUNISSEN, R. Adaptive vector validation in image velocimetry to minimise the influence of outlier clusters. Experiments in Fluids, p. 33, 2016.

MERKER, G. P.; SCHWARZ, C.; TEICHMANN, R. Combustion Engines Development - Mixture Formation, Combustion Emissions and Simulation. Berlin: Springer, 2009. ISBN 978-3-642-02951-6.

MILLER, J. Reaction time analysis with outlier exclusion: Bias varies with sample size. The Quarterly Journal of Experimental Psychology, v. 43, n. 4, p. 907912, 1991.

MOON, S. et al. Measurements of droplet size distribution and in-cylinder mixture formation from a slit injector in a direct-injection gasoline engine. Third Internation Conference on Optical and Laser Diagnostics. [S.1.]: [s.n.]. 2007.

MOON, S. et al. Gas entrainment characteristics of diesel spray injected by a group-hole nozzle. Fuel, v. 89, p. 3287-3299, Maio 2010.

MOREAL, V. F. S. et al. APLICAÇÃO DA TÉCNICA DE SUPERFÍCIE AQUECIDA EM MOTORES DE COMBUSTÃO ESPONTÂNEA COM UTILIZAÇÃ̃ DE ETANOL. Instituto Mauá de Tecnologia. São Caetano do Sul, p. 96. 2017. Trabalho de Conclusão de Curso.

MOREAL, V. F. S. et al. Aplicação da técnina de superfície aquecida em motores de combustão espontânea com utilização de etanol visando a redução de emissão de CO2 e o aumento de eficiência. AEA. São Paulo: [s.n.]. 2018.

MOURA, H. L. QUALITY ANALYSIS OF F-PIV MEASUREMENTS AND FLUID DYNAMICS STUDY IN A BUBBLE COLUMN USING CHAOTIC INVARIANTS. UNICAMP. Campinas, p. 175. 2017. Tese de Doutorado.

NEAL, D. R. et al. Collaborative framework for PIV uncertainty quantification: the experimental database. Measurement Science and Technology, v. 26, p. 74003, 2015. 
NOGUEIRA, J.; LECUONA, A.; RODRÍGUEZ, P. A. Data validation, false vectors correction and derived magnitudes calculation on PIV data. Measurement Science and Technology, p. 1493-1501, 1997.

OECD/ITF. ITF Transport Outlook 2017. ITF Transport Outlook. Paris: OECD Publishing. 2017. p. 224.

PROSPERI, B.; DELAY, G.; BAZILE, R. FPIV study of gas entrainment by a hollow cone spray submitted to variable density. Experiments in Fluids, v. 43, 2007. 315-327.

PUN, C.-S.; SUSANTO, A.; DABIRI, D. Mode-ratio bootstrapping method for PIV outlier correction. Measurement Science and Technology, p. 3511-3522, 2007.

RAFFEL, M. et al. Particle Image Velocimetry: A Practical Guide. [S.1.]: Springer-Verlag, 2007. Acesso em: 2 jun. 2019.

ROTTENKOLBER, G. et al. Spray analysis of a gasoline direct injector by means of two-phase PIV. Springer-Verlag, 2002. 710-721.

SAGE, D.; UNSER, M. Teaching Image-Processing Programming in Java. IEEE Signal Processing Magazine, v. 20, n. 6, p. 43-52, Novembro 2003.

SANTOLAYA, J. L. et al. Effects of droplet collision phenomena on the development of pressure swirl spray. Interntional Journal of Multiphase Flow, p. 160$171,2013$.

SCARANO, F. Iterative image deformation methods in PIV. Measurement and Science Tecnology, p. 1-19, 2001. ISSN DOI: 10.1088/0957-0233/13/1/201.

SCARANO, F.; RIETHMULLER, M. L. Iterative multigrid approach in PIV image processing with discrete window offset. Experiments in Fluids, v. 26, p. 513-523, 1999. ISSN Print ISSN 0723-4864.

SCARANO, F.; RIETHMULLER, M. L. Advances in iterative multigrid PIV image processing. Experiments in Fluids, v. Suppl., p. 51-60, 2000. 
SCHARNOWSKI, S.; KÄHLER, C. J. On the loss-of-correlation due to PIV image noise. Experiments in Fluids, v. 57, n. 7, p. 119, 2016a. ISSN DOI 10.1007/s00348-016-2203-z. Disponivel

em: <https://link.springer.com/article/10.1007/s00348-016-2203-z>. Acesso em: 4 jun. 2019.

SCHARNOWSKI, S.; KÄHLER, C. J. Estimation and optimization of loss of pair uncertainties based on PIV correlation functions. Experiments in Fluids, Fevereiro 2016b. ISSN DOI:10.1007/s00348-015-2108-2.

SCHARNOWSKI, S.; SCIACCHITANO, A.; KÄHLER, C. J. On the universality of Keane \& Adrian's valid detection probability in PIV. Measurement Science and Technology, v. 30, p. 035203, 2019.

SCIACCHITANO, A. et al. Collaborative framework for PIV uncertainty quantification: comparative assessment of methods. Measurement Science and Technology, v. 26, p. 074004, jun. 2015. Disponivel em: <https://doi.org/10.1088\%2F0957-0233\%2F26\%2F7\%2F074004>.

SCIACCHITANO, A.; WIENEKE, B.; SCARANO. PIV uncertainty quantification by image matching. Measurement Science and Technology, v. 24, p. 45302, 2013.

SCIACCHITANO, A.; WIENEKE, B.; SCARANO, F. PIV uncertainty quantification by image matching. Measurement Science and Technology, v. 24, p. 045302, mar. 2013. Disponivel em: <https://doi.org/10.1088\%2F09570233\%2F24\%2F4\%2F045302>.

SHAVIT, U.; LOWE, R. J.; STEINBUCK, J. V. Intensity Capping: a simple method to improve cross-correlation PIV results. Experiments in Fluids, p. 225-240, 2007.

SHINNEEB, A. M.; BUGG, J. D.; BALACHANDAR, R. Variable threshold outlier identification in PIV data. Measurement Science and Technology, p. 1722-1732, 2004. 
SILVÉRIO, V.; CARDOSO, S.; MOREIRA, A. L. N. Laser induced fluorescence thermometry to characterize flow boiling Laser induced fluorescence thermometry to characterize flow boiling. 18th International Symposium on the Application of Laser and Imaging Techniques to Fluid Mechanics. Lisboa (Portugal): [s.n.]. 2016.

SOID, S.; ZAINAL, Z. Spray and combustion characterization for internal combustion engines using optical measuring techniques - a review. Energy, 36, 2011. 724-741.

SOLOMON, C.; BRECKON, T. Fundamentals of Digital Image Processing A practical approach with examples in MatLab. [S.1.]: John Wiley \& Sons, LTD, 2011.

SORNEK, R. J.; DOBASHI, R.; HIRANO, T. Effect of turbulence on vaporization, mixing and combustion of liquid-fuel sprays. Combustion Flame, p. 479491, 2000.

TIMMINS, B. H. et al. A method for automatic estimation of instantaneous local uncertainty in particle image velocimetry measurements. Experiments in Fluids, v. 53, p. 1133-1147, 2012.

TIMMINS, B. H.; SMITH, B. L.; VLACHOS, P. P. Automatic Particle Image Velocimetry Uncertainty Quantification. 3rd Joint US-European Fluids Engineering Summer Meeting. [S.1.]: [s.n.]. 2010. v.1, Symposia - Parts A, B, and C. Anais. ASME, 2010.

TISCHER, V.; POLETTE, M. Metropolis Notebook. Cadernos Metrópole, São Paulo, 3 Junho 2019. Acesso em: 15 Julho 2019. Disponível em: http://dx.doi.org/10.1590/2236-9996.2019-4506.

TODARO, R. H. et al. EFEITO DA TEMPERATURA DO AR DE ADMISSÃO NO ATRASO DE IGNIÇÃO DE UM MOTOR A ETANOL DE IGNIÇÃO ASSISTIDA POR SUPERFÍCIE AQUECIDA. SIMEA 2019. São Paulo: [s.n.]. 2019. 
TOWERS, D.; TOWERS, C. B. C. H.; REEVES, M. A colour PIV system employing fluorescent particles for two-phase flow measurements. Measurement Science and Technology, 10, 1999. 824-830.

TSANG, K. S.; Z.H., Z.; CHEUNG, C. S. . C. T. L. Reducing Emissions of a Diesel Engine Using Fumigation Ethanol and a Diesel Oxidation Catalyst. Energy Fuel, v. 24, p. 6156-6165, 2010.

TURNER, J. W. G.; AL., E. Alcohol-based Fuels in High Performance Engines. SAE Technical Paper 2007-01-0056, 2007. DOI: 10.4271/2007-01-0056.

WESTERWEEL, J. Fundamentals of digital particle image velocimetry. Measurement Science and Technology, v. 8, p. 1379-1392, 1997. ISSN PII: S09570233(97)84477-3.

WESTERWEEL, J. On velocity gradients in PIV interrogation. Experiments in Fluids, v. $44, \quad$ n. $5, \quad$ p. 831-842, 2008. Disponivel em: <https://link.springer.com/content/pdf/10.1007/s00348-007-0439-3.pdf >. Acesso em: 4 jun. 2019.

WESTERWEEL, J.; ELSINGA, G. E.; ADRIAN, R. J. Particle Image Velocimetry for Complex and Turbulent Flows. Annual Review of Fluid Mechanics, p. 409-436, Março 2013.

WESTERWEEL, J.; SCARANO, F. Universal outlier detection for PIV data. Experiments in Fluids, v. 39, p. 1096-1100, 2005.

WIENEKE, B. PIV uncertainty quantification from correlation statistics. Measurement Science and Technology, v. 26, p. 074002, jun. 2015. Disponivel em: <https://doi.org/10.1088\%2F0957-0233\%2F26\%2F7\%2F074002>.

WILLERT, C. The fully digital evaluation of photographic PIV recordings. Applied Scientific Research, v. 56, p. 79-102, Junho 1996.

XUE, Z.; CHARONKO, J. J.; VLACHOS, P. P. Particle image velocimetry correlation signal-to-noise ratio metrics and measurement uncertainty quantification. Measurement Science and Technology, v. 25, p. 115301, 2014. 
XUE, Z.; CHARONKO, J. J.; VLACHOS, P. P. Particle image pattern mutual information and uncertainty estimation for particle image velocimetry. Measurement Science and Technology, v. 26, p. 74001, 2015.

ZABEU, C. B. Investigações de estratégias de injeção e ignição de etanol em câmara de combustão de volume constante. Universidade de São Paulo. São Paulo, p. 270. 2018. Tese de Doutorado.

ZHANG, M.; XU, M.; HUNG, D. L. S. Simultaneous two-phase flow measurement of spray mixing process by means of high-speed two-color PIV. Measureament Science and Technology, p. 8, Julho 2014.

ZHU, K. K.; NISHIDA, O.; MOON, S. Quantitative analyses of fuel spray ambient gas interaction by means of LIF-PIV technique. Atomization and Sprays, 21, n. 6, 2011. 447-465.

ZHU, L. et al. Emissions characteristics of a diesel engine operating on biodiesel and biodiesel blended with ethanol and methanol. Science of the Total Environment, v. 408, p. 921-941, 2010.

ZHU, L.; CHEUNG, C. S.; ZHANG, W. G. Combustion, performance and emission characteristics of a DI diesel engine fueled with ethanol-biodiesel blends. Fuel, v. 90, p. $1743-1750,2011$. 


\section{APÊNDICE A - FILTROS MORFOLÓGICOS}

Neste tópico apresentar-se-á uma síntese sobre os elementos necessários para compor o processamento morfológico de imagens binárias, com o intuito de possibilitar ao leitor a melhor compreensão sobre a forma com a qual a etapa de filtragem morfológica foi desenvolvida na seção 3.2.1.1.

A lógica atrelada ao processamento morfológico de imagens é caracterizada pelo uso de métodos matemáticos rebuscados, uma vez que a sua definição é fortemente baseada na teoria dos conjuntos. Deste modo, embora o rigor matemático embutido na aplicação da morfologia seja uma vantagem substancial, o processamento morfológico não é acessível aos usuários que não estejam familiarizados com a base matemática empregada, fato que motiva a compreensão das ferramentas associadas à lógica morfológica por meio de discussões de cunho prático voltadas a um interesse comum: a extração de informações diretamente associadas à topologia e à geometria presentes em uma imagem (SOLOMON e BRECKON, 2011; MARQUES, 2011). Os filtros morfológicos atuam nas imagens binárias e definidas em escala de cinza com o aporte de operadores morfológicos, os quais têm grande capacidade de identificar e extrair descritores com base em propriedades de contornos e formas, segundo Breckon e Solomon (2016). De acordo com os autores, para que o processamento de imagens por meio de lógica morfológica seja realizado, a participação conjunta de três fatores é imprescindível: a imagem, o tipo de operação morfológica e o elemento estruturante.

O primeiro refere-se simplesmente à matriz de pixels que será processada, isto é, a imagem propriamente dita. Já o segundo, consiste no tipo de operação morfológica que será realizada, sendo este entendido como uma função do objetivo pretendido com o processamento morfológico. Cabe ao último o papel mais importante em qualquer tratamento de imagem com ferramentas morfológicas, pois é a entidade que determina os pixels que serão alterados em uma determinada vizinhança e é função dos objetivos pretendidos com a aplicação da lógica morfológica.

De acordo com Gonzalez e Woods (2010) e com Marques (2011), o elemento estruturante é uma matriz de pixels descrita por valores 0 ou 1, cuja forma e tamanho afetam os resultados da aplicação de um determinado operador morfológico em uma 
imagem. Segundo Solomon e Breckon (2016), este elemento pode definir qualquer vizinhança que for de interesse ao usuário, desde que o preenchimento com zeros seja tal que a forma retangular da matriz seja preservada. A Figura A.1 mostra dois exemplos de elementos estruturantes, voltados a tratamento de imagens binárias, junto às respectivas representações matriciais. Nela, o ponto preto refere-se ao pixel central (referência para os operadores morfológicos), os quadrados cinzas descrevem os elementos da matriz que têm intensidades iguais à unidade, enquanto os quadrados brancos representam os zeros e preenchem o elemento estruturante para garantir o arranjo retangular.

Figura A.1 - Exemplos de elementos estruturantes e suas respectivas representações por matrizes binárias: (a) quadrado de lado 3; (b) círculo de raio unitário.

(a) - Quadrado

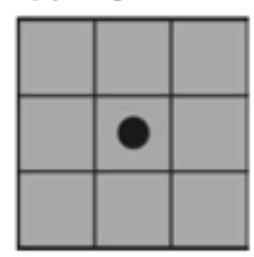

$\left[\begin{array}{lll}1 & 1 & 1 \\ 1 & 1 & 1 \\ 1 & 1 & 1\end{array}\right]$ (b) - Disco

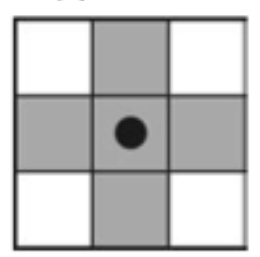

$\left[\begin{array}{lll}0 & 1 & 0 \\ 1 & 1 & 1 \\ 0 & 1 & 0\end{array}\right]$

Fonte: Autor.

No tocante às operações matemáticas pertencentes à morfologia, a Erosão e a Dilatação são as operações fundamentais que regem os algoritmos de processamento morfológico de imagens. Tratando-se de imagens binárias, em geral a Dilatação é uma operação que produz um efeito de "engrossar" objetos, isto é, de torná-los ligeiramente mais robustos e destacados. No entanto, a intensidade com a qual a robustez acontece é função do tamanho e da forma do elemento estruturante utilizado na Dilatação. Dissemelhantemente, a Erosão destina às imagens binárias o efeito de "encolher" ou “afinar" descritores presentes, também controlável pela escolha do elemento estruturante. As Equações A.1 e A.2 apresentam, nessa ordem, as representações matemáticas das operações de Dilatação e Erosão de uma imagem A utilizando um elemento estruturante B. A Figura A.2 e a Figura A.3 mostram, a partir de uma determinada imagem e nesta ordem, os efeitos típicos produzidos pela dilatação e pela erosão, ambas efetuadas considerando círculos com raios iguais a 5, 10 e 20 como elementos estruturantes. 


$$
\begin{gathered}
A \oplus B=\left\{z \mid(\widehat{B})_{Z} \cap A \neq \emptyset\right\} \\
A \ominus B=\left\{z \mid(\hat{B})_{Z} \cup A^{C} \neq \varnothing\right\}
\end{gathered}
$$

Mediante a análise da Figura A.2, percebe-se que a operação de dilatação combinada ao aumento da ordem da matriz que define o elemento estrutural tornou os todos os elementos geométricos presentes cada vez mais grosseiros, o que gerou um aumento considerável da quantidade de pixels com valor unitário e a perda do discernimento entre as partes que definem a imagem original. De modo antitético, com o aumento do elemento estruturante utilizado para erodir a imagem tida como referência, verifica-se que as linhas são cada vez mais apagadas à medida que o raio do elemento aumenta, enquanto o quadrado localizado ao centro permanece inalterado, com exceção das bordas que o limita. Por conseguinte, percebe-se que as imagens erodidas com elementos maiores apresentam-se mais escuras frente àquelas processadas com círculos menores e/ou sem tratamento morfológico.

Figura A.2 - Efeitos produzidos pela dilatação de uma imagem sem tratamento (a) por discos de raio 5 (b), 10(c) e 20 (d).

(a)

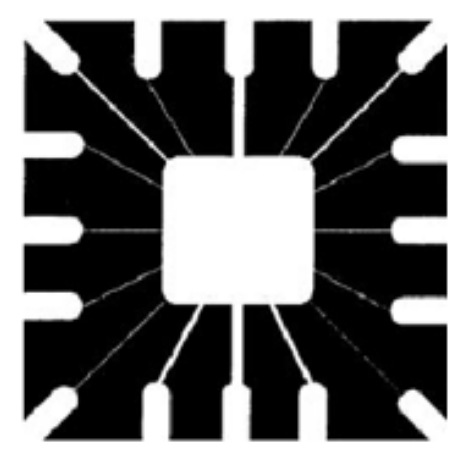

(c)

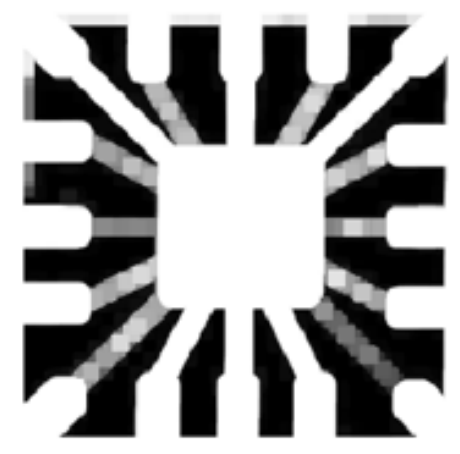

(b)

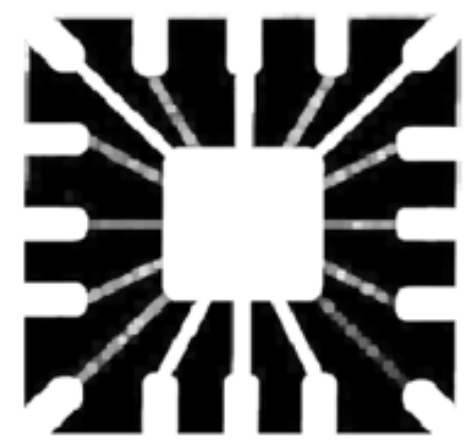

(d)

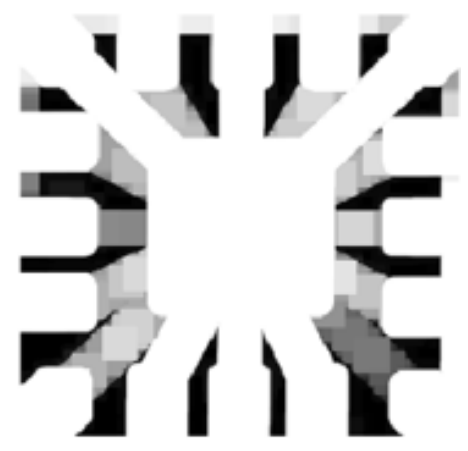

Fonte: Autor. 
Figura A.3 - Efeitos produzidos pela erosão de uma imagem sem tratamento (a) por discos de raio 5 (b), 10(c) e 20 (d).

(a)

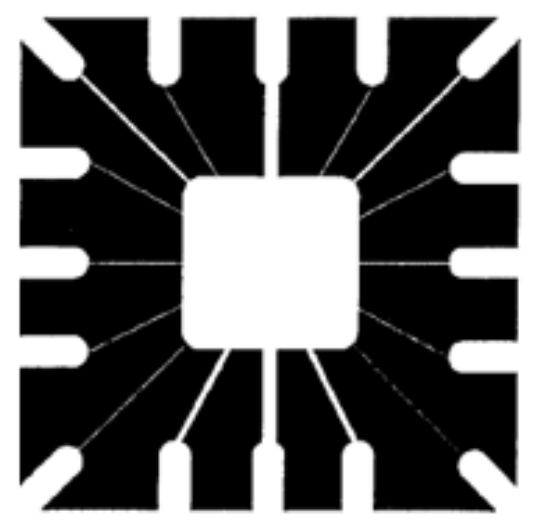

(c)

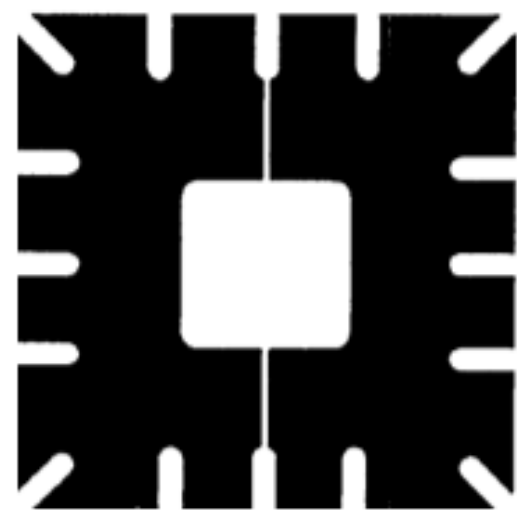

(b)

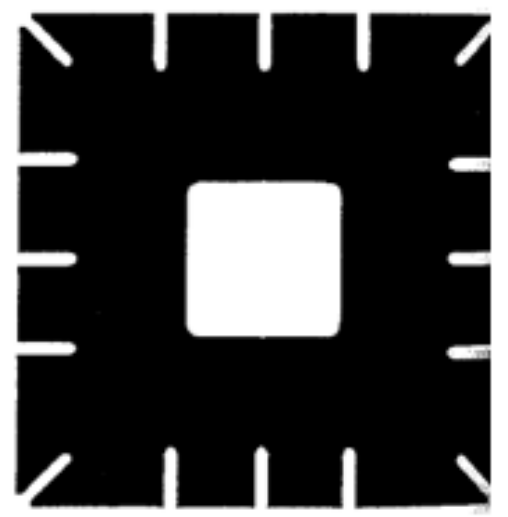

(d)

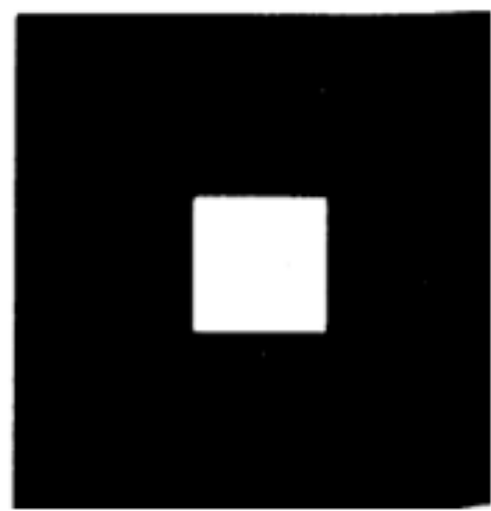

Fonte: Autor.

Por fim, tratando-se de imagens em escala de cinza, são poucas as ferramentas voltadas ao processamento morfológico de imagens binárias que devem ser alteradas para serem utilizadas. No caso das operações principais que governam os algoritmos de morfologia de imagens, as alterações são sutis e podem ser definidas de diversas formas. A começar do elemento estruturante, Solomon e Breckon (2011) mostram que para trabalhar com imagens em escala de cinza, o mesmo é definido em duas partes (tipo NonFlat). A primeira, denominada por $b$, é uma matriz de zeros e uns que define a vizinhança local que será considerada em uma determinada operação morfológica (proposta idêntica à do elemento $\mathrm{B}$, nesse caso chamada de Flat). A segunda, $v_{b}$, consiste em uma matriz de mesmo tamanho que contém os verdadeiros valores numéricos que pretende-se utilizar no elemento estruturante. No tocante aos principais operadores 
morfológicos, os autores apresentam um procedimento capaz de erodir uma imagem em escala de cinza, $A$, utilizando um elemento estruturante $B$, que compreende a consecução das seguintes etapas:

- posicionar o elemento estrutural B sucessivamente sobre cada posição na imagem A;

- em casa posição, selecionar o menor valor de A - B que ocorre na vizinhança local definida pelo elemento estruturante.

Analogamente, Solomon e Breckon (2011) descrevem o procedimento de dilatação de $A$, utilizando um elemento estruturante $\mathrm{B}$, da seguinte forma:

- posicionar o elemento estrutural B sucessivamente sobre cada posição na imagem A;

- em casa posição, selecionar o maior valor de $\mathrm{A}+\mathrm{B}$ que ocorre na vizinhança local definida pelo elemento estruturante.

Um exemplo sobre a forma geral da erosão de uma parte de uma imagem quantizada com 4 bits é dado a seguir. Para tanto, estabelece-se que o elemento estruturante $b$ é um círculo de raio unitário, além de que $v_{b}$ e A representa, nesta ordem, a matriz de coeficientes do elemento $b$ e a matriz que representa a intensidade dos pixels da imagem considerada.

$$
\begin{gathered}
v_{b}=\left[\begin{array}{ccc}
0 & v_{12} & 0 \\
v_{21} & 1 & v_{23} \\
0 & v_{32} & 0
\end{array}\right]=\left[\begin{array}{lll}
0 & 3 & 0 \\
3 & 1 & 3 \\
0 & 3 & 0
\end{array}\right] \\
A=\left[\begin{array}{lll}
a_{11} & a_{12} & a_{13} \\
a_{21} & a_{22} & a_{23} \\
a_{31} & a_{32} & a_{33}
\end{array}\right]=\left[\begin{array}{ccc}
12 & 13 & 11 \\
7 & 14 & 8 \\
10 & 9 & 10
\end{array}\right]
\end{gathered}
$$

Deste modo, a fim de demonstrar o procedimento de erosão proposto por Solomon e Breckon (2011) calcular-se-á o valor do pixel central de $A, \overline{A_{E}}$, após a erosão de $A$ por $v_{b}$ de acordo com a Equação A.3. O resultado é apresentado em negrito na Equação A.4.

$$
\begin{gathered}
\bar{A}_{E}=\min \left\{\left(a_{21}-v_{21}\right) ;\left(a_{12}-v_{12}\right) ;\left(a_{22}-1\right) ;\left(a_{32}-v_{32}\right) ;\left(a_{23}-v_{23}\right)\right\} \\
\bar{A}_{E}=\min \{(7-3) ;(13-3) ;(14-1) ;(9-3) ;(8-3)\}=\mathbf{4}
\end{gathered}
$$


Visto o procedimento de cálculo referente à erosão de $A$ pelo elemento estruturante NonFlat, $v_{b}$, propõe-se utilizar as mesmas informação para exemplificar o método de obtenção dos valor do pixel central de $A$ por dilatação. Para tanto, de acordo com a proposta de Solomon e Breckon (2011), a intensidade do pixel central, $\bar{A}_{D}$, após a dilatação de $A$ por $v_{b}$ é calculada pela Equação A.5. O resultado é divulgado em destaque pela Equação A.6.

$$
\begin{gathered}
\bar{A}_{E}=\min \left\{\left(a_{21}+v_{21}\right) ;\left(a_{12}+v_{12}\right) ;\left(a_{22}+1\right) ;\left(a_{32}+v_{32}\right) ;\left(a_{23}+v_{23}\right)\right\} \\
\bar{A}_{E}=\min \{(7+3) ;(13+3) ;(14+1) ;(9+3) ;(8+3)\}=\mathbf{1 6}
\end{gathered}
$$

Por fim, a Figura A.4 ilustra uma representação matricial da imagem $A$ processada uma única vez pelos filtros morfológicos de dilatação e erosão. No caso do processamento de uma imagem completa, os procedimentos de cálculo supracitados são efetuados em todos os pixels da imagem de interesse.

Figura A.4 - Representação da matriz de pixels da matriz $A$ submetida à erosão (a) e à dilatação (b) pelo elemento estruturante $v_{b}$.

(a)

\begin{tabular}{|c|c|c|}
\hline 12 & 13 & 11 \\
\hline 7 & 4 & 8 \\
\hline 10 & 9 & 10 \\
\hline
\end{tabular}

(b)

\begin{tabular}{|c|c|c|}
\hline 12 & 13 & 11 \\
\hline 7 & 16 & 8 \\
\hline 10 & 9 & 10 \\
\hline
\end{tabular}

Fonte: Autor.

Amplo arrazoado teórico acerca do processamento morfológico de imagens são encontrados nas obras de Gonzalez e Woods (2010) e de Marques (2011). No presente trabalho, as ferramentas de processamento morfológico foram utilizadas para produzir uma máscara capaz de suprir as regiões ruidosas das imagens primárias da fase gasosa. 


\section{APÊNDICE B - FILTRO GAUSSIANO}

O Filtro Gaussiano é um filtro espacial do tipo passa-baixa. Devido a essa classificação, o mesmo traz contribuições à imagem processada similares às que seriam esperadas se a matriz de pixels fosse tratada com ferramentas de tratamento de imagens no domínio da frequência voltadas a preservar as regiões com frequências baixas e a suavizar aquelas com frequências maiores. Por conseguinte, o filtro em discussão é indicado para reduzir ruídos e preservar regiões homogêneas, além de ser capaz produzir o efeito blur - efeito de atenuação destinado a todo o espaço de imagem que pode ser percebido através de um aspecto borrado presente imagem tratada (Marques, 2011).

De acordo com Solomon e Breckon (2011), a aplicação do Filtro Gaussiano se dá com o uso de uma máscara de convolução (kernel) composta por coeficientes oriundos da aproximação discreta da Equação B.1. Nela, $x$ e $y$ referem-se à posição do pixel no kernel adotado e o parâmetro $\sigma$ refere-se ao desvio padrão, responsável por controlar a forma com a qual a superfície Gaussiana é produzida (maiores $\sigma$ produzem superfícies mais achatadas). Neste filtro, o tamanho do kernel é definido pelo usuário através de uma matriz quadrada de ordem $N$.

$$
f(x, y)=\frac{1}{2 \pi \sigma^{2}} \exp \left(-\frac{x^{2}+y^{2}}{2 \sigma^{2}}\right)
$$

A Figura B.1 mostra dois exemplos de máscaras de convolução gerados com a aplicação da Equação 7.1 para as seguintes configurações: (a) $\sigma=1$ e $N=3$; (b) $\sigma=2$ e $N=11$. As matrizes $G_{1}$ e $G_{2}$ referem-se às máscaras produzidas a partir das configurações (a) e (b), respectivamente. A Figura B.2 apresenta um exemplo sobre os efeitos que os filtros gaussianos configurados com os parâmetros dados por (a) e (b) produzem em uma imagem tida como referência para verificar procedimentos de tratamento de imagens. Nela, é possível notar que a suavização produzida é mais pronunciada na imagem tratada com o filtro de maior desvio padrão e que detalhes finos são perdidos com maior intensidade para maiores $\sigma$. Adicionalmente, a presença mais marcante de bordas escuras na imagem processada com (b) ocorre graças à maior quantidade de valores nulos nas bordas da máscara de convolução. Vale destacar que, segundo Solomon e Breckon (2011), o tamanho do kernel não tem influência significativa 
no grau de suavização obtido com a aplicação do filtro Gaussiano, uma vez que a atenuação gerada é fortemente atrelada ao desvio padrão imposto à Equação B.1. Contudo, verifica-se que o resultado mostrado na Figura B.2 corrobora as afirmações de Solomon e Breckon (2011).

$$
G_{2}=\left[\begin{array}{lllllllllll}
0 & G_{1}=\left[\begin{array}{ccc}
8 & 12 & 8 \\
12 & 15 & 12 \\
8 & 12 & 8
\end{array}\right] \\
0 & 0 & 0 & 0 & 0 & 0 & 0 & 0 & 0 & 0 & 0 \\
0 & 0 & 0 & 0 & 0 & 1 & 0 & 0 & 0 & 0 & 0 \\
0 & 0 & 1 & 1 & 1 & 1 & 1 & 1 & 0 & 0 & 0 \\
0 & 0 & 1 & 2 & 3 & 4 & 3 & 2 & 1 & 0 & 0 \\
0 & 1 & 1 & 2 & 4 & 4 & 4 & 2 & 1 & 1 & 0 \\
0 & 0 & 1 & 2 & 3 & 4 & 3 & 2 & 1 & 0 & 0 \\
0 & 0 & 1 & 1 & 2 & 2 & 2 & 1 & 1 & 0 & 0 \\
0 & 0 & 0 & 1 & 1 & 1 & 1 & 1 & 0 & 0 & 0 \\
0 & 0 & 0 & 0 & 0 & 1 & 0 & 0 & 0 & 0 & 0 \\
0 & 0 & 0 & 0 & 0 & 0 & 0 & 0 & 0 & 0 & 0
\end{array}\right]
$$

Figura B.1 - Máscaras de convolução oriundas do filtro Gaussiano configurado com os parâmetros dados por (a), à esquerda, e por (b), à direita.
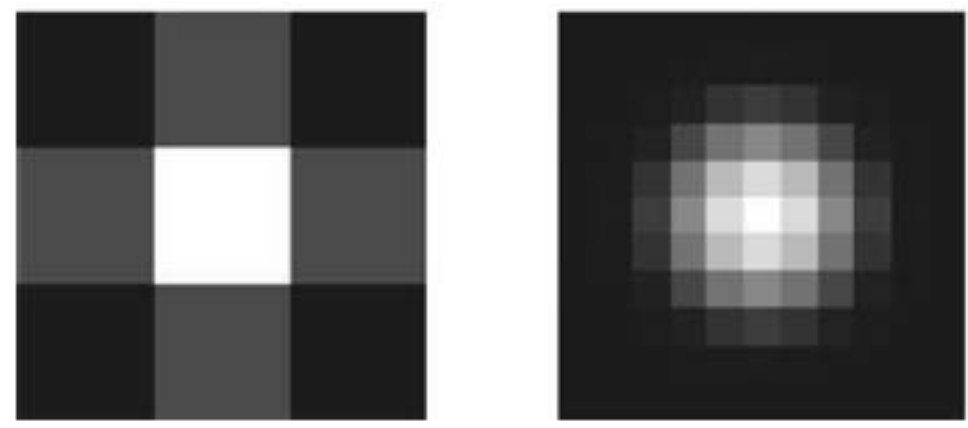

Fonte: Adaptado de Solomon e Breckon (2011). 
Figura B.2 - Efeitos da filtragem Gaussiana à uma imagem-referência (à esquerda) aplicada com $\sigma=1 ; N=3$ (meio) e $\sigma=2 ; N=11$ (à dir.).
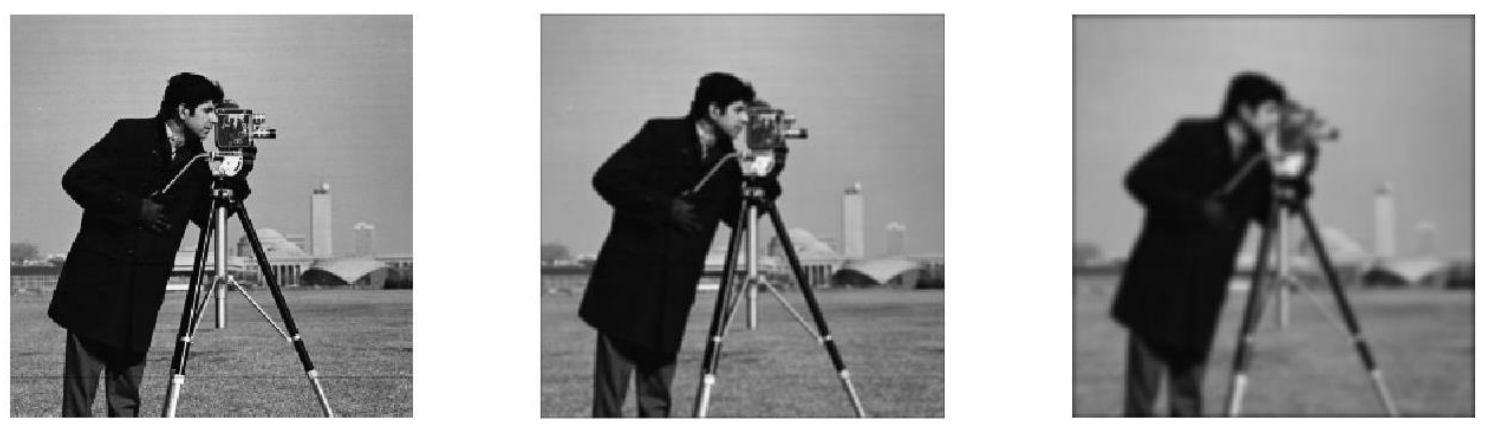

Fonte: Autor. 


\section{APÊNDICE C - FILTRO SSM}

No tocante aos conceitos básicos de processamento de imagens apontados pela literatura, a conectividade de vizinhança é uma ferramenta absolutamente indispensável quando o objetivo que deve ser alcançado com o tratamento digital requer definir uma região de influência ou de interesse (ROI, sigla em inglês). Nesse âmbito, refere-se à conectividade de vizinhança os pixels que estão conectados entre si para serem processados por um determinado algoritmo de tratamento digital de imagem. Contudo, ao definir uma vizinhança-4, significa que apenas os pixels que estão acima, abaixo e aos lados esquerdo e direito do pixel central (ou pixel alvo) serão processados juntos a ele. Analogamente, ao definir uma vizinhança- 8 significa que, além dos quatro anteriormente citados, os quatro pixels que estão diagonalmente posicionados mais próximos ao pixel central serão também considerados nos cálculos. Deste modo, a vizinhança- 8 pode ser identificada a partir de uma matriz $3 \times 3$, onde o elemento central é entendido como o pixel alvo, enquanto os demais são os vizinhos conectados a ele (GONZALEZ e WOODS, 2010; SOLOMON e BRECKON, 2011). Um exemplo simples que permite a compreensão fácil do conceito em discussão é apresentado na Figura C.1, onde o conjunto $\{N, S, L, O\}$ corresponde aos pixels conectados a $(i, j)$ por uma vizinhança-4, enquanto os pixels contidos no conjunto $\{N, S, L, O, N O, N E, S O, S E\}$ estão conectados a $(i, j)$ no caso de uma vizinhança-8.

Figura C.1 - Reprodução simbólica do conceito de conectividade de vizinhança, considerando uma imagem representada nove pixels (a), sendo (i,j) o central. (b) refere-se aos pixels conectados por vizinhança-4; (c) por vizinhança-8.

(a)

\begin{tabular}{|c|c|c|}
\hline $\mathrm{NO}$ & $\mathrm{N}$ & $\mathrm{NE}$ \\
\hline $\mathrm{O}$ & $(i, j)$ & $\mathrm{L}$ \\
\hline $\mathrm{SO}$ & $\mathrm{S}$ & $\mathrm{SE}$ \\
\hline
\end{tabular}

(b)

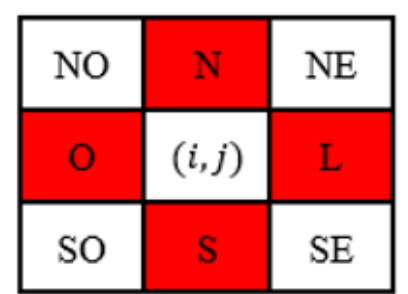

(c)

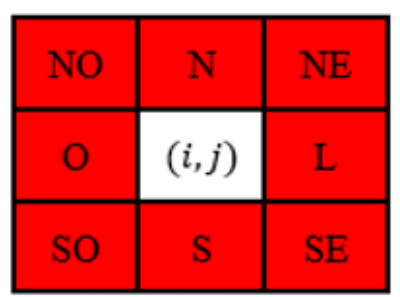

Fonte: Autor. 
No caso das operações de filtragem que requerem a imposição de uma vizinhança local delimitada por uma matriz $N x N$, as mesmas consideram uma determinada posição de pixel $(i, j)$ em termos de sua vizinhança local de pixels indexada a partir de um incremento de deslocamento, $k$. Consequentemente, tanto as dimensões quanto a escala da vizinhança podem ser ambas controladas pelo parâmetro $N$ e os pixels que serão relacionados durante as operações são indexados por $(i \pm k, j \pm k)$. Em geral, o incremento de deslocamento é metade (arredondada para baixo, com incremento igual a um, quando $N$ é ímpar) do parâmetro que define a vizinhança local, o qual é igual a três para a maioria das operações. Vale destacar que, em geral, as operações de filtragem destinadas a processar toda a imagem são efetuadas como uma sequência de operações governadas por algoritmos em vizinhanças locais, utilizando o princípio da janela deslizante (Window Sliding, em inglês), isto é, cada pixel pertencente à imagem original é processado com base em uma operação realizada em sua respectiva região de influência (SOLOMON e BRECKON, 2011).

Uma das técnicas de processamento de imagens que utiliza diretamente a ferramenta de Window Sliding para realizar as operações que a define é a Subtração pelo Mínimo Deslizante (Subtract Sliding Minimum - SSM, em inglês). Essa técnica consiste simplesmente em subtrair de uma região deslizante, formada por uma janela $N x N$, o menor dentre os $N^{2}$ valores de intensidades encontrados na ROI. Segundo Marques (2011), o aumento de contraste dos elementos destacados em uma imagem é o efeito esperado com a aplicação dessa técnica. Adicionalmente, voltado às aplicações dirigidas à velocimetria por imagens de partículas, Moura (2017) destaca que a técnica de SSM aplicada a imagens $P I V$ é capaz de remover a iluminação de fundo e/ou destacar as imagens de partículas. Entretanto, o Moura (2017) frisa que, apesar das benesses, o filtro pode produzir o efeito inconveniente de elevar a diferença de intensidade entre as populações de traçadores, e então comprometer a homogeneidade da distribuição de intensidades. Para evitar o infortúnio citado pelo último autor e um possível prejuízo à qualidade da correlação entre as imagens PIV mencionado por ele, Shavit et al. (2007) sugere aos usuários da técnica $P I V$, interessados em utilizar a filtragem por $S S M$, que um limite de intensidade seja estabelecido durante a aplicação das janelas deslizantes em todo o espaço de imagem, isto é, uma condição que torne nula a intensidade de um pixel que estiver quantizado a quem de um determinado valor. 


\section{APÊNDICE D - O MÉTODO DA CAPA DE INTENSIDADE}

Pontos ou conglomerados brilhantes (bright spots - BS, em inglês) são frequentemente percebidos em imagens PIV primárias e representam as regiões do domínio espacial onde as intensidades luminosas dos pixels são muito superiores à intensidade média da imagem em sua totalidade. Tais elementos se mostram destacados frente aos demais que compõem a matriz de pixels e são oriundos de partículas coalescidas ou simplesmente estão localizados em regiões de alta incidência de laser. Adicionalmente, anomalias na câmara utilizada para gravar as imagens primárias podem produzir o efeito de brilho intenso, tanto pelo acréscimo de intensidade, quanto pelo aumento da área da imagem de partícula (SHAVIT, LOWE e STEINBUCK, 2007).

No âmbito da aplicação da técnica de velocimetria por imagens de partículas, a preservação dos pontos brilhantes em uma imagem primária pode acarretar na perda de qualidade dos resultados obtidos com a aplicação da correlação cruzada. O principal prejuízo causado pelos $B S$ é a diminuição do discernimento das imagens de partículas que formam a população de imagens abrangida pela janela de interrogação durante a correlação entre os pares de frames, segundo Shavit, Lowe e Steinbuck (2007). Deste modo, a presença dos pontos ou conglomerados brilhantes deve ser evitada, a fim de impedir que o número efetivo de partículas seja inferior ao mínimo necessário e vetores espúrios sejam formados nas regiões de intensidade luminosa consideravelmente discrepante da média, consequentemente. Descrições detalhadas e atualizadas sobre o Número Efetivo de Partículas podem ser encontradas na seção 2.2.1 do presente trabalho ou nos trabalhos de Scharnowski e Kähler (2016a) e de Scharnowski, Sciacchitano e Kähler (2019).

Motivado pela supressão dos pontos brilhantes presentes em imagens $P I V$ primárias, o Método da Capa de Intensidade (Intensity Capping Method, em inglês) surge como uma estratégia de pré-processamento capaz de garantir a boa qualidade aos resultados provenientes da aplicação do método de $P I V$, quando da presença de $B S$. Desenvolvido por Shavit, Lowe e Steinbuck (2007), o procedimento restringe-se a afetar apenas os pixels que representem os $B S$ e é limitado a não promover modificações nas imagens tais que possam ser potencialmente prejudiciais à qualidade PIV. Segundo os idealizadores do método, a melhoria do discernimento entre as imagens de partículas 
representadas erroneamente com o elevado brilho é alcançada graças à imposição de um limite superior de intensidade luminosa, restrito a valores quantizados em escala de cinza.

Para descrever o Método da Capa de Intensidade, Shavit, Lowe e Steinbuck (2007) adotaram uma janela de interrogação fixa e genérica, responsável por abrigar partículas que se moveram em $d x$ unidades de comprimento entre duas imagens consecutivas e quantizadas em níveis de cinza. A primeira e a segunda imagens são descritas por $f$ e $g$, sendo a correlação cruzada bidimensional entre ambas definida por $\phi_{f g}$, conforme a Equação D.1. Nela, $x^{\prime}$ é uma variável espacial, $m$ é mudança no plano de correlação e as variáveis escritas em negritos são bidimensionais. Definido $\phi_{f g}(\boldsymbol{m})$, o deslocamento da população de partículas é identificado a partir da localização do máximo local da função citada, conforme mostra a Equação D.2.

$$
\begin{gathered}
\phi_{f g}(\boldsymbol{m})=\int f\left(\boldsymbol{x}^{\prime}+\boldsymbol{m}\right) g\left(\boldsymbol{x}^{\prime}\right) d \boldsymbol{x}^{\prime} \\
\phi_{f g}(d \boldsymbol{x})=\max \left(\phi_{f g}(\boldsymbol{m})\right)
\end{gathered}
$$

Considerando que as imagens $f$ e $g$ têm pontos brilhantes, os autores descompuseram-nas em $f=f_{1}+f_{2}$ e $g=g_{1}+g_{2}$, onde o subscrito 1 indica uma imagem sem os $B S$, enquanto 2 os considera. Substituindo as formas de $f$ e $g$ decompostas na Equação D.1, tem-se:

$$
\phi_{f g}(\boldsymbol{m})=\phi_{f 1 g 1}(\boldsymbol{m})+\phi_{f 1 g 2}(\boldsymbol{m})+\phi_{f 2 g 1}(\boldsymbol{m})+\phi_{f 2 g 2}(\boldsymbol{m})
$$

Sendo:

$$
\begin{aligned}
& \phi_{f 1 g 1}(\boldsymbol{m})=\int f_{1}\left(\boldsymbol{x}^{\prime}+\boldsymbol{m}\right) g_{1}\left(\boldsymbol{x}^{\prime}\right) d \boldsymbol{x}^{\prime} \\
& \phi_{f 1 g_{2}}(\boldsymbol{m})=\int f_{1}\left(\boldsymbol{x}^{\prime}+\boldsymbol{m}\right) g_{2}\left(\boldsymbol{x}^{\prime}\right) d \boldsymbol{x}^{\prime} \\
& \phi_{f 2 g_{1}}(\boldsymbol{m})=\int f_{2}\left(\boldsymbol{x}^{\prime}+\boldsymbol{m}\right) g_{1}\left(\boldsymbol{x}^{\prime}\right) d \boldsymbol{x}^{\prime} \\
& \phi_{f 2 g_{2}}(\boldsymbol{m})=\int f_{2}\left(\boldsymbol{x}^{\prime}+\boldsymbol{m}\right) g_{2}\left(\boldsymbol{x}^{\prime}\right) d \boldsymbol{x}^{\prime}
\end{aligned}
$$

Finalmente, substituindo a Equação D.3 na Equação D.2, resulta:

$$
\phi_{f g}(d \boldsymbol{x})=\max \left(\phi_{f 1 g 1}(\boldsymbol{m})+\phi_{f 1 g 2}(\boldsymbol{m})+\phi_{f 2 g 1}(\boldsymbol{m})+\phi_{f 2 g 2}(\boldsymbol{m})\right)
$$


Tendo em vista o procedimento matemático proposto, Shavit, Lowe e Steinbuck (2007) assumem que o número de pontos brilhantes dentro de uma janela de interrogação é pequeno, de modo que $\phi_{f 1 g 1}(\boldsymbol{m})$ representa a maior contribuição de todas as partículas à correlação. Sendo assim, os termos $\phi_{f 1 g 2}(\boldsymbol{m}), \phi_{f 2 g 1}(\boldsymbol{m})$ e $\phi_{f 2 g 2}(\boldsymbol{m})$ representam as contribuições dos pontos brilhantes à correlação. Logo, vale destacar que se as intensidades dos pontos brilhantes forem significativas, as imagens $f_{2}$ e $g_{2}$ são pronunciadas e a correlação cruzada pode ser altamente influenciada pela presença dos $B S$. Deste modo, se os conglomerados com alto brilho não representarem adequadamente o escoamento, $\phi_{f g}(\boldsymbol{m})$ pode ser tendenciado e falsos vetores podem ser gerados.

Para evitar a má contribuição à fidelidade dos resultados oriunda das participações de $\phi_{f 1 g 2}(\boldsymbol{m}), \phi_{f 2 g 1}(\boldsymbol{m})$ e $\phi_{f 2 g 2}(\boldsymbol{m})$, os autores propuseram um limite superior de intensidade, $I_{\text {máx }}$, para todos os pixels que formavam $f$ e $g$, descrito na Equação D.9. Nela, $I_{0}$ e $\sigma$ representam a mediana e o desvio padrão de todas as intensidades presentes na imagem, respectivamente, enquanto $n$ é especificado pelo usuário do método. Para os pixels com intensidade superior a $I_{\text {máx }}$, atribui-se a ele o valor de $I_{\text {máx }}$. A Figura D.1 mostra o histograma utilizado como exemplo pelos proponentes do Método da Capa de Intensidade para ilustrar o $I_{\text {máx }}$ calculado a partir de $I_{0}$, considerando $n=2$, além da presença dos pontos brilhantes. Os últimos foram identificados graças à presença de pixels saturados.

$$
I_{m a ́ x}=I_{0}+n \cdot \sigma
$$

Segundo Shavit, Lowe e Steinbuck (2007), a aplicação do método de Intensity Capping reduz substancialmente as intensidades de $f_{2}$ e $g_{2}$ e as contribuições de $\phi_{f 1 g 2}(\boldsymbol{m}), \phi_{f 2 g 1}(\boldsymbol{m})$ e $\phi_{f 2 g 2}(\boldsymbol{m})$ são minimizadas. Consequentemente, o valor de $d x$ calculado a partir da correlação cruzada do par de imagens processadas com $\mathrm{o}$ algoritmo ora descrito reflete melhor a média dos deslocamento da população de partículas abrigada pela janela de interrogação. Adicionalmente, a produção de vetores espúrios oriundos da existência de $B S$ é minimizada. 
Figura D.1 - Histograma de uma imagem utilizada como referencia para ilustrar os parâmetros utilizados no Metodo Intensity Capping e para permitir a identificação dos pixels que se comportam como bright spots.

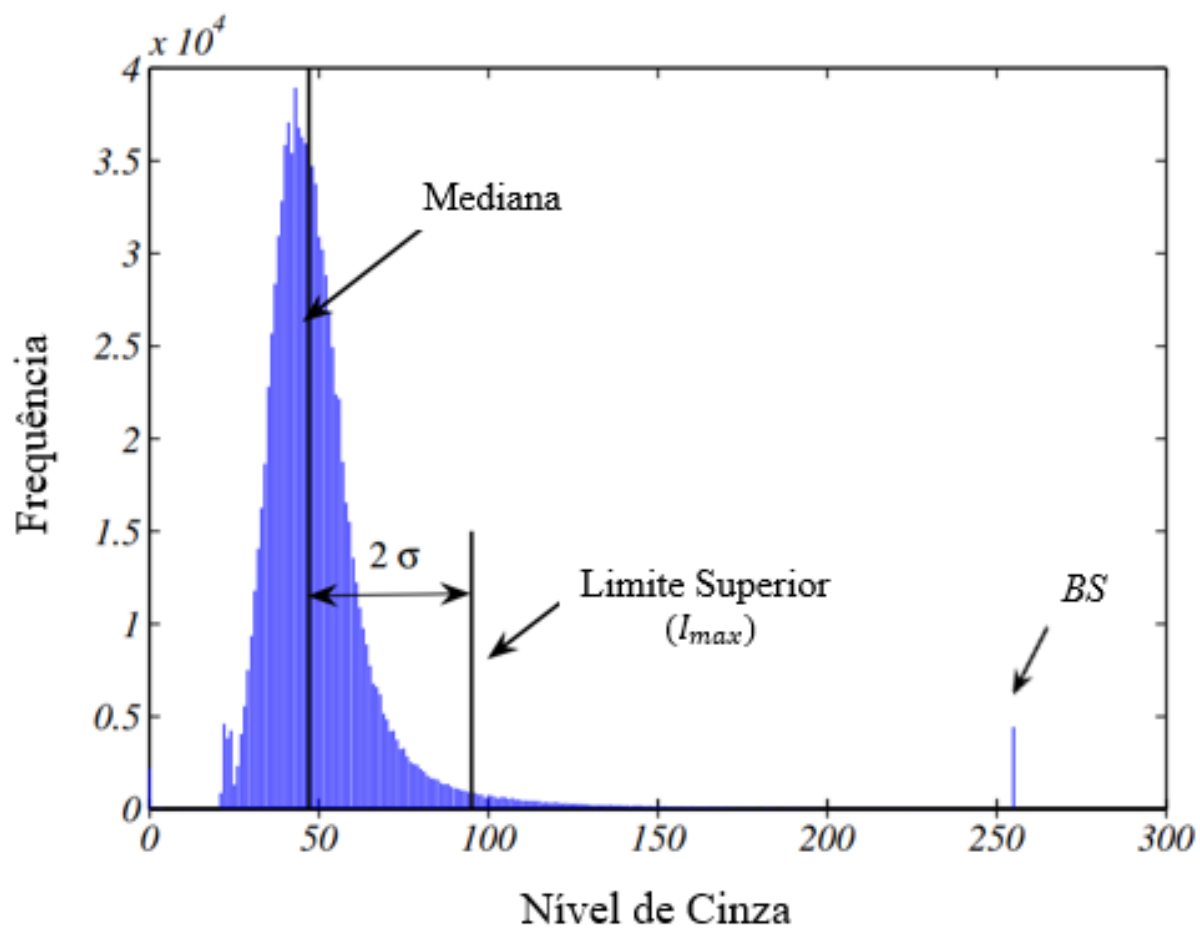

Fonte: Adaptado de Shavit, Lowe e Steinbuck (2007). 


\section{APÊNDICE E - ESTRATÉGIA DE SOBREPOSIÇÃO DE JANELAS DE INTERROGAÇÃO}

A sobreposição (overlap, em inglês) é uma estratégia de janelamento capaz de aumentar a resolução espacial de medidas $P I V$ sem diminuir o tamanho das janelas de interrogação. De acordo com a literatura, a estratégia de overlap consiste na construção de janelas de interrogação entre janelas vizinhas, a qual é realizada em conformidade a uma porcentagem de justaposição. Tal porcentagem pode ser definida nas direções horizontal e vertical (Duarte, 2005; LaVision, 2017). A Figura E.1 mostra em destaque uma janela de interrogação gerada com $50 \%$ de overlap na direção horizontal e $75 \%$ na vertical.

Figura E.1 - Exemplo ilustrativo de uma sobreposição de janela de interrogação, considerando $50 \%$ na direção horizontal e $75 \%$ na direção vertical.

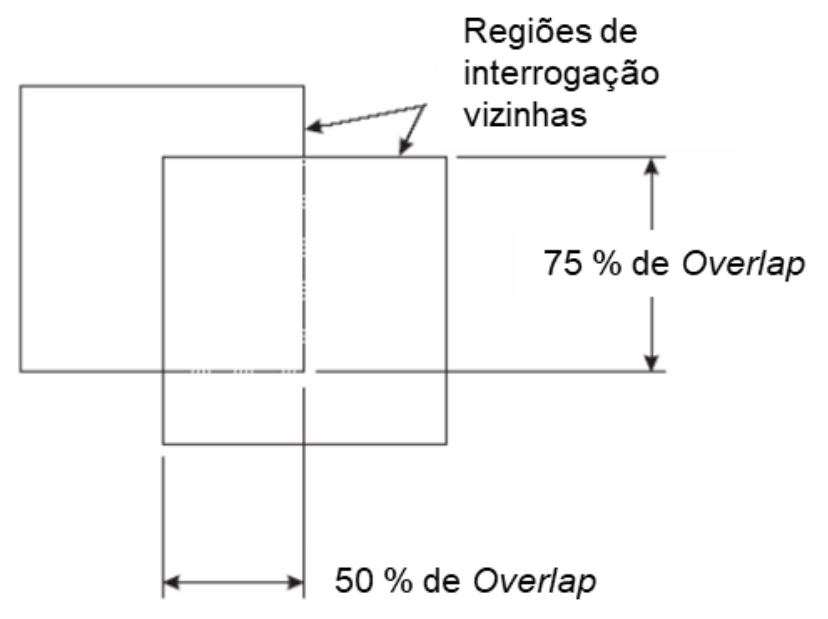

Fonte: Adaptado de Duarte (2005).

A fim de exemplificar a estratégia de overlap, consideremos uma imagem PIV definida em $1280 \times 1024$ pixels e discretizada por janelas de interrogação com tamanho igual a $64 \times 64$ pixels. Ao estipular 0\% de sobreposição, 320 janelas descreverão a imagem através de uma malha formada por $20 \times 16$ janelas de interrogação, de modo que 320 vetores comporão o campo vetorial de deslocamento médio. No entanto, ao definir $50 \%$ de sobreposição nas duas direções, uma malha $39 \times 31$ é formada e 1209 vetores serão obtidos após o processamento. Deste modo, fica evidenciado que a sobreposição atua diretamente no tamanho com o qual as regiões de discretização de uma imagem PIV 
são formadas, isto é, o grid. A Figura E.2 apresenta um exemplo capaz de tornar facilmente compreensível a relação existente entre o tamanho da janela de interrogação, a porcentagem de sobreposição e o tamanho das regiões que discretizam a imagem.

Figura E.2 - Exemplo ilustrativo da relação de dependência existente entre a localização dos vetores, o tamanho da janela de interrogação e a porcentagem de sobreposição. (a) $I W=32$ pixels; $0 \%$ de overlap; grid $=32$ pixels. (b) $I W=32$ pixels; $50 \%$ de overlap; grid $=16$ pixels.
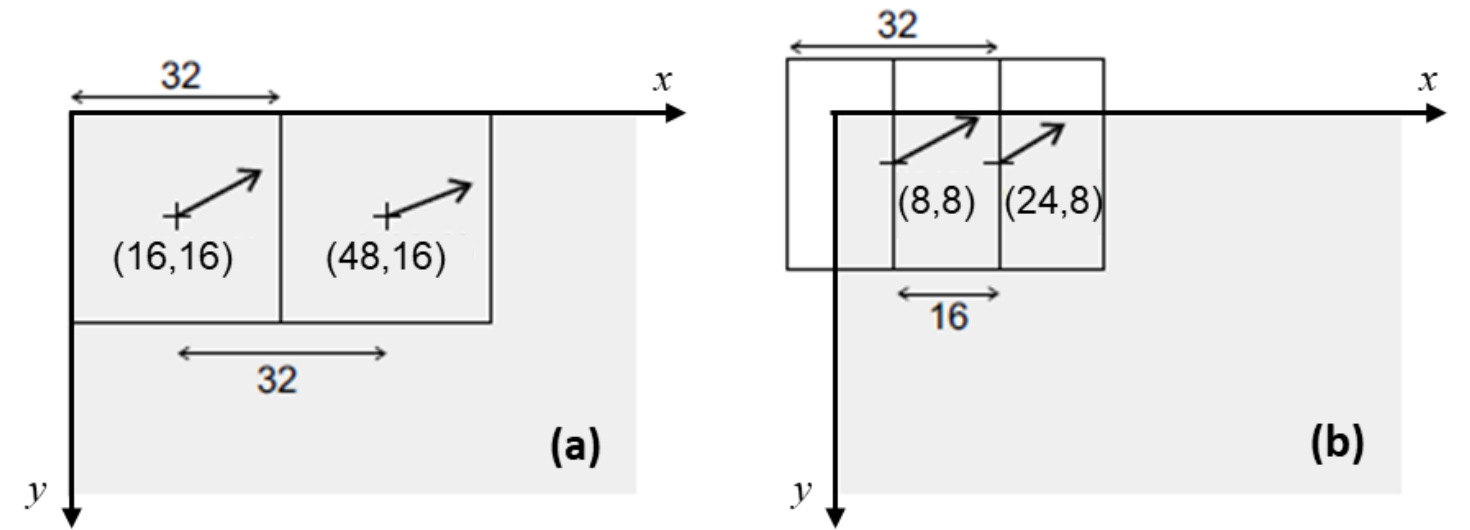

Fonte: Adaptado de LaVision (2017). 


\section{APÊNDICE F - MÉTODO DE PROCESSAMENTO PIV POR MÚLTIPLOS PASSOS}

Como forma de melhorar a convergência dos resultados que podem ser obtidos via aplicação de PIV padrão, a estratégia de múltiplos passos (multi-pass, em inglês) pode ser empregada durante a etapa de processamento. Há dois tipos de processamento multipass: Tamanho simples ou decrescente.

A estratégia de múltiplos passos com tamanho simples (multi-pass constant size, em inglês) determina o campo vetorial de deslocamento médio a partir de um número arbitrário de iterações na mesma imagem, considerando uma imagem discretizada com janelas de interrogação de tamanhos iguais e constantes entre as interações. Em cada passo uma operação de correlação cruzada é realizada, e então, um vetor de referência é obtido como fonte de informação precedente à iteração subsequente. Consequentemente, a convergência do resultado após as iterações ocorre de forma pronunciada e a relação sinal-ruído é aumentada de modo generalizado. Já a estratégia de múltiplos passos com tamanho decrescente (multi-pass decreasing size, em inglês) considera as mesmas premissas que a primeira, mas propõe a diminuição pré-definida do tamanho das janelas de interrogação à medida em que as interações acontecem. Deste modo, o campo vetorial é definido de forma mais refinada e com melhor confiabilidade, uma vez que a resolução espacial é diretamente afetada sem denegrir o número efetivo de partículas em relação à escolha de janela inicial. Isso se sucede pelo fato de as mesmas partículas serem correlacionadas umas às outras de forma iterativa, ao invés de correlacionar populações formadas por poucas imagens de partículas através de janelas menores (LaVision, 2017).

A Figura F.1 mostra o efeito que as estratégias de múltiplos passos têm sobre um campo vetorial obtido com o processamento de um par de imagens PIV com janelas de interrogação de 16 x 16 pixels e com uma iteração. 
Figura F.1 - Campo vetorial processado a partir de imagens primárias de um escoamento rotacional utilizando SCC. (a) $I W=16$ pixels, sem multi-pass; (b) $I W=8$ pixels, sem multipass; (c) $I W=32$ pixels; com multi-pass decrescente até 8 pixels.

(a)

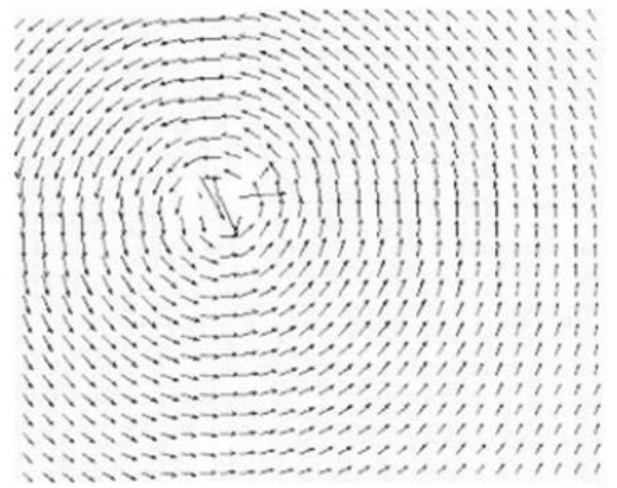

(b)

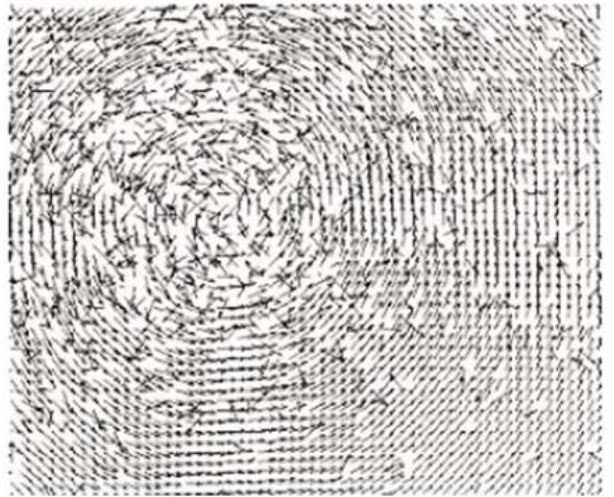

(c)

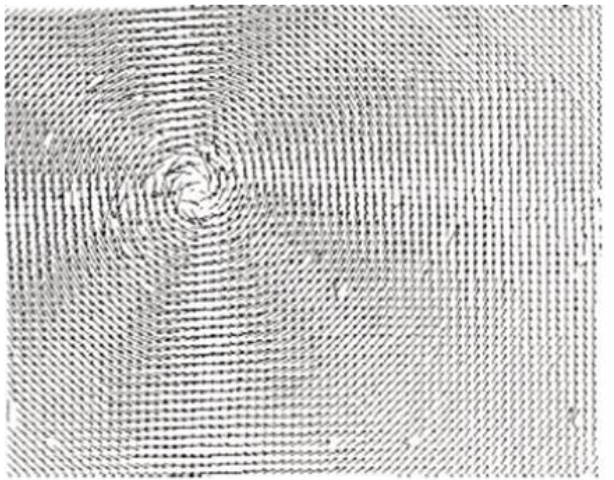

Fonte: Adaptado de LaVision (2017). 


\section{APÊNDICE G - MEDIDAS DO ESCOAMENTO DE AR CIRCUNDANTE OBTIDAS PARA O CASO 1}

Nesta seção são apresentadas as distribuições média-temporais dos parâmetros $|\bar{U}|$, do $S N R$ e do $R M S$ do módulo da flutuação de velocidade, $|U|^{\prime}$, calculadas a partir da correlação das imagens primárias processadas com as metodologias Alfa e Beta no intervalo sem a presença do spray, utilizando a abordagem SCC. Adicionalmente, os resultados obtidos com a aplicação do algoritmo $R P C$ às imagens primárias são apresentados. Todos os dados foram obtidos considerando a condição experimental em que a pressão de injeção é 100 bar e a vazão de ar vale $0,066 \mathrm{~kg} / \mathrm{s}$.

Figura G.1 - Medidas do escoamento do ar sem o spray, para 100 bar e $0,066 \mathrm{~kg} / \mathrm{s}$ utilizando a abordagem SCC a partir da imagem após o Pré-processamento Beta. Média temporal do Módulo de velocidade (a) e da relação sinal-ruído (b). (c) $R M S$ da flutuação do módulo de velocidade.
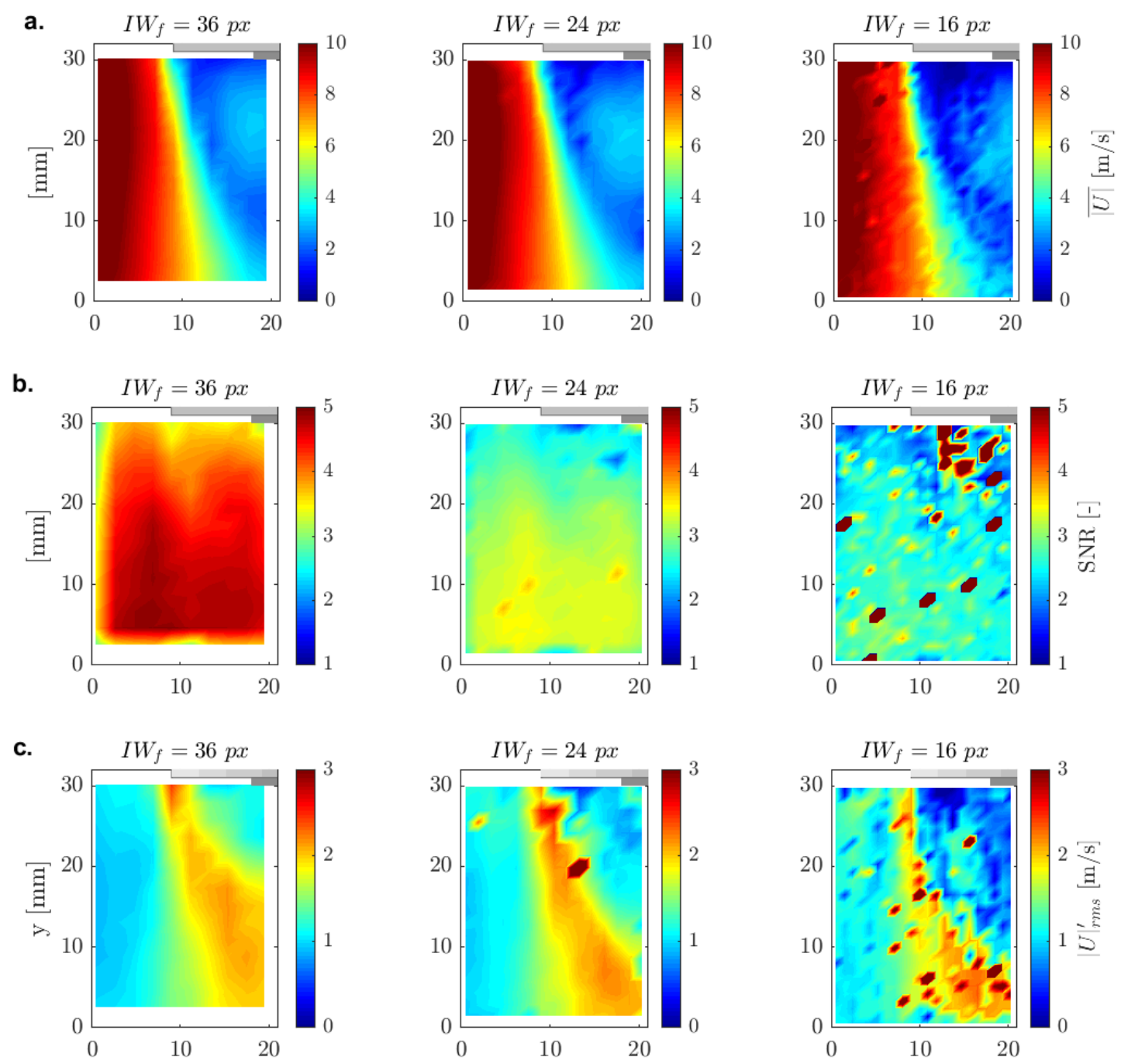

Fonte: Autor. 
Figura G.2 - Medidas do escoamento do ar sem o spray, para 100 bar e 0,066 kg/s utilizando a abordagem SCC a partir da imagem após o Pré-processamento Beta. Média temporal do Módulo de velocidade (a) e da relação sinal-ruído (b). RMS da flutuação do módulo de velocidade.
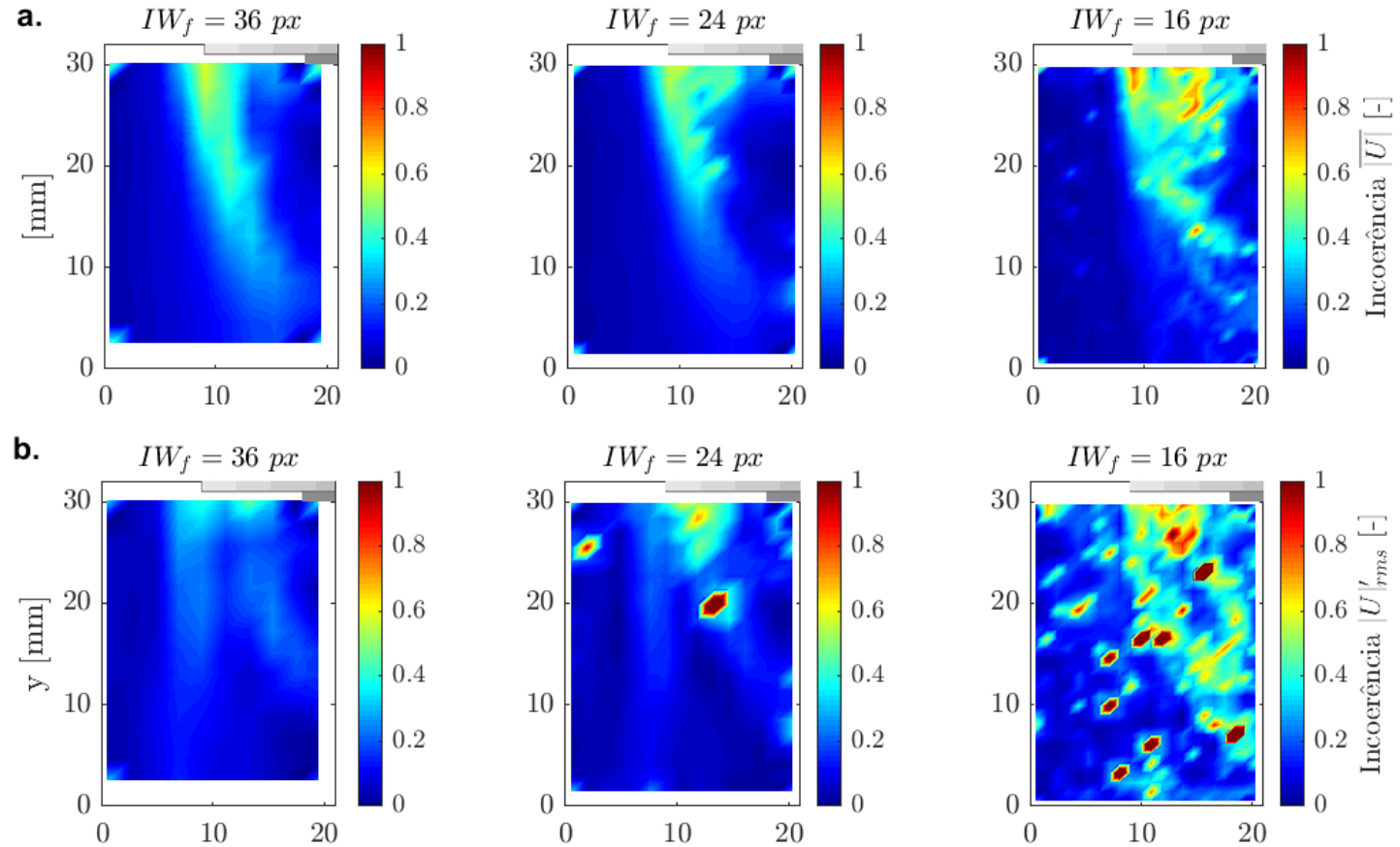

Fonte: Autor. 
Figura G.3 - Medidas do escoamento do ar sem o spray, para 100 bar e 0,066 kg/s utilizando a abordagem SCC a partir da imagem após o Pré-processamento Alfa. Média temporal do Módulo de velocidade (a) e da relação sinal-ruído (b). (c) $R M S$ da flutuação do módulo de velocidade.
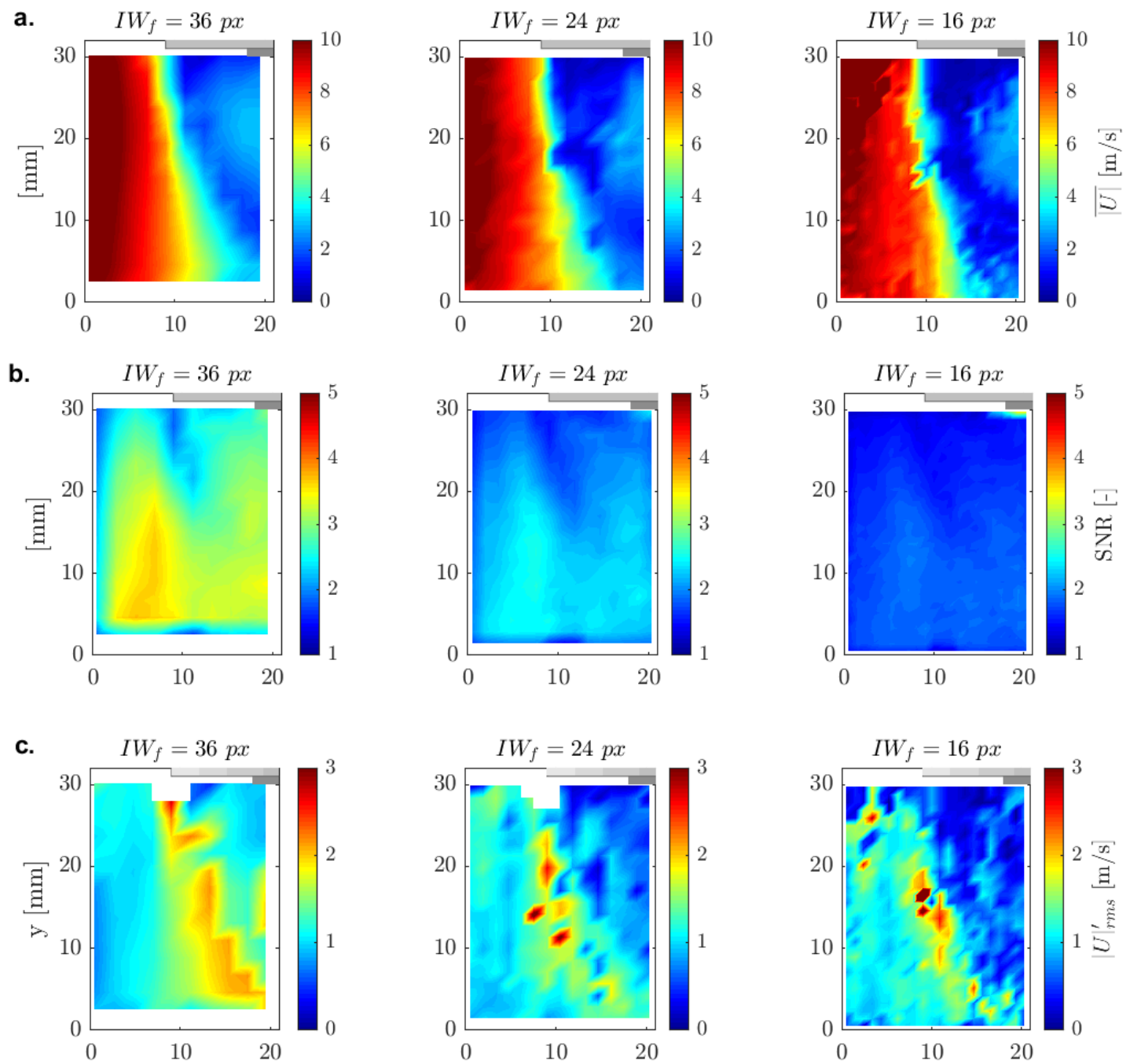

Fonte: Autor. 
Figura G.4 - Medidas do escoamento do ar sem o spray, para 100 bar e 0,066 kg/s utilizando a abordagem SCC a partir da imagem após o Pré-processamento Alfa. Média temporal do Módulo de velocidade (a) e da relação sinal-ruído (b). RMS da flutuação do módulo de velocidade.

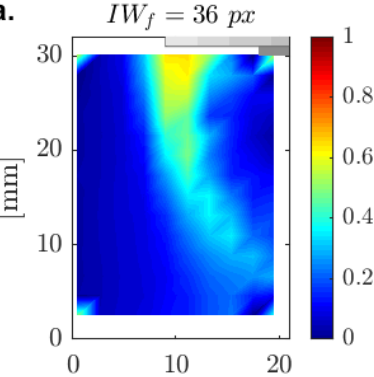

b.

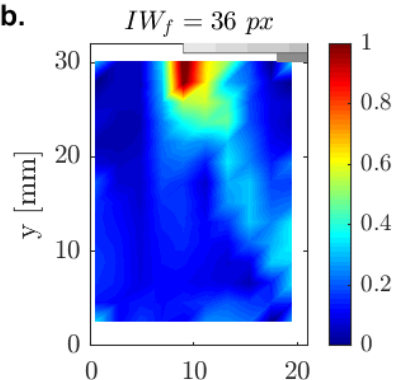

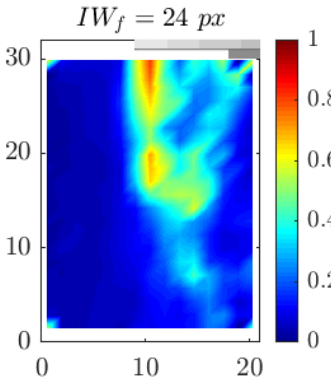

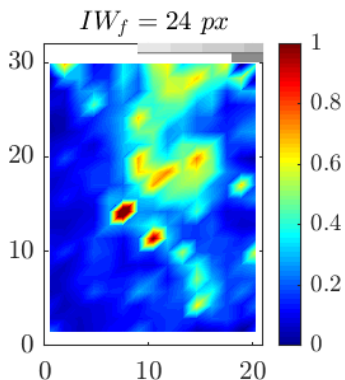

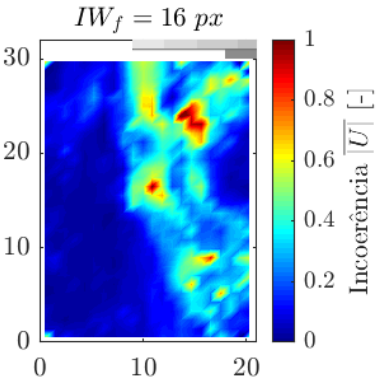

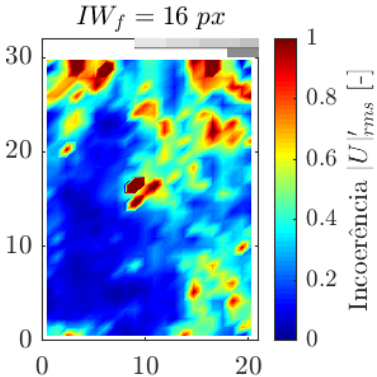

Fonte: Autor. 
Figura G.5 - Medidas do escoamento do ar sem o spray, para 100 bar e 0,066 kg/s utilizando a abordagem RPC a partir das imagens primárias. Média temporal do Módulo de velocidade (a) e da relação sinal-ruído (b). (c) RMS da flutuação do módulo de velocidade.
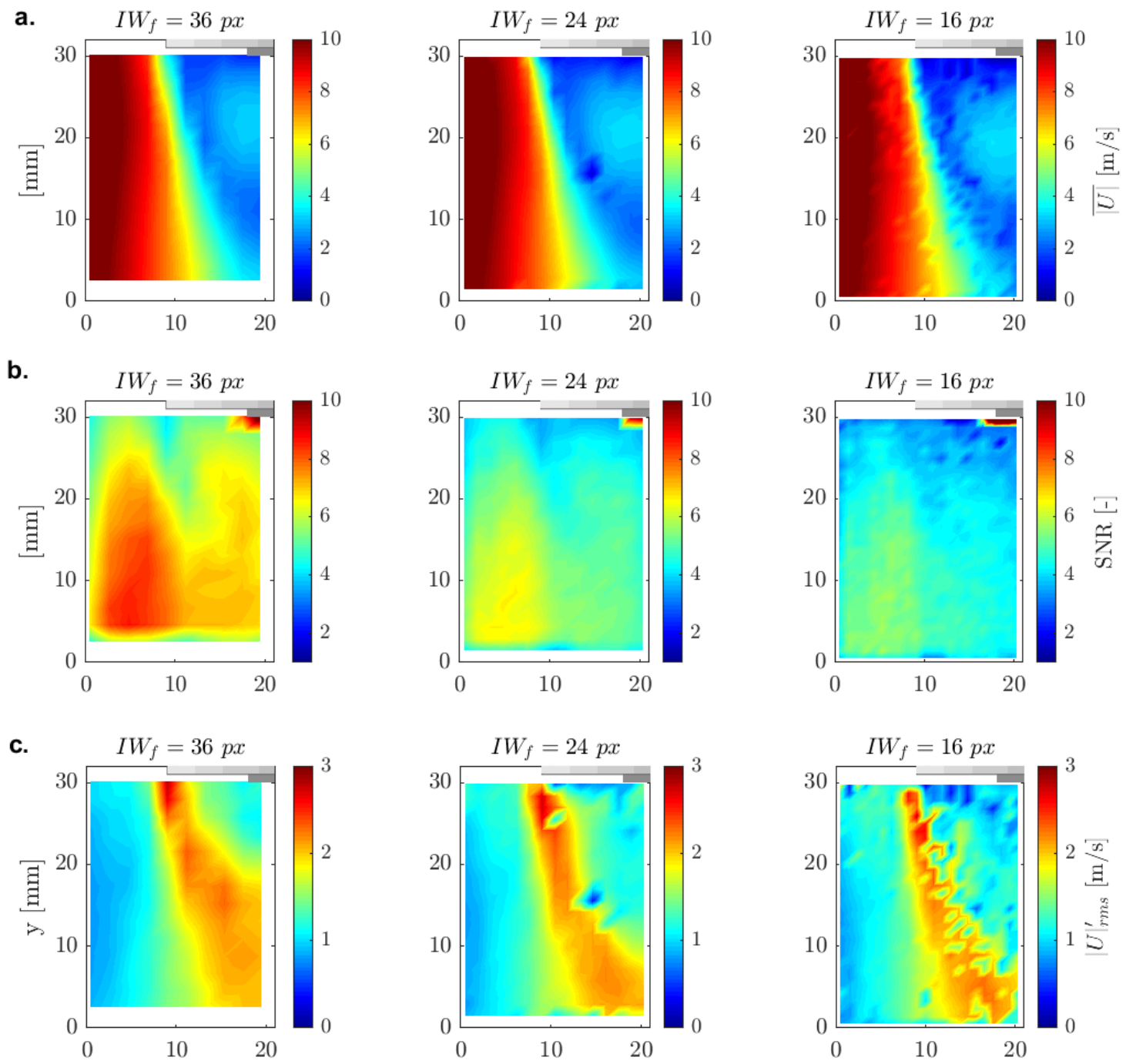

Fonte: Autor. 
Figura G.6 - Medidas do escoamento do ar sem o spray, para 100 bar e 0,066 kg/s utilizando a abordagem RPC a partir das imagens primárias. Média temporal do Módulo de velocidade (a) e da relação sinal-ruído (b). RMS da flutuação do módulo de velocidade.
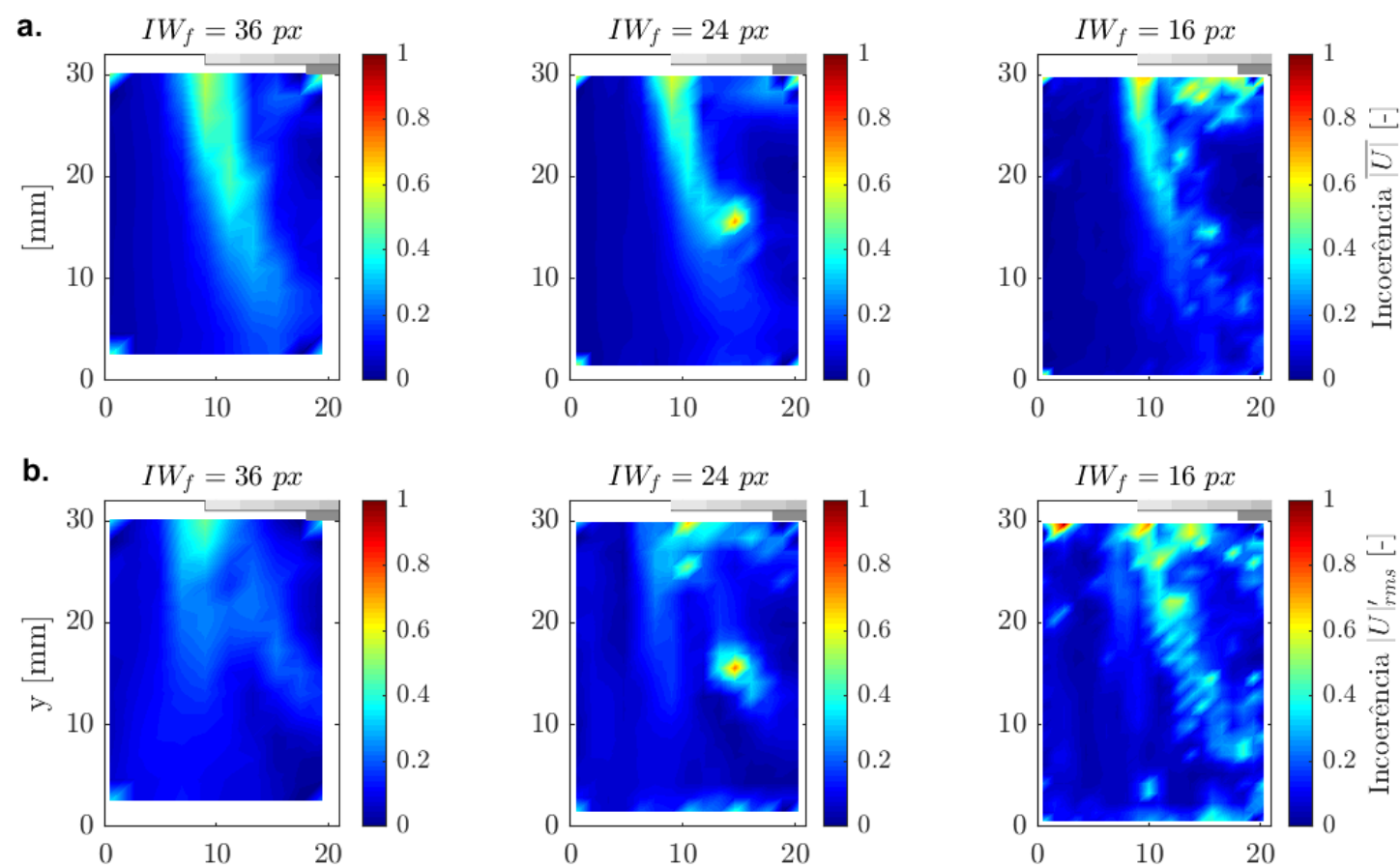

Fonte: Autor. 


\section{APÊNDICE H - FLUXOGRAMAS DAS ETAPAS DE PRÉ- PROCESSAMENTO E PROCESSAMENTO UTILIZADAS NO MÉTODO DE OTIMIZAÇÃO PIV}

Neste apêndice são apresentados fluxogramas que objetivam sintetizar os procedimentos de pré-processamento e processamento PIV considerados no desenvolvimento do método de otimização de medidas PIV proposto. A Figura H.1 mostra o procedimento lógico adotado durante a realização do pré-processamento, enquanto a Figura H.2 evidencia os passos realizados durante a etapa de interrogação e processamento. Além disso, a Figura H.2 explicita os critérios de pós-processamento considerados no trabalho. Mais informações sobre cada etapa contida no fluxograma mostrado pela Figura H.1 podem ser acessadas na seção 3.2.1, enquanto o conteúdo embutido na Figura H.2 está difundido entre as seções 3.2.2, 3.2.3, 4.1 e 4.2. A Figura H.3 mostra o fluxograma referente à aplicação da estratégia de pré-processamento escolhida para tratar as imagens primárias processadas segundo a abordagem SCC e utilizada na geração dos campos RPC-SCC. Por fim, a Figura H.4 mostra o fluxograma referente à estratégia de pós-processamento utilizada no presente trabalho.

Figura H.1 - Fluxograma da estratégia de pré-processamento adotada para tratar as imagens primárias utilizadas na análise gás-spray (continua).

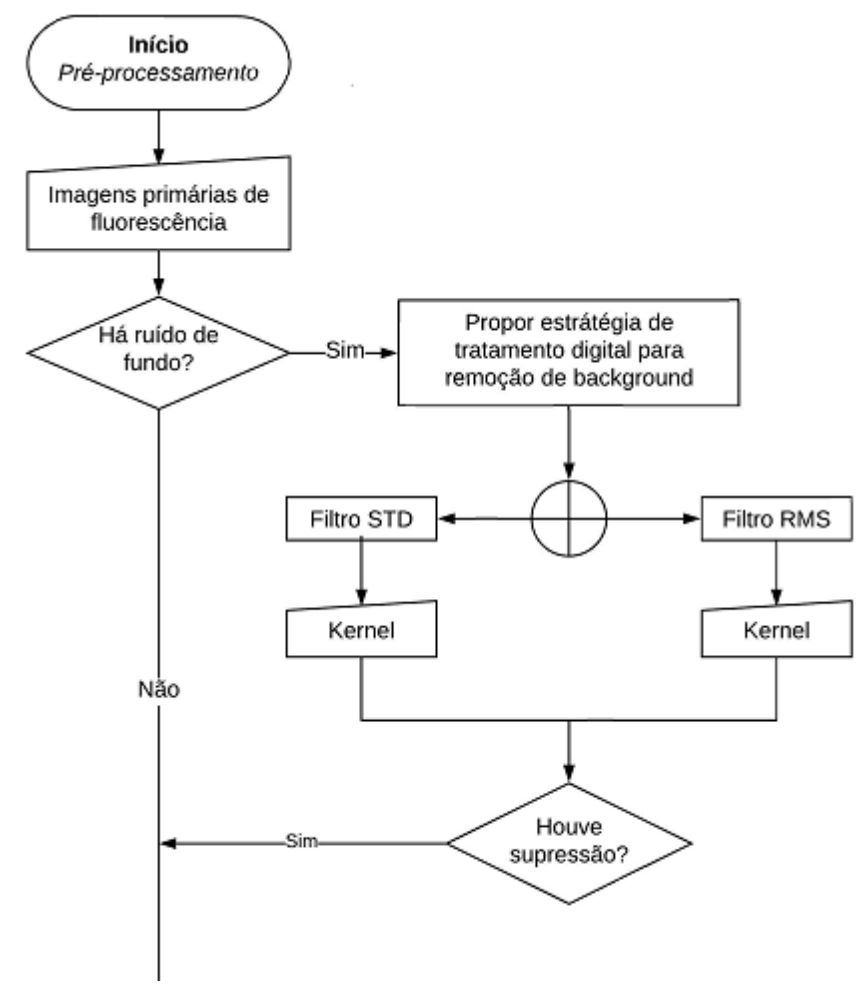


Figura H.1 - Fluxograma da estratégia de pré-processamento adotada para tratar as imagens primárias utilizadas na análise gás-spray (conclusão).

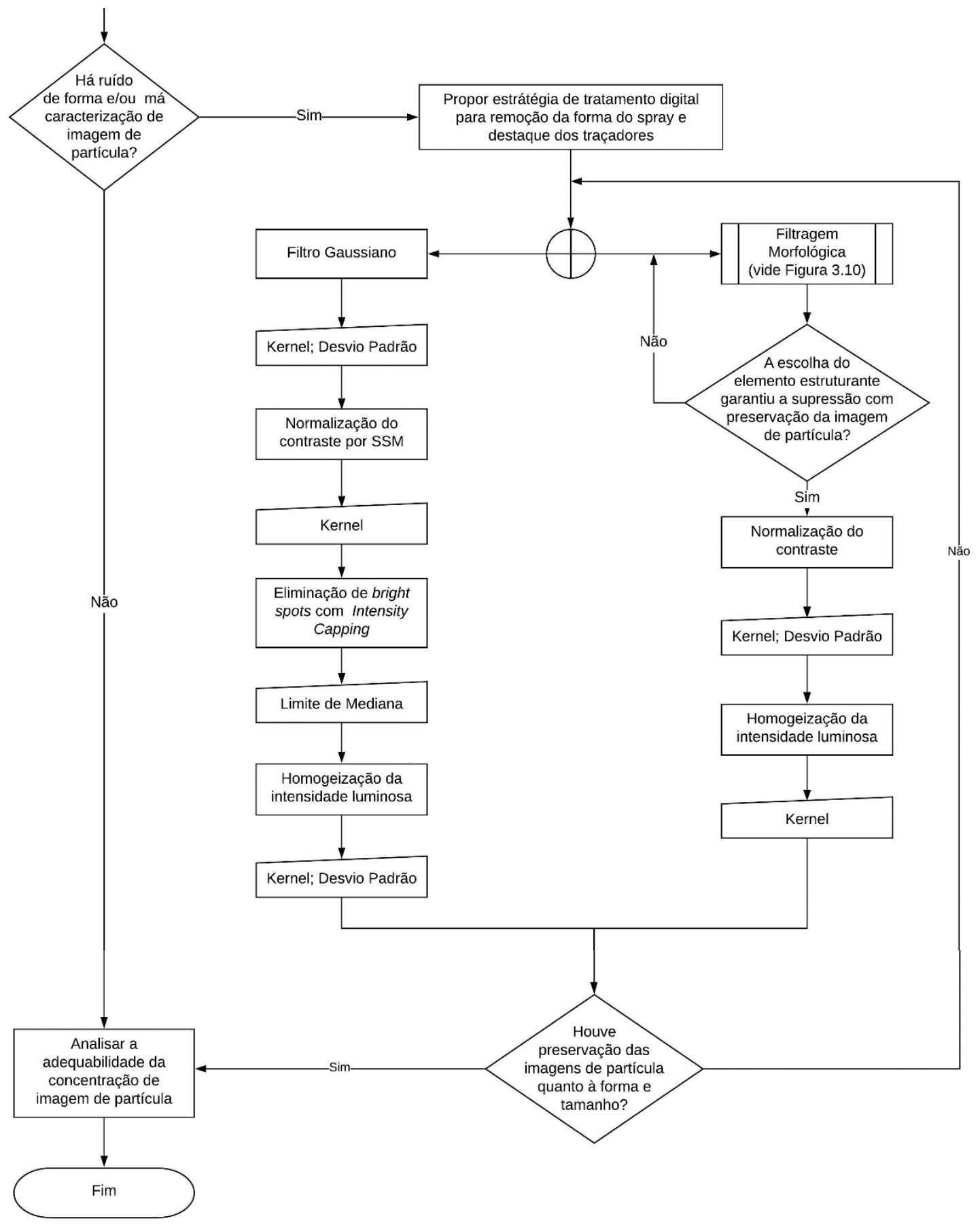

Fonte: Autor. 
Figura H.2 - Fluxograma da estratégia de processamento adotada para gerar os campos híbridos.

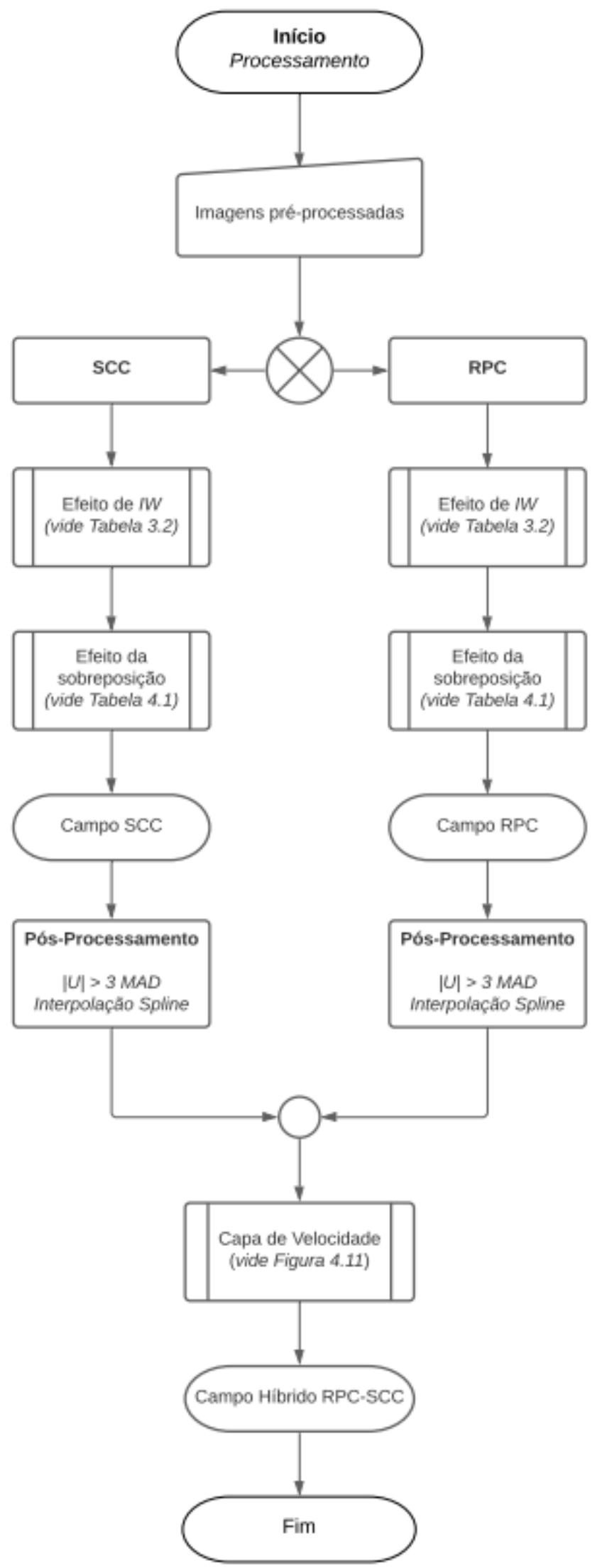

Fonte: Autor. 
Figura H.3 - Fluxograma da estratégia de pré-processamento empregada para gerar os campos SCC utilizados na composição dos campos híbridos.

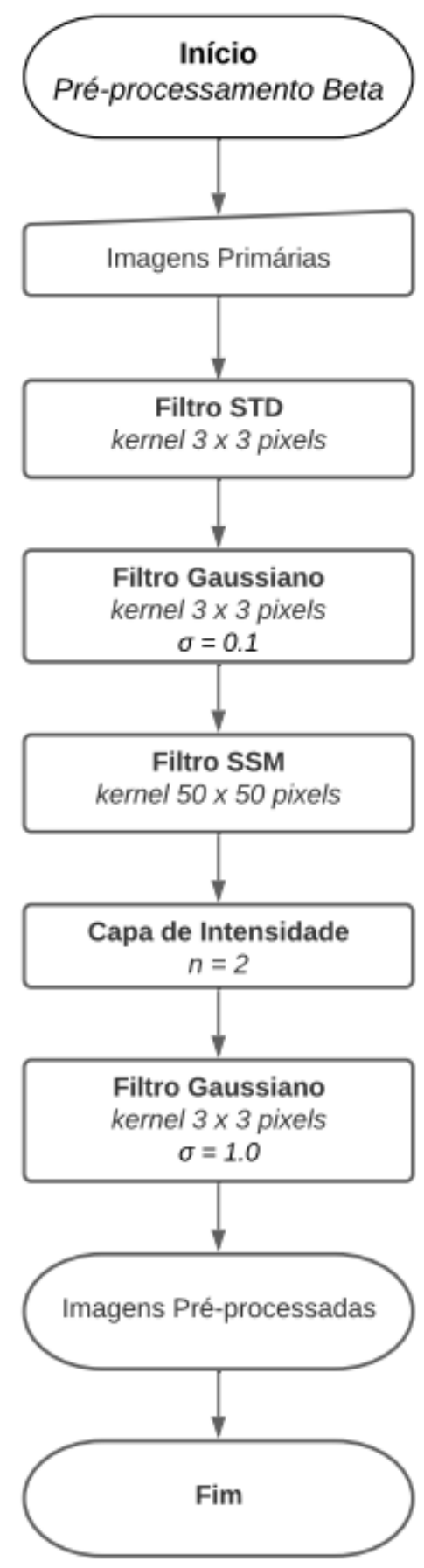

Fonte: Autor. 
Figura H.4 - Fluxograma da estratégia de pós-processamento completa utilizada na geração dos campos híbridos.

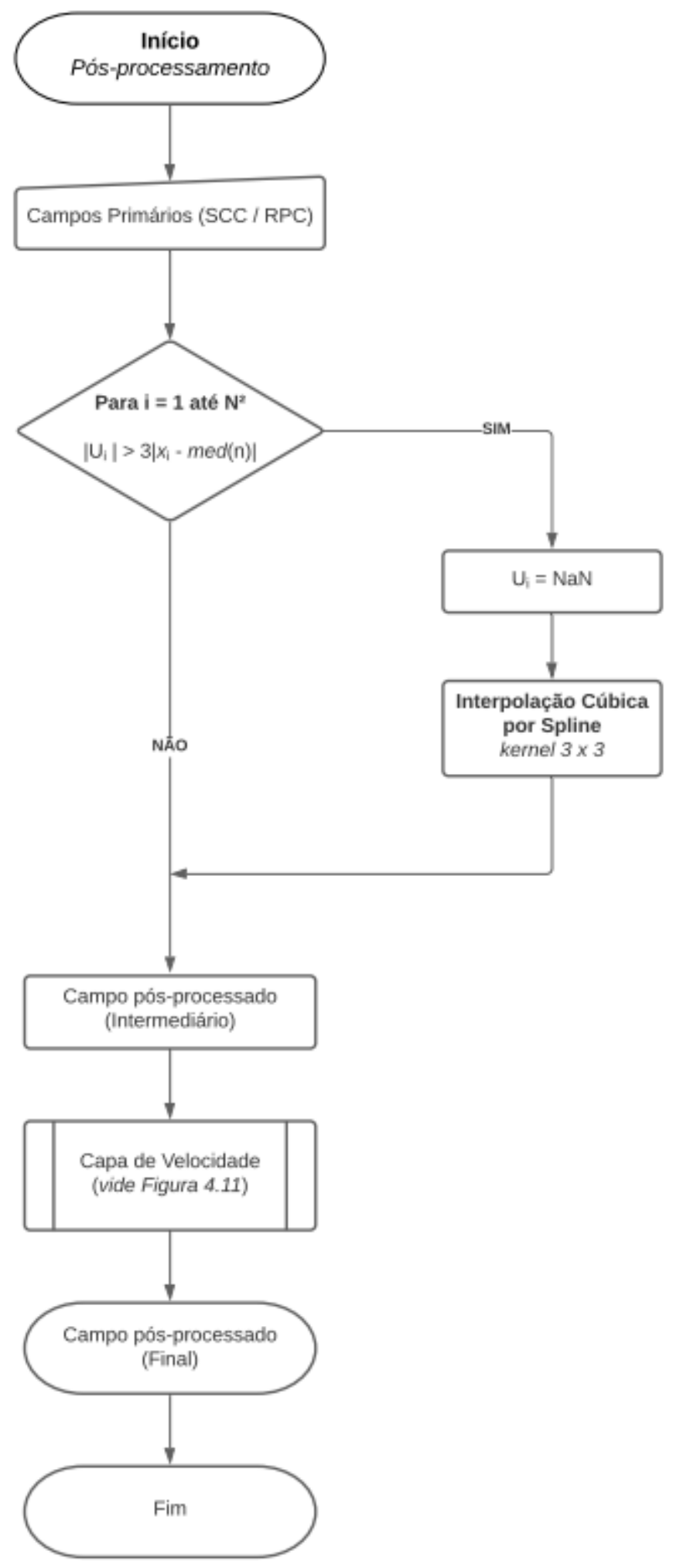

Fonte: Autor. 